Florida International University FIU Digital Commons

$11-3-2015$

\title{
Correlates of Vitamin D Status in Healthy Older Adults Living in Miami-Dade and its Association with Non-Skeletal Outcomes: A Cross-Sectional Study
}

Johanna Lopez

Florida International University, jlope143@fiu.edu

DOI: $10.25148 /$ etd.FIDC000148

Follow this and additional works at: https:// digitalcommons.fiu.edu/etd

3 Part of the Cardiovascular Diseases Commons, Dietetics and Clinical Nutrition Commons, Nutritional and Metabolic Diseases Commons, and the Physical Therapy Commons

\section{Recommended Citation}

Lopez, Johanna, "Correlates of Vitamin D Status in Healthy Older Adults Living in Miami-Dade and its Association with Non-Skeletal Outcomes: A Cross-Sectional Study" (2015). FIU Electronic Theses and Dissertations. 2256.

https://digitalcommons.fiu.edu/etd/2256 


\section{FLORIDA INTERNATIONAL UNIVERSITY \\ Miami, Florida}

CORRELATES OF VITAMIN D STATUS IN HEALTHY OLDER ADULTS LIVING

IN MIAMI-DADE AND ITS ASSOCIATION WITH NONSKELETAL OUTCOMES: A CROSS-SECTIONAL STUDY

A dissertation submitted in partial fulfillment of the requirements for the degree of DOCTOR OF PHILOSOPHY in DIETETICS AND NUTRITION

by

Johanna Lopez 
To: Interim Dean Mark Williams

R. Stempel College of Public Health and Social Work

This dissertation, written by Johanna Lopez, and entitled Correlates of Vitamin D Status in Healthy Older Adults Living in Miami-Dade and its Association with Non-Skeletal Outcomes: A Cross-Sectional Study, having been approved in respect to style and intellectual content, is referred to you for judgment.

We have read this dissertation and recommend that it be approved.

Juan P. Liuzzi

Fatma G. Huffman

Tan Li

John E. Lewis

Adriana Campa, Major Professor

Date of Defense: November 3, 2015

The dissertation of Johanna Lopez is approved.

Interim Dean Mark Williams

R.Stempel College of Public Health and Social Work

Dean Lakshmi N. Reddi

University Graduate School

Florida International University, 2015 
C Copyright 2015 by Johanna Lopez

All rights reserved. 


\section{DEDICATION}

I dedicate this dissertation to my family and friends who have constantly supported and encouraged me through the challenging journey of graduate school. This work is especially dedicated to my parents, Javier Alonso Lopez and Maria Cristina Ciro, and my brother, Javier Alexander Lopez, who believed in me when I stopped believing in myself and taught me perseverance to achieve my dreams. 


\section{ACKNOWLEDGMENTS}

I would like to acknowledge all of those who made this dissertation possible, especially my committee members who guided me all these years. I would like to express my inmost appreciation to my Major Professor, Dr. Adriana Campa, for her guidance, support, patience and for believing in me. I would also like to express my deepest gratitude to Dr. John E. Lewis for giving me the opportunity to pursue my research idea by allowing me to conduct my dissertation study as part of his study. I am grateful to Dr. Juan P. Liuzzi, who provided me with valuable guidance and input for my dissertation, and accepted to be part of my committee late in its conception. I would also like to thank Dr. Fatma G. Huffman, for recruiting me into the program, her continuous support, and encouragement. I am grateful to Dr. Tan Li for his assistance with my statistical data analysis. A very special thanks to the Lewis research team, especially Dr. Eduard Tiozzo, Steven Atlas, Ana H. Martinez, Serena M. Ferris, and Dott Carungcong for helping me screen, recruit and assess participants for my data collection. This research would not have been possible without their assistance. I would also like to express my gratitude to the Department of Physical Therapy for providing the equipment and training needed to pursue this project, especially Dr. Edgar Vieira. Finally, I would like to thank my fellow Ph.D. students, especially Christina Fleetwood, my roommates Gia Marotta, Erika Richardson and Diana Mogrobejo, and my Miami family and friends who have been there for me along the way. This journey would not have been the same without the amazing people God put in my life. 
ABSTRACT OF THE DISSERTATION

CORRELATES OF VITAMIN D STATUS IN HEALTHY OLDER ADULTS LIVING

IN MIAMI-DADE AND ITS ASSOCIATION WITH NONSKELETAL OUTCOMES: A

CROSS-SECTIONAL STUDY

by

Johanna Lopez

Florida International University, 2015

Miami, Florida

Professor Adriana Campa, Major Professor

Examining factors that affect vitamin $\mathrm{D}$ status in the fast-growing elderly population of Miami-Dade, Florida, is needed. Vitamin D deficiency in older adults has been linked to correlates of disability, including falls and fractures, and cardiovascular disease. The purpose of this study was to determine the proportion of vitamin D insufficient individuals and their relationship with vitamin D insufficiency in older adults ( $\mathrm{n}=97$ ) living in Miami-Dade. We evaluated the association between vitamin D status and 1) dual task physical performance to understand the link between vitamin $D$ and cognition in the context of mobility; and 2) cardiometabolic risk, measured by galvanic skin response, pulse oximetry, and blood pressure to create a composite score based on autonomic nervous system and endothelial function. Participants completed baseline assessments that included serum levels of vitamin D, anthropometrics, body composition, dual task physical performance and cardiometabolic risk. Surveys to evaluate vitamin D intake, sun exposure, physical activity, and depressive symptoms were completed. Spearman's correlations, independent t-tests, paired t-tests, repeated measures ANOVAs, 
and multiple logistic and linear regressions were used to examine the relationship of vitamin D insufficiency $(25(\mathrm{OH}) \mathrm{D}<30 \mathrm{ng} / \mathrm{ml})$ and sufficiency $(25(\mathrm{OH}) \mathrm{D} \geq 30 \mathrm{ng} / \mathrm{ml}$ ) with determinants of vitamin $\mathrm{D}$ status, dual task physical performance variables and cardiometabolic risk scores. Although the proportion of vitamin D insufficient individuals was lower when compared to the prevalance of the general United States elderly population, it was still common in healthy community-dwelling older adults living in Miami-Dade County, especially among Hispanics. Factors that affected skin synthesis (ethnicity, and sun exposure), and bioavailability/metabolism (obesity) were significant predictors of vitamin D status. Vitamin D insufficiency was not significantly correlated with worse dual task physical performance; however, cognitive performance was worse in the vitamin D insufficient group. Our results suggest a relationship of vitamin D insufficiency with executive dysfunction, and support an association with cardiometabolic risk using an innovative electro-sensor complex, possibly by modulating autonomic nervous system activity and vascular function, thus affecting cardiac performance. 


\section{TABLE OF CONTENTS}

CHAPTER

PAGE

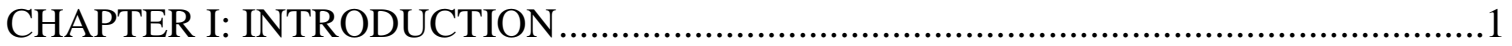

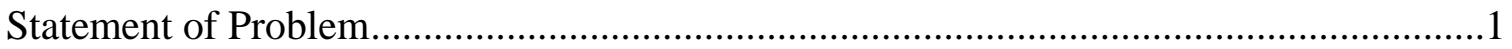

Significance of Proposed Study ..................................................................................

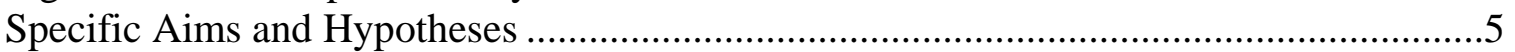

CHAPTER II: LITERATURE REVIEW ............................................................19

Vitamin D Deficiency in the Elderly .........................................................................19

Defining Vitamin D Deficiency Based on its Main Function ...........................................19

Recommended Vitamin D Intake, Vitamin D Sources, and the Older Adult.....................21

Vitamin D, Fall Risk, and Mobility as Measured by Gait Speed in the Elderly................26

Vitamin D Deficiency, Cognitive Impairment, and Executive Dysfunction in

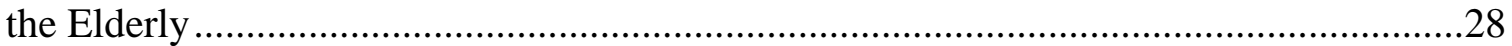

Vitamin D and Other Non-Skeletal Outcomes: Cardiovascular Disease ............................32

Vitamin D and Cardiovascular Health: Possible Mechanism...........................................34

The Relationship Between Vitamin D and Cardiac Autonomic Nervous System..............35

VItamin D and Its Relationship to Other Cardiovascular Risk Correlates .........................39

Literature Review Summary .....................................................................................

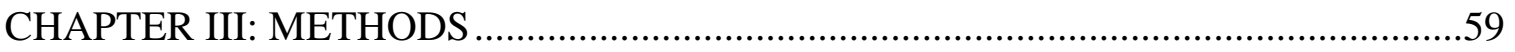

CHAPTER IV: CORRELATES OF VITAMIN D DEFICIENCY IN SOUTH

FLORIDA OLDER ADULTS

CHAPTER V: ASSOCIATION OF VITAMIN D STATUS WITH DUAL TASK

PHYSICAL PERFORMANCE IN OLDER ADULTS ....................................................133

CHAPTER VI: RELATIONSHIP BETWEEN VITAMIN D STATUS AND

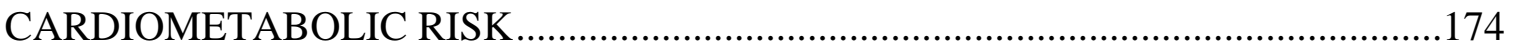

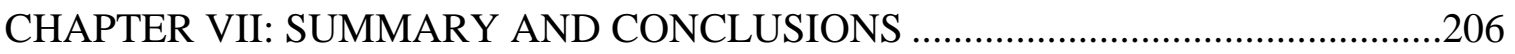

CHAPTER VIII: STRENGTHS AND LIMITATIONS................................................212

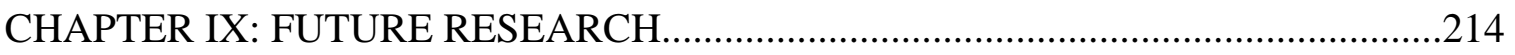

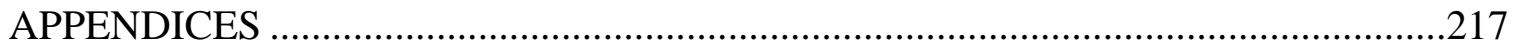

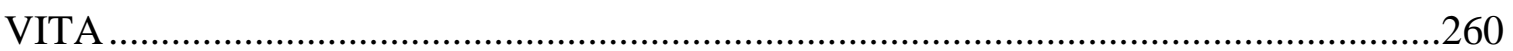




\section{LIST OF TABLES}

TABLE

PAGE

\section{CHAPTER I}

Table 1: Summary of Hypotheses and Statistical Methods

\section{CHAPTER II}

Table 1: Vitamin D Status in Relation to Bone Health.

\section{CHAPTER III}

Table 1: Inclusion and Exclusion Criteria

Table 2: Statistical Analyzes Methods for individual Hypotheses

\section{CHAPTER IV}

Table 1: Comparison of Vitamin D Related Variables and Sociodemographic

Characteristics Between Vitamin D Insufficient and Sufficient Participants

Table 2: One-Way ANOVA Comparison of Vitamin D Levels Between Ethnic

Groups

Table 3: Comparison of Vitamin D Levels, Vitamin D Intake, Sun Exposure and

Other Potential Correlates Between Vitamin D Insufficient and Sufficient

Participants.

Table 4: Vitamin D Status Correlation with Vitamin D Intake, Sun Exposure, and

Other Potential Predictors

Table 5: The Relationship Between Vitamin D Status and Potential Correlates in Multiple Linear Regressions

Table 6: The Relationship Between Vitamin D Status and Potential Correlates in Multiple Logistic Regression.....

\section{CHAPTER V}

Table 1: Characteristics of Participants

Table 2: Vitamin D Status Correlation with Dual Task Physical Performance

Variables

Table 3: Comparison of Dual Task Physical Performance Variables Between

Vitamin D Insufficient And Sufficient Participants

Table 4: The Relationship Between Vitamin D Status and Dual to Single Task

Difference in Gait Velocity and Counting Rate in Multiple Logistic Regressions

\section{CHAPTER VI}

Table 1: Characteristics of Participants

Table 2: Comparison of Cardiometabolic Risk Scores (CMRS) Between Vitamin D Insufficient and Sufficient Participants.

Table 3: The Relationship Between Vitamin D Levels and CMRS in Multiple Linear

Regressions 


\section{APPENDIX A}

Table 1: Observational Studies Investigating the Association Between Vitamin D

Status and Gait Velocity in Healthy Community-Dwelling Older Adults

Table 2: Interventional Studies Investigating the Effect of Vitamin D on Gait

Velocity in Healthy Community-Dwelling Elderly

Table 3: Observational Studies Investigating the Association Between Vitamin D

Status and Cognition in Healthy Community-Dwelling Older Adults

Table 4: Observational Studies Investigating the Association Between Vitamin D

Status, Gait Velocity and Cognition (Independently) in Healthy Community-

Dwelling Older Adults

APPENDIX B

Table 1: Description of ESC software variables used to calculate CMRS 


\section{LIST OF FIGURES}

FIGURE

PAGE

CHAPTER V

Figure 1: Comparison of Dual and Single Task Gait Velocity Within and Between

Vitamin D Insufficient and Sufficient Participants......................................................158

Figure 2: Comparison of Dual and Single Task Counting Rate Within and Between

Vitamin D Insufficient and Sufficient Participants....................................................159

\section{APPENDIX B}

Figure 1: The GAITRite Walkay for the Assessment of Gait

Figure 2: The Electro Sensor Complex Device and Procedure ......................................242

Figure 3: Heart Rate Variability Time and Frequency Domains ...................................243 


\section{ABBREVIATIONS AND ACRONYMS}

\begin{tabular}{|c|c|}
\hline $1,25(\mathrm{OH})_{2} \mathrm{D}$ & 1, 25-dihydroxyvitamin D \\
\hline 25(OH)D & 25- hydroxyvitamin D \\
\hline ANS & Autonomic Nervous System \\
\hline BDI & Beck Depression Inventory \\
\hline BIA & Bioelectrical Impedance \\
\hline BMD & Bone Mineral Density \\
\hline BMI & Body Mass Index \\
\hline CDC & Center for Disease Control and Prevention \\
\hline $\mathrm{CI}$ & Confidence Interval \\
\hline CKD & Chronic Kidney Disease \\
\hline $\mathrm{CV}$ & Coefficient of Variability \\
\hline CVD & Cardiovascular Disease \\
\hline DBP & Diastolic Blood Pressure \\
\hline d.f. & Degrees of freedom \\
\hline DRI & Dietary Reference Intakes \\
\hline DSM-IV & Diagnostic and Statistical Manual of Mental Disorders, $4^{\text {th }}$ Edition \\
\hline DVP & Digital Volume Pulse wave \\
\hline ESC & Electro Sensor Complex \\
\hline ESKD & End Stage Kidney Disease \\
\hline FES-I & Fall Efficacy Scale International \\
\hline FFM & Fat-Free Mass \\
\hline FFQ & Food Frequency Questionnaire \\
\hline FIU & Florida International University \\
\hline FM & Fat Mass \\
\hline FTT & Fourier Transform \\
\hline GABA & Gamma-Aminobutyric Acid \\
\hline
\end{tabular}




\begin{tabular}{ll} 
HC & Hip Circumference \\
HF & Heart Failure \\
HHHQ & Health Habits History Questionnaire \\
HR & Heart Rate \\
HRV & Heart Rate Variability \\
ICMA & Immunochemiluminometric Assay \\
IGT & Impaired Glucose Tolerance \\
IOM & Institute of Medicine \\
IPAQ & International Physical Activity Questionnaire \\
IR & Insulin Resistance \\
IRB & Institutional Review Board \\
IU & International Unit \\
MD & Mean Difference \\
MMSE & Mini Mental State Examination \\
MRI & Magnetic Resonance Imaging \\
ng/ml & Nanogram per milliliter \\
NHANES & National Health and Nutrition Examination Survey \\
Nmol/L & Nanomol per liter \\
PNS & Parasympathetic Nervous System \\
OGTT & Oral Glucose Tolerance \\
OR & Odds Ratio \\
PTG & Plethysmograph \\
PTGHF & Plethysmograph High Frequency \\
PTGi & Plethysmograph index \\
PTGLF & Plethysmograph Low Frequency \\
PTGTP & Plethysmograph Total Power \\
PTGVLF & Plethograph Very Low Frequency \\
\hline
\end{tabular}




\begin{tabular}{ll} 
RCT & Randomized Controlled Trial \\
RMSSD & Root of Mean Squared Standard Deviation \\
RXR & Retinol X Receptor \\
SD & Standard Deviation \\
SDNN & Standard Deviation of Normal to Normal wave \\
SBP & Systolic Blood Pressure \\
SCD & Sudden Cardiac Death \\
SNS & Sympathetic Nervous System \\
SPMSQ & Short Portable Mental Status Questionnaire \\
UM & University of Miami \\
VDBP & Vitamin D Binding Protein \\
VDR & Vitamin D Receptor \\
WC & Waist Circumference \\
WHI & Women’s Health Initiative \\
WHR & Waist to Hip Ratio \\
\hline
\end{tabular}




\section{CHAPTER I: INTRODUCTION}

\section{Statement of Problem}

Approximately one billion people in the world have deficient or insufficient levels of vitamin D. ${ }^{1}$ The National Health and Nutrition Examination Survey (NHANES) 20052006 revealed that $41.6 \%$ of United States adults (18 years or older) had deficient vitamin D levels, defined as $<20 \mathrm{ng} / \mathrm{ml}$ of 25-hydroxyvitamin D (25(OH)D). ${ }^{2,3}$ Elderly are at higher risk of vitamin D deficiency. NHANES 1988-1994 data indicated that serum vitamin D levels among adults 65 years and older were lower when compared to middle aged (40-59 years of age) and younger adults (18-29 years of age). Of these older adults, 23\% and 62.5\% had vitamin D deficient ( $<20 \mathrm{ng} / \mathrm{ml})$ and insufficient ( $<30 \mathrm{ng} / \mathrm{ml}$ ) levels, respectively. ${ }^{4,5}$ The main sources of vitamin D are skin synthesis and dietary intake. Vitamin D deficiency may be more prevalent in theelderly population due to a complex interplay between several factors affecting dietary intake, skin synthesis and bioavailability. These include age-related decreased appetite, impaired intestinal absorption, decreased capacity of the skin to synthesize vitamin D, and less sun exposure, which may be related to physical inactivity and decreased outdoor activities. ${ }^{6,7}$ Furthermore, elderly are at higher risk of vitamin D deficiency due to age-related increased adiposity, which may be secondary to decreased metabolic rate, use of medications and the presence of comorbidities that affect vitamin D metabolism., ${ }^{8,9}$

In the United States, very few foods contain significant amounts of vitamin D; therefore, vitamin D intake through food may be minimal as shown in NHANES 19881994. ${ }^{10,11}$ Although supplement use may compensate for the lack of vitamin D intake 
from foods; however, low vitamin D intakes from food and supplements have been reported in the elderly populations and associated with low serum vitamin D. ${ }^{6,712}$ Thus, for those who are not meeting the vitamin D requirements through diet, sunlight is often the main source of vitamin D. ${ }^{13,14}$ The skin's ability to synthesize vitamin D depends on the amount of solar radiation reaching the biosphere that is influenced by latitude, season and time of day. ${ }^{8,15}$ Based on the impact of sunlight exposure on vitamin D status, it has been assumed that vitamin D deficiency is less prevalent in populations living at lower latitudes and/or where seasonal variations are not as pronounced, like in South Florida, where the weather is sunny and warm year-round. ${ }^{9}$ However, other investigators have reported that the prevalence of hypovitaminosis $\mathrm{D}(25(\mathrm{OH}) \mathrm{D}<20 \mathrm{ng} / \mathrm{ml})$ is $38-40 \%$ in adult men and women ( $>18$ years of age) living in South Florida. ${ }^{9}$

Vitamin D deficiency in older adults has been linked to non-skeletal outcomes that go beyond bone health. In 2010, of the 30 leading causes of disability and death in the United States, 19 were associated with deficient vitamin D levels, including cancer, diabetes, falls and fractures, and cardiovascular disease. ${ }^{16-25}$ Vitamin D deficiency has received much attention as a risk factor for falls because of its effect on musculoskeletal health thus affecting gait. ${ }^{26-33}$ The mechanism by which vitamin $\mathrm{D}$ affects mobility and fall risk, however, may go beyond its role in musculoskeletal health. Since mobility depends on the musculoskeletal and nervous systems, it could be possible that the role of vitamin D in fall risk is not only through its effects on musculoskeletal health but also through its role in brain function and cognition. ${ }^{34}$ Several investigators have reported the association of vitamin D deficiency with higher risk of cognitive impairment and/or 
lower scores on cognitive performance tests. ${ }^{5,17,35-54}$ Little is known, however, about the role of this nutrient in cognitive function in the context of mobility.

Another potential role of vitamin D in the brain is on the regulation of cardiac autonomic nervous system (ANS) function, affecting cardiovascular health. Vitamin D deficiency and cardiovascular disease (CVD) are prevalent worldwide. ${ }^{1,55}$ Furthermore, the prevalence of vitamin D deficiency is high among those with CVD ${ }^{56,57}$ Several observational studies and meta-analyses have demonstrated associations between vitamin D deficiency and outcomes related to CVD and CVD-related deaths. ${ }^{58-72}$ Furthermore, dysfunction of cardiac autonomic function, more specifically of the cardioprotective parasympathetic tone, results in an imbalance between sympathetic (SNS) and parasympathetic (PNS) nervous systems. This imbalance has been well-established as a risk factor for adverse cardiovascular events, such as sudden cardiac death (SCD) or congestive heart failure. ${ }^{73-78}$ Besides affecting heart rate, the ANS also influences cardiac performance by controlling vascular dynamics and blood pressure, which in part is also affected by endothelial health. Low vitamin D status has been independently associated with ANS and endothelial dysfunction; thus affecting cardiovascular health. ${ }^{55,57,79,80}$ The observations that vitamin D deficiency, cardiac ANS, and endothelial dysfunction are independently linked to each other and CVD-related outcomes suggest a potential mechanism by which vitamin D affects CVD risk. The mechanisms that explains the relationship between vitamin D deficiency and CVD-related outcomes and mortality is unclear and therefore, a growing area of research. ${ }^{55}$ 


\section{Significance of the Proposed Study}

Currently, vitamin D status and factors associated with vitamin D serum levels in the elderly population in Miami-Dade have not been well studied. This is important because according to the Florida Department of Elder Affairs, the top county for elders in 2010 and 2012 was Miami-Dade, with 14.9\% of the Miami-Dade population being over the age of 65 in $2010 .^{81}$ Also, Miami is the fourth city in the national ranking that is graying the fastest. ${ }^{81-85}$ Between 2007 and 2009, falls were the leading cause of injury of residents in Miami-Dade aged over 65 years and responsible for $79 \%$ of injury hospitalizations. One-third of hospitalizations related to falls resulted in a hip fracture and $11 \%$ involved traumatic brain injury. ${ }^{86}$

Vitamin D deficiency, which is still common among elderly living in warm South Florida, despite year-round sunshine, is associated with the risk of falls. ${ }^{28,87-94}$ The role of vitamin D deficiency in increasing the risk of falls may be dual; through its function in both the musculoskeletal and nervous systems. Vitamin D is involved in brain physiology. Lower vitamin D status has been associated with impaired neuronal function in the caudal primary motor cortex of older adults, which may contribute to the pathophysiology of gait disorders in older adults with vitamin D deficiency. ${ }^{95}$ Furthermore, several studies have demonstrated an association of vitamin D deficiency, with gait impairment (slower gait speed), global cognitive impairment and impaired executive function. ${ }^{5,17,35-54}$ Studies that investigated vitamin D status' relationship to gait and cognition, however, have looked at these factors independently. Until now, no crosssectional study has evaluated how vitamin D status is related to cognitive processing during motor activity. 
To date very few studies have investigated the role of vitamin D deficiency in the development of cardiac ANS and vascular dysfunctions, which are risk factors for poor cardiovascular related health. ${ }^{58,71,96}$ In addition, no studies have correlated vitamin D insufficiency with cardiometabolic risk, as assessed by cardiovascular risk indicators such as ANS dysfunctions, endothelial dysfunction and anthropometric characteristics.

Objectives of this study were:

1. To determine the proportion of vitamin insufficient individuals and correlates of vitamin D status in a healthy older adult ( $>55$ years of age) sample living in Miami-Dade County.

2. To investigate the association of vitamin D status with cognitive processing during movement, as measured using the dual task physical performance tests.

3. To investigate the association between vitamin $\mathrm{D}$ status and cardiometabolic risk, measured by a combination of body composition, ANS activity, and endothelial function markers.

\section{Specific Aims and Hypotheses}

Specific Aim 1: To determine the proportion of vitamin $D$ insufficient individuals and correlates of vitamin $D$ status in a healthy older adult ( $>55$ years old) population living in Miami-Dade County.

Hypothesis 1a: The proportion of vitamin D insufficient individuals (25(OH)D $<30$ $\mathrm{ng} / \mathrm{ml}$ ) in a healthy older adult ( $>55$ years old) sample living in Miami-Dade will be lower than the prevalence reported for the general United States population. 
Hypothesis 1b: Vitamin D dietary intake will not be a determinant of vitamin D status in an older adult sample living in Miami-Dade. Thus vitamin D intake will not predict vitamin D status and will not be significantly different between vitamin D insufficient $(25(\mathrm{OH}) \mathrm{D}<30 \mathrm{ng} / \mathrm{ml})$ and vitamin $\mathrm{D}$ sufficient $(25(\mathrm{OH}) \mathrm{D} \geq 30 \mathrm{ng} / \mathrm{ml})$ individuals.

Hypothesis 1c: Sun exposure will be a significant positive correlate of vitamin D status in older adults living in Miami-Dade County. Those who are vitamin D insufficient (25(OH)D $<30 \mathrm{ng} / \mathrm{ml}$ ) will have significantly lower sun exposure scores than those who are vitamin D sufficient (25(OH)D $\geq 30 \mathrm{ng} / \mathrm{ml})$.

\section{Specific Aim 2: To investigate the association of vitamin D status with cognitive processing during movement as measured using the dual task physical performance tests.}

Hypothesis 2: Vitamin D status of healthy older adults ( $>55$ years old) will be significantly associated with worse performance in dual tasking compared to single tasking.

Hypothesis 2a: Participants who are vitamin D insufficient (25(OH)D $<30 \mathrm{ng} / \mathrm{ml})$ will have significantly slower dual task velocities as well as a larger dual to single task gait velocity difference than those who are vitamin D sufficient $(25(\mathrm{OH}) \mathrm{D} \geq 30 \mathrm{ng} / \mathrm{ml})$ Hypothesis 2b: Participants who are vitamin D insufficient (25(OH)D $<30 \mathrm{ng} / \mathrm{ml}$ ) will have significantly slower dual task counting rates and a larger dual to single task counting rate difference than those who are vitamin $\mathrm{D}$ sufficient $(25(\mathrm{OH}) \mathrm{D} \geq 30 \mathrm{ng} / \mathrm{ml})$. 
Specific Aim 3: To investigate the association between vitamin D status and cardiometabolic risk (CMR), measured by integrating markers of body composition, ANS activity function, and endothelial function markers. Hypothesis 3: Vitamin D status of healthy older adults ( $>55$ years old) will be significantly and inversely associated with cardiometabolic risk (as calculated from the assessment of body composition, ANS activity and endothelial function).

Hypothesis 3a: Participants who are vitamin D insufficient $(25(\mathrm{OH}) \mathrm{D}<30 \mathrm{ng} / \mathrm{ml})$ will have significantly higher cardiometabolic risk scores than those who are vitamin D sufficient (25(OH)D $\geq 30 \mathrm{ng} / \mathrm{ml})$. 


\begin{tabular}{|c|c|c|c|}
\hline Hypotheses & $\begin{array}{c}\text { Independent } \\
\text { Variable and } \\
\text { Assessment } \\
\end{array}$ & $\begin{array}{c}\text { Dependent } \\
\text { Variable and } \\
\text { Assessment } \\
\end{array}$ & Statistics \\
\hline $\begin{array}{l}\text { 1a } \\
\text { Prevalence of vitamin D status }\end{array}$ & & $\begin{array}{l}\text { Vitamin D status } \\
\text { Serum 25(OH)D } \\
\text { Categorical } \\
\text { (insufficient <30 } \\
\text { ng/ml, sufficient } \geq \\
30 \mathrm{ng} / \mathrm{ml} \text { ) }\end{array}$ & $\begin{array}{l}\text { Vitamin D status was described using } \\
\text { frequencies, percentages, ranges, means and } \\
\text { standard deviations. Spearman’s correlations } \\
\text { were used to estimate associations between } \\
\text { vitamin D status and correlates. Independent t- } \\
\text { tests and chi-squares were used to compare } \\
\text { potential correlates of vitamin D status between } \\
\text { vitamin D insufficient }(25(\mathrm{OH}) \mathrm{D}<30 \mathrm{ng} / \mathrm{ml}) \text { and } \\
\text { sufficient }(25(\mathrm{OH}) \mathrm{D} \geq 30 \mathrm{ng} / \mathrm{ml}) \text { participants. } \\
\text { Multiple linear and logistic regressions were } \\
\text { used to examine the relationship between } \\
\text { vitamin D status and explanatory variables. }\end{array}$ \\
\hline $\begin{array}{l}\text { 1b } \\
\text { Vitamin D status and dietary intake }\end{array}$ & $\begin{array}{l}\text { Vitamin D intake } \\
\text { Vitamin D and } \\
\text { calcium short food } \\
\text { frequency } \\
\text { questionnaire } \\
\text { Continuous }\end{array}$ & $\begin{array}{l}\text { Vitamin D status } \\
\text { Serum 25(OH)D }\end{array}$ & $\begin{array}{l}\text { Vitamin D intake was described using } \\
\text { frequencies, percentages, ranges, means and } \\
\text { standard deviations. Spearman correlations were } \\
\text { performed to evaluate the relationship between } \\
\text { vitamin D status and vitamin D intake. } \\
\text { Independent t-tests were used to compare } \\
\text { vitamin D insufficient ( } 25(\mathrm{OH}) \mathrm{D}<30 \mathrm{ng} / \mathrm{ml}) \text { and } \\
\text { sufficient }(25(\mathrm{OH}) \mathrm{D} \geq 30 \mathrm{ng} / \mathrm{ml}) \text { participants in } \\
\text { vitamin D dietary intake. Multiple linear and } \\
\text { logistic regressions were used to examine the } \\
\text { relationship between vitamin D status and } \\
\text { vitamin D intake. }\end{array}$ \\
\hline
\end{tabular}




\begin{tabular}{|c|c|c|c|}
\hline Hypotheses & $\begin{array}{c}\text { Independent Variable } \\
\text { and Assessment }\end{array}$ & $\begin{array}{c}\text { Dependent Variable } \\
\text { and Assessment }\end{array}$ & Statistics \\
\hline $\begin{array}{l}\text { 1c } \\
\text { Vitamin D status and sun } \\
\text { exposure and related factors }\end{array}$ & $\begin{array}{l}\text { Sun exposure } \\
\text { Sun exposure } \\
\text { questionnaire } \\
\text { Continuous }\end{array}$ & $\begin{array}{l}\text { Vitamin D status } \\
\text { Serum } 25(\mathrm{OH}) \mathrm{D} \\
\text { Categorical } \\
\text { (insufficient }<30 \mathrm{ng} / \mathrm{ml} \text {, } \\
\text { sufficient } \geq 30 \mathrm{ng} / \mathrm{ml} \text { ) }\end{array}$ & $\begin{array}{l}\text { Sun exposure was described using frequencies, } \\
\text { percentages, ranges, means and standard } \\
\text { deviations. Spearman correlations were performed } \\
\text { to evaluate the relationship between vitamin D } \\
\text { status and sun exposure. Independent t-tests and } \\
\text { chi-squares were used to compare vitamin D } \\
\text { insufficient }(25(\mathrm{OH}) \mathrm{D}<30 \mathrm{ng} / \mathrm{ml}) \text { and sufficient } \\
(25(\mathrm{OH}) \mathrm{D} \geq 30 \mathrm{ng} / \mathrm{ml}) \text { participants in sun } \\
\text { exposure. Multiple linear and logistic regressions } \\
\text { were used to examine the relationship between } \\
\text { vitamin D status and sun exposure. }\end{array}$ \\
\hline $\begin{array}{l}\text { 2a } \\
\text { Vitamin D status, dual task } \\
\text { velocity and dual to single task } \\
\text { gait velocity difference. }\end{array}$ & $\begin{array}{l}\text { Dual task gait speed } \\
\text { GAITRite system will } \\
\text { record gait speed when } \\
\text { walking while counting } \\
\text { backward by from } 50 \\
\text { by } 1 . \\
\text { Continuous }\end{array}$ & $\begin{array}{l}\text { Vitamin D status } \\
\text { Serum 25(OH)D }\end{array}$ & $\begin{array}{l}\text { Gait speed variables were described using } \\
\text { frequencies, percentages, ranges, means and } \\
\text { standard deviations. Spearman correlations were } \\
\text { performed to evaluate the relationship between } \\
\text { vitamin D status and single task, dual task and the } \\
\text { dual to single task difference in gait speed. Paired } \\
\text { t-tests were used to compare dual and single task } \\
\text { gait velocities. Independent t-tests were performed } \\
\text { to compare mean single and dual task gait } \\
\text { velocities between vitamin D insufficient } \\
(25(\mathrm{OH}) \mathrm{D}<30 \mathrm{ng} / \mathrm{ml}) \text { and sufficient ( } 25(\mathrm{OH}) \mathrm{D} \\
\geq 30 \mathrm{ng} / \mathrm{ml}) \text { participants. One-way repeated } \\
\text { measures ANOVAs were used to compare the } \\
\text { dual to single task difference in gait velocity } \\
\text { between vitamin D status categories. Multiple } \\
\text { logistic regressions were used to examine the } \\
\text { relationship between vitamin D insufficiency and } \\
\text { the dual to single task difference in gait speed. }\end{array}$ \\
\hline
\end{tabular}




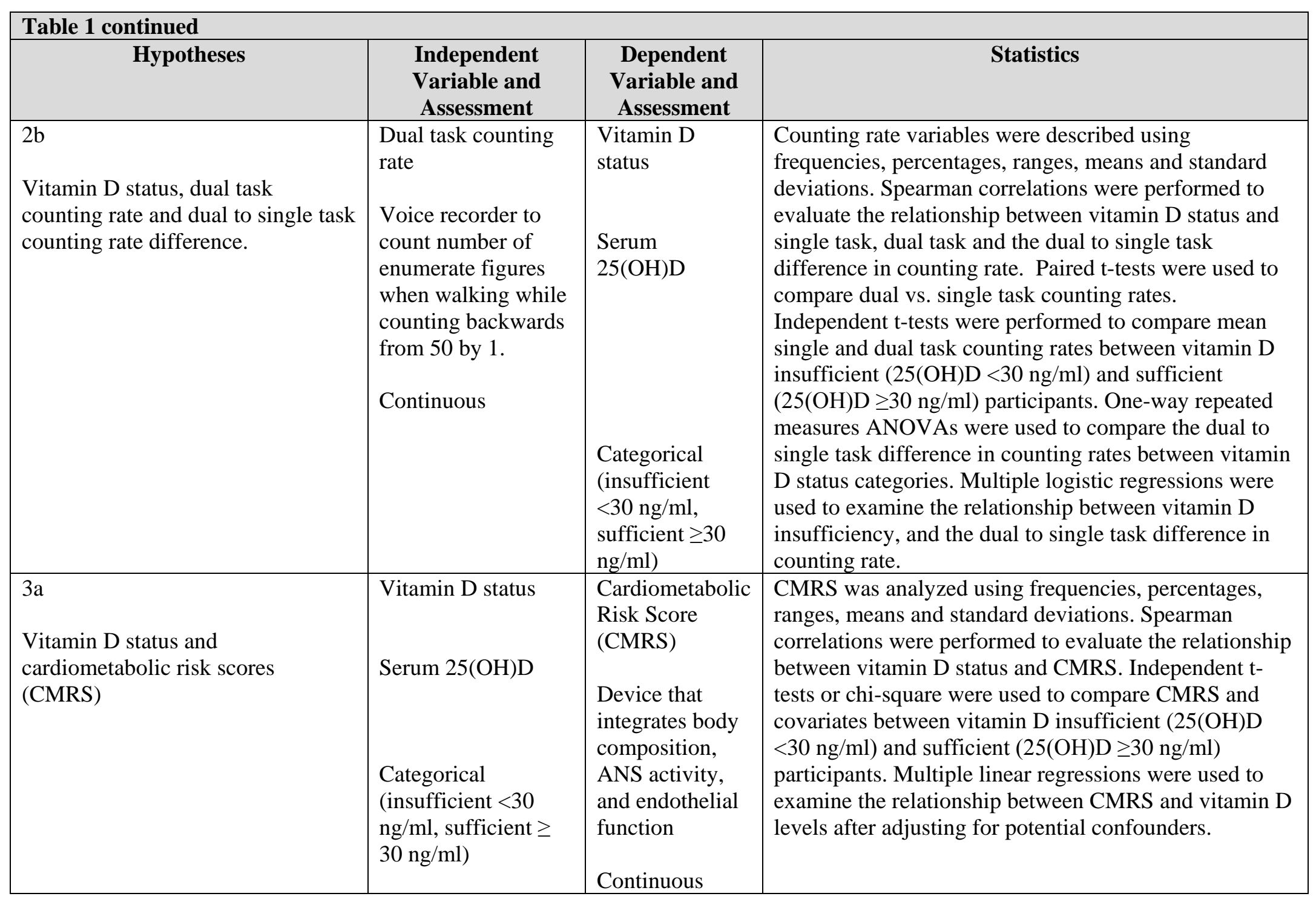




\section{References}

1. Holick MF. Vitamin D deficiency. N Engl J Med. 2007;357(3):266-281.

2. Hollis BW, Wagner CL, Drezner MK, Binkley NC. Circulating vitamin D3 and 25hydroxyvitamin D in humans: An important tool to define adequate nutritional vitamin D status. J Steroid Biochem Mol Biol. 2007;103(3-5):631-634.

3. Forrest KY, Stuhldreher WL. Prevalence and correlates of vitamin D deficiency in U.S. adults. Nutr Res. 2011;31(1):48-54.

4. Zadshir A, Tareen N, Pan D, Norris K, Martins D. The prevalence of hypovitaminosis D among U.S. adults: Data from the NHANES III. Ethn Dis. 2005;15(4 Suppl 5):97-101.

5. Llewellyn DJ, Lang IA, Langa KM, Melzer D. Vitamin D and cognitive impairment in the elderly U.S. population. J Gerontol A Biol Sci Med Sci. 2011;66(1):59-65.

6. Moore C, Murphy MM, Keast DR, Holick MF. Vitamin D intake in the United States. J Am Diet Assoc. 2004;104(6):980-983.

7. Brock K, Huang WY, Fraser DR, et al. Low vitamin D status is associated with physical inactivity, obesity and low vitamin D intake in a large U.S. sample of healthy middle-aged men and women. J Steroid Biochem Mol Biol. 2010;121(1-2):462-466.

8. Chen TC, Chimeh F, Lu Z, et al. Factors that influence the cutaneous synthesis and dietary sources of vitamin D. Arch Biochem Biophys. 2007;460(2):213-217.

9. Levis S, Gomez A, Jimenez C, et al. Vitamin D deficiency and seasonal variation in an adult South Florida population. J Clin Endocrinol Metab. 2005;90(3):1557-1562.

10. Whiting SJ, Calvo MS. Correcting poor vitamin D status: Do older adults need higher repletion doses of vitamin D3 than younger adults? Mol Nutr Food Res. 2010;54(8):1077-1084.

11. Whiting SJ, Calvo MS. Dietary recommendations to meet both endocrine and autocrine needs of vitamin D. J Steroid Biochem Mol Biol. 2005;97(1-2):7-12.

12. Segal E, Dvorkin L, Lavy A, et al. Bone density in axial and appendicular skeleton in patients with lactose intolerance: Influence of calcium intake and vitamin D status. $J$ Am Coll Nutr. 2003;22(3):201-207.

13. Prentice A, Goldberg GR, Schoenmakers I. Vitamin D across the lifecycle: Physiology and biomarkers. Am J Clin Nutr. 2008;88(2):500-506. 
14. Salamone LM, Dallal GE, Zantos D, Makrauer F, Dawson-Hughes B. Contributions of vitamin D intake and seasonal sunlight exposure to plasma 25-hydroxyvitamin D concentration in elderly women. Am J Clin Nutr. 1994;59(1):80-86.

15. Holick MF. Photobiologyof vitamin D. In: Feldman D, Pike JW, Adams JS, eds. Vitamin D. 3rd ed. San Diego, CA: Elsevier Academic Press; 2011:113-122.

16. Baggerly CA, Cuomo RE, French CB, et al. Sunlight and vitamin D: Necessary for public health. J Am Coll Nutr. 2015;34(4):359-365.

17. Toffanello ED, Perissinotto E, Sergi G, et al. Vitamin D and physical performance in elderly subjects: The Pro.V.A study. PLoS One. 2012;7(4):1-9.

18. Zamboni M, Zoico E, Tosoni P, et al. Relation between vitamin D, physical performance, and disability in elderly persons. J Gerontol A Biol Sci Med Sci. 2002;57(1):7-11.

19. Muir SW, Montero-Odasso M. Effect of vitamin D supplementation on muscle strength, gait and balance in older adults: A systematic review and meta-analysis. $J$ Am Geriatr Soc. 2011;59(12):2291-2300.

20. Bischoff-Ferrari HA, Giovannucci E, Willett WC, Dietrich T, Dawson-Hughes B. Estimation of optimal serum concentrations of 25-hydroxyvitamin D for multiple health outcomes. Am J Clin Nutr. 2006;84(1):18-28.

21. Dukas L, Staehelin HB, Schacht E, Bischoff HA. Better functional mobility in community-dwelling elderly is related to D-hormone serum levels and to daily calcium intake. J Nutr Health Aging. 2005;9(5):347-351.

22. Gallagher JC. The effects of calcitriol on falls and fractures and physical performance tests. J Steroid Biochem Mol Biol. 2004;89-90(1-5):497-501.

23. Houston DK, Cesari M, Ferrucci L, et al. Association between vitamin D status and physical performance: The InCHIANTI study. J Gerontol A Biol Sci Med Sci. 2007;62(4):440-446.

24. Wicherts IS, van Schoor NM, Boeke AJ, et al. Vitamin D status predicts physical performance and its decline in older persons. J Clin Endocrinol Metab. 2007;92(6):20582065.

25. Semba RD, Houston DK, Bandinelli S, et al. Relationship of 25-hydroxyvitamin D with all-cause and cardiovascular disease mortality in older community-dwelling adults. Eur J Clin Nutr. 2010;64(2):203-209. 
26. Annweiler C, Montero-Odasso M, Schott AM, Berrut G, Fantino B, Beauchet O. Fall prevention and vitamin $\mathrm{D}$ in the elderly: An overview of the key role of the non-bone effects. J Neuroeng Rehabil. 2010;7(1):50-63.

27. Annweiler C, Schott AM, Berrut G, Fantino B, Beauchet O. Vitamin D-related changes in physical performance: A systematic review. J Nutr Health Aging. 2009;13(10):893-898.

28. Bischoff-Ferrari HA, Dawson-Hughes B, Willett WC, et al. Effect of vitamin D on falls: A meta-analysis. JAMA. 2004;291(16):1999-2006.

29. Dhesi JK, Jackson SH, Bearne LM, et al. Vitamin D supplementation improves neuromuscular function in older people who fall. Age Ageing. 2004;33(6):589-595.

30. Haroon M, FitzGerald O. Vitamin D deficiency: Subclinical and clinical consequences on musculoskeletal health. Curr Rheumatol Rep. 2012;14(3):286-293.

31. Janssen HC, Samson MM, Verhaar HJ. Vitamin D deficiency, muscle function, and falls in elderly people. Am J Clin Nutr. 2002;75(4):611-615.

32. Rejnmark L. Effects of vitamin D on muscle function and performance: A review of evidence from randomized controlled trials. Ther Adv Chronic Dis. 2011;2(1):25-37.

33. Stechschulte SA, Kirsner RS, Federman DG. Vitamin D: Bone and beyond, rationale and recommendations for supplementation. Am J Med. 2009;122(9):793-802.

34. Montero-Odasso M, Wells JL, Borrie MJ, Speechley M. Can cognitive enhancers reduce the risk of falls in older people with mild cognitive impairment? A protocol for a randomised controlled double blind trial. BMC Neurol. 2009;9(8):42-54.

35. Przybelski RJ, Binkley NC. Is vitamin D important for preserving cognition? A positive correlation of serum 25-hydroxyvitamin D concentration with cognitive function. Arch Biochem Biophys. 2007;460(2):202-205.

36. Buell JS, Scott TM, Dawson-Hughes B, et al. Vitamin D is associated with cognitive function in elders receiving home health services. J Gerontol A Biol Sci Med Sci. 2009;64(8):888-895.

37. Lee DM, Tajar A, Ulubaev A, et al. The association between different cognitive domains and age in a multi-centre study of middle-aged and older European men. Int $J$ Geriatr Psychiatry. 2009;24(11):1257-1266.

38. Llewellyn DJ, Langa KM, Lang IA. Serum 25-hydroxyvitamin D concentration and cognitive impairment. J Geriatr Psychiatry Neurol. 2009;22(3):188-195. 
39. Wilkins CH, Birge SJ, Sheline YI, Morris JC. Vitamin D deficiency is associated with worse cognitive performance and lower bone density in older African Americans. $J$ Natl Med Assoc. 2009;101(4):349-354.

40. Annweiler C, Schott AM, Allali G, et al. Association of vitamin D deficiency with cognitive impairment in older women: Cross-sectional study. Neurology. 2010;74(1):2732.

41. Llewellyn DJ, Lang IA, Langa KM, et al. Vitamin D and risk of cognitive decline in elderly persons. Arch Intern Med. 2010;170(13):1135-1141.

42. Annweiler C, Rolland Y, Schott AM, et al. Higher vitamin D dietary intake is associated with lower risk of Alzheimer's disease: A 7-year follow-up. J Gerontol A Biol Sci Med Sci. 2012;67(11):1205-1211.

43. Slinin Y, Paudel M, Taylor BC, et al. Association between serum 25(OH) vitamin D and the risk of cognitive decline in older women. J Gerontol A Biol Sci Med Sci. 2012;67(10):1092-1098.

44. Brouwer-Brolsma EM, van de Rest O, Tieland M, et al. Serum 25-hydroxyvitamin D is associated with cognitive executive function in Dutch prefrail and frail elderly: A cross-sectional study exploring the associations of 25-hydroxyvitamin D with glucose metabolism, cognitive performance and depression. J Am Med Dir Assoc. 2013;14(11):8529-85217.

45. Annweiler C, Maby E, Meyerber M, Beauchet O. Hypovitaminosis D and executive dysfunction in older adults with memory complaint: A memory clinic-based study. Dement Geriatr Cogn Disord. 2014;37(5-6):286-293.

46. Chei CL, Raman P, Yin ZX, Shi XM, Zeng Y, Matchar DB. Vitamin D levels and cognition in elderly adults in China. J Am Geriatr Soc. 2014;62(11):2125-2129.

47. Hooshmand B, Lokk J, Solomon A, et al. Vitamin D in relation to cognitive impairment, cerebrospinal fluid biomarkers, and brain volumes. J Gerontol A Biol Sci Med Sci. 2014;69(9):1132-1138.

48. Toffanello ED, Coin A, Perissinotto E, et al. Vitamin D deficiency predicts cognitive decline in older men and women: The Pro.V.A. study. Neurology. 2014;83(24):22922298.

49. Wilson VK, Houston DK, Kilpatrick L, et al. Relationship between 25hydroxyvitamin D and cognitive function in older adults: The Health, Aging and Body Composition study. J Am Geriatr Soc. 2014;62(4):636-641. 
50. Houston DK, Tooze JA, Neiberg RH, et al. 25-hydroxyvitamin D status and change in physical performance and strength in older adults: The health, aging, and body composition study. Am J Epidemiol. 2012;176(11):1025-1034.

51. Peterson A, Mattek N, Clemons A, et al. Serum vitamin D concentrations are associated with falling and cognitive function in older adults. $J$ Nutr Health Aging. 2012;16(10):898-901.

52. Menant JC, Close JC, Delbaere K, et al. Relationships between serum vitamin D levels, neuromuscular and neuropsychological function and falls in older men and women. Osteoporos Int. 2012;23(3):981-989.

53. Houston DK, Neiberg RH, Tooze JA, et al. Low 25-hydroxyvitamin D predicts the onset of mobility limitation and disability in community-dwelling older adults: The Health ABC study. J Gerontol A Biol Sci Med Sci. 2013;68(2):181-187.

54. Gschwind YJ, Bischoff-Ferrari HA, Bridenbaugh SA, Hardi I, Kressig RW. Association between serum vitamin D status and functional mobility in memory clinic patients aged 65 years and older. Gerontology. 2014;60(2):123-129.

55. Mann MC, Hollenberg MD, Hanley DA, Ahmed SB. Vitamin D, the autonomic nervous system, and cardiovascular risk. Physiol Rep. 2015;3(4):123491-1234914.

56. Kim DH, Sabour S, Sagar UN, Adams S, Whellan DJ. Prevalence of hypovitaminosis $\mathrm{D}$ in cardiovascular diseases (from the National Health and Nutrition Examination Survey 2001 to 2004). Am J Cardiol. 2008;102(11):1540-1544.

57. Norman PE, Powell JT. Vitamin D and cardiovascular disease. Circ Res. 2014;114(2):379-393.

58. Deo R, Katz R, Shlipak MG, et al. Vitamin D, parathyroid hormone, and sudden cardiac death: Results from the cardiovascular health study. Hypertension. 2011;58(6):1021-1028.

59. Wang TJ, Pencina MJ, Booth SL, et al. Vitamin D deficiency and risk of cardiovascular disease. Circulation. 2008;117(4):503-511.

60. Perna L, Schottker B, Holleczek B, Brenner H. Serum 25-hydroxyvitamin D and incidence of fatal and nonfatal cardiovascular events: A prospective study with repeated measurements. J Clin Endocrinol Metab. 2013;98(12):4908-4915.

61. Schottker B, Jorde R, Peasey A, et al. Vitamin D and mortality: Meta-analysis of individual participant data from a large consortium of cohort studies from Europe and the United States. BMJ. 2014;348(3656):1-15. 
62. Parker J, Hashmi O, Dutton D, et al. Levels of vitamin D and cardiometabolic disorders: Systematic review and meta-analysis. Maturitas. 2010;65(3):225-236.

63. Drechsler C, Pilz S, Obermayer-Pietsch B, et al. Vitamin D deficiency is associated with sudden cardiac death, combined cardiovascular events, and mortality in haemodialysis patients. Eur Heart J. 2010;31(18):2253-2261.

64. Thadhani R, Appelbaum E, Pritchett Y, et al. Vitamin D therapy and cardiac structure and function in patients with chronic kidney disease: The PRIMO randomized controlled trial. JAMA. 2012;307(7):674-684.

65. Wang L, Song Y, Manson JE, et al. Circulating 25-hydroxy-vitamin D and risk of cardiovascular disease: A meta-analysis of prospective studies. Circ Cardiovasc Qual Outcomes. 2012;5(6):819-829.

66. Schottker B, Haug U, Schomburg L, et al. Strong associations of 25-hydroxyvitamin $\mathrm{D}$ concentrations with all-cause, cardiovascular, cancer, and respiratory disease mortality in a large cohort study. Am J Clin Nutr. 2013;97(4):782-793.

67. Giovannucci E, Liu Y, Hollis BW, Rimm EB. 25-hydroxyvitamin D and risk of myocardial infarction in men: A prospective study. Arch Intern Med. 2008;168(11):11741180.

68. Autier P, Gandini S. Vitamin D supplementation and total mortality: A meta-analysis of randomized controlled trials. Arch Intern Med. 2007;167(16):1730-1737.

69. Gotsman I, Shauer A, Zwas DR, et al. Vitamin D deficiency is a predictor of reduced survival in patients with heart failure; vitamin D supplementation improves outcome. Eur J Heart Fail. 2012;14(4):357-366.

70. Pilz S, Dobnig H, Fischer JE, et al. Low vitamin D levels predict stroke in patients referred to coronary angiography. Stroke. 2008;39(9):2611-2613.

71. Dobnig H, Pilz S, Scharnagl H, et al. Independent association of low serum 25hydroxyvitamin D and 1,25-dihydroxyvitamin D levels with all-cause and cardiovascular mortality. Arch Intern Med. 2008;168(12):1340-1349.

72. Wang L, Manson JE, Song Y, Sesso HD. Systematic review: Vitamin D and calcium supplementation in prevention of cardiovascular events. Ann Intern Med. 2010;152(5):315-323.

73. Dekker JM, Schouten EG, Klootwijk P, Pool J, Swenne CA, Kromhout D. Heart rate variability from short electrocardiographic recordings predicts mortality from all causes in middle-aged and elderly men: The Zutphen study. Am J Epidemiol. 1997;145(10):899908. 
74. Tsuji H, Venditti FJ,Jr, Manders ES, et al. Determinants of heart rate variability. J Am Coll Cardiol. 1996;28(6):1539-1546.

75. Tsuji H, Larson MG, Venditti FJ,Jr, et al. Impact of reduced heart rate variability on risk for cardiac events: The Framingham Heart Study. Circulation. 1996;94(11):28502855.

76. La Rovere MT, Pinna GD, Maestri R, et al. Short-term heart rate variability strongly predicts sudden cardiac death in chronic heart failure patients. Circulation. 2003;107(4):565-570.

77. Goldberger JJ, Cain ME, Hohnloser SH, et al. American Heart association/American College of Cardiology Foundation/Heart Rhythm society: Scientific statement on noninvasive risk stratification techniques for identifying patients at risk for sudden cardiac death: A scientific statement from the American Heart Association council on clinical cardiology committee on electrocardiography and arrhythmias and council on epidemiology and prevention. Circulation. 2008;118(14):1497-1518.

78. Lauer MS. Autonomic function and prognosis. Cleve Clin J Med. 2009;76(Suppl 2):S18-22.

79. Pilz S, Tomaschitz A, Drechsler C, Dekker JM, Marz W. Vitamin D deficiency and myocardial diseases. Mol Nutr Food Res. 2010;54(8):1103-1113.

80. Liu LC, Voors AA, van Veldhuisen DJ, et al. Vitamin D status and outcomes in heart failure patients. Eur J Heart Fail. 2011;13(6):619-625.

81. Corley CT. Senior fact sheet 2010. Florida Department of Elder Affairs Web site. http://elderaffairs.state.fl.us/doea/publications.php;. Updated 2010. Accessed August 31, 2015.

82. U.S. Census Bureau. State \& County quick facts: Miami-Dade County, Florida. http://quickfacts.census.gov/qfd/states/12/12086.html. Accessed April 20, 2013.

83. Werner CA. The older population: 2010 census briefs. United States Census Bureau Web site. https://www.census.gov/prod/cen2010/briefs/c2010br-09.pdf. Updated 2011. Accessed August 31, 2015.

84. Scott R, Corley CT. Senior fact sheets 2012. Florida Department of Elder Affairs Web site. http://elderaffairs.state.fl.us/doea/publications.php;. Updated 2012. Accessed August 31, 2015.

85. Scott R, Corley CT. State plan on aging 2013-2016. Florida Department of Elder Affairs Web site. http://elderaffairs.state.fl.us/doea/publications.php;. Updated 2012. Accessed August 31, 2015. 
86. Florida Department of Health in Miami-Dade County. Injury deaths and hospitalizations, 2007-2009 residents of miami-dade county aged 65+ yrs. Florida Department of Health in Miami-Dade County Web site. http://miamidade.floridahealth.gov/programs-and-services/wellnessprograms/injury-and-violence-prevention/_documents/DC-HD\%20200709\%20Age\%2065.pdf;. Updated 2011. Accessed August 31, 2015.

87. Ross AC, Manson JE, Abrams SA, et al. The 2011 report on Dietary Reference Intakes for calcium and vitamin $\mathrm{D}$ from the Institute of Medicine: What clinicians need to know. J Clin Endocrinol Metab. 2011;96(1):53-58.

88. Robertson MC, Gillespie LD. Fall prevention in community-dwelling older adults. JAMA. 2013;309(13):1406-1407.

89. Kalyani RR, Stein B, Valiyil R, Manno R, Maynard JW, Crews DC. Vitamin D treatment for the prevention of falls in older adults: Systematic review and meta-analysis. J Am Geriatr Soc. 2010;58(7):1299-1310.

90. Bischoff-Ferrari HA, Dawson-Hughes B, Staehelin HB, et al. Fall prevention with supplemental and active forms of vitamin D: A meta-analysis of randomised controlled trials. BMJ. 2009;339(3692):1-11.

91. Jackson C, Gaugris S, Sen SS, Hosking D. The effect of cholecalciferol (vitamin D3) on the risk of fall and fracture: A meta-analysis. QJM. 2007;100(4):185-192.

92. Murad MH, Elamin KB, Abu Elnour NO, et al. Clinical review: The effect of vitamin D on falls: A systematic review and meta-analysis. J Clin Endocrinol Metab. 2011;96(10):2997-3006.

93. Cranney A, Horsley T, O'Donnell S, et al. Evidence report/technology assessment: Effectiveness and safety of vitamin D in relation to bone health. Evid Rep Technol Assess (Full Rep). 2007;158(8):1-235.

94. Thomas MK, Lloyd-Jones DM, Thadhani RI, et al. Hypovitaminosis D in medical inpatients. N Engl J Med. 1998;338(12):777-783.

95. Annweiler C, Beauchet O, Bartha R, Hachinski V, Montero-Odasso M. Vitamin D and caudal primary motor cortex: A magnetic resonance spectroscopy study. PLoS One. 2014;9(1):873141-873145.

96. De Novellis V, Loffreda A, Vitagliano S, et al. Effects of dietary vitamin D deficiency on the cardiovascular system. Res Commun Chem Pathol Pharmacol. 1994;83(2):125-144. 


\section{CHAPTER II: LITERATURE REVIEW}

\section{Vitamin D Deficiency in the Elderly}

Approximately one billion people in the world have deficient or insufficient levels

of vitamin D. ${ }^{1}$ The National Health and Nutrition Examination Survey 2005-2006 revealed that $41.6 \%$ of United States adults (18 years or older) had deficient vitamin D levels, defined as 25(OH)D $<20 \mathrm{ng} / \mathrm{ml}$. ${ }^{2,3}$ The elderly are at a higher risk of vitamin D deficiency as indicated in the National Health and Nutrition Examination Survey (NHANES) 1988-1994 data that serum vitamin D levels were lower among adults 65 years and older compared to middle aged (40-59 years of age) and younger adults (18-29 years of age). Of these older adults, $23 \%$ and $62.5 \%$ had vitamin D deficient $(<20 \mathrm{ng} / \mathrm{ml})$ and insufficient ( $<30 \mathrm{ng} / \mathrm{ml}$ ) levels, respectively. ${ }^{4,5}$ The main sources of vitamin D are skin synthesis and dietary intake. Vitamin D deficiency may be more prevalent in the elderly population due to a complex interplay between several age-related factors affecting these sources like decreased dietary intake, bioavailability and skin synthesis, as discussed below. 6,7

\section{Defining Vitamin D Deficiency Based on its Main Function}

Vitamin D deficiency in the elderly has received much attention as a risk factor for falls because of its effect on musculoskeletal health, thus affecting gait. ${ }^{8-15}$ The most studied physiological role of vitamin D is in calcium homeostasis and maintenance of bone health through its endocrine function in the intestine, bone, parathyroid glands, and kidneys. ${ }^{1}$ Vitamin D2 (ergocalciferol from plant sources) and D3 (cholecalciferol from 
animal sources) are transported to the liver bound to Vitamin D Binding Protein (VDBP), where it is hydroxylated by microsomal 25-alpha hydroxylase (CYP2R1) to 25hydroxyvitamin D (25(OH)D or calcidiol).$^{16}$ 25(OH)D binds to VDBP and is transported to the kidney or extra-renal tissues, where it is hydroxylated again by mitochondrial 1alpha hydroxylase (CYP27B1) to the most biologically active form, 1,25 dihydroxyvitamin $\mathrm{D}\left(1,25(\mathrm{OH})_{2} \mathrm{D}\right.$ or calcitriol). ${ }^{16,17}$ This active form binds to nuclear vitamin D receptors (VDRs) with high affinity (Kd $10^{-10} \mathrm{M}$ compared to $25(\mathrm{OH}) \mathrm{D}$ Kd $10^{-}$ ${ }^{8} \mathrm{M}$ ), causing VDR heterodimerization with other transcription factors like retinol $\mathrm{X}$ receptors (RXR) to induce or repress genomic signaling of more than 200 target genes. ${ }^{16}$ $1,25(\mathrm{OH})_{2} \mathrm{D}$ is catabolized in the kidney and extra-renal tissue by mitochondrial 24hydroxylase (CYP24A1), producing a series of 24-hydroxylated inactive metabolites. ${ }^{16}$ Serum $25(\mathrm{OH}) \mathrm{D}$, and not $1,25(\mathrm{OH})_{2} \mathrm{D}$ (the active form), is widely accepted as the best clinical indicator of vitamin D status. Compared to $1,25(\mathrm{OH})_{2} \mathrm{D}, 25(\mathrm{OH}) \mathrm{D}$ is the major circulating form of vitamin D (500-1000 times more abundant), and it has a halflife of 2-3 weeks, compared to 4-6 hours for $1,25(\mathrm{OH})_{2} \mathrm{D}$. Also, it reflects both dietary and sun exposure sources from the previous 4-6 weeks, while $1,25(\mathrm{OH})_{2} \mathrm{D}$ reflects immediate physiological needs due to the tight regulation of 25(OH)D hydroxylation and $1,25(\mathrm{OH})_{2} \mathrm{D}$ catabolism. ${ }^{18,19}$

Through the regulation of genes involved in bone remodeling, intestinal calcium absorption, and calcium and phosphate renal reabsorption, vitamin D maintains blood levels of calcium and phosphorus for the mineralization of bones to preserve bone mineral density. ${ }^{16}$ It is well known that vitamin D deficiency leads to a reduction in calcium absorption and eventually in the release of calcium from bones to maintain blood 
circulating levels of calcium. In adults, the most common manifestation of severe vitamin D deficiency is osteomalacia, in which the newly formed bone matrix does not mineralize and is characterized by symptoms of muscle weakness and discomfort, and throbbing aching bone pain. ${ }^{20}$ However, studies in the last two decades have provided evidence on roles of vitamin D that go beyond calcium homeostasis and bone health. ${ }^{21}$

Vitamin D “non-bone” effects may be achieved through its modulation of gene expression by binding VDRs in other tissues. Recent data have shown that VDRs are found in other tissues such as macrophages, liver, pancreas, colon, lung, breast, skin, adipose tissue, muscle, and brain. ${ }^{17,22}$

\begin{tabular}{|l|l|l|l|}
\hline \multicolumn{3}{|c|}{ Table 1: Vitamin D Status in Relation to Bone Health ${ }^{22,23}$} \\
\hline Category & $\mathbf{n g} / \mathbf{m l}$ & $\mathbf{n m o l} / \mathbf{L}$ & \multicolumn{1}{c|}{ Clinical symptoms } \\
\hline Very Deficient & $<25$ & $<10$ & $\begin{array}{l}\text { Rickets, osteomalacia, myopathy } \\
\text { Severe hyperparathyroidism } \\
\text { Calcium malabsorption }\end{array}$ \\
\hline Deficient & $25-50$ & $10-20$ & $\begin{array}{l}\text { Mild hyperparathyroidism } \\
\text { Decreased calcium absorption } \\
\text { Decreased bone mineral density (osteoporosis) } \\
\text { May have subclinical myopathy }\end{array}$ \\
\hline Insufficient & $50-75$ & $20-30$ & Parathyroid hormone may be high \\
\hline Sufficient & $75-375$ & $30-150$ & No vitamin D dependent function disturbances \\
\hline Toxicity & $>375$ & $>150$ & $\begin{array}{l}\text { Hypercalemcia } \\
\text { Soft tissue calcification }\end{array}$ \\
\hline
\end{tabular}

Recommended Vitamin D Intake, Vitamin D Sources, and the Older Adult

Vitamin D is considered a steroid hormone obtained naturally from dietary sources and synthesized by the body from sunlight. Vitamin D is not stored in the muscle and fat tissue until serum concentrations are higher than $20 \mathrm{ng} / \mathrm{ml}$. Only then is the body able to use vitamin D reserves independently of sun exposure and dietary intakes. ${ }^{2,23,24}$ 
For older adults, however, reaching this vitamin D threshold is difficult due to complex interactions between factors that affect dietary intake, bioavailability and skin synthesis.

The body of an older adult tends to draw more vitamin $\mathrm{D}$ reserves than a younger person. ${ }^{2,23,24}$ Several explanations have been proposed to explain why reaching optimal serum vitamin D levels is harder for the elderly compared to younger adults. First of all, vitamin D intake is below recommendations for older adults. The 2010 report of the Institute of Medicine (IOM) committee established Dietary Reference Intakes (DRIs) for vitamin D of 600 International Units (IU) per day for adults below the age of 70, and 800 IU per day for adults over the age of 70, with a tolerable upper limit of 4,000 IU per day, to maintain serum 25(OH)D above $20 \mathrm{ng} / \mathrm{ml}$, which was deemed necessary to preserve bone health. ${ }^{20,25-27}$ The Endocrine Society, however, recommended that adults over the age of 18 should take between 1500 and 2000 IU/day, with an upper limit of 10,000 IU/day, to maintain 25(OH)D between $40-60 \mathrm{ng} / \mathrm{ml}$ and preserve physiological functions that go beyond bone health, based on $100 \mathrm{IU}$ of vitamin D3 increasing 25(OH)D by 1 $\mathrm{ng} / \mathrm{ml}$ in serum. ${ }^{28}$

In the United States, very few foods contain significant amounts of vitamin D; thus, dietary intake may minimally affect 25(OH)D status. ${ }^{29-31}$ Dietary sources include fatty fish like salmon, tuna, sardines, and fish oil, egg yolks, organ meats, mushrooms, and fortified foods like milk and dairy products, breakfast cereals, bread, margarine, spreads, and vegetable oils. ${ }^{29,30}$ Supplement use may compensate for the lack of vitamin D intake from foods. Use of vitamin D supplement has increased over time in adults, as 25\% reporting use of vitamin D supplements in NHANES 1999-2002 and 37\% in 
NHANES 2003-2006..$^{32}$ Low vitamin D intakes from food and supplements, however, have been reported in older adults, and it has been associated with low serum vitamin D. ${ }^{6,7,33}$

Recommended dietary intake of vitamin D is higher for the elderly; however, dietary intake usually decreases with age. ${ }^{34}$ This may be due to physiological and psychological factors, such as depression, age-related lactose intolerance that limits the intake of fortified milk products, and hormonal factors regulating satiety. ${ }^{3,34-39}$ Age is an important and complex risk factor for vitamin D deficiency because it affects bioavailability due to impaired gut absorption of vitamin D. ${ }^{3,34}$ Bioavailability is also decreased due to the age-related decrease in metabolic rate with hormonal changes that occur during aging that often result in weight gain, as seen in the growing prevalence of obesity among the elderly in the United States. ${ }^{40,41}$ Obesity has been correlated with low vitamin D status in the elderly, probably due to the sequestration of vitamin D by increased body fat. ${ }^{3,7,34}$ Besides obesity, the presence of other comorbidities and behavioral factors, such as liver, kidney, and gastrointestinal diseases, and the use of medication, tobacco and alcohol, may directly affect vitamin D metabolism and bioavailability. ${ }^{34}$

For those who are not taking adequate amounts of vitamin $\mathrm{D}$ through diet, sunlight would often be their main source of vitamin D. ${ }^{17,42}$ Vitamin D is mostly synthesized in the skin from 7-dehydrocholesterol after solar exposure, where ultraviolet B (UVB, 290-315 nm) light from the sun causes a photochemical rearrangement of 7dehydrocholesterol to pre-vitamin D3, which then undergoes thermal isomerization into vitamin D3. ${ }^{17,30,43,44}$ It is believed that sunlight exposure of arms and legs for 5-15 
minutes at midday during the summer months could produce about 3,000 IU of vitamin D. ${ }^{23}$ The effectiveness of vitamin D synthesis in the skin, however, is determined by skin pigmentation, amount of skin exposed and sunscreen use, and amount of solar radiation, which depends on the latitude, season, time of day, and time in the sun.

Darker pigmentation decreases the skin's capacity to use sunlight for making vitamin D because melanin absorbs UVB radiation effectively. ${ }^{6,47}$ Ethnicity and race are often used as a proxy for skin pigmentation, and a substantial amount of evidence that indicates a significant difference in vitamin D deficiency between different ethnic groups. ${ }^{44}$ For example, NHANES 2005-2006 revealed that the prevalence of vitamin D deficiency ( $<20 \mathrm{ng} / \mathrm{ml}$ ) was higher in blacks (82.1\%), followed by Hispanics (69.2\%) and whites (30.9\%). ${ }^{3}$ A more recent study evaluated vitamin D status in a communitydwelling elderly population (>60 years old) in South Florida and found a higher prevalence of vitamin D insufficiency $(<25 \mathrm{ng} / \mathrm{ml})$ among Afro-Caribbeans (30.8\%) and African Americans (30.4\%) compared to Hispanics (13\%) and European Americans (13\%). ${ }^{45}$ Those with darker skin pigmentation need four to10 times more sun exposure than lighter skin individuals. ${ }^{28}$

Unfortunately, most people avoid sunshine in order to stay cool, prevent skin aging, and reduce the risk of skin cancer by covering the skin with clothes and using sunscreen, all of which interfere with UVB transmission to the skin. ${ }^{34}$ A study in Europe in 1995 showed that wearing short sleeves instead of long, and thus bearing arms as well as the face, is associated with better vitamin D status in older people living in sunnier climates. ${ }^{46}$ Likewise, sufficient exposure to sunlight is unusual with modern lifestyles, since most people live and work indoors. ${ }^{34}$ Outdoor activity is associated with vitamin D 
status as shown by an analysis of NHANES 1988-1994 data that revealed that those who were 60 years or older and participated in daily outdoor activities had optimal vitamin D levels (>30 ng/ml) similar to young adults. ${ }^{47}$ Furthermore, physical activity, which is often used as a surrogate for outdoor activity, has been positively associated with serum vitamin D levels, such that lower levels of serum vitamin D have been correlated with physical inactivity in middle-aged and older adults. ${ }^{7,48}$

Also, the skin's ability to synthesize vitamin D depends on the amount of solar radiation reaching the biosphere, which depends on latitude, season and time of day. ${ }^{30,43}$ Based on the impact of sunlight exposure on vitamin D status, it has been assumed that vitamin D deficiency is less prevalent in populations living in lower latitudes and/or where seasonal variations are not as pronounced as in South Florida, where the weather is sunny and warm year-round. ${ }^{31}$ In contrast, other investigators reported a prevalence of $38-40 \%$ of hypovitaminosis $\mathrm{D}(25(\mathrm{OH}) \mathrm{D}<20 \mathrm{ng} / \mathrm{ml})$ in adult men and women $(>18$ years old) living in South Florida. ${ }^{31}$ A more recent study evaluated vitamin D status in a community-dwelling elderly population (>60 years old) in South Florida and found a prevalence of vitamin D insufficiency (<25 ng/ml) of $15.6 \% .^{45}$

In summary, vitamin D deficiency and insufficiency in the elderly may be a result of the complex interplay between age-related factors that affect dietary intake, bioavailability, and skin biosynthesis. Since $90-95 \%$ of vitamin D comes from skin synthesis, it would be expected that vitamin D deficiency is not a public health concern in populations where sunlight for synthesis is available year round. ${ }^{6,7}$ This is not the case for older adults living in Miami-Dade, however, and understanding the factors that affect vitamin D status in this population is deemed necessary. 


\section{Vitamin D, Fall Risk, and Mobility as Measured by Gait Speed in the Elderly}

Besides vitamin D deficiency, falls is another common public health concern among older adults living in Miami-Dade. Vitamin D deficiency in older adults has been linked to important correlates of disability, including falls and fractures. ${ }^{49-57}$ The major cause of physical disability in the elderly is mobility limitations, which eventually may lead to falls. ${ }^{58}$ According to the World Health Organization (WHO), a fall is defined as an event that results in the person unintentionally coming to rest on the ground or other lower level that is not due to a major intrinsic event, like seizure, stroke, loss of consciousness, epilepsy, or excess alcohol, or an environmental hazard like sustaining a blow. ${ }^{59}$ It is estimated that approximately $30 \%$ of community-dwelling adults and $50 \%$ of institutionalized adults more than 65 years of age experience one fall each year. ${ }^{60,61}$

In the United States, the elderly population (>65 years of age) is expected to increase by $20 \%-50 \%$ by the year $2030 .{ }^{62}$ Miami is the fourth city in the United States that is graying the fastest, and Florida Department of Elder Affairs reported that the top county for elders >60 years of age in 2010 and 2012 was Miami-Dade, with $14.9 \%$ of the population in this age range. ${ }^{63}$ Furthermore, the Miami-Dade County Department of Health in 2003 observed that falls were among the three leading causes of hospitalizations due to injury (36.7\% of all injury hospitalizations). Of these, $67.3 \%$ were attributed to residents over the age of $65 .{ }^{64}$ In later years, between 2007 and 2009, falls were the leading cause of injury of residents of Miami-Dade aged over 65 years and responsible for $79 \%$ of injury hospitalizations. One-third of hospitalizations related to falls resulted in hip fracture and $11 \%$ involved traumatic brain injury. ${ }^{65}$ 
Falls can result in increased morbidity and mortality and decreased quality of life, all of which translate to greater burden for the individual and healthcare system.${ }^{60}$ Hence, understanding the risk factors and mechanisms behind falls is important for the development of effective interventions that protect the elderly from disability.

An extensive amount of research supports the relationship between the risks of falls and vitamin D deficiency and the reduction of this risk by vitamin D supplementation in the elderly. ${ }^{10,25,60,66-71}$ For instance, a recent meta-analysis found that fallers have lower 25(OH)D concentrations $(25(\mathrm{OH}) \mathrm{D}<20 \mathrm{ng} / \mathrm{ml})$, more often than nonfallers. ${ }^{72}$ The mechanism by which vitamin $\mathrm{D}$ is related to fall risk is still unclear but it may be through its relationship with gait and cognition.

Gait impairments are one of the main risk factors for falls in the elderly. ${ }^{73}$ Older adults, compared to their younger counterparts, have significantly reduced gait speed ${ }^{73-75}$ and those over the age of 70 years have a $12-16 \%$ decline in gait speed per decade. ${ }^{76-79}$ This decline may be due to a compensatory adaptation to the age-related neuro-motor changes that increase the complexity of walking to provide a safer gait. Although these changes in gait pattern may be compensatory to stabilize posture, sometimes they are dysfunctional and are correlated with increased risk of accidental falls. ${ }^{80}$

One of the ways vitamin D may be related to fall risk is through its role in mobility as measured by gait speed. A systematic search of Medline Ovid found 11 observational and 6 interventional studies evaluating the relationship between vitamin D status and gait speed, or the effect of vitamin D supplementation on gait speed in community-dwelling older adults (Appendix A). Six of the 11 studies found a significant positive association between vitamin D deficiency and slower gait speed. ${ }^{81-85}$ In these 
studies, gait speed was measured on its own or as part of a physical performance battery, and it involved different tasks such as timed walking at different distances (6 meters ${ }^{82,86}$, 5 meters $^{84}, 8$ feet $^{83}$, and 30 meters and returning ${ }^{81}$ ), or walking on electronic walkways. ${ }^{85}$ Of the six randomized controlled trials, only two found an improvement in gait speed with vitamin D supplementation. ${ }^{52,87}$ One of the studies did not adjust for potential confounders and included calcium supplementation and exercise training, ${ }^{87}$ while the other did not report initial and final vitamin D levels, walking speeds, and involved other interventions such as hormone treatment. ${ }^{52}$ In these two studies, gait speed was also measured as part of a physical performance battery, and gait tasks included timed 6-meter walks ${ }^{52}$ and distance walking for 12 minutes. ${ }^{87}$ These studies demonstrate that vitamin D may play a role in mobility as measured by gait speed; however, the exact mechanism is unclear since vitamin D can affect gait through its role in the musculoskeletal and/or nervous systems and cognition.

\section{Vitamin D Deficiency, Cognitive Impairment, and Executive Dysfunction in the Elderly}

Cognitive impairment is another major cause of physical disability in the elderly ${ }^{88}$ Cognitive and mobility problems tend to coexist in the same individual; older adults with cognitive problems are twice as likely to fall, when compared with cognitively normal older adults. ${ }^{88}$ Since mobility depends on the musculoskeletal and nervous systems, it could be possible that the role of vitamin D in the risk of a fall is not only through its effects on the musculoskeletal system, but also through its role in the brain and cognition that affect mobility. 
Vitamin D receptors have been found to be expressed in neurons and glial cells, especially in areas that regulate behavior and motor activity such as the limbic system, cerebellum, hippocampus, hypothalamus, cortex, and spinal motor zones. ${ }^{8,89}$ Through these receptors, vitamin D is involved in the expression of proteins involved in DNA repair and genome stability, synaptogenesis and synaptic plasticity, calcium signaling/homeostasis, neurotransmission, and differentiation and survival of neurons and glial cells. ${ }^{90-95}$ Furthermore, vitamin $\mathrm{D}$ is involved in the metabolism of neurotransmitters such as gamma-aminobutyric acid (GABA), serotonin, dopamine, and acetylcholine, which implies its role in cognition, behavior, and motor activity. ${ }^{94,96-98}$ Recently, a study found that older adults who had the VDR receptor FF genotype had higher MMSE scores than the ff genotype, suggesting that single nucleotide polymorphisms may be possibly involved in cognitive function and supporting vitamin D's role in cognition. ${ }^{99}$ Additionally, lower vitamin D status has been associated with reduced neuronal function in the caudal primary motor cortex, which may explain the pathophysiology of gait disorders in older adults with lower vitamin D status. ${ }^{100}$

The association between vitamin $\mathrm{D}$ and cognitive status has been explored in several studies. A systematic search in Medline, Ovid found 20 observational studies evaluating the relationship between vitamin D status and cognitive impairment or scores in cognitive tests in community-dwelling older adults (Appendix A). Only one randomized clinical trial of 1,000mg of calcium carbonate and $400 \mathrm{IU}$ of vitamin D3 per day or placebo reported no association between treatment assignment and incident of cognitive impairment. ${ }^{101}$ This trial included 4,143 women over the age of 65 , who did not 
have probable dementia at baseline, and participated in the WHI Calcium and Vitamin D trial and WHI Memory Study.

Of the 20 observational studies, 16 found a significant positive correlation between vitamin $\mathrm{D}$ and cognitive impairment and/or decline $\mathrm{s}^{5,102-109}$ or cognitive test scores. ${ }^{108-115}$ The studies that found that vitamin D status was associated with the incidence of cognitive impairment used different definitions based on either multidisciplinary meetings that evaluated standardized neuropsychological tests, physical examination, blood tests, and MRI imaging ${ }^{116}$; pre-established characteristics ${ }^{107}$; composite scores of different tests ${ }^{5}$; or cutoff scores in cognitive performance tests such as the Pfeiffer Short Portable Mental State Questionnaire (SPMSQ) ${ }^{103}$, Abbreviated Mental Test Score ${ }^{102}$, Mini Mental State Examination (MMSE) ${ }^{105,106,109}$, and Trails Making Test B. ${ }^{105}$ The studies that found a significant association between vitamin D and cognitive performance scores used one or more tests to assess global cognition like the MMSE ${ }^{112,113,117}$ and/or executive function/information processing (Digit Symbol Substitution Test ${ }^{109-111}$, Trail Making Test $\mathrm{A}^{110,113,115}$, Trail Making Test $\mathrm{B}^{110,113,115,118 \text {, }}$ Block Design ${ }^{110}$, and Verbal Fluency). ${ }^{110,115}$ Overall, these studies support the association between vitamin $\mathrm{D}$ and cognition, especially in executive cognitive function.

A recent meta-analysis of cross-sectional and longitudinal studies suggests that there is an increased risk of cognitive impairment in those with low vitamin D compared with normal vitamin D (OR 2.39; CI 1.91-3.00; $P<0.0001) .{ }^{119}$ Another meta-analysis of observational and interventional studies showed that lower vitamin D concentration was significantly associated with executive dysfunction in processing speed, mental shifting, and information updating. ${ }^{120}$ Executive function refers to the cognitive processes that 
orchestrate goal-directed behavior and decision-making, such as problem-solving, initiating and maintaining tasks, working memory (holding multiple pieces of transitory information and manipulating it), abstract reasoning, and dividing attention. ${ }^{121,122}$ Interestingly, age-related decline in executive function is common among elderly ${ }^{123-125}$, and it has been associated with an increased fall risk and gait impairments, including slower gait speed, even with no obvious cognitive impairments. ${ }^{122,126-135}$

With aging the ability to perform automatic tasks, such as walking, becomes harder and more cognitively demanding. ${ }^{80}$ According to recent evidence, age-related deficits in mobility might be partially compensated by effortful higher order cognitive strategies involving executive function that replace the automated sensorimotor processing. ${ }^{80}$ As people age, their cognitive capacity, however, tends to decrease as well, and their compensatory response becomes impaired. Hence, cognitive resources like attention allotted to movement in older adults are no longer accessible for other activities such as talking, avoiding obstacles, watching for traffic, or other gait-unrelated tasks. ${ }^{80}$ Consequently, older adults often have more problems than younger adults to orchestrate tasks simultaneously, as shown by decreased gait speed and stride length and increased stride time variability of older adults during dual task performance ${ }^{80}$ This may be due to lack of coordination of limited cognitive resources and decreased mental processing speed, which is especially evident in the elderly and people with cognitive problems.

Dual task physical performance tests, in which participants are asked to perform an automatic task like walking while performing an executive function cognitive task like counting backwards, have been used to evaluate the interaction between cognition and mobility as an indicator of fall risk in older adults. ${ }^{136}$ Thus, dual task physical 
performance tests can be used to assess the relationship between lower vitamin D concentration with executive dysfunction in the context of mobility. ${ }^{120}$

\section{Vitamin D and Other Non-Skeletal Outcomes: Cardiovascular Disease}

Besides its association with fall risk and fractures, vitamin D deficiency has also been associated with cardiovascular disease (CVD). Vitamin D deficiency and cardiovascular disease (CVD) are prevalent worldwide. ${ }^{1,137}$ Furthermore, the prevalence of vitamin D deficiency is high among those with CVD. Analysis of data from the NHANES 2001-2004, showed 68\% of whites, $88 \%$ of Hispanics and 97\% of blacks with CVD also had vitamin D levels, as measured by 25-hydroxyvitamin D (25(OH)D), of less than $30 \mathrm{ng} / \mathrm{ml} .{ }^{138,139}$ The possible relationship between vitamin D deficiency and CVDrelated outcomes and mortality in both diseased and healthy populations is a growing area of research. ${ }^{137}$

Several observational studies and meta-analyses have demonstrated associations between vitamin D deficiency and outcomes associated with CVD and CVD-related deaths. ${ }^{140-154}$ In 2008, Wang et al. ${ }^{141}$ observed that normotensive participants from the Framingham Offspring Study, free of CVD and with 25(OH)D of $<15 \mathrm{ng} / \mathrm{ml}$ at baseline, had a 62\% higher CVD risk (i.e., myocardial infarction) over a 5.4 year follow-up. Giovannucci et al. ${ }^{149}$ reported from the Health Professionals Follow-up study a graded independent correlation between low 25(OH)D and myocardial infarction risk in 18,225 men aged 40-75 years, who were free of CVD at baseline. They found that those who had levels of $25(\mathrm{OH}) \mathrm{D}<15 \mathrm{ng} / \mathrm{ml}$ compared to those with $\geq 30 \mathrm{ng} / \mathrm{ml}$ had a relative risk of CVD of 2.1. Deo et al. ${ }^{140}$ in their report from the Cardiovascular Health Study showed 
that lower 25(OH)D levels were independently associated with increased risk of sudden cardiac death (SCD) in healthy adults. Perna et al. ${ }^{142}$ investigated the relationship between serum 25(OH)D and the incidence of fatal and nonfatal cardiovascular events and found that low 25(OH)D levels were associated with a moderate increase in CVD risk, which was stronger for fatal than nonfatal events. In their dose-response analysis, cardiovascular risk increased at 25(OH)D $<30 \mathrm{ng} / \mathrm{ml}$. A study of 9,578 German participants, 50-74 years of age, followed for 5 years as part of the ESTHER study, found vitamin D deficiency (25(OH)D < 12 ng/ml) and insufficiency (25(OH)D 12-20 ng/ml) increased overall and cardiac mortalities. ${ }^{148}$ They risk increased at 25(OH)D concentrations of $<30 \mathrm{ng} / \mathrm{ml}$. This was supported by results from a meta-analysis in 2012 that found a linear, inverse association of 25(OH)D levels between 8-24 ng/ml and CVD risk. $^{147}$

Other systematic reviews and meta-analyses have further supported a potential link between CVD risk and vitamin D status and the benefit of vitamin D supplementation on heart health. A meta-analysis found strong associations between 25(OH)D and all-cause and cardiac mortality, which was consistent after adjusting for confounders. ${ }^{143}$ Another meta-analysis of 28 studies showed that higher 25(OH)D levels were associated with a 33\% lower risk of CVD in middle-aged and elderly individuals. Wang et al. ${ }^{154}$ reported in their systematic review of 5 prospective studies that patients taking vitamin D supplements had a reduction in CVD-related mortality. A meta-analysis of 18 randomized controlled trials (RCTs) showed that vitamin D intake of more than 500 IU/day improved all-cause mortality, partly by decreasing cardiovascular deaths. ${ }^{144,150}$ 
Besides cardiovascular mortality in the general healthy populations, other studies have investigated the relationship between vitamin $\mathrm{D}$ and heart-related outcomes in diseased populations. Gotsman et al. ${ }^{151}$ reported that vitamin D deficiency was significantly higher in heart failure (HF) patients compared to healthy controls, with vitamin D deficiency being an independent predictor of increased mortality in HF patients, and prescription of vitamin D supplementation independently associated with reduced mortality risk. In a study by Dobnig et al. ${ }^{153}$, of the 3,258 patients referred for coronary angiography, those within the lowest quartiles of 25(OH)D $(<14 \mathrm{ng} / \mathrm{ml})$ were at highest risk of sudden cardiac death (SCD). Pliz et al. ${ }^{152}$ studied another cohort of patients referred for coronary angiography over a period of 7.7 years and found that after adjusting for CVD risk factors the risk of SCD was higher in those with severe vitamin D deficiency (25(OH)D $<10 \mathrm{ng} / \mathrm{ml}$ ) compared to those with 25(OH)D $<30 \mathrm{ng} / \mathrm{ml}$. Drechsler et al. ${ }^{145}$ found vitamin D deficiency in diabetic patients on hemodialysis was associated with SCD, combined cardiovascular events, and mortality, after four years. They observed that vitamin D deficiency had a three-fold higher risk of SCD compared to those with sufficient vitamin D.

\section{Vitamin D and Cardiovascular Health: Possible Mechanism}

The mechanism by which vitamin D affects heart health is still unclear. Vitamin D affects multiple cellular signaling pathways via genomic and non-genomic actions that have the potential to affect cardiovascular health. These include vitamin D effects on parathyroid hormone (PTH), the renin-angiotensin-aldosterone system (RAAS), cytokine production, endothelial growth and function, and myocyte calcium influx. ${ }^{155}$ 
Furthermore, vitamin D has also been shown to be involved in molecular mechanisms like biosynthesis of neurotransmitters and inflammatory signaling in areas of the central nervous system (CNS) that regulate cardiovascular activity. ${ }^{98,156}$ Vitamin D has been shown to permeate the blood-brain barrier and bind to VDRs located in extremely high concentrations in the midbrain and brainstem where some autonomic nervous system (ANS) neurons are located. ${ }^{98,156}$ These findings, together with previous evidence of the effect of vitamin D in neurotransmitter biosynthesis and nervous system activity, suggest that vitamin D may contribute to the function of the cardiac ANS and subsequently, contribute to CVD-risk by orchestrating non-genomic regulatory activity at higher brain centers of the ANS. ${ }^{137}$

The Relationship Between Vitamin D and Cardiac Autonomic Nervous System

The ANS is a branch of the peripheral nervous system that controls involuntary processes throughout the body to regulate the internal environment and body functions like hemodynamics, blood glucose levels, sweating, and other visceral functions, including digestion, bladder and sexual organ function, respiration, and cardiovascular activity. ${ }^{157}$ The ANS controls autonomic body functions by the balanced opposition of the stimulatory sympathetic (SNS) and inhibitory parasympathetic (vagal) nervous systems (PNS). The cardiac ANS is composed of post-ganglionic sympathetic plexus of nerves and the parasympathetic Vagus nerve, both of which innervate the heart at the atrioventricular and sinoatrial nodes. Both act concomitantly to control cardiac performance and thus, changes in the duration of time between heartbeats can be attributed to changes in the balance between the SNS and PNS. Dysfunction of cardiac 
autonomic function, more specifically of the cardioprotective vagal tone, results in an imbalance between SNS and PNS. This imbalance has been well-established as a risk factor for adverse cardiovascular events such as SCD or congestive heart failure. ${ }^{158-163}$ Furthermore, cardiovascular autonomic neuropathy (CAN), which is a consequence of damage to the cardiac autonomic nerve fibers, results in abnormalities in heart rate (i.e., reduced heart rate variability or HRV) and irregular vascular dynamics (i.e., changes in blood flow, volume and pressure). ${ }^{164,165}$

Several lines of evidence support a relationship between vitamin $\mathrm{D}$ and cardiac ANS. In animal studies, cardiac myocytes isolated from VDR knockout mice display accelerated contractility rates when compared to wild type. ${ }^{166}$ When stimulated to increase contractility, exposure to $1,25(\mathrm{OH}) 2 \mathrm{D}$ only attenuated the rapid contractility in the wild type but not the VDR knockout cardiac myocyte, suggesting a relationship between vitamin $\mathrm{D}$ and parasympathetic inhibitory activity. Another study showed that rats fed with a vitamin D deficient diet had increased ventricular and vascular muscle contraction and increased sensitivity to the sympathetic neurotransmitter norepinephrine. ${ }^{167}$ In arteries of spontaneously hypertensive rats, vitamin D supplementation normalized the relaxant and hyperpolarizing effects of the vagal neurotransmitter acetylcholine. ${ }^{168}$ In isolated chick myocardial cells, beta-adrenergic signal transduction was enhanced in the presence of activated vitamin D3. ${ }^{169}$

To date, very few studies have investigated the role of vitamin D in modulation of cardiac ANS, a risk factor for poor CV-related outcomes in diseased and healthy humans. ${ }^{140,153,170}$ Some evidence has shown a relationship between vitamin D and ANS function in diseased populations. For instance, in 36 patients with non-ischemic dilated 
cardiomyopathy (NIDCM) 25(OH)D was positively correlated with HRV parameters, with vitamin D insufficiency having deleterious effects on cardiac ANS function. ${ }^{171}$ Krause et al. ${ }^{172}$ showed that chronic kidney disease (CKD) patients, who have impaired vitamin D synthesis, when exposed to short-term artificial sunlight heliotherapy had a significant increase in 25(OH)D levels and in measurements of vagal activity that were severely depressed at baseline. The magnitude of 25(OH)D increase was directly correlated with the level of elevated cardioprotective parasympathetic activity, implying that vitamin D levels may constitute an important role in the development of CVDrelated outcomes by affecting the ANS. Also, Chan et al. ${ }^{173}$ reported that patients with CKD demonstrated poor cardiac ANS activity, which was characterized by decreased activity of the inhibitory PNS. Furthermore, in the end-stage kidney disease (ESKD) population, in which the prevalence of vitamin D deficiency is high, depressed HRV is extremely common and usually presents as suppressed PNS activity with increased SNS input to the sino-atrial node. ${ }^{173,174}$ For the doctoral dissertation by Mann, a crossover study was conducted in which 56 participants with ESKD on hemodialysis were randomized to either conventional ( $0.25 \mathrm{mg}$ alfacalcidol 3 times per week plus placebo 3 times per week for 6 weeks) or intensive ( $0.25 \mathrm{mg}$ alfacalcidol 3 times per week plus 50,000 IU ergocalciferol once a week plus placebo 2 days per week for 6 weeks) vitamin D therapy followed by a 12-week washout period and another 6 weeks of vitamin D therapy. ${ }^{174}$ They did not observe significant changes in measures of cardiac autonomic tone, mineral metabolism, or RAAS activity. However, an exploratory subgroup analysis found that after treatment participants who remained vitamin D deficient $(25(\mathrm{OH}) \mathrm{D}<20$ $\mathrm{ng} / \mathrm{ml}$ ), compared to those who achieved sufficiency, had significant ANS imbalance. In 
the ESKD population, the association between low vitamin D levels and SCD may be mediated by ANS dysfunction. ${ }^{173,175-180}$

The association of vitamin D and cardiac ANS function has also been observed in healthy adult populations. A study in 2014 observed that 25(OH)D was positively associated with decreased HRV in a healthy Korean population over the age of 20 years. ${ }^{181}$ They observed that vitamin D deficient individuals $(25(\mathrm{OH}) \mathrm{D}<15 \mathrm{ng} / \mathrm{ml})$ were 3.1 times more likely to have low HRV. In 2013, Mann et al. ${ }^{181}$ used power spectral analysis of electrocardiogram recordings to measure HRV and thus assess cardiac ANS activity at baseline and during a graded angiotensin II challenge in 34 healthy humans. They found a significant suppression of ANS balance in vitamin D deficient (25(OH)D $<20 \mathrm{ng} / \mathrm{ml}$ ) participants at baseline, but no difference was observed during the challenge. In an intervention study, the same group demonstrated that healthy adults supplemented with 10,000 IU of vitamin D for four weeks had a significant improvement in cardiac ANS balance, more specifically in enhancing the cardio-protective PNS activity. ${ }^{182}$

Studies that evaluated the relationship between vitamin D and ANS activity have measured HRV only at baseline. Since the early 1970’s, valid cardiovascular reflex tests have been used to assess cardiac ANS function and diagnose CAN by measuring the variations in heart rate and blood pressure in response to the Valsalva maneuver, deep breathing, and postural change (i.e., standing up). ${ }^{183}$ HRV parameters measured during cardiac autonomic function tests have been proven to detect ANS dysfunction and CAN in asymptomatic patients (i.e., patients without any symptoms of cardiovascular disease or CVD). ${ }^{165,184}$ To date, only one study has evaluated the relationship between vitamin D status and CAN in type 2 diabetics using cardiac autonomic reflex tests. ${ }^{185}$ In this study, 
several HRV parameters during ANS tests were assessed and scored as normal, borderline, and abnormal to calculate a CAN risk score. They found that vitamin D deficiency $(25(\mathrm{OH}) \mathrm{D}<10 \mathrm{ng} / \mathrm{ml})$ was significantly correlated with decreased HRV in the supine and upright position, and those with vitamin D levels $<10 \mathrm{ng} / \mathrm{ml}$ had significantly increased CAN risk compared to those with 25(OH)D between 10-20 ng/ml. ${ }^{185}$

\section{Vitamin D and Its Relationship to Other Cardiovascular Risk Correlates}

Besides modulating heart rate, the ANS influences vascular dynamics and blood pressure, which is also affected by endothelial function. Endothelial function is related to the blood vessel's ability to dilate when necessary; therefore, dysfunction is characterized by decreased ability to balance vasodilation and vasoconstriction, usually due to an imbalance of nitric oxide bioavailability. ${ }^{139,186-189}$ Endothelial dysfunction is also related to prothrombotic and proinflammatory states that increase arterial stiffness. Human endothelial cells express VDRs, and recent studies have suggested an association between endothelial function and vitamin D status. ${ }^{139,186-189}$ In healthy individuals, 25(OH)D levels were independently associated with several tests of endothelial function, arterial stiffness, and coronary flow reserve tests. ${ }^{187,190}$ Other studies have demonstrated that

vitamin D treatment improved arterial stiffness measured by pulse wave velocity. ${ }^{191,192}$ Thus, vitamin D has a role in vascular physiology by either directly affecting the endothelium or indirectly via modulation of ANS.

The observations that vitamin D deficiency, cardiac ANS, and endothelial dysfunction are independently linked to each other and CVD-related outcomes suggests a potential mechanism by which vitamin D deficiency affects CVD risk. 


\section{Literature Review Summary}

Vitamin D insufficiency and deficiency are still common among older adult populations living in communities where with more opportunity for vitamin D skin synthesis through sun exposure, which is the main source of vitamin D. ${ }^{28,31,193}$ The elderly population in Miami-Dade is increasing rapidly, falls are a major cause of injury in this community-dwelling population, and vitamin D deficiency is still a major public health issue among them. ${ }^{64,65,194,195}$ The determinants of vitamin D status are not well documented among Miami-Dade older adults. Assessing the factors affecting vitamin D status of this older adult community is important to help improve health outcomes such as gait impairments and cognition related to the risk of falls. ${ }^{10,25,60,66-71}$

Furthermore, the role of vitamin $\mathrm{D}$ in the mechanism of falls needs further investigation. Several studies have demonstrated an association between vitamin D deficiency, gait impairment (slower gait speed), global cognitive impairment and impaired executive function. Studies that investigate vitamin D status' relationship to gait and cognition have looked at these factors independently. A systematic search in Medline Ovid found eight observational studies evaluating the relationship between vitamin D status, gait and cognitive impairment, independently, in community-dwelling adults (Appendix A). Of these, two studies found gait speed only ${ }^{21,196}$, one study found cognitive performance only ${ }^{197}$, and five studies found that both gait speed and cognitive performance were associated with vitamin D status. ${ }^{57,198-201}$ Among the latter four studies, gait speed was measured as part of a physical performance battery including timed walking at different distances (20 meters ${ }^{199,200}, 6$ meters $^{198}$, and 4 meters ${ }^{57}$ ) or electronic walkway ${ }^{201}$, and cognition was measured by global cognitive performance tests 
(MMSE) $)^{57,198-201}$ or tests of executive function (Trail Making Test B). ${ }^{198}$ Even though evidence indicates that vitamin D levels are associated with cognition and gait, independently, until now no cross-sectional study has evaluated how vitamin D status is related to cognitive processing during motor activity.

In addition, vitamin D can affect other non-skeletal outcomes, like cardiovascular health. Since CVD and vitamin D deficiency are prevalent worldwide, the relationship between these two health problems has become a growing area of translational research. ${ }^{140,153,170}$ Vitamin D deficiency, cardiac ANS and endothelial dysfunctions are independently linked to each other and CVD-related outcomes, suggesting a potential relationship between vitamin D deficiency and CVD risk. To date, very few studies have investigated the role of vitamin D in modulation of cardiac ANS and endothelial function. ${ }^{140,153,170}$ Furthermore, until today no study has evaluated the relationship between low vitamin $\mathrm{D}$ levels and cardiometabolic risk, using a non-invasive rapid test that integrates the assessment of other cardiovascular risk factors like body composition, ANS activity function markers, and endothelial function markers. 


\section{References}

1. Holick MF. Vitamin D deficiency. N Engl J Med. 2007;357(3):266-281.

2. Hollis BW, Wagner CL, Drezner MK, Binkley NC. Circulating vitamin D3 and 25hydroxyvitamin D in humans: An important tool to define adequate nutritional vitamin D status. J Steroid Biochem Mol Biol. 2007;103(3-5):631-634.

3. Forrest KY, Stuhldreher WL. Prevalence and correlates of vitamin D deficiency in U.S. adults. Nutr Res. 2011;31(1):48-54.

4. Zadshir A, Tareen N, Pan D, Norris K, Martins D. The prevalence of hypovitaminosis D among U.S. adults: Data from the NHANES III. Ethn Dis. 2005;15(4 Suppl 5):97-101.

5. Llewellyn DJ, Lang IA, Langa KM, Melzer D. Vitamin D and cognitive impairment in the elderly U.S. population. J Gerontol A Biol Sci Med Sci. 2011;66(1):59-65.

6. Moore C, Murphy MM, Keast DR, Holick MF. Vitamin D intake in the united states. $J$ Am Diet Assoc. 2004;104(6):980-983.

7. Brock K, Huang WY, Fraser DR, et al. Low vitamin D status is associated with physical inactivity, obesity and low vitamin D intake in a large U.S. sample of healthy middle-aged men and women. J Steroid Biochem Mol Biol. 2010;121(1-2):462-466.

8. Annweiler C, Montero-Odasso M, Schott AM, Berrut G, Fantino B, Beauchet O. Fall prevention and vitamin $\mathrm{D}$ in the elderly: An overview of the key role of the non-bone effects. J Neuroeng Rehabil. 2010;7(1):50-63.

9. Annweiler C, Schott AM, Berrut G, Fantino B, Beauchet O. Vitamin D-related changes in physical performance: A systematic review. J Nutr Health Aging. 2009;13(10):893-898.

10. Bischoff-Ferrari HA, Dawson-Hughes B, Willett WC, et al. Effect of vitamin D on falls: A meta-analysis. JAMA. 2004;291(16):1999-2006.

11. Dhesi JK, Jackson SH, Bearne LM, et al. Vitamin D supplementation improves neuromuscular function in older people who fall. Age Ageing. 2004;33(6):589-595.

12. Haroon M, FitzGerald O. Vitamin D deficiency: Subclinical and clinical consequences on musculoskeletal health. Curr Rheumatol Rep. 2012;14(3):286-293.

13. Janssen HC, Samson MM, Verhaar HJ. Vitamin D deficiency, muscle function, and falls in elderly people. Am J Clin Nutr. 2002;75(4):611-615. 
14. Rejnmark L. Effects of vitamin D on muscle function and performance: A review of evidence from randomized controlled trials. Ther Adv Chronic Dis. 2011;2(1):25-37.

15. Stechschulte SA, Kirsner RS, Federman DG. Vitamin D: Bone and beyond, rationale and recommendations for supplementation. Am J Med. 2009;122(9):793-802.

16. Haussler MR, Whitfield GK, Kaneko I, et al. Molecular mechanisms of vitamin D action. Calcif Tissue Int. 2013;92(2):77-98.

17. Prentice A, Goldberg GR, Schoenmakers I. Vitamin D across the lifecycle: Physiology and biomarkers. Am J Clin Nutr. 2008;88(2):500-506.

18. Binkley N, Krueger DC, Morgan S, Wiebe D. Current status of clinical 25hydroxyvitamin D measurement: An assessment of between-laboratory agreement. Clin Chim Acta. 2010;411(23-24):1976-1982.

19. Holick MF. Vitamin D status: Measurement, interpretation, and clinical application. Ann Epidemiol. 2009;19(2):73-78.

20. Pludowski P, Holick MF, Pilz S, et al. Vitamin D effects on musculoskeletal health, immunity, autoimmunity, cardiovascular disease, cancer, fertility, pregnancy, dementia and mortality- a review of recent evidence. Autoimmun Rev. 2013;12(10):976-989.

21. Houston DK, Tooze JA, Hausman DB, et al. Change in 25-hydroxyvitamin D and physical performance in older adults. J Gerontol A Biol Sci Med Sci. 2011;66(4):430-436.

22. Zittermann A, Gummert JF. Nonclassical vitamin D action. Nutrients. 2010;2(4):408425.

23. Cesari M, Incalzi RA, Zamboni V, Pahor M. Vitamin D hormone: A multitude of actions potentially influencing the physical function decline in older persons. Geriatr Gerontol Int. 2011;11(2):133-142.

24. Heaney RP, Armas LA, Shary JR, Bell NH, Binkley N, Hollis BW. 25-hydroxylation of vitamin D3: Relation to circulating vitamin D3 under various input conditions. Am J Clin Nutr. 2008;87(6):1738-1742.

25. Ross AC, Manson JE, Abrams SA, et al. The 2011 report on dietary reference intakes for calcium and vitamin $\mathrm{D}$ from the institute of medicine: What clinicians need to know. J Clin Endocrinol Metab. 2011;96(1):53-58.

26. Rosen CJ, Abrams SA, Aloia JF, et al. IOM committee members respond to endocrine society vitamin D guideline. J Clin Endocrinol Metab. 2012;97(4):1146-1152. 
27. Holick MF, Binkley NC, Bischoff-Ferrari HA, et al. Evaluation, treatment, and prevention of vitamin D deficiency: An endocrine society clinical practice guideline. $J$ Clin Endocrinol Metab. 2011;96(7):1911-1930.

28. Holick MF. The D-lightful vitamin for health. Seminar presented: Nutrition Matters Conference at the University of Miami Miller School of Medicine. April 12 2015;Miami, Fl.

29. Chen TC, Shao A, Heath H,3rd, Holick MF. An update on the vitamin D content of fortified milk from the united states and canada. N Engl J Med. 1993;329(20):1507-1507.

30. Chen TC, Chimeh F, Lu Z, et al. Factors that influence the cutaneous synthesis and dietary sources of vitamin D. Arch Biochem Biophys. 2007;460(2):213-217.

31. Levis S, Gomez A, Jimenez C, et al. Vitamin D deficiency and seasonal variation in an adult south florida population. J Clin Endocrinol Metab. 2005;90(3):1557-1562.

32. Bailey RL, Dodd KW, Goldman JA, et al. Estimation of total usual calcium and vitamin D intakes in the united states. J Nutr. 2010;140(4):817-822.

33. Segal E, Dvorkin L, Lavy A, et al. Bone density in axial and appendicular skeleton in patients with lactose intolerance: Influence of calcium intake and vitamin D status. J Am Coll Nutr. 2003;22(3):201-207.

34. Boucher BJ. The problems of vitamin D insufficiency in older people. Aging Dis. 2012;3(4):313-329.

35. Serra Prat M, Fernandez X, Ribo L, Palomera E, Papiol M, Serra P. Loss of appetite in elderly people in the community and its relationship with functional capacity. Med Clin (Barc). 2008;130(14):531-533.

36. Lee JS, Frongillo EA,Jr. Nutritional and health consequences are associated with food insecurity among U.S. elderly persons. J Nutr. 2001;131(5):1503-1509.

37. Jaddou HY, Batieha AM, Khader YS, Kanaan SH, El-Khateeb MS, Ajlouni KM. Depression is associated with low levels of 25-hydroxyvitamin D among jordanian adults: Results from a national population survey. Eur Arch Psychiatry Clin Neurosci. 2012;262(4):321-327.

38. Hoogendijk WJ, Lips P, Dik MG, Deeg DJ, Beekman AT, Penninx BW. Depression is associated with decreased 25-hydroxyvitamin D and increased parathyroid hormone levels in older adults. Arch Gen Psychiatry. 2008;65(5):508-512. 
39. Bertone-Johnson ER, Powers SI, Spangler L, et al. Vitamin D intake from foods and supplements and depressive symptoms in a diverse population of older women. Am J Clin Nutr. 2011;94(4):1104-1112.

40. Pannemans DL, Westerterp KR. Energy expenditure, physical activity and basal metabolic rate of elderly subjects. Br J Nutr. 1995;73(4):571-581.

41. Houston DK, Nicklas BJ, Zizza CA. Weighty concerns: The growing prevalence of obesity among older adults. J Am Diet Assoc. 2009;109(11):1886-1895.

42. Salamone LM, Dallal GE, Zantos D, Makrauer F, Dawson-Hughes B. Contributions of vitamin D intake and seasonal sunlight exposure to plasma 25-hydroxyvitamin D concentration in elderly women. Am J Clin Nutr. 1994;59(1):80-86.

43. Holick MF. Photobiologyof vitamin D. In: Feldman D, Pike JW, Adams JS, eds. Vitamin D. 3rd ed. San Diego, CA: Elsevier Academic Press; 2011:113-122.

44. Clemens TL, Adams JS, Henderson SL, Holick MF. Increased skin pigment reduces the capacity of skin to synthesize vitamin D3. Lancet. 1982;1(8263):74-76.

45. Smolar DE, Engstrom GA, Diaz S, Tappen R, Ouslander JG. Ethnic differences in vitamin D insufficiency in south florida community-dwelling older adults. J Am Geriatr Soc. 2012;60(10):1990-1991.

46. van der Wielen RP, Lowik MR, van den Berg H, et al. Serum vitamin D concentrations among elderly people in europe. Lancet. 1995;346(8969):207-210.

47. Scragg R, Camargo CA,Jr. Frequency of leisure-time physical activity and serum 25hydroxyvitamin D levels in the US population: Results from the third national health and nutrition examination survey. Am J Epidemiol. 2008;168(6):577-591.

48. Tran B, Armstrong BK, McGeechan K, et al. Predicting vitamin D deficiency in older australian adults. Clin Endocrinol (Oxf). 2013;79(5):631-640.

49. Muir SW, Montero-Odasso M. Effect of vitamin D supplementation on muscle strength, gait and balance in older adults: A systematic review and meta-analysis. $J$ Am Geriatr Soc. 2011;59(12):2291-2300.

50. Bischoff-Ferrari HA, Giovannucci E, Willett WC, Dietrich T, Dawson-Hughes B. Estimation of optimal serum concentrations of 25-hydroxyvitamin D for multiple health outcomes. Am J Clin Nutr. 2006;84(1):18-28.

51. Dukas L, Staehelin HB, Schacht E, Bischoff HA. Better functional mobility in community-dwelling elderly is related to D-hormone serum levels and to daily calcium intake. J Nutr Health Aging. 2005;9(5):347-351. 
52. Gallagher JC. The effects of calcitriol on falls and fractures and physical performance tests. J Steroid Biochem Mol Biol. 2004;89-90(1-5):497-501.

53. Houston DK, Cesari M, Ferrucci L, et al. Association between vitamin D status and physical performance: The InCHIANTI study. J Gerontol A Biol Sci Med Sci. 2007;62(4):440-446.

54. Semba RD, Garrett E, Johnson BA, Guralnik JM, Fried LP. Vitamin D deficiency among older women with and without disability. Am J Clin Nutr. 2000;72(6):1529-1534.

55. Zamboni M, Zoico E, Tosoni P, et al. Relation between vitamin D, physical performance, and disability in elderly persons. J Gerontol A Biol Sci Med Sci. 2002;57(1):7-11.

56. Wicherts IS, van Schoor NM, Boeke AJ, et al. Vitamin D status predicts physical performance and its decline in older persons. J Clin Endocrinol Metab. 2007;92(6):20582065.

57. Toffanello ED, Perissinotto E, Sergi G, et al. Vitamin D and physical performance in elderly subjects: The pro.V.A study. PLoS One. 2012;7(4):1-9.

58. Montero-Odasso M, Casas A, Hansen KT, et al. Quantitative gait analysis under dualtask in older people with mild cognitive impairment: A reliability study. J Neuroeng Rehabil. 2009;6(1):35-40.

59. Pieterse AJ, Luttikhold TB, de Laat K, Bloem BR, van Engelen BG, Munneke M. Falls in patients with neuromuscular disorders. J Neurol Sci. 2006;251(1-2):87-90.

60. Kalyani RR, Stein B, Valiyil R, Manno R, Maynard JW, Crews DC. Vitamin D treatment for the prevention of falls in older adults: Systematic review and meta-analysis. J Am Geriatr Soc. 2010;58(7):1299-1310.

61. Centers for Disease Control and Prevention. Self-reported falls and fall-related injuires among persons aged $>65$ years-united states, 2006. CDC.gov Web site. http://www.cdc.gov/mmwr/preview/mmwrhtml/mm5709a1.htm. Updated 2008. Accessed August 31, 2015.

62. Federal Interagency Forum on Aging-Related Statistics. Older americans 2004: Key indicators of well-being. AgingStats.gov Web site. http://www.agingstats.gov/Main_Site/Data/2004_Documents/entire_report.pdf. Updated 2004. Accessed August 31, 2015.

63. Corley CT. Senior fact sheet 2010. Florida Department of Elder Affairs Web site. http://elderaffairs.state.fl.us/doea/publications.php;. Updated 2010. Accessed August 31, 2015. 
64. Zhang G, Leguen F, Lawrence J, Blanco J. Falls: Among elderly adults aged 65 years and older. Florida Department of Health in Miami-Dade County Web site. http://miamidade.floridahealth.gov/programs-and-services/infectious-diseaseservices/disease-control/_documents/2005-epi-may.pdf. Updated 2005. Accessed August 31, 2015.

65. Florida Department of Health in Miami-Dade County. Injury deaths and hospitalizations, 2007-2009 residents of miami-dade county aged 65+ yrs. Florida Department of Health in Miami-Dade County Web site. http://miamidade.floridahealth.gov/programs-and-services/wellnessprograms/injury-and-violence-prevention/_documents/DC-HD\%20200709\%20Age\%2065.pdf;. Updated 2011. Accessed August 31, 2015.

66. Robertson MC, Gillespie LD. Fall prevention in community-dwelling older adults. JAMA. 2013;309(13):1406-1407.

67. Bischoff-Ferrari HA, Dawson-Hughes B, Staehelin HB, et al. Fall prevention with supplemental and active forms of vitamin D: A meta-analysis of randomised controlled trials. BMJ. 2009;339(3692):1-11.

68. Jackson C, Gaugris S, Sen SS, Hosking D. The effect of cholecalciferol (vitamin D3) on the risk of fall and fracture: A meta-analysis. QJM. 2007;100(4):185-192.

69. Murad MH, Elamin KB, Abu Elnour NO, et al. Clinical review: The effect of vitamin D on falls: A systematic review and meta-analysis. J Clin Endocrinol Metab. 2011;96(10):2997-3006.

70. Cranney A, Horsley T, O'Donnell S, et al. Evidence report/technology assessment: Effectiveness and safety of vitamin D in relation to bone health. Evid Rep Technol Assess (Full Rep). 2007;158(8):1-235.

71. Thomas MK, Lloyd-Jones DM, Thadhani RI, et al. Hypovitaminosis D in medical inpatients. N Engl J Med. 1998;338(12):777-783.

72. Annweiler C, Beauchet O. Questioning vitamin D status of elderly fallers and nonfallers: A meta-analysis to address a 'forgotten step'. J Intern Med. 2015;277(1):1644.

73. Bridenbaugh SA, Kressig RW. Laboratory review: The role of gait analysis in seniors' mobility and fall prevention. Gerontology. 2011;57(3):256-264.

74. Winter DA, Patla AE, Frank JS, Walt SE. Biomechanical walking pattern changes in the fit and healthy elderly. Phys Ther. 1990;70(6):340-347. 
75. Menz HB, Lord SR, Fitzpatrick RC. Age-related differences in walking stability. Age Ageing. 2003;32(2):137-142.

76. Judge JO, Davis RB, Ounpuu S. Step length reductions in advanced age: The role of ankle and hip kinetics. J Gerontol A Biol Sci Med Sci. 1996;51(6):303-312.

77. Judge JO, Ounpuu S, Davis RB. Effects of age on the biomechanics and physiology of gait. Clin Geriatr Med. 1996;12(4):659-678.

78. Krebs DE, Jette AM, Assmann SF. Moderate exercise improves gait stability in disabled elders. Arch Phys Med Rehabil. 1998;79(12):1489-1495.

79. Barak Y, Wagenaar RC, Holt KG. Gait characteristics of elderly people with a history of falls: A dynamic approach. Phys Ther. 2006;86(11):1501-1510.

80. Beurskens R, Bock O. Age-related deficits of dual-task walking: A review. Neural Plast. 2012;2012(131608):1-9.

81. Gerdhem P, Ringsberg KA, Obrant KJ, Akesson K. Association between 25-hydroxy vitamin $\mathrm{D}$ levels, physical activity, muscle strength and fractures in the prospective population-based OPRA study of elderly women. Osteoporos Int. 2005;16(11):14251431.

82. Annweiler C, Schott AM, Montero-Odasso M, et al. Cross-sectional association between serum vitamin $\mathrm{D}$ concentration and walking speed measured at usual and fast pace among older women: The EPIDOS study. J Bone Miner Res. 2010;25(8):1858-1866.

83. Bischoff-Ferrari HA, Dietrich T, Orav EJ, et al. Higher 25-hydroxyvitamin D concentrations are associated with better lower-extremity function in both active and inactive persons aged > or =60 y. Am J Clin Nutr. 2004;80(3):752-758.

84. Suzuki T, Kwon J, Kim H, et al. Low serum 25-hydroxyvitamin D levels associated with falls among japanese community-dwelling elderly. J Bone Miner Res. 2008;23(8):1309-1317.

85. Boersma D, Demontiero O, Mohtasham Amiri Z, et al. Vitamin D status in relation to postural stability in the elderly. J Nutr Health Aging. 2012;16(3):270-275.

86. Kositsawat J, Barry LC, Kuchel GA. C-reactive protein, vitamin D deficiency, and slow gait speed. J Am Geriatr Soc. 2013;61(9):1574-1579.

87. Bunout D, Barrera G, Leiva L, et al. Effects of vitamin D supplementation and exercise training on physical performance in chilean vitamin $\mathrm{D}$ deficient elderly subjects. Exp Gerontol. 2006;41(8):746-752. 
88. Montero-Odasso M, Wells JL, Borrie MJ, Speechley M. Can cognitive enhancers reduce the risk of falls in older people with mild cognitive impairment? A protocol for a randomised controlled double blind trial. BMC Neurol. 2009;9(8):42-54.

89. Bouvard B, Annweiler C, Salle A, et al. Extraskeletal effects of vitamin D: Facts, uncertainties, and controversies. Joint Bone Spine. 2011;78(1):10-16.

90. McCann JC, Ames BN. Is there convincing biological or behavioral evidence linking vitamin D deficiency to brain dysfunction? FASEB J. 2008;22(4):982-1001.

91. Clemens TL, Garrett KP, Zhou XY, Pike JW, Haussler MR, Dempster DW. Immunocytochemical localization of the 1,25-dihydroxyvitamin D3 receptor in target cells. Endocrinology. 1988;122(4):1224-1230.

92. Prufer K, Veenstra TD, Jirikowski GF, Kumar R. Distribution of 1,25dihydroxyvitamin D3 receptor immunoreactivity in the rat brain and spinal cord. $J$ Chem Neuroanat. 1999;16(2):135-145.

93. Balion C, Griffith LE, Strifler L, et al. Vitamin D, cognition, and dementia: A systematic review and meta-analysis. Neurology. 2012;79(13):1397-1405.

94. Lu'o'ng KV, Nguyen LT. The beneficial role of vitamin D in alzheimer's disease. Am J Alzheimers Dis Other Demen. 2011;26(7):511-520.

95. Fernandes de Abreu DA, Eyles D, Feron F. Vitamin D, a neuro-immunomodulator: Implications for neurodegenerative and autoimmune diseases. Psychoneuroendocrinology. 2009;34(Suppl 1):S265-277.

96. Annweiler C, Schott AM, Berrut G, et al. Vitamin D and ageing: Neurological issues. Neuropsychobiology. 2010;62(3):139-150.

97. Sonnenberg J, Luine VN, Krey LC, Christakos S. 1,25-dihydroxyvitamin D3 treatment results in increased choline acetyltransferase activity in specific brain nuclei. Endocrinology. 1986;118(4):1433-1439.

98. Garcion E, Wion-Barbot N, Montero-Menei CN, Berger F, Wion D. New clues about vitamin D functions in the nervous system. Trends Endocrinol Metab. 2002;13(3):100105.

99. Najmi Varzaneh F, Sharifi F, Hossein-Nezhad A, et al. Association of vitamin D receptor with longevity and healthy aging. Acta Med Iran. 2013;51(4):236-241.

100. Annweiler C, Beauchet O, Bartha R, Hachinski V, Montero-Odasso M. Vitamin D and caudal primary motor cortex: A magnetic resonance spectroscopy study. PLoS One. 2014;9(1):873141-873145. 
101. Rossom RC, Espeland MA, Manson JE, et al. Calcium and vitamin D supplementation and cognitive impairment in the women's health initiative. J Am Geriatr Soc. 2012;60(12):2197-2205.

102. Llewellyn DJ, Langa KM, Lang IA. Serum 25-hydroxyvitamin D concentration and cognitive impairment. J Geriatr Psychiatry Neurol. 2009;22(3):188-195.

103. Annweiler C, Schott AM, Allali G, et al. Association of vitamin D deficiency with cognitive impairment in older women: Cross-sectional study. Neurology. 2010;74(1):2732.

104. Annweiler C, Rolland Y, Schott AM, et al. Higher vitamin D dietary intake is associated with lower risk of alzheimer's disease: A 7-year follow-up. J Gerontol A Biol Sci Med Sci. 2012;67(11):1205-1211.

105. Slinin Y, Paudel M, Taylor BC, et al. Association between serum 25(OH) vitamin D and the risk of cognitive decline in older women. J Gerontol A Biol Sci Med Sci. 2012;67(10):1092-1098.

106. Chei CL, Raman P, Yin ZX, Shi XM, Zeng Y, Matchar DB. Vitamin D levels and cognition in elderly adults in china. J Am Geriatr Soc. 2014;62(11):2125-2129.

107. Hooshmand B, Lokk J, Solomon A, et al. Vitamin D in relation to cognitive impairment, cerebrospinal fluid biomarkers, and brain volumes. J Gerontol A Biol Sci Med Sci. 2014;69(9):1132-1138.

108. Toffanello ED, Coin A, Perissinotto E, et al. Vitamin D deficiency predicts cognitive decline in older men and women: The pro.V.A. study. Neurology. 2014;83(24):2292-2298.

109. Wilson VK, Houston DK, Kilpatrick L, et al. Relationship between 25hydroxyvitamin $\mathrm{D}$ and cognitive function in older adults: The health, aging and body composition study. J Am Geriatr Soc. 2014;62(4):636-641.

110. Buell JS, Scott TM, Dawson-Hughes B, et al. Vitamin D is associated with cognitive function in elders receiving home health services. J Gerontol A Biol Sci Med Sci. 2009;64(8):888-895.

111. Lee DM, Tajar A, Ulubaev A, et al. Association between 25-hydroxyvitamin D levels and cognitive performance in middle-aged and older european men. $J$ Neurol Neurosurg Psychiatry. 2009;80(7):722-729.

112. Wilkins CH, Birge SJ, Sheline YI, Morris JC. Vitamin D deficiency is associated with worse cognitive performance and lower bone density in older african americans. $J$ Natl Med Assoc. 2009;101(4):349-354. 
113. Llewellyn DJ, Lang IA, Langa KM, et al. Vitamin D and risk of cognitive decline in elderly persons. Arch Intern Med. 2010;170(13):1135-1141.

114. Seamans KM, Hill TR, Scully L, et al. Vitamin D status and measures of cognitive function in healthy older european adults. Eur J Clin Nutr. 2010;64(10):1172-1178.

115. Brouwer-Brolsma EM, van de Rest O, Tieland M, et al. Serum 25-hydroxyvitamin $\mathrm{D}$ is associated with cognitive executive function in dutch prefrail and frail elderly: A cross-sectional study exploring the associations of 25-hydroxyvitamin D with glucose metabolism, cognitive performance and depression. J Am Med Dir Assoc. 2013;14(11):8529-85217.

116. Annweiler C, Fantino B, Schott AM, Krolak-Salmon P, Allali G, Beauchet O. Vitamin D insufficiency and mild cognitive impairment: Cross-sectional association. Eur J Neurol. 2012;19(7):1023-1029.

117. Przybelski RJ, Binkley NC. Is vitamin D important for preserving cognition? A positive correlation of serum 25-hydroxyvitamin D concentration with cognitive function. Arch Biochem Biophys. 2007;460(2):202-205.

118. Annweiler C, Maby E, Meyerber M, Beauchet O. Hypovitaminosis D and executive dysfunction in older adults with memory complaint: A memory clinic-based study. Dement Geriatr Cogn Disord. 2014;37(5-6):286-293.

119. Etgen T, Sander D, Bickel H, Sander K, Forstl H. Vitamin D deficiency, cognitive impairment and dementia: A systematic review and meta-analysis. Dement Geriatr Cogn Disord. 2012;33(5):297-305.

120. Annweiler C, Montero-Odasso M, Llewellyn DJ, Richard-Devantoy S, Duque G, Beauchet $\mathrm{O}$. Meta-analysis of memory and executive dysfunctions in relation to vitamin D. J Alzheimers Dis. 2013;37(1):147-171.

121. Suchy Y. Executive functioning: Overview, assessment, and research issues for nonneuropsychologists. Ann Behav Med. 2009;37(2):106-116.

122. Kearney FC, Harwood RH, Gladman JR, Lincoln N, Masud T. The relationship between executive function and falls and gait abnormalities in older adults: A systematic review. Dement Geriatr Cogn Disord. 2013;36(1-2):20-35.

123. Herman T, Mirelman A, Giladi N, Schweiger A, Hausdorff JM. Executive control deficits as a prodrome to falls in healthy older adults: A prospective study linking thinking, walking, and falling. J Gerontol A Biol Sci Med Sci. 2010;65(10):1086-1092. 
124. Prakash RS, Erickson KI, Colcombe SJ, Kim JS, Voss MW, Kramer AF. Agerelated differences in the involvement of the prefrontal cortex in attentional control. Brain Cogn. 2009;71(3):328-335.

125. Royall DR, Palmer R, Chiodo LK, Polk MJ. Declining executive control in normal aging predicts change in functional status: The freedom house study. $J$ Am Geriatr Soc. 2004;52(3):346-352.

126. Ijmker T, Lamoth CJ. Gait and cognition: The relationship between gait stability and variability with executive function in persons with and without dementia. Gait Posture. 2012;35(1):126-130.

127. Springer S, Giladi N, Peretz C, Yogev G, Simon ES, Hausdorff JM. Dual-tasking effects on gait variability: The role of aging, falls, and executive function. Mov Disord. 2006;21(7):950-957.

128. van Iersel MB, Kessels RP, Bloem BR, Verbeek AL, Olde Rikkert MG. Executive functions are associated with gait and balance in community-living elderly people. $J$ Gerontol A Biol Sci Med Sci. 2008;63(12):1344-1349.

129. Yogev-Seligmann G, Hausdorff JM, Giladi N. The role of executive function and attention in gait. Mov Disord. 2008;23(3):329-342.

130. Hausdorff JM, Doniger GM, Springer S, Yogev G, Simon ES, Giladi N. A common cognitive profile in elderly fallers and in patients with parkinson's disease: The prominence of impaired executive function and attention. Exp Aging Res. 2006;32(4):411-429.

131. Holtzer R, Friedman R, Lipton RB, Katz M, Xue X, Verghese J. The relationship between specific cognitive functions and falls in aging. Neuropsychology. 2007;21(5):540-548.

132. Atkinson HH, Rosano C, Simonsick EM, et al. Cognitive function, gait speed decline, and comorbidities: The health, aging and body composition study. J Gerontol A Biol Sci Med Sci. 2007;62(8):844-850.

133. Persad CC, Jones JL, Ashton-Miller JA, Alexander NB, Giordani B. Executive function and gait in older adults with cognitive impairment. J Gerontol A Biol Sci Med Sci. 2008;63(12):1350-1355.

134. Alexander NB, Hausdorff JM. Guest editorial: Linking thinking, walking, and falling. J Gerontol A Biol Sci Med Sci. 2008;63(12):1325-1328. 
135. Allali G, Assal F, Kressig RW, Dubost V, Herrmann FR, Beauchet O. Impact of impaired executive function on gait stability. Dement Geriatr Cogn Disord. 2008;26(4):364-369.

136. Lundin-Olsson L, Nyberg L, Gustafson Y. "Stops walking when talking" as a predictor of falls in elderly people. Lancet. 1997;349(9052):617-618.

137. Mann MC, Hollenberg MD, Hanley DA, Ahmed SB. Vitamin D, the autonomic nervous system, and cardiovascular risk. Physiol Rep. 2015;3(4):123491-1234914.

138. Kim DH, Sabour S, Sagar UN, Adams S, Whellan DJ. Prevalence of hypovitaminosis $\mathrm{D}$ in cardiovascular diseases (from the national health and nutrition examination survey 2001 to 2004). Am J Cardiol. 2008;102(11):1540-1544.

139. Norman PE, Powell JT. Vitamin D and cardiovascular disease. Circ Res. 2014;114(2):379-393.

140. Deo R, Katz R, Shlipak MG, et al. Vitamin D, parathyroid hormone, and sudden cardiac death: Results from the cardiovascular health study. Hypertension. 2011;58(6):1021-1028.

141. Wang TJ, Pencina MJ, Booth SL, et al. Vitamin D deficiency and risk of cardiovascular disease. Circulation. 2008;117(4):503-511.

142. Perna L, Schottker B, Holleczek B, Brenner H. Serum 25-hydroxyvitamin D and incidence of fatal and nonfatal cardiovascular events: A prospective study with repeated measurements. J Clin Endocrinol Metab. 2013;98(12):4908-4915.

143. Schottker B, Jorde R, Peasey A, et al. Vitamin D and mortality: Meta-analysis of individual participant data from a large consortium of cohort studies from europe and the united states. BMJ. 2014;348(3656):1-15.

144. Parker J, Hashmi O, Dutton D, et al. Levels of vitamin D and cardiometabolic disorders: Systematic review and meta-analysis. Maturitas. 2010;65(3):225-236.

145. Drechsler C, Pilz S, Obermayer-Pietsch B, et al. Vitamin D deficiency is associated with sudden cardiac death, combined cardiovascular events, and mortality in haemodialysis patients. Eur Heart J. 2010;31(18):2253-2261.

146. Thadhani R, Appelbaum E, Pritchett Y, et al. Vitamin D therapy and cardiac structure and function in patients with chronic kidney disease: The PRIMO randomized controlled trial. JAMA. 2012;307(7):674-684. 
147. Wang L, Song Y, Manson JE, et al. Circulating 25-hydroxy-vitamin D and risk of cardiovascular disease: A meta-analysis of prospective studies. Circ Cardiovasc Qual Outcomes. 2012;5(6):819-829.

148. Schottker B, Haug U, Schomburg L, et al. Strong associations of 25-hydroxyvitamin $\mathrm{D}$ concentrations with all-cause, cardiovascular, cancer, and respiratory disease mortality in a large cohort study. Am J Clin Nutr. 2013;97(4):782-793.

149. Giovannucci E, Liu Y, Hollis BW, Rimm EB. 25-hydroxyvitamin D and risk of myocardial infarction in men: A prospective study. Arch Intern Med. 2008;168(11):11741180.

150. Autier P, Gandini S. Vitamin D supplementation and total mortality: A metaanalysis of randomized controlled trials. Arch Intern Med. 2007;167(16):1730-1737.

151. Gotsman I, Shauer A, Zwas DR, et al. Vitamin D deficiency is a predictor of reduced survival in patients with heart failure; vitamin $\mathrm{D}$ supplementation improves outcome. Eur J Heart Fail. 2012;14(4):357-366.

152. Pilz S, Dobnig H, Fischer JE, et al. Low vitamin D levels predict stroke in patients referred to coronary angiography. Stroke. 2008;39(9):2611-2613.

153. Dobnig H, Pilz S, Scharnagl H, et al. Independent association of low serum 25hydroxyvitamin D and 1,25-dihydroxyvitamin D levels with all-cause and cardiovascular mortality. Arch Intern Med. 2008;168(12):1340-1349.

154. Wang L, Manson JE, Song Y, Sesso HD. Systematic review: Vitamin D and calcium supplementation in prevention of cardiovascular events. Ann Intern Med. 2010;152(5):315-323.

155. Beveridge LA, Witham MD. Vitamin D and the cardiovascular system. Osteoporos Int. 2013;24(8):2167-2180.

156. DeLuca GC, Kimball SM, Kolasinski J, Ramagopalan SV, Ebers GC. Review: The role of vitamin D in nervous system health and disease. Neuropathol Appl Neurobiol. 2013;39(5):458-484.

157. Kapa S, Venkatachalam KL, Asirvatham SJ. The autonomic nervous system in cardiac electrophysiology: An elegant interaction and emerging concepts. Cardiol Rev. 2010;18(6):275-284.

158. Dekker JM, Schouten EG, Klootwijk P, Pool J, Swenne CA, Kromhout D. Heart rate variability from short electrocardiographic recordings predicts mortality from all causes in middle-aged and elderly men: The zutphen study. Am J Epidemiol. 1997;145(10):899908. 
159. Tsuji H, Venditti FJ,Jr, Manders ES, et al. Determinants of heart rate variability. $J$ Am Coll Cardiol. 1996;28(6):1539-1546.

160. Tsuji H, Larson MG, Venditti FJ,Jr, et al. Impact of reduced heart rate variability on risk for cardiac events: The framingham heart study. Circulation. 1996;94(11):28502855.

161. La Rovere MT, Pinna GD, Maestri R, et al. Short-term heart rate variability strongly predicts sudden cardiac death in chronic heart failure patients. Circulation. 2003;107(4):565-570.

162. Goldberger JJ, Cain ME, Hohnloser SH, et al. American heart association/ american college of cardiology foundation/ heart rhythm society: Scientific statement on noninvasive risk stratification techniques for identifying patients at risk for sudden cardiac death: A scientific statement from the american heart association council on clinical cardiology committee on electrocardiography and arrhythmias and council on epidemiology and prevention. Circulation. 2008;118(14):1497-1518.

163. Lauer MS. Autonomic function and prognosis. Cleve Clin J Med. 2009;76(Suppl 2):S18-22.

164. Vinik AI, Freeman R, Erbas T. Diabetic autonomic neuropathy. Semin Neurol. 2003;23(4):365-372.

165. Lewis JE, Lantigua L, Atlas SE, et al. A cross-sectional assessment to detect type 2 diabetes with endothelial and autonomic nervous system markers using a novel system. $J$ Diabetes Metab Disord. 2014;13(1):118-125.

166. Tishkoff DX, Nibbelink KA, Holmberg KH, Dandu L, Simpson RU. Functional vitamin D receptor (VDR) in the t-tubules of cardiac myocytes: VDR knockout cardiomyocyte contractility. Endocrinology. 2008;149(2):558-564.

167. Weishaar RE, Simpson RU. Vitamin D3 and cardiovascular function in rats. J Clin Invest. 1987;79(6):1706-1712.

168. Borges AC, Feres T, Vianna LM, Paiva TB. Effect of cholecalciferol treatment on the relaxant responses of spontaneously hypertensive rat arteries to acetylcholine. Hypertension. 1999;34(4 Pt 2):897-901.

169. Santillan GE, Vazquez G, Boland RL. Activation of a beta-adrenergic-sensitive signal transduction pathway by the secosteroid hormone 1,25-(OH)2-vitamin D3 in chick heart. J Mol Cell Cardiol. 1999;31(5):1095-1104. 
170. De Novellis V, Loffreda A, Vitagliano S, et al. Effects of dietary vitamin D deficiency on the cardiovascular system. Res Commun Chem Pathol Pharmacol. 1994;83(2):125-144.

171. Cetin M, Kozdag G, Ural D, et al. Could decreased vitamin D levels be related with impaired cardiac autonomic functions in patients with chronic heart failure: An observational study. Anadolu Kardiyol Derg. 2014;14(5):434-441.

172. Krause M, Anschutz W, Vettorazzi E, Breer S, Amling M, Barvencik F. Vitamin D deficiency intensifies deterioration of risk factors, such as male sex and absence of vision, leading to increased postural body sway. Gait Posture. 2014;39(1):166-171.

173. Chan CT, Levin NW, Chertow GM, et al. Determinants of cardiac autonomic dysfunction in ESRD. Clin J Am Soc Nephrol. 2010;5(10):1821-1827.

174. Mann MC. Vitamin D and cardiac autonomic tone: Cardiovascular implications in humans with and without chronic kidney disease. [Dissertation]. Calgary, Alberta: University of Calgary; 2015.

175. Oikawa K, Ishihara R, Maeda T, et al. Prognostic value of heart rate variability in patients with renal failure on hemodialysis. Int J Cardiol. 2009;131(3):370-377.

176. Pilz S, Iodice S, Zittermann A, Grant WB, Gandini S. Vitamin D status and mortality risk in CKD: A meta-analysis of prospective studies. Am J Kidney Dis. 2011;58(3):374-382.

177. Chan CT. Heart rate variability in patients with end-stage renal disease: An emerging predictive tool for sudden cardiac death? Nephrol Dial Transplant. 2008;23(10):3061-3062.

178. Drechsler C, Verduijn M, Pilz S, et al. Vitamin D status and clinical outcomes in incident dialysis patients: Results from the NECOSAD study. Nephrol Dial Transplant. 2011;26(3):1024-1032.

179. Dusso AS, Tokumoto M. Defective renal maintenance of the vitamin D endocrine system impairs vitamin D renoprotection: A downward spiral in kidney disease. Kidney Int. 2011;79(7):715-729.

180. Nishimura M, Tokoro T, Nishida M, et al. Sympathetic overactivity and sudden cardiac death among hemodialysis patients with left ventricular hypertrophy. Int $J$ Cardiol. 2010;142(1):80-86.

181. Mann MC, Exner DV, Hemmelgarn BR, et al. Vitamin D levels are associated with cardiac autonomic activity in healthy humans. Nutrients. 2013;5(6):2114-2127. 
182. Mann MC, Exner DV, Hemmelgarn BR, et al. Vitamin D supplementation is associated with improved modulation of cardiac autonomic tone in healthy humans. Int $J$ Cardiol. 2014;172(2):506-508.

183. Ewing DJ, Martyn CN, Young RJ, Clarke BF. The value of cardiovascular autonomic function tests: 10 years experience in diabetes. Diabetes Care. 1985;8(5):491498.

184. Task Force of the European Society of Cardiology and the North American Society of Pacing and Electrophysiology. Heart rate variability: Standards of measurement, physiological interpretation and clinical use. Circulation. 1996;93(5):1043-1065.

185. Jung $\mathrm{CH}$, Jung SH, Kim KJ, et al. The relationship between vitamin D status and cardiac autonomic neuropathy in patients with type 2 diabetes mellitus. Diab Vasc Dis Res. 2015;12(5):342-351.

186. Tarcin O, Yavuz DG, Ozben B, et al. Effect of vitamin D deficiency and replacement on endothelial function in asymptomatic subjects. J Clin Endocrinol Metab. 2009;94(10):4023-4030.

187. Al Mheid I, Patel R, Murrow J, et al. Vitamin D status is associated with arterial stiffness and vascular dysfunction in healthy humans. J Am Coll Cardiol. 2011;58(2):186-192.

188. Mayer O,Jr, Filipovsky J, Seidlerova J, et al. The association between low 25hydroxyvitamin D and increased aortic stiffness. J Hum Hypertens. 2012;26(11):650-655.

189. Giallauria F, Milaneschi Y, Tanaka T, et al. Arterial stiffness and vitamin D levels: The baltimore longitudinal study of aging. J Clin Endocrinol Metab. 2012;97(10):37173723.

190. Karohl C, Vaccarino V, Veledar E, et al. Vitamin D status and coronary flow reserve measured by positron emission tomography: A co-twin control study. J Clin Endocrinol Metab. 2013;98(1):389-397.

191. Dong Y, Stallmann-Jorgensen IS, Pollock NK, et al. A 16-week randomized clinical trial of 2000 international units daily vitamin D3 supplementation in black youth: 25hydroxyvitamin D, adiposity, and arterial stiffness. J Clin Endocrinol Metab. 2010;95(10):4584-4591.

192. Breslavsky A, Frand J, Matas Z, Boaz M, Barnea Z, Shargorodsky M. Effect of high doses of vitamin $\mathrm{D}$ on arterial properties, adiponectin, leptin and glucose homeostasis in type 2 diabetic patients. Clin Nutr. 2013;32(6):970-975. 
193. Lagari V, Gomez-Marin O, Levis $\mathrm{S}$. The role of vitamin $\mathrm{D}$ in improving physical performance in the elderly. J Bone Miner Res. 2013;28(10):2194-2201.

194. U.S. Census Bureau. State \& county quick facts: Miami-dade county, florida. http://quickfacts.census.gov/qfd/states/12/12086.html. Accessed April 20, 2013.

195. Florida Department of Health in Miami-Dade County. Miami-dade county injury facts: Unintentional fall injuries, all ages, 2007-2009. Florida Department of Health in Miami-Dade County Web site. http://miamidade.floridahealth.gov/programs-andservices/wellness-programs/injury-and-violenceprevention/_documents/Fall\%20Stats\%20all\%20ages.pdf;. Updated 2011. Accessed August 31, 2015.

196. Beauchet O, Annweiler C, Verghese J, Fantino B, Herrmann FR, Allali G. Biology of gait control: Vitamin D involvement. Neurology. 2011;76(19):1617-1622.

197. Peterson A, Mattek N, Clemons A, et al. Serum vitamin D concentrations are associated with falling and cognitive function in older adults. J Nutr Health Aging. 2012;16(10):898-901.

198. Menant JC, Close JC, Delbaere K, et al. Relationships between serum vitamin D levels, neuromuscular and neuropsychological function and falls in older men and women. Osteoporos Int. 2012;23(3):981-989.

199. Houston DK, Neiberg RH, Tooze JA, et al. Low 25-hydroxyvitamin D predicts the onset of mobility limitation and disability in community-dwelling older adults: The health ABC study. J Gerontol A Biol Sci Med Sci. 2013;68(2):181-187.

200. Houston DK, Tooze JA, Neiberg RH, et al. 25-hydroxyvitamin D status and change in physical performance and strength in older adults: The health, aging, and body composition study. Am J Epidemiol. 2012;176(11):1025-1034.

201. Gschwind YJ, Bischoff-Ferrari HA, Bridenbaugh SA, Hardi I, Kressig RW. Association between serum vitamin D status and functional mobility in memory clinic patients aged 65 years and older. Gerontology. 2014;60(2):123-129. 


\section{CHAPTER III: METHODS}

\section{Design}

This was an observational study. Its purpose was to determine the proportion of vitamin D insufficient individuals and investigate the correlates of vitamin D status (i.e., vitamin D intake, sun exposure, etc.) in community-dwelling adults over the age of 55. In addition, it evaluated the possible relationships between vitamin D status with dual task physical performance and cardiovascular disease (CVD) risk factors. The study used the baseline assessment data from the parent study, which was a randomized placebo controlled trial (RCT) that examined the effects of vitamin D supplementation on vitamin D status, musculoskeletal health markers and physical performance, conducted by John E. Lewis, Ph.D., Principal Investigator at the University of Miami. This study was approved by the Institutional Review Board (IRB) at University of Miami (20120195) and Florida International University (13-0390).

\section{Selection of Participants and Eligibility Criteria}

\begin{tabular}{|c|c|}
\hline Inclusion: & Exclusion: \\
\hline $\begin{array}{l}\text { - } \text { Age } 55 \text { or older men and women } \\
\text { - } \text { English/Spanish speaking } \\
\text { - } \text { Community dwelling } \\
\text { - Scoring 0-2 errors in Short Portable } \\
\text { Mental Status Questionnaire (SPMSQ) } \\
\text { - Ability to give informed consent } \\
\text { - } \text { Ability to perform motor tasks without } \\
\text { aid } \\
\text { - Participating in the parent study }\end{array}$ & $\begin{array}{l}\text { - } \text { Age younger than } 55 \text { years } \\
\text { - } \text { Not English/Spanish speaking } \\
\text { - Living in nursing home/ } \\
\text { institutionalized } \\
\text { - Scoring >2 errors in SPMSQ } \\
\text { - Unable to consent } \\
\text { - } \quad \text { Unable to walk without aid } \\
\text { - } \text { Not participating in parent study }\end{array}$ \\
\hline
\end{tabular}




\section{Sample Size}

Using a two-tailed independent t-test with 5\% significance and $80 \%$ power and assuming an allocation ratio of 60/40 (1.5), based on published prevalence of vitamin D deficiency in the general United States older adult population, and an effect size of 0.5 for the dual task gait speed as the primary outcome variable, the total sample size calculated using G power statistical software was 134 (expected 54 vitamin D deficient and 80 vitamin D sufficient). Due to financial constraints, only 101 participants were enrolled in the study of which 4 were excluded from the analysis due to incomplete assessments and missing data.

\section{Recruitment}

Participants for this study were recruited from the parent study at the University of Miami. For the parent study, potential participants were identified through the clinicians and researchers from the Department of Medicine and Psychiatry clinics on a daily basis. The clinicians determined the level of interest in participating in the study by briefly describing the purpose of the study without using any coercive or suggestive language to imply that participation in the study was expected or demanded. All study personnel were CITI certified for human research and were familiar with enrolling patients and the issues of confidentiality and respect of human subjects in research.

Patients who expressed interest in participating in the study were instructed to call study staff to proceed with the formal screening and enrollment process. Study staff was informed of any potential participant who had consented to be contacted. The study staff called the individual to set up a screening/appointment. 


\section{$\underline{\text { Screening }}$}

Participants for the parent study were screened over the phone to determine if they met the inclusion and exclusion criteria. Each potential participant was given a brief introduction to the nature and purpose of the study and then asked if they would like to participate. Once the person agreed to participate, they were administered the Short Portable Mental Status Questionnaire (SPMSQ) to evaluate mental functioning and thus, assess participant competency, or in other words, mental capacity to understand information, appreciate risks/benefits of choices, make rational decisions regarding personal health, and communicate choice during the process of informed consent. Subjects were allowed up to 2 errors on the SPMSQ. Once they answered the SPMSQ successfully, then they were asked a series of questions related to the general inclusion criteria such as age, medical history, medication use and general exclusions. If responses to the inclusion/exclusion criteria were satisfactory, those who were still interested in participating were scheduled to undergo the consent process and their assessment visit. Potential participants who did not meet the inclusion criteria were thanked for their time and told they did not meet study eligibility.

\section{$\underline{\text { Informed Consents }}$}

There were two informed consents were signed at the initial visit. The informed consent for University of Miami explained this study and the intervention study. The informed consent for Florida International University explained this study only. Both informed consent forms were available in English and Spanish, and the information was presented in a language understandable to the subject population. The consent forms 
contained the studies' purposes, procedures, confidentiality/privacy methods, risks/discomforts, benefits, and alternatives associated with the studies. They contained in bold an explanation of whom to contact for answers to pertinent questions about the studies, their subject rights, and protocols in case of any research-related injury. The statement also had the number and contact person at both IRBs and the office numbers of John E. Lewis, Ph.D. (the PI) and the student investigator, Johanna Lopez, in case of additional questions or if they wanted to place any complaint.

The informed consent procedure took place in a private room in either Dr. Lewis' office or the Department of Psychiatry and Behavioral Sciences interviewing rooms. All of the information on the consent form was verbally explained including but not limited to the purpose, procedures and expected duration of the study. Once the participant had expressed interest in taking part in the study, adequate time was given to read the IRB approved informed consent form before signing it to avoid the possibility of coercion. If the participant was unable to read or had any limitation, the consent form was read to the potential participant. Sufficient time was provided to allow the participant the opportunity to consider enrollment in the study and to receive answers to any questions. Once the informed consents were signed, the participant received a copy of both. Participants were also asked to sign a HIPAA Research Authorization Template form, which authorizes the researcher to use and disclose health information from medical and research records that were relevant to the research.

Following receipt of signed informed consent, participants were assigned a study Participant Identification (PID) number to track the participant's responses over time. A 
master list of the participant PIDs is being kept in the PI's office in a locked file cabinet. Participant PIDs were created following a coded alphanumeric combination.

\section{Assessments}

Participants were reimbursed for time, travel and effort by the parent study sponsor. The reimbursement was believed to be fair and not constitute coercion, given the commitment required for completing the entire protocol. Once the participant consented, the study staff collected the outcome measurements. To decrease observer bias, all researchers were trained for administering all screening and assessments battery using standardized procedures and uniform protocols. A research chart identified only by the PID was created for every participant containing a checklist of documents completed during screening and assessments and copies of socio-demographic and medical history questionnaires, laboratory test results, and the outcome assessments in questionnaires. Copies of the screening forms and informed consents, which contained the participant personal information and list of PID codes, were stored separately in the principal investigator's locked file cabinet in his office.

The assessments were performed in 2 baseline visits, one which lasted about 3 to 3.5 hours and the second took 15 to 20 minutes. All of the participants included in this analysis were seen between February and June 2015, before randomization to parent study intervention. The following measures were assessed during the baseline assessment visit for the parent study, which were used for this study: 


\section{$\underline{\text { Vitamin D Status }}$}

Vitamin D status was measured by serum 25-hydroxyvitamin D (25(OH)D). Fasting venous blood (15 ml) was collected from every participant by a certified phlebotomist in the morning. The samples were sent the same day they were collected for analysis to LabCorp (2700 N. 29 ${ }^{\text {th }}$ Ave, Suite 203A, Hollywood, Fl 33020) identified with the date of the draw and the subject PID number. Lab Corp used the immunochemiluminometric assay (ICMA) on the DiaSorin Liaison instrument to assess serum $25(\mathrm{OH}) \mathrm{D}$. The dynamic range of the assay is $4.0-150 \mathrm{ng} / \mathrm{ml}$, with a functional sensitivity of $<4 \mathrm{ng} / \mathrm{ml}$, a specificity of $100 \%$ and a high correlation with the DiaSorin 25( $\mathrm{OH}) \mathrm{D}$ radioimmunoassay, which has been used as the standard for clinical diagnosis for many years. ICMA is a competitive chemiluminescence immunoassay that uses magnetic particles coated with 25(OH)D antibody and 25(OH)D conjugated to the chemiluminescent isoluminol derivative. These beads are incubated with the sample, and the $25(\mathrm{OH}) \mathrm{D}$ in the sample competes with the labeled vitamin $\mathrm{D}$ bound to the particles. Then the sample is incubated with the labeled 25(OH)D tracer and the unbound material is washed off. The sample is reacted with substances that cause a chemiluminescent reaction that is measured by a photomultiplier. The signal is inversely related to the levels of $25(\mathrm{OH}) \mathrm{D} .{ }^{1}$ This is a highly automated test that measures total $25(\mathrm{OH}) \mathrm{D}$, and it has been widely used by others.

\section{Vitamin D Intake}

Vitamin D intake (continuous variable) was measured by a vitamin D and calcium specific short food frequency questionnaire (FFQ) developed by Blalock et al. ${ }^{2}$ based on 
the Block-National Cancer Institute Health Habits and History Questionnaire (HHHQ), a tool that is widely used in epidemiological studies and has been previously validated for measuring vitamin D in a population of postmenopausal women by comparing it to a 3day food records and in university employees by comparing it to 7 -day food records. ${ }^{2-6} \mathrm{It}$ includes only 23 foods and beverages that were identified in the HHHQ as rich in either or both vitamin $\mathrm{D}$ and calcium. This self-administered questionnaire asks how frequently (never or less than once per month; 1/ month; 2-3/month; 1/week; 2/weeks; 3-4/week; 56/week; 1/day; 2-3/day) and how much of each of these foods was consumed based on serving sizes (small, medium, large). The short FFQ is associated with a database; therefore, allowing the estimation of nutrient intakes for the reported portion size. Vitamin D and calcium values for the 23 foods were recorded from the Diet History Questionnaire database developed by the National Cancer Institute, according to serving size. The raw values were multiplied by the frequencies to calculate the amount of vitamin D and calcium per day using Microsoft Access. ${ }^{2}$

The advantage of this instrument is that it is short; therefore, decreasing the burden on the participant, and it does not mix many different foods into one category, thus not affecting the respondents' cognitive complexity. ${ }^{7}$ Furthermore, Blalock et al. ${ }^{2}$ validated this tool showing that the vitamin $\mathrm{D}$ and calcium intakes estimated from this short FFQ were significantly correlated with estimates from the 7-day food diary $(\mathrm{r}=0.72$ and 0.66; respectively) and the original HHHQ ( $r=0.65$ and 0.66 , respectively). Positive predictive values of $100 \%$ for vitamin D and $91.7 \%$ for calcium were reported for the short instrument to identify those with low intakes as based on the 7-day food record. 


\section{$\underline{\text { Sun Exposure }}$}

Sun exposure (continuous variable) was assessed using a questionnaire developed by Hanwell et al. ${ }^{8}$ This tool categorically measures the amount of time spent outdoors and amount of skin exposed for every day of the week. A scoring system is used to quantify sun exposure by multiplying time outdoors, $(<5$ minutes $=0 ; 5-30$ minutes $=1$; and $>30 \min =2$ ); to amount of skin exposed (hands and face $=0$; hands, face, arms $=1$; hands, face, arms, legs = 2; bathing suit $=3$ ) for every day. The sum of the scores for each day was added for a total score.

The researchers who developed this tool found that the sun exposure score was significantly correlated with serum vitamin D levels during the summer, which was mostly explained by the time in the sun than by the amount of skin exposed. The sun exposure score, however, did not correlate with vitamin D levels during the winter. ${ }^{8}$

\section{Dual Task Physical Performance}

Dual task physical performance tests have been used to evaluate the interaction between cognition and mobility as an indicator of fall risk in older adults. ${ }^{9}$ The dual task physical performance test was developed with the consultation of the Department of Physical Therapy. We conducted an extensive review of literature, overseen by Edgar Ramos Vieira, P.T., Ph.D., to investigate the methodological variations implicated in dual task analysis using mental tracking as the secondary task, and walking as the primary motor task. This was done by investigating the types of mental tracking task, secondary task outcomes, gait tasks, methods for the assessment of gait, the gait outcomes, and how dual tasking affects gait and secondary task and predicts falls in selected studies. 
From this systematic review, it was evident that the gait task most commonly used was straight forward walking at different distances ranging from 3 to 25 meters, at selfselected pace, using own footwear and a pressure pad system like the GAITRite. Of all the spatiotemporal variables measured in all of the studies, decrease in speed during dual tasking was consistently found to predict falls in older adults. In these studies, however, speed was calculated by measuring distance and dividing it by ambulation time. Experts suggest using pressure pads or other systems instead, because they are more reliable and allow for the measurement of changes in other gait parameters that may be more relevant for assessing fall risk besides speed. ${ }^{10}$ Some researchers, however, argue that a pressure pad systems like GAITRite, which has been shown to be a reliable tool for measuring spatiotemporal parameters in the elderly, have the limitation that they are of short length, hence, limiting the measurement of gait variability. ${ }^{11}$ Given this shortcoming, for this study participants were asked to repeat the trial three times to get at least ten steps.

Our review of literature also indicated that the most common mental tracking tasks, which predicted fall outcomes, were serial subtractions by one and three. When measuring the secondary task, different outcomes have been described from number of enumerated figures to number of mistakes; therefore, for this study number of enumerated figures was measured, and counting rate (number of enumerated figures divided by time) was calculated. In most studies, task order was randomized, and participants were not asked to prioritize either task during the dual task. When participants prioritize either task, fewer changes are observed in that particular task. Therefore, it is important to measure both the gait and cognitive task, because dual task performance results from the interference that is caused by the competing demands of 
two tasks for attention resources. ${ }^{12,13}$ Hence, in the present study, task order was randomized, and participants were not asked to prioritize either task, and thus performance in both tasks were measured.

Despite the heterogeneity of the populations studied and the diverse sample sizes, the results from our systematic review indicated that changes in speed and stride variability while performing a simple gait task, such as walking in a straight line, and a simple mental tracking secondary task, such as counting backwards from 50 by 1, using the speed analysis method or even better, a spatiotemporal assessment system like the GAITRite, yield enough sensitivity and predictive value for falls. Therefore, for this study, a dual task test that involved walking in a straight line while counting backward from 50 by 1 using the GAITRite system was used to measure gait speed as the primary outcome variable.

Description of Dual Task Test:

After a practice walk, participants were asked to perform the following tasks in a random order, determined from a random order table.

- Usual walking (single gait task)

- Counting backward from 50 by one while standing (single cognitive task) ${ }^{14}$

- Counting backward from 50 by one while walking (dual task)

\section{Gait Speed}

Gait speed (distance walked/time; cm/s; continuous variable) was measured using the GAITRite system (Appendix B). The GAITRite system includes a 6 meter-long and 
64 centimeter-wide walkway mat that is used to measure spatiotemporal gait parameters through its embedded sensors that are activated and deactivated according to foot pressure. The participants wore comfortable, low-heeled shoes. Before each trial, participants' leg length was measured using a measuring tape from the trochanter of the femur to the medial malleolus (bony part of the ankle). The GAITRite software was initiated to enter the participant ID, height, weight and leg length. Participants were given a demonstration of how to walk on the walkway from the start to the finish line that was located 2 meters before and after the walkway to account for acceleration and deceleration. Data collection was initiated by pressing "START."

Participants were given standardized instructions for practice and data collection trials in which they were asked to walk only or walk while dual tasking without prioritizing either task on the GAITRite walkway at their preferred gait speed. The instructions for the practice trials were: "This is the walkway that we will use for some walking tests. For each walk, you must start behind the line in front of you and continue walking until you pass the line at the other end of the walkway. To familiarize yourself with the walkway, start at this line and walk across the mat at the pace you prefer during daily activities. Do not run. Continue walking until you reach the line on the other side. You can start when you are ready.” The instructions for the single gait task were: "Starting at this line, walk across the mat at a pace you prefer during daily activities. Do not run. Continue walking until you reach the line on the other side. You can start whenever you are ready." The instructions for the dual task were: "For the following test, you will walk across the mat at a pace you prefer during daily activities while you simultaneously count backward out from 50 by one. Do not run. If you make mistakes 
during counting keep on going. Continue walking without prioritizing either of the tasks until you reach the line on the other side. You can start when you are ready.”

Participants were required to perform three trials per data recording session. To ensure safety, the researcher walked beside the walkway, slightly behind the participants. The GAITRite software was used to process the information and gather the data. The first ten gait cycles were used in each gait condition to determine spatial-temporal gait parameters, which were normalized by individual leg length.

\section{Counting Rate in Secondary Cognitive Task}

Counting rate (continuous variable) was used to assess cognitive secondary task performance. It was measured by using a voice recorder while single and dual tasking. The number of enumerated figures was defined as the number achieved at the completion of the walking distance for the dual task. For the single task, the number of enumerated figures was defined as those spoken during the same time required for the completion of the dual task. ${ }^{15}$ The instructions for the single cognitive task were: "For the following test, you will remain standing the whole time, no walking. You will count backward out loud from 50 by one while you are standing. If you make mistakes during counting keep on going. You can start when you are ready.” They were recorded until they stopped walking if dual tasking or reached 30 if single tasking. The time to complete the dual task was used to calculate the number of figures enumerated during the single task. For instance, if the participant took 30 seconds to finish counting during the dual task, the number of enumerated figures for the single task was counted in the first 30 seconds of single tasking. The average of the three trials was used. 


\section{Cardiometabolic Risk Score (CMRS)}

We used the FDA approved and patented Electro Sensor Complex (ESC) software, which combines three devices (ES-BC, TM-Oxi and SudoPath) that use bioelectrical impedance, galvanic skin response, spectrophotometry, and an oscillometric blood pressure device. It measures different parameters of body composition, endothelial function and autonomic nervous system (ANS) function during baseline and the

performance of cardiac autonomic function tests. ${ }^{16,17}$ Steps of the procedure are shown in Appendix B. Briefly, study staff, trained by the manufacturer, asked participants to sit on a comfortable chair with their shoes and socks off, feet on the metal plates, right index finger in the pulse oximeter, and blood pressure cuff on the left arm. After inputting demographic, anthropometric and physical activity data, the software initiated the baseline assessment for 1-2 minutes while the participant was sitting relaxed. Then the participant was asked to perform the Valsalva maneuver by clamping their nose with their left hand while trying to breath out for 15 seconds with their mouth closed, building pressure like when popping ears. After releasing their nose, participants were asked to breath deeply for 30 seconds, inhaling for 5 seconds and exhaling for 5 seconds. Finally, participants were asked to stand up, while straightening their left arm to their side and keeping their index finger in the pulse oximeter. The whole assessment lasted about 5 minutes.

Details of the devices are discussed in previous publications and the manufacturer's website (http://www.ldteck.com). ${ }^{16,17}$ The Electro-Sensor Body Composition (ES-BC) device uses a single-frequency bioelectrical impedance analyzer in a tetrapolar mode to measure current, voltage, and phase angle to calculate impedance 
resistance and reactance. ${ }^{16}$ This information is used by the software to compute percent body fat mass (\%FM) using accepted peer-reviewed published algorithms tailored to the general and obese population based on gender, height, weight, age, and activity level. ${ }^{16,18-}$ ${ }^{21}$ The accuracy of ES-BC has been compared to dual-energy X-ray absorptiometry (DXA) and found an adequate relative and absolute agreement for \%FM between both. ${ }^{16}$

The TM-Oxi system assesses cardiac autonomic nervous system ANS function, including both sympathetic (SNS) and parasympathetic nervous systems (PNS), during baseline and validated cardiac autonomic reflex tests (i.e., Valsalva maneuver, deep breathing, and change from sitting to standing) (Appendix B). ${ }^{22}$ The software uses an automatic oscillometric blood pressure device and pulse oximeter, which uses an optical technique (spectrophotometry) to measure vascular dynamics and HRV. ${ }^{23,24}$ Briefly, the pulse oximeter directs red and infrared light into the nail bed area of the right index finger, which is absorbed, reflected, and scattered by blood hemoglobin. During systole, the arteries' diameter increases as blood fills the capillary beds at the fingertip, increasing the concentration of hemoglobin in the vessels in the nail bed and thus affecting the absorption, reflection and scattering of light that is measured by the photosensor. The change in light absorption, reflection, and scattering between systole and diastole creates a pulsatile signal or waveform, illustrated as a plethysmograph (PTG), which varies in time with each heartbeat (Appendix B). From the time domain, the TM-Oxi calculates the standard deviation of the normal wave ( SDNN, the variation between each successive heart beat) and the square root of the mean squared differences of successive normal to normal R-R intervals (RMS SD, indicator of parasympathetic activity) (Appendix B). ${ }^{25}$ 
The TM-Oxi applies a mathematical algorithm, the Fast Fourier Transform (FFT), to the PTG recording (FFTPTG) to manipulate the beat to beat RR intervals into a sine wave function thus converting the signal from a time domain to a frequency domain (Appendix B). The frequency domains are then categorized by oscillating frequency, which are the three frequencies of HRV: (1) very low frequency (PTGVLF) associated with thermoregulation and sweating that results in oscillation in vasomotor tone controlled by SNS; (2) low frequency (PTGLF) related to baroreflex which is under control of both SNS and PNS; and (3) high frequency (PTGHF) associated with R-R interval changes associated with breathing under PNS control. ${ }^{17}$ From these components, the software calculates PTG total power (PTGTP, the sum of the areas under the curve covered by the 3 frequency domains) and PTG index (PTGi, the sum of the amplitudes of the 3 frequency domains) which are used to assess baseline ANS function (Appendix B).

After baseline evaluation, the software measures heart rate and blood pressure changes during autonomic reflex tests (Appendix B). The first test to be performed is the Valsalva maneuver in which the participant is asked to perform a moderately forceful exhalation against a closed airway by pinching the nose shut, closing the mouth, and pressing out like popping the ears for 15 seconds and then breathing normally. ${ }^{16,17}$ This test involves 4 phases: (1) straining and beginning on intrathoracic pressure increase; (2) maintenance of increased intrathoracic pressure, resulting in decreased systemic blood pressure and increased heart rate; (3) release of breathing and sudden drop in intrathoracic pressure; and (4) transient bradycardia resulting from the baroreflex response to the sudden increase in aortic pressure due to increased cardiac output. Phase 2 can be divided into 2 phases: (1) early phase in which preload and stroke volume are 
reduced causing a fall in cardiac output despite tachycardia that resulted from decreased vagal activity; and (2) late phase in which total peripheral resistance rises due to increased sympathetic discharge and plasma epinephrine concentration, stopping the fall in blood pressure. The vagal function is evaluated by calculating the heart rate ratio (Valsalva ratio) during phase four and two, which are compared to age-adjusted normal Valsalva ratios. Sympathetic function is evaluated by the beat to beat blood pressure response during phase 2 and phase $4 .^{16,17}$

The second autonomic reflex test is deep breathing, which measures PNS function since the vagal nerve mediates heart rate changes in response to deep breathing. ${ }^{16,17}$ During the inspiration phase, intrathoracic pressure is reduced, decreasing venous return from the pulmonary circulation to the left atrium, decreasing preload, and thus causing an increase in heart rate to compensate and maintain cardiac output. During expiration, the opposite happens. Vagal function during this test is measured by the heart rate ratio between expiration and inspiration (E/I ratio). The final cardiac autonomic reflex test is changing in posture. The participant is in a seated position and asked to stand up. Heart rate increases during the first 15 seconds and decreases until it stabilizes at 30 seconds. At the same time, the blood pressure increases at the standing position, and this change should be greater than $10 \mathrm{mmHg}$ when compared to blood pressure while sitting. PNS is evaluated by measuring the heart rate ratio at 15 and 30 seconds (K30/15). SNS is evaluated by measuring the systolic blood pressure response to standing (BPRS). ${ }^{16,17}$ PTG also provides information about arterial stiffness and endothelial function. The TM-Oxi system quantizes PTG into a digital volume pulse (DVP) waveform that represents the pressure wave that spreads from the heart to the periphery (systolic peak) 
and reflects back to the heart (diastolic peak) during the cardiac cycle. ${ }^{17,26-28}$ Arterial stiffness, which is partially a result of endothelial dysfunction, is defined as the opposition to the pressure wave in the arteries, resulting in abnormal systolic and diastolic peaks. Thus, the DVP waveform, which may be affected by perfusion and body temperature, is mainly regulated by myocardial and arterial characteristics and is used by the software to calculate indicators of vascular health and arterial status (i.e., reflection index, and stress index). ${ }^{16,17}$

Finally, the SudoPath system measures sudomotor activity, which is controlled by post sympathetic cholinergic nerve fibers (C-fibers) that innervate sweat glands, using 2 stainless steel electrodes on which the participant places the soles of the feet, where very high density of sweat glands are located. ${ }^{17}$ This system evaluates skin blood flow (microcirculation), C-fiber condition, and sweat gland activity using galvanic skin response. Briefly, the SudoPath system measures the electrical conductance of the skin that is dependent on the amount of sweat-induced moisture. The device generates a low voltage signal with weak DC current that is fed to the active electrode, passes through interstitial fluid, and reaches the skin in contact with the passive electrode. This current electrically stimulates C-fibers, which release acetylcholine, and thus, stimulate nicotinic muscarinic receptors (M-receptors) in the skin and sweat glands. ${ }^{17,29}$ In the skin, activation of M-receptors result in nitric oxide (NO) production, which causes vasodilation of vascular smooth muscle and increase blood flow to the skin. In the sweat glands, activation of M-receptors result in chloride movement across the apical membrane of sweat gland cells, depolarizing it and thus generating a negative potential that drives water and sodium into the lumen of the sweat gland cells to produce sweat. ${ }^{29}$ 
The change in blood flow and sweat production disturbs the electrical conductance of the skin, which is then measured by the device using the principles of electrolysis as the electric skin response to nitric oxide, a marker for SNS function. ${ }^{17}$

The ESC complex software calculates the cardiometabolic risk score (CMRS) using the variables input into the software (age, gender, height, weight, and physical activity level) and those measured by the three devices (systolic and diastolic blood pressure, ANS function and endothelial function) during baseline and autonomic cardiac reflex tests. Appendix B shows the ten markers (in gray) and the variables used to calculate the score for each marker. Each marker measured is scored as $0=$ normal, $1=$ borderline or $2=$ abnormal and then used to calculate CMRS, which is normal if $\leq 4$, or represents mild risk (5-7), moderate risk (8-10) or high risk ( $\geq 11)$ (Appendix B). ${ }^{17}$ Previous studies have shown the accuracy of these three devices, compared to standardized assessments of body composition, ANS activity, and cardiac output, thus supporting the usefulness of these devices in detecting complications related to metabolic syndrome, diabetes and CVD. ${ }^{16}$ Recently, a study comparing diabetic and healthy controls showed that the CMRS calculated by this software is significantly correlated with glucose and insulin measured during the oral glucose tolerance tests (OGTT) and was significantly higher in participants with diabetes. Also, specificity (92\%) and sensitivity (83\%) were high for the CMRS in differentiating patients with diabetes and healthy controls. ${ }^{17}$ 


\section{Assessment of Potential Covariates and Other Outcomes for All Specific Aims:}

Sociodemographics were assessed by a questionnaire developed by parent study staff that asked about gender, marital status, race/ethnicity, socioeconomic status, and other.

Health history and medications were assessed by a questionnaire developed by parent study staff on current health status and medication use. It included questions about the participant's current health status that was used to confirm inclusion criteria and for data analysis purposes. It asked whether they were currently under the care of a healthcare professional, had seen the health care professional in the past three months (specifying reason), had surgeries or hospitalization (including dates and reasons), had injuries like fractures, dislocations ,or sprains (including date), and had any diagnosed diseases or conditions. It also asked about the use of prescription and over-the-counter medications and vitamin/dietary supplement use. The questionnaire asked about health risk behaviors including coffee and alcohol consumption and smoking status. The final section asked about the history of falls in the past 12 months and the reason for the fall.

Physical activity, which may be a surrogate for outdoor activity, has been positively associated with serum vitamin D levels such that lower levels of serum vitamin D have been correlated with physical inactivity in middle-aged and older adults, and was measured using the International Physical Activity Questionnaire (IPAQ). ${ }^{30,31}$ The IPAQ provides individual domain-specific scores for walking, moderate-intensity, and vigorous activity within the domains of work, transportation, domestic chores and gardening, and leisure-time. ${ }^{32}$ The tool asks about the time spent doing a specific physical activity in the last seven days, defining for the participant vigorous physical activity as that which takes 
hard physical effort and makes breathing harder than normal and moderate activaties as that which takes moderate physical effort and makes breathing somewhat harder than normal. For total scores, the duration (in minutes) and frequency for all types of activities in all domains are summed, while specific domain scores are calculated by the summation of the walking, moderate-intensity, and vigorous-intensity activities within the specific domain. The scores for the specific type of activity across domains are added. To measure the volume of activity, each type of activity is weighted by its energy requirement defined as the MET-min. METs are metabolic equivalents that are computed for each specific activity using formulas defined in the manual (see below for example) and then MET is multiplied by the minutes performed. These MET-minute scores are equal to kilocalories for a $60 \mathrm{~kg}$ person; therefore, kilocalories for a specific individual may be calculated by multiplying the MET-min by the person's weight divided by $60 \mathrm{~kg} \cdot{ }^{32}$

The IPAQ was developed to derive comparable measurements of physical activity in international settings; therefore, being suitable for use in different languages and cultural contexts like in an ethnically-diverse city as Miami. ${ }^{33,34}$ It has also been validated in different age groups against objective measures of physical activity, physical fitness and health outcomes. ${ }^{35}$ For instance, it was validated in an adult population (mean \pm SD: $40.7 \pm 10.3$ years old) and found to have a strong positive relationship with an activity monitor and a physical activity $\log ($ rho $=0.55, P<0.001) .{ }^{36}$ It has also validated and used in a population of elderly men and found to be reliable (test-retest reliability of 0.95) and valid as compared against pedometer use and the physical activity log with similar results reported for postmenopausal women. ${ }^{37,38}$ Other studies have validated the IPAQ and used 
it successfully in populations of middle-aged and older adults and adults with different diseases, like schizophrenia and breast cancer. ${ }^{34,39-42}$ The IPAQ correlated with measurements to other physical activity assessment methods, such as the 2001 Behavioral Risk Factor Surveillance System (BRFSS) physical activity, accelerometers, and energy expenditure as measured by doubly-labeled water, among others. ${ }^{35,43-46}$

Depressive symptoms were measured as a potential covariate since it has been associated with vitamin D deficiency. ${ }^{47,48}$ In addition, those who are depressed tend to walk slower and take a longer time to respond to cognitive challenges ${ }^{49}$ Depression was assessed using the Beck Depression Inventory (BDI), which measures the existence and severity of depressive symptoms based on the DSM-IV. It is a self-report 21-item instrument to assess the existence and severity of depressive symptoms based on the DSM-IV; thus having content validity. Each item corresponds to a symptom of depression and has a four-point scale ranging from 0 to 3 , except for two items that have seven options to indicate decrease or increase in appetite and sleep. The score of all items is summed to give a single score. A total score of 0-13 is considered minimal, 14-19 mild, 20-28 moderate, and 29-63 severe. ${ }^{47}$ Construct validity has been assessed on its ability to differentiate non-depressed and depressed patients ( 0.92 for outpatients and 0.93 for college students). Test-retest reliability was found to be significant at 0.93 . This tool has been used in populations ages $13-80$ years. ${ }^{47,50-52}$ In an elderly population, BDI-II has good internal consistency (0.86), has been positively correlated with other measures of depression, measures of stress, anxiety, and negatively to well-being. Research with this toll has shown that there are no statistically significant effects for ethnicity, gender, and age on BDI-II scores. ${ }^{53}$ Because item 9 of the BDI inquires about "suicidal thoughts 
or wishes," we immediately notified Dr. Judi Woolger, study physician at the University of Miami Internal Medicine Department, if a participant responded affirmatively to this question, which may be indicative of suicidal ideation (SI).

Fear of falling was another potential parameter that may have interfered with the physical assessment battery; therefore, it was assessed using the Fall Efficacy Scale International (FES-I), which is a 16-question assessment tool that evaluates the fear of falling while performing everyday activities. ${ }^{49,54}$ Participants were asked to rate on a scale of 0 to 4 how concerned they are about the possibility of falling while performing these activities with 0 meaning "not at all concerned,” 1 being "a little concerned,” 2 being “somewhat concerned,” 3 being "fairly concerned" and 4 being "very concerned. The scores of every item were added and used as a score out of 64 . The higher the score, the more the concern for falling while performing these activities. ${ }^{54}$ The FES-I was developed by the Prevention of Falls Network Europe (ProFaNE) to measure the elderly's level of concern about falling while performing physical and social activities inside or outside the home. ${ }^{55}$ This tool is based on the original Falls Efficacy Scale, ${ }^{56}$ which measures the levels of confidence in performing certain activities without falling, and it is correlated with measures of balance and gait. FES also predicts future incidence of falls and decline in physical functioning, and it is sensitive to change in fear after clinical interventions. ${ }^{57-65}$ The FES-I was adapted from the original FES to be used in different languages, including Spanish, and cultural contexts, which deems it appropriate for the culturally-diverse population in Miami.

Both the internal and test-retest reliabilities of FES-I are 0.96. The inter-item correlation ranged from 0.29 to 0.79 with an average of $0.55 .{ }^{55} \mathrm{FES}$-I responses were 
significantly different between those who reported no falls, one fall, and multiple falls in the last year. They were also significantly higher in older participants, women, and those with lower occupational categories. Furthermore, those who reported a fall risk factor like falling in the past year, chronic diseases, polypharmacy, use of psychoactive medication, and dizziness also had higher total FES-I scores. These data indicate FES-I is sensitive to group differences related to risk factors and demographics. ${ }^{55}$ FES-I convergent validity has been confirmed for fall history, depression, disability, quality of life, and physical impairment (poor balance, slow gait, low muscle strength), and its predictive validity has also been confirmed, since it can discriminate between certain risk factors for falling, overall disability, and multiple fallers after 12 months. ${ }^{59,66-72}$ Scores above 23 may indicate a high concern of falling. ${ }^{71}$

Anthropometrics were measured to assess for obesity. Obesity, whether it is measured using body mass index (BMI), waist circumference (WC), or waist-to-hip ratio (WHR), has been linked to vitamin D deficiency. ${ }^{73-75}$ Obesity also increases the risk of impaired physical function. ${ }^{76}$ Therefore, obesity in this population was measured using BMI. Height was measured using a stadiometer with a movable headpiece. Participants were asked to stand with their back to the height rule with their feet together, while the back of the head, back, buttocks, calves, and heels touched the upright tape. The participant was asked to look straight ahead so that the ear canal was level with the cheek bone. The headpiece was lowered so that the hair was pressed flat. Weight and height were recorded to the nearest $0.1 \mathrm{~kg}$ and $0.1 \mathrm{~cm}$, respectively. Participants were asked to remove shoes, and heavy outer garments like coats, and to stand in the center of the balance so that the weight is distributed evenly on both feet. Participants were asked to 
stand with their back to the height rule with their feet together, while the back of the head, back, buttocks, calves, and heels were touching the upright tape. The participant was asked to look straight ahead so that the ear canal level with the cheek bone. The headpiece was then be lowered so that the hair was pressed flat. Weight and height were recorded to the nearest $0.1 \mathrm{~kg}$ and $0.1 \mathrm{~cm}$, respectively. BMI was calculated using the formula: weight $(\mathrm{kg}) /$ height $(\mathrm{m})^{2}$ and accordingly, participants were classified into categories based on the National Heart, Lung and Blood Institute recommendations: underweight $\left(<18.5 \mathrm{~kg} / \mathrm{m}^{2}\right)$, normal weight $\left(18.5-24.9 \mathrm{~kg} / \mathrm{m}^{2}\right)$; overweight (25-29.9 $\left.\mathrm{kg} / \mathrm{m}^{2}\right)$, and obese $\left(>30 \mathrm{~kg} / \mathrm{m}^{2}\right)$.

BMI is not a good measure of body composition and adiposity because it does not distinguish between lean mass and fat mass. Since one of the theories that explain the link between vitamin $\mathrm{D}$ deficiency and obesity is the sequestration of vitamin $\mathrm{D}$ in adipose tissue, \%FM was also measured in this population using the ES-BC device described above, which utilizes bioelectrical impedance (BIA).${ }^{77}$ Furthermore, the incidence of CVD is also linked to vitamin D deficiency; therefore, WC and WHR were used to measure body fat distribution around the abdomen and evaluate the risk of CVD. ${ }^{75,78,79}$ WC was measured at the umbilicus and hip circumference (HC) was measured at the broadest circumference below the waist. Both of these measurements were done using a flexible but not stretchable measuring tape in three replicates to ensure reliability. The average of the three values were used to calculate WHR by dividing WC by HC. 


\section{Data Management}

The security and confidentiality of participant's information are of greatest concern, and appropriate data management procedures, and security clearances were established. The confidential nature of the data was maintained by using unique PID numbers, which were used in all research forms. The list of participants with their assigned PIDs and the research charts were kept in a locked cabinet in the locked office

of the PI. The questionnaires and forms were carefully reviewed for completeness and illogical, inappropriate, and discrepant responses. Data entry was started simultaneously with the receipt of completed questionnaires and assessment forms. After entry of data into the computer, the data were verified, checked for inconsistencies, and edited using PIDs. Regular checks of the data were used to identify duplicate and missing data. In cases of duplicate or missing data, the research coordinator was notified immediately.

\section{$\underline{\text { Statistical Analysis }}$}

Data were analyzed using frequencies, percentages, ranges, means, and standard deviations. Independent t-tests or chi-square were used to compare socio-demographic characteristic between vitamin D status groups. Pearson (for two or more continuous variables) and Spearman (for two or more categorical variables) correlations were performed to evaluate the relationship of (1) vitamin D status categories to vitamin D intake and sun exposure; and (2) vitamin D status categories to dual task gait velocity and counting rate, and the dual to single task difference in gait velocity and counting rate; and (3) vitamin D status and CMRS. Independent and dependent variables were also correlated with potential covariates, such as gender, age, and race/ethnicity to determine 
the presence of multicollinearity. If multicollinearity existed between any independent variable and one of the dependent variables of interest, then multiple linear or logistic regressions were performed. Independent t-tests and chi-squares were used to compare potential covariates between vitamin D insufficient and sufficient groups. Independent sample t-tests were performed to determine differences between vitamin D sufficient and insufficient groups in CMRS, single task and dual task gait velocity and counting rates. Paired t-tests were used to compare single to dual task gait velocity, and counting rates in the whole population and within each vitamin D status group. One-way repeated measures ANOVA was used to determine the dual to single task difference between vitamin D status categories. Multiple linear and logistic regressions were used to examine the relationship between vitamin D status and possible correlates. Multiple logistic regressions were used to examine the group effect (based on dual to single task difference in gait speed and counting rate) on vitamin D status. Multiple linear regressions were also used to examine the effect size and the change in CMRS for one unit change in vitamin D levels when controlling for covariates. The significance level was set at $\alpha=0.05$, and statistical analyzes were performed using SPSS 21 . The following table summarizes the hypotheses, and the statistical analysis used for hypothesis testing. 


\begin{tabular}{|c|c|}
\hline Hypothesis & Statistical Analyses \\
\hline $\begin{array}{l}\text { Hypothesis } \\
\text { 1a } \\
\text { Analyses }\end{array}$ & $\begin{array}{l}\text { Vitamin D status was described using frequencies, percentages, ranges, } \\
\text { means and standard deviations. Spearman’s correlations were used to } \\
\text { estimate, associations between vitamin D status and correlates. } \\
\text { Independent t-tests and chi-squares were used to compare potential } \\
\text { correlates of vitamin D status between vitamin D insufficient (25(OH)D } \\
<30 \mathrm{ng} / \mathrm{ml}) \text { and sufficient (25(OH)D } \geq 30 \mathrm{ng} / \mathrm{ml}) \text { participants. Multiple } \\
\text { linear and logistic regressions were used to examine the relationship } \\
\text { between vitamin D status and explanatory variables. }\end{array}$ \\
\hline $\begin{array}{l}\text { Hypothesis } \\
\text { 1b } \\
\text { Analyses }\end{array}$ & $\begin{array}{l}\text { Vitamin D intake was described using frequencies, percentages, ranges, } \\
\text { means, and standard deviations. Spearman correlations were performed } \\
\text { to evaluate the relationship between vitamin D status and vitamin D } \\
\text { intake. Independent t-tests were used to compare vitamin D insufficient } \\
(25(\mathrm{OH}) \mathrm{D}<30 \mathrm{ng} / \mathrm{ml}) \text { and sufficient }(25(\mathrm{OH}) \mathrm{D} \geq 30 \mathrm{ng} / \mathrm{ml}) \text { participants } \\
\text { in vitamin D dietary intake. Multiple linear and logistic regressions were } \\
\text { used to examine the relationship between vitamin D status and vitamin D } \\
\text { intake. }\end{array}$ \\
\hline $\begin{array}{l}\text { Hypothesis } \\
\text { 1c } \\
\text { Analyses }\end{array}$ & $\begin{array}{l}\text { Sun exposure was described using frequencies, percentages, ranges, } \\
\text { means, and standard deviations. Spearman correlations were performed } \\
\text { to evaluate the relationship between vitamin D status and sun exposure. } \\
\text { Independent t-tests and chi-squares were used to compare vitamin D } \\
\text { insufficient }(25(\mathrm{OH}) \mathrm{D}<30 \mathrm{ng} / \mathrm{ml}) \text { and sufficient }(25(\mathrm{OH}) \mathrm{D} \geq 30 \mathrm{ng} / \mathrm{ml}) \\
\text { participants in sun exposure. Multiple linear and logistic regressions were } \\
\text { used to examine the relationship between vitamin D status and sun } \\
\text { exposure. }\end{array}$ \\
\hline $\begin{array}{l}\text { Hypothesis } \\
\text { 2a } \\
\text { Analyses }\end{array}$ & $\begin{array}{l}\text { Gait speed variables were described using frequencies, percentages, } \\
\text { ranges, means, and standard deviations. Spearman correlations were } \\
\text { performed to evaluate the relationship between vitamin D status and } \\
\text { single task, dual task, and the dual to single task difference in gait speed. } \\
\text { Independent t-tests were performed to determine the difference in mean } \\
\text { single and dual task gait velocities between vitamin D insufficient } \\
(25(\mathrm{OH}) \mathrm{D}<30 \mathrm{ng} / \mathrm{ml}) \text { and sufficient }(25(\mathrm{OH}) \mathrm{D} \geq 30 \mathrm{ng} / \mathrm{ml}) \text { participants. } \\
\text { Paired t-tests were performed to compare dual and single task gait } \\
\text { velocities. One-way repeated measures ANOVAs were used to compare } \\
\text { the dual to single task difference in gait velocity between vitamin D } \\
\text { status categories. Multiple logistic regressions were used to examine the } \\
\text { relationship between vitamin D insufficiency and the dual to single task } \\
\text { difference in gait speed. }\end{array}$ \\
\hline
\end{tabular}




\begin{tabular}{|l|l|}
\hline Table 2 continued. \\
\hline Hypothesis & Statistical Analyses \\
\hline $\begin{array}{l}\text { Hypothesis } \\
\text { Analyses }\end{array}$ & $\begin{array}{l}\text { Counting rate variables were described using frequencies, percentages, } \\
\text { ranges, means, and standard deviations. Spearman correlations were } \\
\text { performed to evaluate the relationship between vitamin D status and } \\
\text { single task, dual task, and the dual to single task difference in counting } \\
\text { rate. Independent t-tests were performed to determine the difference in } \\
\text { mean single and dual task counting rates between vitamin D insufficient } \\
\text { (25(OH)D <30 ng/ml) and sufficient (25(OH)D } \geq 30 \text { ng/ml) participants. } \\
\text { Paired t-tests were performed to compare dual and single task counting } \\
\text { rates. One-way repeated measures ANOVAs were used to compare the } \\
\text { dual to single task difference in counting rates between vitamin D status } \\
\text { categories. Multiple logistic regressions were used to examine the } \\
\text { relationship between vitamin D insufficiency and the dual to single task } \\
\text { difference in counting rate. }\end{array}$ \\
\hline $\begin{array}{l}\text { Hypothesis } \\
\text { 3a }\end{array}$ & $\begin{array}{l}\text { CMRS was analyzed using frequencies, percentages, ranges, means, and } \\
\text { standard deviations. Spearman correlations were performed to evaluate } \\
\text { the relationship between vitamin status and CMRS. Independent t-tests or } \\
\text { chi-squares were used to compare CMRS and covariates between vitamin } \\
\text { D insufficient (25(OH)D }<30 \text { ng/ml) and sufficient (25(OH)D } \geq 30 \\
\text { ng/ml) participants. Multiple linear regressions were used to examine the } \\
\text { effect size and the change in CMRS expected from a one-unit change in } \\
\text { vitamin D levels after adjusting for potential confounders. }\end{array}$ \\
\hline
\end{tabular}




\section{References}

1. Wagner D, Hanwell HE, Vieth R. An evaluation of automated methods for measurement of serum 25-hydroxyvitamin D. Clin Biochem. 2009;42(15):1549-1556.

2. Blalock SJ, Norton LL, Patel RA, Cabral K, Thomas CL. Development and assessment of a short instrument for assessing dietary intakes of calcium and vitamin D. J Am Pharm Assoc. 2003;43(6):685-693.

3. Block G, Hartman AM, Naughton D. A reduced dietary questionnaire: Development and validation. Epidemiology. 1990;1(1):58-64.

4. Block G, Wakimoto P, Block T. A revision of the block dietary questionnaire and database, based on NHANES III

data. http://www.nutritionquest.com/products/B98_DEV.pdf. Updated 1998. Accessed April 22, 2013.

5. Block G, Thompson FE, Hartman AM, Larkin FA, Guire KE. Comparison of two dietary questionnaires validated against multiple dietary records collected during a 1-year period. J Am Diet Assoc. 1992;92(6):686-693.

6. Hacker-Thompson A, Schloetter M, Sellmeyer DE. Validation of a dietary vitamin D questionnaire using multiple diet records and the block 98 health habits and history questionnaire in healthy postmenopausal women in northern california. J Am Diet Assoc. 2011;112(3):419-423.

7. Thompson FE, Subar AF. Dietary assessment methodology. In: Coulston A, Rock C, Monsen E, eds. Nutrition in the prevention and treatment of disease. 2nd ed. San Diego: Academic Press; 2001:3-39.

8. Hanwell HE, Vieth R, Cole DE, et al. Sun exposure questionnaire predicts circulating 25-hydroxyvitamin D concentrations in caucasian hospital workers in southern italy. $J$ Steroid Biochem Mol Biol. 2010;121(1-2):334-337.

9. Lundin-Olsson L, Nyberg L, Gustafson Y. "Stops walking when talking" as a predictor of falls in elderly people. Lancet. 1997;349(9052):617-618.

10. Eastlack ME, Arvidson J, Snyder-Mackler L, Danoff JV, McGarvey CL. Interrater reliability of videotaped observational gait-analysis assessments. Phys Ther. 1991;71(6):465-472.

11. Hartmann A, Murer K, de Bie RA, de Bruin ED. Reproducibility of spatio-temporal gait parameters under different conditions in older adults using a trunk tri-axial accelerometer system. Gait Posture. 2009;30(3):351-355. 
12. Bloem BR, Steijns JA, Smits-Engelsman BC. An update on falls. Curr Opin Neurol. 2003;16(1):15-26.

13. Woollacott M, Shumway-Cook A. Attention and the control of posture and gait: A review of an emerging area of research. Gait Posture. 2002;16(1):1-14.

14. Beauchet O, Annweiler C, Allali G, Berrut G, Dubost V. Dual task-related changes in gait performance in older adults: A new way of predicting recurrent falls? J Am Geriatr Soc. 2008;56(1):181-182.

15. Beauchet O, Dubost V, Allali G, Gonthier R, Hermann FR, Kressig RW. 'Faster counting while walking' as a predictor of falls in older adults. Age Ageing. 2007;36(4):418-423.

16. Lewis JE, Tannenbaum SL, Gao J, et al. Comparing the accuracy of ES-BC, EIS-GS, and ES oxi on body composition, autonomic nervous system activity, and cardiac output to standardized assessments. Med Devices (Auckl). 2011;4:169-177.

17. Lewis JE, Lantigua L, Atlas SE, et al. A cross-sectional assessment to detect type 2 diabetes with endothelial and autonomic nervous system markers using a novel system. $J$ Diabetes Metab Disord. 2014;13(1):118-125.

18. Brodie D, Moscrip V, Hutcheon R. Body composition measurement: A review of hydrodensitometry, anthropometry, and impedance methods. Nutrition. 1998;14(3):296310 .

19. Chumlea WC, Guo SS, Kuczmarski RJ, et al. Body composition estimates from NHANES III bioelectrical impedance data. Int J Obes Relat Metab Disord. 2002;26(12):1596-1609.

20. Rigaud B, Morucci JP, Chauveau N. Bioelectrical impedance techniques in medicine. part I: Bioimpedance measurement. second section: Impedance spectrometry. Crit Rev Biomed Eng. 1996;24(4-6):257-351.

21. Schoeller DA. Bioelectrical impedance analysis. what does it measure? Ann N Y Acad Sci. 2000;904:159-162.

22. Spallone V, Ziegler D, Freeman R, et al. Cardiovascular autonomic neuropathy in diabetes: Clinical impact, assessment, diagnosis, and management. Diabetes Metab Res Rev. 2011;27(7):639-653.

23. Task Force of the European Society of Cardiology and the North American Society of Pacing and Electrophysiology. Heart rate variability: Standards of measurement, physiological interpretation and clinical use. Circulation. 1996;93(5):1043-1065. 
24. Rolim LC, de Souza JS, Dib SA. Tests for early diagnosis of cardiovascular autonomic neuropathy: Critical analysis and relevance. Front Endocrinol (Lausanne). 2013;4(173):1-4.

25. Tak YJ, Lee JG, Kim YJ, Lee SY, Cho BM. 25-hydroxyvitamin D and its relationship with autonomic dysfunction using time- and frequency-domain parameters of heart rate variability in korean populations: A cross-sectional study. Nutrients. 2014;6(10):43734388.

26. Alty SR, Angarita-Jaimes N, Millasseau SC, Chowienczyk PJ. Predicting arterial stiffness from the digital volume pulse waveform. IEEE Trans Biomed Eng. 2007;54(12):2268-2275.

27. Anderson TJ. Arterial stiffness or endothelial dysfunction as a surrogate marker of vascular risk. Can J Cardiol. 2006;22(Suppl B):72-80.

28. Stoner L, Young JM, Fryer S. Assessments of arterial stiffness and endothelial function using pulse wave analysis. Int J Vasc Med. 2012;2012(903107):1-9.

29. Wilke K, Martin A, Terstegen L, Biel SS. A short history of sweat gland biology. Int J Cosmet Sci. 2007;29(3):169-179.

30. Brock K, Huang WY, Fraser DR, et al. Low vitamin D status is associated with physical inactivity, obesity and low vitamin D intake in a large U.S. sample of healthy middle-aged men and women. J Steroid Biochem Mol Biol. 2010;121(1-2):462-466.

31. Tran B, Armstrong BK, McGeechan K, et al. Predicting vitamin D deficiency in older australian adults. Clin Endocrinol (Oxf). 2013;79(5):631-640.

32. The IPAQ Group. Guidelines for data processing and analysis of the International Physical Activity Questionnaire (IPAQ) - short and long forms. IPAQ Web site. http://www.ipaq.ki.se/scoring.pdf. Accessed April 24, 2013.

33. Rutten A, Ziemainz H, Schena F, et al. Using different physical activity measurements in eight European countries. results of the European physical activity surveillance system (EUPASS) time series survey. Public Health Nutr. 2003;6(4):371376.

34. Bassett DR,Jr. International physical activity questionnaire: 12-country reliability and validity. Med Sci Sports Exerc. 2003;35(8):1381-1395.

35. The IPAQ Group. The International Physical Activity Questionnaire. IPAQ Web site. https://sites.google.com/site/theipaq/. Accessed April 24, 2013. 
36. Hagstromer M, Oja P, Sjostrom M. The International Physical Activity Questionnaire (IPAQ): A study of concurrent and construct validity. Public Health Nutr. 2006;9(6):755762.

37. Benedetti TRB, de Cesaro Antunes P, Rodriguez-Anez CR, Mazo GZ, Petrozki EL. Reproducibility and reliability of the International Physical Activity Questionnaire in ederly men. Rev Bras Med Esporte. 2007;13 (1):9-13.

38. Benedetti TRB, Mazo GZ, Barros MV. Application of the International Physical Activity Questionnaire (IPAQ) for evaluation of elderly women: Concurrent validity and test-retest reproducibility. Rev Bras Ciên e Mov. 2004;12(1):25-34.

39. Mader U, Martin BW, Schutz Y, Marti B. Validity of four short physical activity questionnaires in middle-aged persons. Med Sci Sports Exerc. 2006;38(7):1255-1266.

40. Kolbe-Alexander TL, Lambert EV, Harkins JB, Ekelund U. Comparison of two methods of measuring physical activity in south african older adults. J Aging Phys Act. 2006;14(1):98-114.

41. Silva RB, Costa-Paiva L, Pinto Neto AM, Braga Ade A, Morais SS. Habitual physical activity and cardiovascular risk in post menopause. Rev Assoc Med Bras. 2006;52(4):242-246.

42. da Silva RB, Costa-Paiva L, Pinto-Neto AM, Braga Ade A, Morais SS. Association between habitual physical activity and parameters of physical fitness in postmenopausal women. Climacteric. 2005;8(4):360-370.

43. Ainsworth BE, Macera CA, Jones DA, et al. Comparison of the 2001 BRFSS and the IPAQ physical activity questionnaires. Med Sci Sports Exerc. 2006;38(9):1584-1592.

44. Ekelund U, Sepp H, Brage S, et al. Criterion-related validity of the last 7-day, short form of the International Physical Activity Questionnaire in swedish adults. Public Health Nutr. 2006;9(2):258-265.

45. Kwak L, Hagstromer M, Sjostrom M. Can the IPAQ-long be used to assess occupational physical activity? J Phys Act Health. 2012;9(8):1130-1137.

46. Arvidsson D, Slinde F, Hulthen L. Physical activity questionnaire for adolescents validated against doubly labelled water. Eur J Clin Nutr. 2005;59(3):376-383.

47. Beck AT, Steer RA, Brown GK. RCMAR measurement tools: Beck depression inventory-2nd edition (BDI-II). Medical University of South Carolina Web site. http://www.musc.edu/dfm/RCMAR/Beck.html. Accessed April 21, 2013. 
48. Howland RH. Vitamin D and depression. J Psychosoc Nurs Ment Health Serv. 2011;49(2):15-18.

49. Hausdorff JM, Schweiger A, Herman T, Yogev-Seligmann G, Giladi N. Dual-task decrements in gait: Contributing factors among healthy older adults. J Gerontol A Biol Sci Med Sci. 2008;63(12):1335-1343.

50. Beck AT, Steer RA. Internal consistencies of the original and revised Beck Depression Inventory. J Clin Psychol. 1984;40(6):1365-1367.

51. Beck AT, Ward CH, Mendelson M, Mock J, Erbaugh J. An inventory for measuring depression. Arch Gen Psychiatry. 1961;4:561-571.

52. Richter P, Werner J, Heerlein A, Kraus A, Sauer H. On the validity of the Beck Depression Inventory. A review. Psychopathology. 1998;31(3):160-168.

53. Segal DL, Coolidge FL, Cahill BS, O'Riley AA. Psychometric properties of the Beck Depression Inventory II (BDI-II) among community-dwelling older adults. Behav Modif. 2008;32(1):3-20.

54. Greenberg SA. Assessment of fear of falling in older adults: The Falls Efficacy ScaleInternational (FES-I). The Hartford Institute for Geriatric Nursing, New York University Web site. http://consultgerirn.org/uploads/File/trythis/try_this_29.pdf. Updated 2011. Accessed August 31, 2015.

55. Yardley L, Beyer N, Hauer K, Kempen G, Piot-Ziegler C, Todd C. Development and initial validation of the Falls Efficacy Scale-International (FES-I). Age Ageing. 2005;34(6):614-619.

56. Tinetti ME, Richman D, Powell L. Falls efficacy as a measure of fear of falling. $J$ Gerontol. 1990;45(6):239-243.

57. Tinetti ME, Mendes de Leon CF, Doucette JT, Baker DI. Fear of falling and fallrelated efficacy in relationship to functioning among community-living elders. $J$ Gerontol. 1994;49(3):140-147.

58. Yardley L, Smith H. A prospective study of the relationship between feared consequences of falling and avoidance of activity in community-living older people. Gerontologist. 2002;42(1):17-23.

59. Cumming RG, Salkeld G, Thomas M, Szonyi G. Prospective study of the impact of fear of falling on activities of daily living, SF-36 scores, and nursing home admission. $J$ Gerontol A Biol Sci Med Sci. 2000;55(5):299-305. 
60. Mendes de Leon CF, Seeman TE, Baker DI, Richardson ED, Tinetti ME. Selfefficacy, physical decline, and change in functioning in community-living elders: A prospective study. J Gerontol B Psychol Sci Soc Sci. 1996;51(4):183-190.

61. Hill KD, Schwarz JA, Kalogeropoulos AJ, Gibson SJ. Fear of falling revisited. Arch Phys Med Rehabil. 1996;77(10):1025-1029.

62. Petrella RJ, Payne M, Myers A, Overend T, Chesworth B. Physical function and fear of falling after hip fracture rehabilitation in the elderly. Am J Phys Med Rehabil. 2000;79(2):154-160.

63. Wolf SL, Barnhart HX, Kutner NG, McNeely E, Coogler C, Xu T. Reducing frailty and falls in older persons: An investigation of tai chi and computerized balance training. J Am Geriatr Soc. 1996;44(5):489-497.

64. Cameron ID, Stafford B, Cumming RG, et al. Hip protectors improve falls selfefficacy. Age Ageing. 2000;29(1):57-62.

65. Tennstedt S, Howland J, Lachman M, Peterson E, Kasten L, Jette A. A randomized, controlled trial of a group intervention to reduce fear of falling and associated activity restriction in older adults. J Gerontol B Psychol Sci Soc Sci. 1998;53(6):384-392.

66. Friedman SM, Munoz B, West SK, Rubin GS, Fried LP. Falls and fear of falling: Which comes first? A longitudinal prediction model suggests strategies for primary and secondary prevention. J Am Geriatr Soc. 2002;50(8):1329-1335.

67. Arfken CL, Lach HW, Birge SJ, Miller JP. The prevalence and correlates of fear of falling in elderly persons living in the community. Am J Public Health. 1994;84(4):565570 .

68. Howland J, Lachman ME, Peterson EW, Cote J, Kasten L, Jette A. Covariates of fear of falling and associated activity curtailment. Gerontologist. 1998;38(5):549-555.

69. Lachman ME, Howland J, Tennstedt S, Jette A, Assmann S, Peterson EW. Fear of falling and activity restriction: The survey of activities and fear of falling in the elderly (SAFE). J Gerontol B Psychol Sci Soc Sci. 1998;53(1):43-50.

70. Brouwer B, Musselman K, Culham E. Physical function and health status among seniors with and without a fear of falling. Gerontology. 2004;50(3):135-141.

71. Delbaere K, Close JC, Mikolaizak AS, Sachdev PS, Brodaty H, Lord SR. The Falls Efficacy Scale International (FES-I). A comprehensive longitudinal validation study. Age Ageing. 2010;39(2):210-216. 
72. Delbaere K, Crombez G, Vanderstraeten G, Willems T, Cambier D. Fear-related avoidance of activities, falls and physical frailty. A prospective community-based cohort study. Age Ageing. 2004;33(4):368-373.

73. Wortsman J, Matsuoka LY, Chen TC, Lu Z, Holick MF. Decreased bioavailability of vitamin D in obesity. Am J Clin Nutr. 2000;72(3):690-693.

74. Mai XM, Chen Y, Camargo CA,Jr, Langhammer A. Cross-sectional and prospective cohort study of serum 25-hydroxyvitamin D level and obesity in adults: The HUNT study. Am J Epidemiol. 2012;175(10):1029-1036.

75. McGill AT, Stewart JM, Lithander FE, Strik CM, Poppitt SD. Relationships of low serum vitamin D3 with anthropometry and markers of the metabolic syndrome and diabetes in overweight and obesity. Nutr J. 2008;7(4):2891-2897.

76. Lang IA, Llewellyn DJ, Alexander K, Melzer D. Obesity, physical function, and mortality in older adults. J Am Geriatr Soc. 2008;56(8):1474-1478.

77. Pludowski P, Holick MF, Pilz S, et al. Vitamin D effects on musculoskeletal health, immunity, autoimmunity, cardiovascular disease, cancer, fertility, pregnancy, dementia and mortality- a review of recent evidence. Autoimmun Rev. 2013;12(10):976-989.

78. Wang L, Song Y, Manson JE, et al. Circulating 25-hydroxy-vitamin D and risk of cardiovascular disease: A meta-analysis of prospective studies. Circ Cardiovasc Qual Outcomes. 2012;5(6):819-829.

79. de Koning L, Merchant AT, Pogue J, Anand SS. Waist circumference and waist-tohip ratio as predictors of cardiovascular events: Meta-regression analysis of prospective studies. Eur Heart J. 2007;28(7):850-856. 


\title{
CHAPTER IV: CORRELATES OF VITAMIN D DEFICIENCY IN SOUTH FLORIDA OLDER ADULTS
}

\begin{abstract}
Objective: The purpose of this cross-sectional analysis is to determine the proportion of vitamin D insufficient individuals and correlates of vitamin D status in an older adult population (>55 years of age) living in Miami-Dade, Florida.

Methods: Participants ( $\mathrm{n}=97)$ completed assessments that included vitamin $\mathrm{D}$ serum levels, surveys to evaluate vitamin D intake, sun exposure, and other variables.

Spearman's correlations, independent t-tests, chi-squares, and multiple linear and logistic regression were used to examine the relationship between vitamin $\mathrm{D}$ status and explanatory variables.
\end{abstract}

Results: The proportion of individuals with vitamin D deficiency (25(OH)D <20 ng/ml), insufficiency (20-30 ng/ml) and sufficiency ( $\geq 30 \mathrm{ng} / \mathrm{ml})$ were $10.3 \%, 36.1 \%$ and $53.6 \%$, respectively. Vitamin D status correlated significantly with higher vitamin/mineral supplement use $(P=0.014)$, and lower \% fat mass $(P=0.008)$ in linear regression models, and increased sun exposure $(P=0.016)$ in logistic regression models. However, ethnicity was consistently an independent predictor of vitamin D levels in both analyses $(P=0.023$ and $P=0.010$, respectively), with Hispanics being at higher risk of insufficiency.

Conclusions: Since vitamin D deficiency is linked to health risk factors, it is important that health professionals become aware of the connections of vitamin D status with intake, bioavailability, and skin synthesis, to identify those at risk and develop and plan pertinent interventions to prevent and correct deficiency.

Keywords: vitamin D insufficiency, vitamin D intake, sun exposure, elderly 


\section{Introduction}

Vitamin D deficiency in the elderly has been linked to factors associated with disability, including cognitive impairment, poor physical performance, and increased risk of falls and fractures. ${ }^{1-7}$ The elderly is at higher risk of vitamin D deficiency as shown by National Health and Nutrition Examination Survey (NHANES) 1988-1994 data that indicated serum vitamin D levels were lower among adults 65 years and older, compared to middle aged (40-59 years of age) and younger adults (18-29 years of age). ${ }^{8,9}$ Vitamin D is considered a steroid hormone obtained naturally from dietary sources and skin synthesis and stored in muscle and fat tissue. The body can use muscle and fat reserves independent of sun exposure and dietary intake, only when vitamin D concentrations are lower than $20 \mathrm{ng} / \mathrm{ml} .{ }^{10-12}$ For older adults, reaching this vitamin D threshold is difficult; they become more dependent on their vitamin D reserve, as they encounter more barriers for adequate dietary and skin sources, which place them at higher risk of deficiency and insufficiency. This may be a consequence of a complex interplay between age-related factors that affect dietary intake, bioavailability, and skin biosynthesis. ${ }^{10-12}$

In the United States, very few foods contain significant amounts of vitamin D. For those who are not taking adequate amounts of vitamin D through diet or supplement use, sunlight would often be their main source of vitamin D. ${ }^{13,14}$ Vitamin D is mostly synthesized in the skin when ultraviolet B (UVB, 290-315 nm) light from the sun causes a photochemical rearrangement of 7-dehydrocholesterol to pre-vitamin D3, which then undergoes thermal isomerization into vitamin D3. ${ }^{13,15,16}$ The skin’s ability to synthesize vitamin D depends on the amount of solar radiation reaching the biosphere that depends on latitude, season, and time of day. ${ }^{15,16}$ Since $90-95 \%$ of vitamin D comes from skin 
synthesis, it would be expected that the prevalence of vitamin D deficiency and insufficiency to be lower in a populations where sunlight for synthesis is available year round. ${ }^{17,18}$ Thus, it has been assumed that vitamin D deficiency and insufficiency is less prevalent in populations living at lower latitudes and/or where seasonal variations are not as pronounced like in South Florida, one of the southernmost regions of the United States (latitude 25.46N) where the weather is sunny and warm all year. ${ }^{19}$ However, research has shown a considerable amount of vitamin D deficient and insufficient individuals. A previous study reported a prevalence of $38-40 \%$ of hypovitaminosis $\mathrm{D}(25(\mathrm{OH}) \mathrm{D}<20$ $\mathrm{ng} / \mathrm{ml}$ ) in adults ( $\geq 18$ years old) living in South Florida. ${ }^{19}$ Lagari et al. ${ }^{20}$ found that $35 \%$ of participants in a study conducted in Miami-Dade were vitamin D insufficient (25(OH)D $<30 \mathrm{ng} / \mathrm{ml})$. Another study conducted in Boca Raton, Florida, evaluated vitamin $\mathrm{D}$ status in a community dwelling elderly population ( $\geq 60$ years old) and found an occurrence of vitamin D insufficiency (25(OH)D $<25 \mathrm{ng} / \mathrm{ml}$ ) of $15.6 \% .^{21}$

The determinants of vitamin D status in the elderly population in Miami-Dade have not been well studied. This is important because Miami occupies the fourth place among cities that are graying the fastest, and it is the top county for elders, with $14.9 \%$ of the Miami-Dade population being over the age of $65 .{ }^{22}$ Understanding the factors that affect vitamin D status in this growing population of older adults, who have an increased opportunity for skin biosynthesis via sun exposure, is critical to promote public health initiatives aimed to correct and prevent nutritional deficiencies. Therefore, the purpose of this cross-sectional analysis was to evaluate correlates of vitamin D insufficiency in older adults living in Miami-Dade. 


\section{Methods}

\section{$\underline{\text { Study Design and Setting }}$}

This study was approved by the IRBs of Florida International University (130390) and the University of Miami (20120195).

\section{Participants}

The study enrolled 101 participants, and four were excluded due to missing data ( $n=97)$. Participants for this study were recruited from the parent study, a double-blinded randomized placebo-controlled clinical trial that examined the effects of vitamin D supplementation on vitamin D level, bone formation, resorption, and mineral density, flexibility, and balance in the elderly, which was conducted at the University of Miami. Briefly, each potential participant was screened over the phone by administering the Short Portable Mental Status Questionnaire (SPMSQ) ${ }^{23}$ to evaluate mental functioning (allowed up to 2 errors) and questions regarding general inclusion criteria such as age, and medical, pharmacological and general exclusions. Inclusion criteria for this study included: (1) Men and women age 55 or older; (2) English and Spanish speakers; (3) Community-dwelling; (4) Ability to give informed consent; (5) Ability to perform motor tasks without aid; and (6) Participating in the parent study. All participants in this study were required to sign IRB approved informed consents for both the University of Miami and Florida International University. 


\section{$\underline{\text { Biomarkers }}$}

\section{Vitamin D Status}

Vitamin D status was measured by serum 25-hydroxyvitamin D (25(OH)D). Fasting venous blood (15 ml) was collected from every participant by a certified phlebotomist in the morning after fasting. The samples were sent the same day for analysis to LabCorp (2700 N. 29 ${ }^{\text {th }}$ Ave, Suite 203A, Hollywood, Fl 33020) that used immunochemiluminometric assays (ICMA) on the DiaSorin Liaison instrument to assess $25(\mathrm{OH}) \mathrm{D}$. This is a highly automated test that measures total $25(\mathrm{OH}) \mathrm{D}$, and it has been widely used by others. ${ }^{24}$

\section{Surveys}

Sociodemographics, Health History, Health Risk Behaviors and Medications

Sociodemographic and health-related data were collected using questionnaires developed by staff of the parent study that asked about gender, marital status, race/ethnicity, socioeconomic status, education, income, current medical diagnoses, medication/ supplement use and health risk behaviors such as coffee, alcohol, and tobacco use.

\section{Vitamin D Intake}

Vitamin D intake was assessed using a vitamin D and calcium specific short food frequency questionnaire (FFQ) developed by Blalock et al. ${ }^{25}$, which is based on the Block-National Cancer Institute Health Habits and History Questionnaire (HHHQ). It includes only 23 foods and beverages that were identified in the HHHQ as rich in either 
vitamin D, calcium or both. The short FFQ is associated with a database; therefore, allowing the estimation of nutrient intakes for the reported portion size. The raw values were multiplied by the frequencies to calculate the amount of vitamin $\mathrm{D}$ and calcium per day using Microsoft Access. ${ }^{25}$ Blalock et al validated this tool and the vitamin D and calcium intakes estimated from this short FFQ were significantly correlated with estimates from the 7-day food diary ( $\mathrm{r}=0.72$ and 0.66 ; respectively) and the original HHHQ ( $r=0.65$ and 0.66 , respectively). ${ }^{25}$ Positive predictive values of $100 \%$ for vitamin D and $91.7 \%$ for calcium were reported for the short instrument in its ability to identify those with low intakes as based on the 7-day food record.

\section{Sun Exposure}

Sun exposure was assessed using a questionnaire developed by Hanwell et al. ${ }^{26}$ This tool measures the amount of time spent outdoors and the amount of skin exposed for every day of the week using a scoring system. The original questionnaire by Hanwell et al. was developed for hospital workers in Southern Italy and designed to report the sun exposure within the last week by recording time outdoors (<5 min; 5-30 min; >30 min) and amount of skin exposed (hands and face; hands, face and arms; hands, face and legs; bathing suit). The amount of time spent outdoors was multiplied by the amount of skin exposed for every day of the week. The sum of the seven days was used as the sun exposure scores. These researchers found that the sun exposure score was significantly correlated with serum vitamin D levels during the summer, which was mostly explained by the time in the sun than by the amount of skin exposed. Other researchers have validated this tool in other populations in South Florida. ${ }^{27,28}$ 


\section{Physical Activity Levels}

Physical activity level was measured using the International Physical Activity

Questionnaire (IPAQ) ${ }^{29}$ which provides individual domain-specific scores for walking, moderate-intensity and vigorous-intensity activity within the domains of work, transportation, domestic chores and gardening, and leisure-time. To measure the volume of activity, each type of activity was weighted by its energy requirement defined as the MET-min. METs are metabolic equivalents that are computed for each specific activity using defined formulas, and then multiplied by the minutes performed to derive METminute scores, which are equal to kilocalories for a $60 \mathrm{~kg}$ person. ${ }^{29}$

The IPAQ was developed to derive comparable measurements of physical activity in international settings; therefore, being suitable for use in different languages and cultural contexts like in an ethnically-diverse city as Miami. ${ }^{30,31}$ It has also been validated in different age groups against objective measures of physical activity, physical fitness, and health outcomes. ${ }^{32}$ For instance, it was validated in an adult population (mean \pm SD age: $40.7 \pm 10.3$ years) and found to have a strong positive relationship with an activity monitor and a physical activity $\log (\mathrm{rho}=0.55, P<0.001) .{ }^{33}$ It was also validated and used in a population of elderly men and found to be reliable (test-retest reliability of 0.95) and valid when compared against pedometer use and the physical activity log, and had similar results in cohorts of postmenopausal women. ${ }^{34,35}$ Other studies have validated the IPAQ and used it successfully in populations of middle-aged and older adults and adults with different diseases, such as schizophrenia and breast cancer. ${ }^{31,36-39}$ The IPAQ correlated with measurements to other physical activity assessment methods such as the 2001 
Behavioral Risk Factor Surveillance System (BRFSS) physical activity, accelerometers, and energy expenditure as measured by doubly-labeled water, among others. ${ }^{32,40-43}$

\section{Depressive Symptoms}

Depressive symptoms were assessed using the Beck Depression Inventory (BDIII), which is a widely validated and used tool that evaluates the existence and severity of depressive symptoms based on the DSM-IV. ${ }^{44}$ It is a self-report, 21-item instrument in which each item corresponds to a symptom of depression and has a four-point scale ranging from 0 to 3 , except for two items that have seven options to indicate decrease or increase in appetite and sleep. The score of all items are summed to give a single score. A total score of 0-13 is considered minimal, $14-19$ mild, 20-28 moderate, and 29-63 severe

depressive symptoms ${ }^{44}$ Construct validity has been assessed on its ability to differentiate non-depressed and depressed patients ( 0.92 for outpatients and 0.93 for college students). Test-retest reliability was found to be significant at 0.93 . This tool has been used in populations ages 13-80 years. ${ }^{44-47}$ In an elderly population, BDI-II has good internal consistency (0.86), and has been positively correlated with other measures of depression, measures of stress, anxiety, and negatively with well-being. Research with this instrument has shown no statistically significant effects for ethnicity, gender, and age on BDI-II scores. ${ }^{48}$ In case a participant reported suicidal ideation, the investigators in this study contacted the study physician and/or University of Miami Mental Health Department, immediately. 


\section{Anthropometrics and Body Composition}

Weight was measured using an electronic balance. Participants were asked to remove shoes and heavy outer garments like coats and to stand in the center of the balance so that the weight was distributed evenly on both feet. Height was measured using a stadiometer with a movable headpiece. Participants were asked to stand with their back to the height rule with their feet together, while the back of the head, back, buttocks, calves, and heels touched the upright tape. The participant was asked to look straight ahead so that the ear canal was level with the cheek bone. The headpiece was lowered so that the hair was pressed flat. Weight and height were recorded to the nearest $0.1 \mathrm{~kg}$ and $0.1 \mathrm{~cm}$, respectively. Body mass index (BMI) was calculated using the formula: body weight (kg)/ height $\left(\mathrm{m}^{2}\right)$ and accordingly, participants were classified into categories based on the National Heart, Lung and Blood Institute recommendations: underweight (<18.5 kg/m²), normal weight (18.5-24.9 kg/m²); overweight (25-29.9 kg/m²), and obese $\left(>30 \mathrm{~kg} / \mathrm{m}^{2}\right)$.

Waist circumference (WC) was measured at the umbilicus and hip circumference (HC) was measured at the broadest circumference below the waist. Both of these measurements were done using a flexible but not stretchable measuring tape in three replicates to ensure reproducibility. The average of the three values was used to calculate waist-to-hip ratio (WHR) by dividing WC by HC. Body composition was measured using bioelectrical impedance (BIA), to determine \% lean (fat-free, \%FFM) and fat mass (\%FM). 


\section{Statistical Analysis}

Statistical analyzes were performed on 97 participants. Data were analyzed using frequencies, percentages, ranges, means, and standard deviations. Variables were checked for non-normality and if necessary, they were transformed to achieve a normal distribution. Spearman correlations between two or more categorical variables were performed to evaluate the relationship between vitamin status, vitamin D intake, sun exposure, sociodemographic characteristics, health-related variables, physical activity, depressive symptoms, and anthropometries. Independent t-tests or chi-squares were used to compare vitamin D insufficient and sufficient categories in vitamin D intake, sun exposure, sociodemographic characteristics, health-related variables, physical activity, depressive symptoms, and anthropometries. Multiple linear regressions were used to examine the effect size and the change in vitamin D levels expected from a one-unit change in a set of independent explanatory variables. Multiple logistic regression were used to examine the relationship between vitamin D insufficiency and a set of explanatory variables to identify independent correlates of vitamin D status and calculate adjusted odds ratio. Collinearity was assessed, and variables that inter-correlated with other independent variables were removed from the regressions. The significance level was set at $\alpha=0.05$, and statistical analyses were performed using SPSS 21 .

\section{Results}

A total of 97 participants aged 55 years or older were included in this analysis. The mean \pm SD of $25(\mathrm{OH}) \mathrm{D}$ concentration was $30.73 \pm 8.73 \mathrm{ng} / \mathrm{ml}$ and ranged from 10.00 to $59.80 \mathrm{ng} / \mathrm{ml}$. Ten percent, $36 \%$, and $54 \%$ of the participants were vitamin D 
deficient (25(OH)D $<20 \mathrm{ng} / \mathrm{ml}$ ), insufficient (20-30 ng/ml) and sufficient ( $\geq 30 \mathrm{ng} / \mathrm{ml})$, respectively. Since the number of vitamin D deficient individuals was low, vitamin D deficient and insufficient individuals were grouped into vitamin D insufficient $(<30$ $\mathrm{ng} / \mathrm{ml}$ ) for data analysis. The mean $\pm \mathrm{SD}$ age was $63.06 \pm 6.48$ and ranged from 55-87 years (Table 1). Participants were $63.9 \%$ and $36.10 \%$ over the age of 60 and 65 respectively, $45 \%$ were males, and $44 \%$ were Hispanics, $35 \%$ white Caucasians, and 15.5\% African-Americans. Comparison of vitamin D status groups revealed no significant difference in age, gender, and the proportion of participants who were married, unemployed and with less than college education and income of $<\$ 30,000$ per year (data not shown).

A significant difference in sun exposure (mean difference: -6.27, $P=0.01$ ) was observed between vitamin D categories, with those who were insufficient having lower sun exposure scores (Table 1). No significant difference was found in vitamin D intake between the categories ( $P=0.957)$. Furthermore, only $2.1 \%$ of the participants met the Dietary Reference Intake (DRI) of 600 IU/day (data not shown).

A comparison between vitamin D status groups revealed several significant differences in potential determinants of vitamin D levels. Those who were vitamin D insufficient lived in the United States significantly fewer years (mean difference:-10.37, $P=0.018$ ). Ethnicities were also significantly different between vitamin $\mathrm{D}$ groups. More Hispanics and less white Caucasians and African Americans were in the vitamin D insufficient group ( $P=0.004)$ (Table 1). A one-way ANOVA comparison between ethnic groups on vitamin D levels showed significant differences between ethnicities (F (d.f.): 6.27 (3), $P=0.001$ ). Hispanics had lower vitamin D levels (mean \pm SD: $27.61 \pm 7.75$ ) 
than White Caucasians (mean \pm SD: $33.37 \pm 7.73, P=0.015$ ) and African-Americans (mean \pm SD: $35.77 \pm 9.60, P=0.007$ ) (Table 2).

Sixty-four percent of participants who were vitamin D insufficient used prescription medications compared to $85 \%$ of those who were sufficient $(P=0.033)$ (Table 3). Also, those in the vitamin D insufficient group were taking significantly fewer prescription medications than those in the vitamin D sufficient group (mean difference: $-0.94, P=0.033)$. Thirty-eight percent of those who were vitamin $\mathrm{D}$ insufficient reported taking vitamin/mineral supplements compared to $54 \%$ of the sufficient group, but this difference was not significant $(P=0.153)$.

Physical activity was significantly different between groups with those who were vitamin D insufficient having significantly less moderate physical activity (mean difference: -928.61, $P=0.043$ ) (Table 3). Height was the only anthropometric variable that was significantly different between groups, with those who were vitamin D insufficient being shorter (mean difference: -6.06, $P=0.004$ ). BMI and \%FM were higher in the vitamin D insufficient group, but the difference was not significant (mean difference: $0.63, P=0.559$, and mean difference: $1.29, P=0.251$, respectively). Spearman correlations showed a significant association between vitamin D categories and potential correlates of vitamin D status (Table 4). Significantly different variables between groups were also significantly correlated with vitamin D status. Sun exposure ( $\mathrm{r}=0.274, P=0.007)$, years lived in the Unites States ( $\mathrm{r}=0.272, P=0.007)$, number of participants taking prescription medications $(\mathrm{r}=0.233, P=0.022)$, and number of prescription medications ( $\mathrm{r}=0.234, P=0.021$ ) were positively correlated with vitamin D status, while ethnicity ( $\mathrm{r}=-0.365, P=0.000)$ and height $(\mathrm{r}=-0.298, P=0.003)$ were 
negatively correlated. Although vitamin D status did not significantly correlate with vitamin $\mathrm{D}$ intake ( $\mathrm{r}=0.05, P=0.728$ ), it was positively correlated with vitamin/mineral supplement use ( $\mathrm{r}=0.277, P=0.006)$. Lastly, vitamin $\mathrm{D}$ status ad a negative association with BMI ( $\mathrm{r}=-0.220, P=0.030)$, and \%FM ( $\mathrm{r}=-0.263, P=0.010)$.

To explain the effect of sun exposure and dietary intake on vitamin D levels, multiple linear regressions were used (Table 6). Vitamin D intake had no significant effect (B (SE): 0.00 (0.01), $P=0.648$ ), while sun exposure significantly predicted $4 \%$ of the variation in vitamin D levels (B (SE): 0.17 (0.07), $P=0.017$ ). In this model, vitamin D levels were expected to increase by $0.17 \mathrm{ng} / \mathrm{ml}$ for every unit increase in sun exposure. Adding ethnicity to the model showed that sun exposure was no longer a predictor of vitamin D levels ( $P=0.052)$. In this model, non-Hispanics compared to Hispanics would be expected to have $5.02 \mathrm{ng} / \mathrm{ml}$ higher vitamin D levels (B (SE): 5.02 (1.70), $P=0.004)$. Thus, sun exposure and ethnicity explained $12 \%$ of the variation in vitamin D levels.

Ethnicity remained a significant predictor of vitamin D levels after adding variables that (1) were significantly different between vitamin D status categories, (2) correlated significantly with vitamin D status; and/or (3) have been shown in previous research to be significantly correlated with vitamin D levels (B (SE): 3.92 (1.70), $P=0.023)$. In this fully adjusted model, ethnicity, \%FM (B (SE): -0.25 (0.09), $P=0.008$ ), and vitamin/mineral supplement use (B (SE): 4.24 (1.70), $P=0.014$ ) explained 18.4\% of the variation in vitamin D levels. For every unit increase in \%FM, vitamin D levels were expected to decrease by $0.25 \mathrm{ng} / \mathrm{ml}$. Furthermore, compared to those who did not use 
supplements, those who reported taking vitamin/mineral supplements were expected to have $4.24 \mathrm{ng} / \mathrm{ml}$ higher vitamin D levels.

Multiple logistic regressions showed that higher sun exposure scores predicted vitamin D levels with those with higher scores being 1.05 times significantly more likely to be vitamin D sufficient (OR: 1.05, 95\% CI: 1.01; 1.09, $P=0.013$ ) (Table 6). In the fully adjusted model, sun exposure relationship to vitamin D levels remained about the same (OR: 1.05, 95\% CI: 1.01; 1.10, $P=0.016)$. In addition, this model revealed that Hispanics were 0.30 times less likely to be vitamin D sufficient (OR: 0.30, 95\% CI: $0.12 ; 0.75, P=0.010)$.

\section{Discussion}

The proportion of vitamin D deficient $(25(\mathrm{OH}) \mathrm{D}<20 \mathrm{ng} / \mathrm{ml})$ and insufficient (25(OH)D $<30 \mathrm{ng} / \mathrm{ml}$ ) individuals in this group of healthy community-dwelling older adults (>55 years old) living in Miami-Dade was 10\% and 36\%, respectively. This was lower than that reported for the general United States adult and older adult population. ${ }^{11,49}$ NHANES $2005-2006$ revealed that $41.6 \%$ of United States adults (18 years or older) had deficient vitamin D levels, defined as $25(\mathrm{OH}) \mathrm{D}<20 \mathrm{ng} / \mathrm{ml} .{ }^{11,49} \mathrm{~A}$ previous study conducted in South Florida showed a prevalence of 38-40\% of hypovitaminosis $\mathrm{D}(25(\mathrm{OH}) \mathrm{D}<20 \mathrm{ng} / \mathrm{ml})$ in adults ( $\geq 18$ years old) ${ }^{19}$ In older adults, NHANES 1988-1994 data indicated that 23\% of adults 65 years and older were vitamin D deficient (25(OH)D $<20 \mathrm{ng} / \mathrm{ml})$, and $62.5 \%$ were vitamin $\mathrm{D}$ insufficient $(25(\mathrm{OH}) \mathrm{D}<30$ ng/ml). ${ }^{8,9}$ Several reports from The Health ABC cohort study described 65-68\% of adults over the age of 70 as vitamin $\mathrm{D}$ insufficient. ${ }^{50-52}$ 
Vitamin D deficiency and insufficiency in our study group was less than half of that previously reported for the general United States older adult population. However, our results are similar to that reported by Lagari et al. ${ }^{20}$ who observed vitamin D insufficiency in 35\% of the older adult population (>65 years of age) participating in a study in Miami-Dade. Furthermore, in older adults ( $\geq 60$ years of age) living in Boca Raton, Florida, Smolar et al. ${ }^{21}$ found a prevalence of $15.6 \%$ vitamin D insufficiency, defined as $25(\mathrm{OH}) \mathrm{D}<25 \mathrm{ng} / \mathrm{ml}$. Using the same cut-off value, we found a higher occurrence with $27 \%$ of our study participants being vitamin D insufficient.

Despite the lower occurrence of vitamin D insufficiency in this study compared to other studies and the general United States older adult population, it is still a public health concern and identifying risk factors is critical to developing effective interventions. As expected, vitamin D intake was not significantly correlated with vitamin D status in our study, and our findings are supported by other studies that have previously shown that dietary intake has minimal contribution to vitamin D status. ${ }^{53,54}$ The Institute of Medicine (IOM) committee reported in 2010 that in order to maintain serum 25(OH)D above 20 $\mathrm{ng} / \mathrm{ml}$, which was deemed necessary to preserve bone health, the intake of vitamin D should be 600 International Units (IU) per day for adults below the age of 70 and $800 \mathrm{IU}$ per day for adults over the age of 70, with a tolerable upper limit of 4000 IU per day. ${ }^{55-58}$ Although these are the established Dietary Reference Intakes (DRIs) for vitamin D, the Endocrine Society recommends adults over the age of 18 should intake between 1,5002,000 IU per day, with an upper limit of 10,000 IU per day, to maintain 25(OH)D between $40-60 \mathrm{ng} / \mathrm{ml}$ to conserve physiological functions that go beyond bone health. ${ }^{59}$ However, in our study only 2\% of the participants met the DRI of 600 IU per day (not 
accounting from vitamin D from supplement use) and the mean \pm SD was $170.33 \pm$ 168.06, with a range of 4.7-1,412.3 IU per day. Inadequate dietary intake of vitamin D is likely due to the limited availability of vitamin D rich foods in the daily diet of the elderly. Good sources of vitamin D include fatty fish such as salmon, tuna, and sardines, fish oil, egg yolks, organ meats, mushrooms, and fortified foods like milk and dairy products, breakfast cereals, bread, margarine, spreads, and vegetable oils. ${ }^{16,60}$ This may be aggravated in the elderly by age-related decline in food intake that results from an interplay between physiological and psychological factors, such as changes in taste/smell, chewing/swallowing problems, polypharmacy, hormonal factors regulating satiety, comorbidities, and age-related lactose intolerance that limits the intake of fortified milk products. $^{49,61-66}$

Supplement use may compensate for the lack of vitamin D intake from foods. Use of vitamin D supplements has increased over time in adults, with $26 \%$ of adults reporting using vitamin D supplement in NHANES 1988-1994, 25\% in NHANES 1999-2002, and 37\% in NHANES 2003-2006. ${ }^{67}$ However, low vitamin D intakes from food and supplements have been reported in older adults and associated with low serum vitamin D. ${ }^{17,18,68}$ Although using vitamin $\mathrm{D}$ and calcium supplements 2 weeks before the study were exclusion criteria in our study, we found that $46 \%$ of participants who reported a history of vitamins/minerals use, 37.8\% were vitamin D insufficient and 53.8\% were sufficient, but this difference was not significant. However, we did find that using vitamin/mineral supplements was a significant and independent predictor of vitamin D levels in adjusted multiple linear regressions, with those using supplements having higher 25(OH)D. In addition, we found significantly more vitamin D sufficient participants who 
reported taking prescription medications and a higher number of prescription medications compared to the insufficient group, and these variables had a significant association with vitamin D status. This relationship could be due to physicians recommending more vitamin $\mathrm{D}$ supplements to their elderly patients because of the increased public health awareness of the consequences of vitamin D deficiency in older adults. It could also be possible that those who are taking prescriptions are more likely to have access to healthcare or be more health conscious. Nonetheless, unlike vitamin/mineral supplement use, receiving prescription medication and a higher number of prescription medications were not predictors of vitamin D levels in neither multiple linear nor logistic regressions.

Other risk factors for vitamin D insufficiency are those that affect bioavailability. The presence of other comorbidities and behavioral factors, like liver, kidney, and gastrointestinal diseases, and the use of certain medications, tobacco, and alcohol, may also affect vitamin D metabolism and bioavailability. ${ }^{66}$ However, our study excluded participants who had any diseases/conditions or were taking any medications that affected vitamin D metabolism and absorption and hence, its bioavailability. Thus, we could not assess their effect on vitamin D status in our sample. We found that the number of diseases and condition, health risk behaviors and history of diseases/conditions, which have been significantly associated with vitamin D deficiency in previous studies, were not significantly different between, associated with, or predictive of vitamin $\mathrm{D}$ status. Obesity was the only condition that we were able to assess its effect on vitamin D status in our sample. ${ }^{49,66}$ In the older adult, a decline in metabolic rate and hormonal changes that occur during aging often result in weight gain, as seen in the growing prevalence of obesity among elderly in the United States. ${ }^{69,70}$ 
Obesity has been correlated with low vitamin D status in the elderly probably due to sequestration of vitamin D by increased body fat. ${ }^{18,49,66}$ In our sample, the mean \pm SD of BMI was $27.09 \pm 5.27$ with $62 \%$ of participants being overweight (BMI $\geq 25$ ). Even though vitamin D insufficient participants had higher BMIs, the number of participants who had a BMI $\geq 25 \mathrm{~kg} / \mathrm{m}^{2}$ was lower, and neither was significantly different compared with those who were vitamin D sufficient. However, BMI was significantly correlated with vitamin D levels, with those with lower vitamin D levels having higher BMI, but this association was no longer significant when adjusting for covariates in regression models. Abdominal fat accumulation, as measured by WC and WHR, were also not significantly correlated with vitamin D levels, nor different between vitamin D groups. However, the \%FM was higher in the vitamin D insufficient group, but this difference was not significant. Nevertheless, it had a significant negative correlation with vitamin D levels, with those with lower 25(OH)D having higher \%FM. Also, \%FM was found to predict vitamin D levels in linear regression models. Thus, body fat is a risk factor for vitamin D deficiency in this Miami-Dade older adult population probably by affecting bioavailability.

The other factor that may affect vitamin D status is skin biosynthesis. For those who are not taking adequate amounts of vitamin D through diet, sunlight would often be their main source of vitamin D. ${ }^{13,14}$ It is believed that sunlight exposure of arms and legs for 5-15 minutes at midday during the summer months could produce about 3,000 IU of vitamin D. ${ }^{12}$ However, the effectiveness of vitamin D synthesis in the skin is determined by skin thickness, 7-dehydrocholesterol content, skin pigmentation, amount of skin 
exposed, sunscreen use, length of sun exposure, and amount of solar radiation (which depends on the latitude, season, time of day, and time in the sun).

Decreased skin thickness and reduction of 7-dehydrocholesterol are two agerelated factors that place elderly at high risk for vitamin D deficiency. ${ }^{71}$ This is aggravated by decreased sun exposure, since most people avoid sunshine to stay cool, prevent skin aging, and reduce the risk of skin cancer by limiting the amount of time spent outdoors. Covering the skin with clothes and using sunscreen are common practices among the elderly, the latter interfering with UVB transmission to the skin. ${ }^{66}$ Thus, sufficient exposure to sunlight is unusual with modern lifestyles, since most people live and work indoors. ${ }^{66}$ A study in Europe showed that wearing short sleeves instead of long, and thus bearing arms as well as the face, is associated with better vitamin D status in older people living in sunnier climates. ${ }^{72}$ Furthermore, outdoor activity is associated with vitamin D status as shown by an analysis of NHANES 1988-1994 data that revealed that those who were 60 years or older and participated in daily outdoor activity had optimal vitamin D levels ( $\geq 30 \mathrm{ng} / \mathrm{ml}$ ) similar to young adults. ${ }^{73}$ In our study, sun exposure was measured by assessing the amount of skin exposed and time spent outdoors during sunny hours, and we found that sun exposure was significantly higher in participants who were vitamin D sufficient. Our data also showed a significant positive correlation between vitamin D status and sun exposure scores. In addition, we found that sun exposure had an effect on vitamin D levels, explaining only 4\% of vitamin D status variability, and this was no longer significant when adjusting for covariates. However, participants with higher sun exposure scores had higher odds of being vitamin D sufficient. 
Furthermore, physical activity, which is often used as a surrogate for outdoor activity, has been positively associated with serum vitamin D levels such that lower levels of serum vitamin D have been correlated with physical inactivity in middle-aged and older adults. ${ }^{18,74}$ We only found that moderate physical activity was significantly different between vitamin D categories, with those insufficient having less activity than those who were sufficient. However, none of the physical activity variables were significantly correlated with or predictive of vitamin D status. Thus in our cohort, unlike in previous studies, physical activity was not a risk factor for vitamin D status.

Besides age-related factors that affect the skin and the usual decreased sun exposure that accompanies modern life, skin complexion places elderly at an even higher risk of vitamin D deficiency. Darker pigmentation decreases the skin's capacity to use sunlight for making vitamin D because melanin competes for UVB radiation effectively. ${ }^{75}$ Ethnicity and race are often used as a proxy for skin pigmentation, and a substantial amount of evidence indicates a significant difference in vitamin D deficiency prevalence between different ethnic groups. ${ }^{75}$ For example, NHANES 2005-2006 revealed that the prevalence of vitamin D deficiency $(25(\mathrm{OH}) \mathrm{D}<20 \mathrm{ng} / \mathrm{ml})$ was higher in blacks (82.1\%), followed by Hispanics (69.2\%) and whites (30.9\%). ${ }^{49} \mathrm{~A}$ more recent study evaluated vitamin D status in a community-dwelling elderly population ( $\geq 60$ years old) in South Florida and found higher prevalence of vitamin D insufficiency (25(OH)D $<25 \mathrm{ng} / \mathrm{ml}$ ) among Afro-Caribbeans (30.8\%) and African Americans (30.4\%) compared to Hispanics (13\%) and European Americans (13\%). ${ }^{21}$ In our study, we did not find lower levels of vitamin D and thus, higher prevalence of vitamin D insufficiency in AfricanAmericans, as expected, and this could be due to the few African Americans/Afro- 
Caribbeans participating in our study. Only $15.5 \%$ of our sample was of African descent while $26 \%$ of the population studied by Smolar et al. ${ }^{21}$ was either African American or Afro-Caribbean. Nevertheless, we did find a significant association between vitamin D status and ethnicity and a significant difference between vitamin D categories in ethnic groups. We found more Hispanics who had vitamin D insufficiency, while more whiteCaucasians and African-Americans were vitamin D sufficient. When comparing ethnic groups, we found significant differences in vitamin D levels, with Hispanics having lower levels compared individually to white-Caucasians and African-Americans. In all of our regression models that included ethnicity, we found that this variable had a significant effect on vitamin D levels, with Hispanics expected to have lower vitamin D levels and higher odds of being insufficient. These results also differ from those of Smolar et al.,21 who reported that the prevalence of 25(OH)D insufficiency was not higher in Hispanic participants compared with European Americans. However, their sample population had only $28 \%$ Hispanics compared with $43 \%$ in our cohort. Thus, ethnicity was the strongest risk factor for vitamin D insufficiency in this study population.

Interestingly, we found a significant difference in height and years lived in the United States, with those who were vitamin D insufficient being shorter and having lived fewer years in the United States. These two factors are related to ethnicity. The average Hispanic person is shorter, and we found a significant difference in height between Hispanics (mean \pm SD: $163.29 \pm 12.21$ ) and non-Hispanics (mean \pm SD: $171.12 \pm 10.30$, $P<0.001)$. Furthermore, Miami being one of the southernmost cities of the U.S, is the home of one of the largest Hispanic communities in the country, which is mostly composed of immigrants. We found a significant difference in years lived in the United 
States between Hispanics and non-Hispanics, with Hispanics having lived here for fewer years (mean \pm SD: $26.63 \pm 17.4$ ) compared with non-Hispanics (mean \pm SD: $59.74 \pm$ 10.66, $P<0.001)$. Immigrant Hispanics may be more likely to be vitamin $\mathrm{D}$ deficient and insufficient due to differences in sun exposure practices, public health awareness initiatives in their home countries and less access to healthcare services due to their immigration status.

In summary, the occurrence of vitamin D deficiency and insufficiency in this study was lower than that of other American and European populations. This was expected in a population that has a greater opportunity for vitamin D skin synthesis by year-round sunlight availability. However, vitamin D insufficiency is still a public health concern even in this population. We found that lack of sun exposure, higher \%FM, and lack of use of vitamin/mineral supplements were risk factors for vitamin D insufficiency. Ethnicity, however, was the most consistent and important risk factor in this study population, since those who were vitamin D insufficient were more likely to be Hispanic. Since vitamin D deficiency is linked to health risk factors, it is important that health professionals become aware of connections between vitamin D status, intake, bioavailability and skin synthesis to develop dietary and other interventions to prevent and correct deficiency and insufficiency effectively.

This study had several limitations. It was cross-sectional and descriptive in nature and even though this type of investigation can establish associations among factors, it does not prove cause and effect. Second, this study may suffer from selection bias. Besides the expected higher sun exposure of this population, the age criterion could be a possible explanation for the lower occurrence of vitamin D insufficiency observed in our 
study. The study recruited a younger older adult population ( $>55$ years of age) to have a wider age range and the opportunity to follow them into the older years. According to the World Health Organization, both 60 or 65 years of age are equivalent to retirement age in most developed countries and hence, considered the beginning of old age. In the United States, the age of 65 has been traditionally considered the beginning of senior age. ${ }^{76}$ Some institutions like the Florida Department of Elder Affairs, however, considers those $>60$ years of age as older adults. ${ }^{77}$ Furthermore, our age criterion may be a limitation because most studies of vitamin D deficiency and insufficiency in the elderly have been done in adults either above the age of 60,65 , or 70 , making our results less comparable. Our study participants were younger than what is considered "old age," with $36 \%$ and $63.8 \%$ of participants being under the age of 60 and 65 , respectively, and thus, adding heterogeneity to our study. Nevertheless, we did not find a significant difference in age, number of participants over the age of 60 , and number of participants over the age of 65, between vitamin D insufficient and sufficient groups. Moreover, age was not a risk factor for vitamin D deficiency in this study population.

The participants in this study were not only younger, but mostly healthier, since criteria for the parent study excluded current diagnoses of numerous diseases/conditions that affect vitamin D metabolism and absorption, medications that disturb vitamin D metabolism, and current vitamin D supplement use. Thus, this sample was not randomly selected from the general older adult population in Miami-Dade, but instead were healthier older adults who volunteered to participate and met inclusion criteria. Thus, the results of this study cannot be extrapolated to the general Miami-Dade older adult population, other populations in the United States or globally. 
Even though questionnaires have been validated and tested, are low-cost, and easily administered, they have some limitations. Over or under-reporting may have occurred due to participants’ desire to please the researchers. Understanding terms and recalling information may interfere with the respondents' ability to answer questions accurately. Thus, self-report may not reflect true answers on questionnaires.

Another weakness of this study is related to vitamin D assessment. First of all, 25(OH)D measured today may not reflect a person's level throughout the year, since it varies with season, having the highest levels during the summer and fall and the lowest in the winter and spring. Hence, it is not known whether the average concentrations during the year, the peak concentration throughout the year, or the difference between the lowest and highest peaks are the most pertinent for the pathophysiology of vitamin D-related diseases. ${ }^{78}$ In addition, it is known that $25(\mathrm{OH}) \mathrm{D}$ measurements do not reflect an individual's long-term status. This means that the assay will not reflect peoples' sun exposure and dietary intake throughout life. For example, it will not differentiate people who have spent a significant amount of time in regions with distinct UVB radiation or who have made lifestyle modifications throughout time like using sunscreen or supplements. Therefore, the intra-individual variation in vitamin D levels over years is not considered in this research. ${ }^{78}$ Besides, the levels of $25(\mathrm{OH}) \mathrm{D}$ need to be considered in the context of phenotype. Genetic polymorphism of vitamin D binding protein, 25hydroxylase, 1-alpha hydroxylase, 24-hydroxylase, and vitamin D receptor, which are involved in the transport, activation, and metabolism of vitamin D may determine peoples’ 25(OH)D levels. ${ }^{78}$ The cutoff values for vitamin D deficiency and sufficiency are also widely debated. Previously, the delineation of vitamin D adequacy was 
associated with bone health and calcium absorption regarding the prediction of rickets in children and osteomalacia in adults. ${ }^{79}$ Increasing evidence, however, indicates that vitamin $\mathrm{D}$ is associated with other diseases beyond those related to calcium homeostasis, so researchers argue that the threshold values should consider the point at which more vitamin $\mathrm{D}$ in the body will no longer provide any health benefits whether these are due to calcemic and/or non-calcemic effects. ${ }^{24,80,81}$ The functions of vitamin D are still not fully understood, so thresholds are hard to define, and optimal cutoff points are difficult to set. Differences in cutoff values for different conditions can change the specificity and sensitivity of the assay when identifying participant's true vitamin D status. Finally, even though clinicians widely use vitamin D serum assays, the inconsistency and variability between assays and laboratories are still concerns, even when using the same assays, due to the lack of reference standards..$^{79,82}$

\section{Conclusions}

Vitamin D insufficiency is common in healthy community-dwelling older adults living in Miami-Dade County, especially among Hispanics. Vitamin D intake from food was not a predictor of vitamin D status; however, use of a vitamins/mineral supplement was an independent predictor of vitamin D levels. Factors that affected skin synthesis (ethnicity and sun exposure) and bioavailability/metabolism (obesity) were also significant predictors of vitamin D status. However, ethnicity was the strongest risk factor for vitamin D insufficiency in this study population. Since vitamin D deficiency is linked to health risk factors, it is important that health professionals become aware of the 
connections of vitamin D status with intake, bioavailability, and skin synthesis and to develop and plan pertinent interventions to prevent and correct deficiency. 


\begin{tabular}{|c|c|c|c|c|c|}
\hline & $\begin{array}{c}\text { Study } \\
\text { population } \\
(\mathbf{n}=97)\end{array}$ & $\begin{array}{c}\text { Vitamin D } \\
\text { Insufficient } \\
<30 \mathrm{ng} / \mathrm{ml} \\
(\mathrm{n}=45)\end{array}$ & $\begin{array}{c}\text { Vitamin D } \\
\text { Sufficient } \\
\geq \mathbf{3 0 ~ n g / m l} \\
(\mathrm{n}=52)\end{array}$ & MD & $\begin{array}{c}P \text { - } \\
\text { value }\end{array}$ \\
\hline $\begin{array}{l}\text { Vitamin D levels } \\
\text { (ng/ml) } \\
(\text { Mean } \pm \text { SD) }\end{array}$ & $30.73 \pm 8.73$ & $23.31 \pm 4.41$ & $37.15 \pm 6.02$ & -13.84 & 0.000 \\
\hline $\begin{array}{l}\text { Vitamin D Intake } \\
\text { (IU/day) } \\
\text { (Mean } \pm \text { SD) }\end{array}$ & $170.3 \pm 168.1$ & $171.3 \pm 209.4$ & $169.5 \pm 123.8$ & 1.86 & 0.957 \\
\hline $\begin{array}{l}\text { Sun Exposure } \\
\text { (Total Score) } \\
\text { (Mean } \pm \text { SD) }\end{array}$ & $19.05 \pm 12.13$ & $15.69 \pm 12.60$ & $21.96 \pm 11.02$ & -6.27 & 0.010 \\
\hline $\begin{array}{l}\text { Age }^{¥} \text { (years) } \\
\text { (Mean } \pm \text { SD) }\end{array}$ & $63.06 \pm 6.48$ & $63.22 \pm 7.65$ & $62.92 \pm 5.34$ & 0.3 & 0.822 \\
\hline $\begin{array}{l}\text { Male gender } \\
(\mathrm{N}(\%))\end{array}$ & $44(45.4)$ & $18(40.0)$ & $26(50.0)$ & & 0.414 \\
\hline $\begin{array}{l}\text { Ethnicity (N (\%)) } \\
\text { Hispanic } \\
\text { White Caucasian } \\
\text { African American }\end{array}$ & $\begin{array}{l}43(44.3) \\
34(35.1) \\
15(15.5)\end{array}$ & $\begin{array}{l}27(60.0) \\
9(20.0) \\
5(11.1)\end{array}$ & $\begin{array}{l}16(30.8) \\
25(48.1) \\
10(19.2)\end{array}$ & & 0.004 \\
\hline $\begin{array}{l}\text { Years lived in } \\
\text { United States } \\
(\text { Mean } \pm S D)\end{array}$ & $45.26 \pm 21.61$ & $39.74 \pm 22.14$ & $50.12 \pm 20.12$ & -10.37 & 0.018 \\
\hline
\end{tabular}

¥ Independent T-tests, ๆ Chi-squares. SD: Standard Deviations; N: Number; MD: Mean Difference; 


\begin{tabular}{|c|c|c|}
\hline Ethnic group & $\begin{array}{c}\text { Vitamin D Levels } \\
(25(\mathrm{OH}) \mathrm{D}, \mathrm{ng} / \mathrm{ml}) \\
(\text { Mean } \pm \text { SD) }\end{array}$ & F (d.f.) (P-value) \\
\hline White, Caucasian $(n=34)$ & $33.37 \pm 7.73$ & \multirow{4}{*}{$6.27(3)(0.001)$} \\
\hline African-American $(n=15)$ & $35.77 \pm 9.60$ & \\
\hline Hispanic, Latino $(n=43)^{*}$ & $27.61 \pm 7.75$ & \\
\hline Other $(n=5)$ & $24.46 \pm 8.73$ & \\
\hline
\end{tabular}




\begin{tabular}{|c|c|c|c|c|c|}
\hline \multicolumn{6}{|c|}{$\begin{array}{l}\text { Table 3: Comparison of Vitamin D Levels, Vitamin D Intake, Sun Exposure } \\
\text { Other Potential Correlates Between Vitamin D Insufficient and Sufficient } \\
\text { Participants }\end{array}$} \\
\hline & $\begin{array}{l}\text { Study } \\
\text { population } \\
(\mathbf{n}=97)\end{array}$ & $\begin{array}{c}\text { Vitamin D } \\
\text { Insufficient } \\
<30 \mathrm{ng} / \mathrm{ml} \\
(\mathbf{n}=\mathbf{4 5})\end{array}$ & \begin{tabular}{|c|} 
Vitamin D \\
Sufficient \\
$\geq 30 \mathrm{ng} / \mathrm{ml}$ \\
$\quad(\mathrm{n}=52)$
\end{tabular} & MD & $\begin{array}{c}P \text { - } \\
\text { value }\end{array}$ \\
\hline $\begin{array}{l}\text { Number of diseases and } \\
\text { conditions reported }^{¥} \\
(\text { Mean } \pm \text { SD) }\end{array}$ & $4.70 \pm 3.03)$ & $4.20 \pm 3.01$ & $5.13 \pm 3.01$ & -0.94 & 0.130 \\
\hline 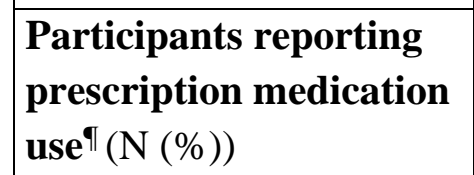 & 73 (75.3) & $29(64.4)$ & $44(84.6)$ & & 0.033 \\
\hline $\begin{array}{l}\text { Number of prescription } \\
\text { medications used }^{¥} \\
(\text { Mean } \pm S D)\end{array}$ & $2.24 \pm 2.20$ & $1.73 \pm 2.01$ & $2.67 \pm 2.29$ & -0.94 & 0.033 \\
\hline $\begin{array}{l}\text { Participants reporting } \\
\text { vitamins/minerals } \\
\text { supplement use }^{\mathbb{I}}(\mathrm{N}(\%))\end{array}$ & $45(46.4)$ & 17 (37.8) & 28 (53.8) & & 0.153 \\
\hline $\begin{array}{l}\text { Depressive symptoms } \\
{\text { (BDI Score })^{¥}}^{(\text {Mean } \pm \mathrm{SD})}\end{array}$ & $7.19 \pm 7.56$ & $6.22 \pm 6.30$ & $8.02 \pm 8.47$ & -1.80 & 0.240 \\
\hline $\begin{array}{l}\text { Height }(\mathbf{c m})^{¥} \\
(\text { Mean } \pm \text { SD) }\end{array}$ & $167.6 \pm 10.41$ & $164.40 \pm 10.65$ & $170.46 \pm 9.43$ & -6.06 & 0.004 \\
\hline $\begin{array}{l}\text { BMI (kg/m2) } \\
(\text { Mean } \pm \text { SD) }\end{array}$ & $27.09 \pm 5.27$ & $27.44 \pm 4.98$ & $26.80 \pm 5.53$ & 0.63 & 0.559 \\
\hline $\begin{array}{l}\text { Overweight } \\
\text { participants }(\mathrm{BMI} \geq \mathbf{2 5})^{\mathrm{q}} \\
(\mathrm{N}(\%))\end{array}$ & 60 (61.9) & $28(62.2)$ & 32 (61.5) & & 1.000 \\
\hline $\begin{array}{l}\text { \%FM }(\mathbf{n}=\mathbf{9 5})^{¥} \\
(\text { Mean } \pm \text { SD) }\end{array}$ & $30.92 \pm 9.01$ & $32.08 \pm 9.24$ & $29.92 \pm 8.93$ & 1.29 & 0.251 \\
\hline $\begin{array}{l}\text { Moderate physical } \\
\text { activity (MET } \\
\text { equivalents per week) }{ }^{¥} \\
(\text { Mean } \pm \text { SD) }\end{array}$ & $1779 \pm 2325$ & $1281 \pm 1644$ & $2209 \pm 2727$ & -929 & 0.043 \\
\hline $\begin{array}{l}\text { Sitting minutes per day } \\
\text { Mean } \pm S D\end{array}$ & $299.04 \pm 186$ & $260.72 \pm 130.5$ & $332.20 \pm 219.3$ & -71.5 & 0.050 \\
\hline
\end{tabular}

¥ Independent T-tests; ๆ Chi-squares; SD: Standard Deviations N: Number; MD: Mean Difference; BDI: Beck Depression Inventory; BMI: Body Mass Index; FM: Fat Mass; MET: Metabolic Equivalents. 


\begin{tabular}{|l|c|c|}
\hline \multicolumn{3}{|c|}{ Table 4: Vitamin D Status Correlation with Vitamin D Intake, Sun Exposure, and } \\
Other Potential Predictors & $\begin{array}{c}\text { Spearman Correlation } \\
\text { Coefficient }\end{array}$ & P value \\
\hline & 0.05 & 0.728 \\
\hline Vitamin D intake (IU/day) at baseline & 0.274 & 0.007 \\
\hline Sun exposure & -0.365 & 0.000 \\
\hline Ethnicity & 0.272 & 0.007 \\
\hline Years lived in the United States & 0.233 & 0.022 \\
\hline Participants taking prescription medications & 0.234 & 0.021 \\
\hline Number of prescription medications & 0.277 & 0.006 \\
\hline $\begin{array}{l}\text { Participants who reported vitamins/minerals } \\
\text { supplement use }\end{array}$ & -0.298 & 0.003 \\
\hline Height (cm) & -0.220 & 0.030 \\
\hline BMI (kg/m2) & -0.263 & 0.010 \\
\hline \%FM & 0.215 & 0.050 \\
\hline Average sitting minutes & & \\
\hline
\end{tabular}

Spearman Correlations between vitamin D status groups (Vitamin D insufficient $=0$; Vitamin D sufficient $=1$ ) and continuous/categorical variables. BMI: Body Mass Index, FM: Fat Mass. 


\begin{tabular}{|c|c|c|c|}
\hline & $\beta$ (S.E.) & $\begin{array}{c}P \text { - } \\
\text { value }\end{array}$ & $\begin{array}{l}\text { Adjusted } \\
\mathbf{R}^{2}\end{array}$ \\
\hline \begin{tabular}{c|l} 
Model & Vitamin D Intake (IU/day) \\
1 & Sun Exposure
\end{tabular} & $\begin{array}{l}0.00(0.01) \\
0.17(0.07)\end{array}$ & $\begin{array}{l}0.648 \\
0.017\end{array}$ & 0.048 \\
\hline \begin{tabular}{c|l} 
Model & Sun Exposure \\
2 & Ethnicity (Non-Hispanic)
\end{tabular} & $\begin{array}{c}0.138(0.07) \\
5.02(1.70)\end{array}$ & $\begin{array}{l}0.052 \\
0.004\end{array}$ & 0.120 \\
\hline \begin{tabular}{c|l} 
Model & Ethnicity (Non-Hispanic) \\
3 & $\%$ FM \\
& Vitamin/Mineral Supplement use
\end{tabular} & $\begin{array}{c}3.92(1.70) \\
-0.25(0.09) \\
4.24(1.70)\end{array}$ & $\begin{array}{l}0.023 \\
0.008 \\
0.014\end{array}$ & 0.184 \\
\hline
\end{tabular}

Stepwise Multiple Linear Regressions. Dependent variable: Vitamin D levels (ng/ml). Model 1: Vitamin D Intake, Sun exposure; Model 2: Model 1 + Ethnicity; Model 3: Model 2 + Years lived in the US, number of participants taking prescription medications, number of prescription medications, height, moderate physical activity, average sitting time per day, education, vitamin/mineral supplement use, BMI, \%FM, age, gender, marital status, employment, income, number of disease, coffee use, alcohol use, smoking, weight, calcium intake, depressive symptoms. $\boldsymbol{\beta}$ : Beta Coefficient; S.E.: Standard Error; CI: Confidence Interval; FM: Fat Mass. 


\begin{tabular}{|c|c|c|c|c|}
\hline & & $\beta$ (S.E.) & OR (95\% CI) & $P$-value \\
\hline Model 1 & Sun Exposure & $0.05(0.02)$ & 1.05 (1.01; 1.09) & 0.013 \\
\hline Model 2 & $\begin{array}{l}\text { Sun exposure } \\
\text { Ethnicity (Being Hispanic) }\end{array}$ & $\begin{array}{c}.05(0.02) \\
-1.21(0.47)\end{array}$ & $\begin{array}{l}1.05(1.01 ; 1.10) \\
0.30(0.12 ; 0.75)\end{array}$ & $\begin{array}{l}0.016 \\
0.010\end{array}$ \\
\hline
\end{tabular}

Forward Logistic Regression. Dependent Variable: Vitamin status $(0=<30 \mathrm{ng} / \mathrm{ml} ; 1=\geq 30 \mathrm{ng} / \mathrm{ml})$. Model 1: Vitamin D intake, Sun Exposure. Model 2: Model $1+$ Ethnicity, Years lived in the US, number of participants taking prescription medications, number of prescription medications, height, moderate physical activity, average sitting time per day, education, vitamin/mineral supplement use, BMI, \%FM, age, gender, marital status, employment, income, number of disease, coffee use, alcohol use, smoking, weight, calcium intake, depressive symptoms. $\boldsymbol{\beta}$ : Beta Coefficient; SE: Standard Error; OR: Odds Ratio; CI: Confidence Interval. 


\section{References}

1. van der Schaft J, Koek HL, Dijkstra E, Verhaar HJ, van der Schouw YT, EmmelotVonk MH. The association between vitamin D and cognition: A systematic review. Ageing Res Rev. 2013;12(4):1013-1023.

2. Balion C, Griffith LE, Strifler L, et al. Vitamin D, cognition, and dementia: A systematic review and meta-analysis. Neurology. 2012;79(13):1397-1405.

3. Etgen T, Sander D, Bickel H, Sander K, Forstl H. Vitamin D deficiency, cognitive impairment and dementia: A systematic review and meta-analysis. Dement Geriatr Cogn Disord. 2012;33(5):297-305.

4. Muir SW, Montero-Odasso M. Effect of vitamin D supplementation on muscle strength, gait and balance in older adults: A systematic review and meta-analysis. $J$ Am Geriatr Soc. 2011;59(12):2291-2300.

5. Murad MH, Elamin KB, Abu Elnour NO, et al. Clinical review: The effect of vitamin D on falls: A systematic review and meta-analysis. J Clin Endocrinol Metab. 2011;96(10):2997-3006.

6. Kalyani RR, Stein B, Valiyil R, Manno R, Maynard JW, Crews DC. Vitamin D treatment for the prevention of falls in older adults: Systematic review and meta-analysis. J Am Geriatr Soc. 2010;58(7):1299-1310.

7. Chu YH, Tang PF, Peng YC, Chen HY. Meta-analysis of type and complexity of a secondary task during walking on the prediction of elderly falls. Geriatr Gerontol Int. 2012;13(2):289-297.

8. Zadshir A, Tareen N, Pan D, Norris K, Martins D. The prevalence of hypovitaminosis D among U.S. adults: Data from the NHANES III. Ethn Dis. 2005;15(4 Suppl 5):97-101.

9. Llewellyn DJ, Lang IA, Langa KM, Melzer D. Vitamin D and cognitive impairment in the elderly U.S. population. J Gerontol A Biol Sci Med Sci. 2011;66(1):59-65.

10. Heaney RP, Armas LA, Shary JR, Bell NH, Binkley N, Hollis BW. 25-hydroxylation of vitamin D3: Relation to circulating vitamin D3 under various input conditions. Am J Clin Nutr. 2008;87(6):1738-1742.

11. Hollis BW, Wagner CL, Drezner MK, Binkley NC. Circulating vitamin D3 and 25hydroxyvitamin D in humans: An important tool to define adequate nutritional vitamin D status. J Steroid Biochem Mol Biol. 2007;103(3-5):631-634. 
12. Cesari M, Incalzi RA, Zamboni V, Pahor M. Vitamin D hormone: A multitude of actions potentially influencing the physical function decline in older persons. Geriatr Gerontol Int. 2011;11(2):133-142.

13. Prentice A, Goldberg GR, Schoenmakers I. Vitamin D across the lifecycle: Physiology and biomarkers. Am J Clin Nutr. 2008;88(2):500-506.

14. Salamone LM, Dallal GE, Zantos D, Makrauer F, Dawson-Hughes B. Contributions of vitamin D intake and seasonal sunlight exposure to plasma 25-hydroxyvitamin D concentration in elderly women. Am J Clin Nutr. 1994;59(1):80-86.

15. Holick MF. Photobiologyof vitamin D. In: Feldman D, Pike JW, Adams JS, eds. Vitamin D. 3rd ed. San Diego, CA: Elsevier Academic Press; 2011:113-122.

16. Chen TC, Chimeh F, Lu Z, et al. Factors that influence the cutaneous synthesis and dietary sources of vitamin D. Arch Biochem Biophys. 2007;460(2):213-217.

17. Moore C, Murphy MM, Keast DR, Holick MF. Vitamin D intake in the united states. J Am Diet Assoc. 2004;104(6):980-983.

18. Brock K, Huang WY, Fraser DR, et al. Low vitamin D status is associated with physical inactivity, obesity and low vitamin D intake in a large U.S. sample of healthy middle-aged men and women. J Steroid Biochem Mol Biol. 2010;121(1-2):462-466.

19. Levis S, Gomez A, Jimenez C, et al. Vitamin D deficiency and seasonal variation in an adult south florida population. J Clin Endocrinol Metab. 2005;90(3):1557-1562.

20. Lagari V, Gomez-Marin O, Levis S. The role of vitamin D in improving physical performance in the elderly. J Bone Miner Res. 2013;28(10):2194-2201.

21. Smolar DE, Engstrom GA, Diaz S, Tappen R, Ouslander JG. Ethnic differences in vitamin D insufficiency in south florida community-dwelling older adults. J Am Geriatr Soc. 2012;60(10):1990-1991.

22. Corley CT. Senior fact sheet 2010. Florida Department of Elder Affairs Web site. http://elderaffairs.state.fl.us/doea/publications.php;. Updated 2010. Accessed August 31, 2015.

23. Erkinjuntti T, Sulkava R, Wikstrom J, Autio L. Short portable mental status questionnaire as a screening test for dementia and delirium among the elderly. $J \mathrm{Am}$ Geriatr Soc. 1987;35(5):412-416.

24. Wagner D, Hanwell HE, Vieth R. An evaluation of automated methods for measurement of serum 25-hydroxyvitamin D. Clin Biochem. 2009;42(15):1549-1556. 
25. Blalock SJ, Norton LL, Patel RA, Cabral K, Thomas CL. Development and assessment of a short instrument for assessing dietary intakes of calcium and vitamin D. $J$ Am Pharm Assoc. 2003;43(6):685-693.

26. Hanwell HE, Vieth R, Cole DE, et al. Sun exposure questionnaire predicts circulating 25-hydroxyvitamin D concentrations in caucasian hospital workers in southern italy. $J$ Steroid Biochem Mol Biol. 2010;121(1-2):334-337.

27. Ajabshir S, Exebio JC, Zarini GG, et al. Skin color and self-reported sun exposure scores are associated with serum 25-hydroxyvitamin D concentrations in a multi-ethnic population living in south florida. BJMHR. 2014;4(34):5313-5323.

28. Exebio JC, Zarini GG, Ajabshir S, Antwi J, Huffman FG. Validation of a sun exposure questionnaire among subjects with type 2 diabetes residing in south florida. $J$ Immigr Minor Health. 2015.

29. The IPAQ Group. Guidelines for data processing and analysis of the international physical activity questionnaire (IPAQ) - short and long forms. IPAQ Web site. http://www.ipaq.ki.se/scoring.pdf. Accessed April 24, 2013.

30. Rutten A, Ziemainz H, Schena F, et al. Using different physical activity measurements in eight european countries. results of the european physical activity surveillance system (EUPASS) time series survey. Public Health Nutr. 2003;6(4):371376.

31. Bassett DR,Jr. International physical activity questionnaire: 12-country reliability and validity. Med Sci Sports Exerc. 2003;35(8):1381-1395.

32. The IPAQ Group. The international physical activity questionnaire. IPAQ Web site. https://sites.google.com/site/theipaq/. Accessed April 24, 2013.

33. Hagstromer M, Oja P, Sjostrom M. The international physical activity questionnaire (IPAQ): A study of concurrent and construct validity. Public Health Nutr. 2006;9(6):755762.

34. Benedetti TRB, de Cesaro Antunes P, Rodriguez-Anez CR, Mazo GZ, Petrozki EL. Reproducibility and reliability of the international physical activity questionnaire in ederly men. Rev Bras Med Esporte. 2007;13 (1):9-13.

35. Benedetti TRB, Mazo GZ, Barros MV. Application of the international physical activity questionnaire (IPAQ) for evaluation of elderly women: Concurrent validity and test-retest reproducibility. Rev Bras Ciên e Mov. 2004;12(1):25-34.

36. Mader U, Martin BW, Schutz Y, Marti B. Validity of four short physical activity questionnaires in middle-aged persons. Med Sci Sports Exerc. 2006;38(7):1255-1266. 
37. Kolbe-Alexander TL, Lambert EV, Harkins JB, Ekelund U. Comparison of two methods of measuring physical activity in south african older adults. J Aging Phys Act. 2006;14(1):98-114.

38. Silva RB, Costa-Paiva L, Pinto Neto AM, Braga Ade A, Morais SS. Habitual physical activity and cardiovascular risk in post menopause. Rev Assoc Med Bras.

2006;52(4):242-246.

39. da Silva RB, Costa-Paiva L, Pinto-Neto AM, Braga Ade A, Morais SS. Association between habitual physical activity and parameters of physical fitness in postmenopausal women. Climacteric. 2005;8(4):360-370.

40. Ainsworth BE, Macera CA, Jones DA, et al. Comparison of the 2001 BRFSS and the IPAQ physical activity questionnaires. Med Sci Sports Exerc. 2006;38(9):1584-1592.

41. Ekelund U, Sepp H, Brage S, et al. Criterion-related validity of the last 7-day, short form of the international physical activity questionnaire in swedish adults. Public Health Nutr. 2006;9(2):258-265.

42. Kwak L, Hagstromer M, Sjostrom M. Can the IPAQ-long be used to assess occupational physical activity? J Phys Act Health. 2012;9(8):1130-1137.

43. Arvidsson D, Slinde F, Hulthen L. Physical activity questionnaire for adolescents validated against doubly labelled water. Eur J Clin Nutr. 2005;59(3):376-383.

44. Beck AT, Steer RA, Brown GK. RCMAR measurement tools: Beck depression inventory-2nd edition (BDI-II). Medical University of South Carolina Web site. http://www.musc.edu/dfm/RCMAR/Beck.html. Accessed April 21, 2013.

45. Beck AT, Steer RA. Internal consistencies of the original and revised beck depression inventory. J Clin Psychol. 1984;40(6):1365-1367.

46. Beck AT, Ward CH, Mendelson M, Mock J, Erbaugh J. An inventory for measuring depression. Arch Gen Psychiatry. 1961;4:561-571.

47. Richter P, Werner J, Heerlein A, Kraus A, Sauer H. On the validity of the beck depression inventory. A review. Psychopathology. 1998;31(3):160-168.

48. Segal DL, Coolidge FL, Cahill BS, O'Riley AA. Psychometric properties of the beck depression inventory II (BDI-II) among community-dwelling older adults. Behav Modif. 2008;32(1):3-20.

49. Forrest KY, Stuhldreher WL. Prevalence and correlates of vitamin D deficiency in U.S. adults. Nutr Res. 2011;31(1):48-54. 
50. Wilson VK, Houston DK, Kilpatrick L, et al. Relationship between 25hydroxyvitamin $\mathrm{D}$ and cognitive function in older adults: The health, aging and body composition study. J Am Geriatr Soc. 2014;62(4):636-641.

51. Houston DK, Tooze JA, Neiberg RH, et al. 25-hydroxyvitamin D status and change in physical performance and strength in older adults: The health, aging, and body composition study. Am J Epidemiol. 2012;176(11):1025-1034.

52. Houston DK, Neiberg RH, Tooze JA, et al. Low 25-hydroxyvitamin D predicts the onset of mobility limitation and disability in community-dwelling older adults: The health ABC study. J Gerontol A Biol Sci Med Sci. 2013;68(2):181-187.

53. Whiting SJ, Calvo MS. Correcting poor vitamin D status: Do older adults need higher repletion doses of vitamin D3 than younger adults? Mol Nutr Food Res. 2010;54(8):1077-1084.

54. Whiting SJ, Calvo MS. Dietary recommendations to meet both endocrine and autocrine needs of vitamin D. J Steroid Biochem Mol Biol. 2005;97(1-2):7-12.

55. Ross AC, Manson JE, Abrams SA, et al. The 2011 report on dietary reference intakes for calcium and vitamin D from the institute of medicine: What clinicians need to know. J Clin Endocrinol Metab. 2011;96(1):53-58.

56. Rosen CJ, Abrams SA, Aloia JF, et al. IOM committee members respond to endocrine society vitamin D guideline. J Clin Endocrinol Metab. 2012;97(4):1146-1152.

57. Pludowski P, Holick MF, Pilz S, et al. Vitamin D effects on musculoskeletal health, immunity, autoimmunity, cardiovascular disease, cancer, fertility, pregnancy, dementia and mortality- a review of recent evidence. Autoimmun Rev. 2013;12(10):976-989.

58. Holick MF, Binkley NC, Bischoff-Ferrari HA, et al. Evaluation, treatment, and prevention of vitamin D deficiency: An endocrine society clinical practice guideline. $J$ Clin Endocrinol Metab. 2011;96(7):1911-1930.

59. Holick MF. The D-lightful vitamin for health. Seminar presented: Nutrition Matters Conference at the University of Miami Miller School of Medicine. April 12 2015;Miami, Fl.

60. Chen TC, Shao A, Heath H,3rd, Holick MF. An update on the vitamin D content of fortified milk from the united states and canada. $N$ Engl J Med. 1993;329(20):1507-1507.

61. Serra Prat M, Fernandez X, Ribo L, Palomera E, Papiol M, Serra P. Loss of appetite in elderly people in the community and its relationship with functional capacity. Med Clin (Barc). 2008;130(14):531-533. 
62. Lee JS, Frongillo EA,Jr. Nutritional and health consequences are associated with food insecurity among U.S. elderly persons. J Nutr. 2001;131(5):1503-1509.

63. Jaddou HY, Batieha AM, Khader YS, Kanaan SH, El-Khateeb MS, Ajlouni KM. Depression is associated with low levels of 25-hydroxyvitamin D among jordanian adults: Results from a national population survey. Eur Arch Psychiatry Clin Neurosci. 2012;262(4):321-327.

64. Hoogendijk WJ, Lips P, Dik MG, Deeg DJ, Beekman AT, Penninx BW. Depression is associated with decreased 25-hydroxyvitamin D and increased parathyroid hormone levels in older adults. Arch Gen Psychiatry. 2008;65(5):508-512.

65. Bertone-Johnson ER, Powers SI, Spangler L, et al. Vitamin D intake from foods and supplements and depressive symptoms in a diverse population of older women. Am J Clin Nutr. 2011;94(4):1104-1112.

66. Boucher BJ. The problems of vitamin D insufficiency in older people. Aging Dis. 2012;3(4):313-329.

67. Bailey RL, Dodd KW, Goldman JA, et al. Estimation of total usual calcium and vitamin D intakes in the united states. J Nutr. 2010;140(4):817-822.

68. Segal E, Dvorkin L, Lavy A, et al. Bone density in axial and appendicular skeleton in patients with lactose intolerance: Influence of calcium intake and vitamin D status. $\mathrm{J} \mathrm{Am}$ Coll Nutr. 2003;22(3):201-207.

69. Pannemans DL, Westerterp KR. Energy expenditure, physical activity and basal metabolic rate of elderly subjects. Br J Nutr. 1995;73(4):571-581.

70. Houston DK, Nicklas BJ, Zizza CA. Weighty concerns: The growing prevalence of obesity among older adults. J Am Diet Assoc. 2009;109(11):1886-1895.

71. Annweiler C, Dursun E, Feron F, et al. 'Vitamin D and cognition in older adults': Updated international recommendations. J Intern Med. 2015;277(1):45-57.

72. van der Wielen RP, Lowik MR, van den Berg H, et al. Serum vitamin D concentrations among elderly people in europe. Lancet. 1995;346(8969):207-210.

73. Scragg R, Camargo CA,Jr. Frequency of leisure-time physical activity and serum 25hydroxyvitamin D levels in the US population: Results from the third national health and nutrition examination survey. Am J Epidemiol. 2008;168(6):577-591.

74. Tran B, Armstrong BK, McGeechan K, et al. Predicting vitamin D deficiency in older australian adults. Clin Endocrinol (Oxf). 2013;79(5):631-640. 
75. Clemens TL, Adams JS, Henderson SL, Holick MF. Increased skin pigment reduces the capacity of skin to synthesize vitamin D3. Lancet. 1982;1(8263):74-76.

76. Werner CA. The older population: 2010 census briefs. United States Census Bureau Web site. https://www.census.gov/prod/cen2010/briefs/c2010br-09.pdf. Updated 2011. Accessed August 31, 2015.

77. Scott R, Corley CT. State plan on aging 2013-2016. Florida Department of Elder Affairs Web site. http://elderaffairs.state.fl.us/doea/publications.php;. Updated 2012. Accessed August 31, 2015.

78. Millen AE, Bodnar LM. Vitamin D assessment in population-based studies: A review of the issues. Am J Clin Nutr. 2008;87(4):1102-1105.

79. Mosekilde L. Vitamin D requirement and setting recommendation levels: Long-term perspectives. Nutr Rev. 2008;66(10 Suppl 2):S170-177.

80. Cashman KD, Hill TR, Lucey AJ, et al. Estimation of the dietary requirement for vitamin D in healthy adults. Am J Clin Nutr. 2008;88(6):1535-1542.

81. Vieth R, Bischoff-Ferrari H, Boucher BJ, et al. The urgent need to recommend an intake of vitamin D that is effective. Am J Clin Nutr. 2007;85(3):649-650.

82. Stechschulte SA, Kirsner RS, Federman DG. Vitamin D: Bone and beyond, rationale and recommendations for supplementation. Am J Med. 2009;122(9):793-802. 


\title{
CHAPTER V: ASSOCIATION OF VITAMIN D STATUS WITH DUAL TASK PHYSICAL PERFORMANCE IN OLDER ADULTS
}

\begin{abstract}
Objective: The purpose of this study is to evaluate the association between vitamin D status with the age-related changes in mobility through higher order cognitive function using a dual task physical performance test.
\end{abstract}

Methods: Participants completed assessments that included serum levels of vitamin D, surveys, and dual task physical performance tests. Spearman's correlations, independent t-tests, repeated measures ANOVAs and multiple logistic regressions were used to examine the relationship between vitamin D insufficiency $(25(\mathrm{OH}) \mathrm{D}<30 \mathrm{ng} / \mathrm{ml})$ and sufficiency ( $\geq 30 \mathrm{ng} / \mathrm{ml}$ ) and dual task physical performance variables. The significance level was set at $\alpha=0.05$.

Results: Dual and single task counting rate were significantly lower in the vitamin D insufficient group compared to the sufficient group ( $P=0.018$ and $P=0.028$, respectively). Using Spearman correlations, a slower single $(P=0.011)$ and dual counting rate $(P=0.006)$ were significantly associated with vitamin D insufficiency.

Conclusions: Cognitive performance for dual or single tasking was worse in the vitamin D insufficient group. Since counting backward is a mental tracking task, which is a component of executive function, our results support a relationship between vitamin D insufficiency and executive dysfunction.

Keywords: vitamin D insufficiency, elderly, dual task, physical performance, executive function. 


\section{Introduction}

In the United States, the elderly population (>65 years of age) is expected to increase by $20 \%-50 \%$ by the year $2030 .{ }^{1}$ The major cause of physical disability in the elderly is mobility limitations, which eventually may lead to falls. ${ }^{2}$ According to the World Health Organization (WHO), a fall is defined as an event that results in the person unintentionally coming to rest on the ground or other lower level, with or without injury, that is not due to a major intrinsic event, like seizure, stroke, loss of consciousness, epilepsy, or excess alcohol, or an environmental hazard like sustaining a blow. ${ }^{3}$ It is estimated that approximately $30 \%$ of community-dwelling adults and $50 \%$ of institutionalized adults $>65$ years of age experience one fall each year. ${ }^{4,5}$ Falls can result in increased morbidity and mortality and decreased quality of life, all of which translate to greater burden for the individual and healthcare system. ${ }^{5}$ Hence, understanding the risk factors and mechanisms behind falls is important for the development of effective interventions that protect the elderly from future disability.

Gait impairments are one of the main risk factors for falls in the elderly. ${ }^{6}$ Elderly, compared to their younger counterparts, have significantly reduced gait speed ${ }^{6-8}$ with those over the age of 70 years experiencing a $12-16 \%$ decline in gait speed per decade. ${ }^{9-12}$ The postural control system positions the body in space for orientation and balance depending on the integration of sensorimotor information in the central nervous system, which, in turn, depends on the information processing capacity of the brain. As people age, the sensorimotor system deteriorates and the information processing capacity of the brain areas involved in postural control and gait declines. ${ }^{13}$ With aging, the ability to perform automatic tasks, such as walking, becomes harder and more cognitively 
demanding. ${ }^{14}$ According to recent evidence, these age-related deficits in mobility might be partially compensated by strenuous higher-order cognitive strategies involving executive function that replace the automated sensorimotor processing..$^{13}$ Executive dysfunction is common among the elderly, ${ }^{15-17}$ and it has been associated with increased fall risk and gait impairments, including slower gait speed. ${ }^{18-28}$ Thus, falls in the older adults commonly occur when they engage in more than one task at a time (i.e., dual tasking) because cognitive resources, such as the attention usually allotted to movement, are no longer accessible for other activities such as talking, avoiding obstacles, watching for traffic, or other gait-unrelated tasks. ${ }^{13}$ Consequently, older adults often have more problems than younger adults in orchestrating tasks simultaneously, due to a lack of coordination of limited cognitive resources and decreased mental processing speed.

Vitamin D deficiency in older adults has been linked to important determinants of disability, including falls and fractures. ${ }^{29-37}$ An extensive amount of research supports the relationship between risk of falls and vitamin D deficiency and the benefit of vitamin D supplementation on reducing fall risk in the elderly., ${ }^{53-45}$ For instance, a recent metaanalysis found that those who fall have lower 25(OH)D concentrations, often $<20 \mathrm{ng} / \mathrm{ml}$, than non-fallers. ${ }^{46}$ The mechanism by which vitamin $\mathrm{D}$ is related to the risk of falls is still unclear, but potentially it may be through its relationship to both gait and cognition by affecting the musculoskeletal and nervous systems. ${ }^{41,47-53}$ In the general older adult population, vitamin D has not only been correlated with decreased muscle strength and dysfunctional mobility, but also with a higher risk of cognitive decline, which together may lead to an increased risk of falls and fractures. ${ }^{54}$ For instance, several studies have demonstrated an association between vitamin D deficiency and impairments of gait 
(slower gait speed), global cognition, and executive function. ${ }^{37,54-74}$ Furthermore, vitamin D status has been associated with impaired neuronal function in the caudal primary motor cortex of older adults, which may contribute to the pathophysiology of gait disorders in older adults with vitamin D deficiency. ${ }^{75}$ Studies that investigated vitamin D status' relationship with gait and cognition, however, have looked at these factors independently. There is lack of research about the role of vitamin $\mathrm{D}$ in cognitive function in the context of mobility.

A way to evaluate the interaction between cognition and mobility as an indicator of risk of falls in older adults is using the dual task paradigm, which refers to performing an automatic primary task while executing a secondary cognitive task..$^{19,28,76-87}$ During dual tasking the information processing capacity of an individual is divided between the performance of the secondary task (i.e., talking) and maintaining postural control and gait stability during the performance of a motor task (i.e., walking) ${ }^{88}$ However, in the older adult, dual tasking becomes more challenging, as the already-limited information processing capacity needs to be divided between two tasks, resulting in poor performance of either one or both tasks ${ }^{88}$ Studies that compared individual's performance during dual tasking to their performance of each task individually (i.e., single vs. dual task) have shown that performing a secondary task while walking has a destabilizing effect on gait, placing older adults at higher risk for falling. ${ }^{14}$ Until now, no study has evaluated the agerelated changes in mobility through higher-order cognitive function in relation to vitamin D status using a dual task physical performance test. The purpose of this study was to investigate the association of vitamin D status with cognitive processing during movement by using the dual task physical performance tests. It was hypothesized that 
those who are vitamin $\mathrm{D}$ insufficient $(25(\mathrm{OH}) \mathrm{D}<30 \mathrm{ng} / \mathrm{ml})$, compared to those who are vitamin D sufficient $(\geq 30 \mathrm{ng} / \mathrm{ml})$, will have significantly worse dual task physical performance, as measured by a larger difference between dual and single task gait and cognitive functioning.

\section{Methods}

\section{Study Design and Setting}

This study was approved by the IRBs of Florida International University (130390) and the University of Miami (20120195).

\section{Participants}

The study enrolled 101 participants, and four were excluded due to missing data ( $\mathrm{n}=97$ ). Participants for this study were recruited from the parent study, a double-blinded randomized placebo-controlled clinical trial that examined the effects of vitamin D supplementation on vitamin D level, bone formation, resorption, and mineral density, flexibility, and balance in the elderly, which was conducted at the University of Miami. Briefly, each potential participant was screened over the phone by administering the Short Portable Mental Status Questionnaire (SPMSQ) ${ }^{89}$ to evaluate mental functioning (allowed up to 2 errors) and questions regarding general inclusion criteria such as age, and medical, pharmacological and general exclusions. Inclusion criteria for this study included: (1) Men and women age 55 or older; (2) English and Spanish speakers; (3) Community-dwelling; (4) Ability to give informed consent; (5) Ability to perform motor tasks without aid; and (6) Participating in the parent study. All participants in this study 
were required to sign IRB approved informed consents for both the University of Miami and Florida International University.

\section{Biomarkers}

Vitamin D Status

Vitamin D status was measured by serum 25-hydroxyvitamin D (25(OH)D). Fasting venous blood (15 ml) was collected from every participant by a certified phlebotomist in the morning after fasting. The samples were sent the same day for analysis to LabCorp (2700 N. 29 ${ }^{\text {th }}$ Ave, Suite 203A, Hollywood, Fl 33020) that used immunochemiluminometric assays (ICMA) on the DiaSorin Liaison instrument to assess $25(\mathrm{OH}) \mathrm{D}$. This is a highly automated test that measures total $25(\mathrm{OH}) \mathrm{D}$, and it has been widely used by others. ${ }^{90}$

\section{Surveys}

Sociodemographics, Health History, Health Risk Behaviors and Medications

Sociodemographic and health-related data were collected using questionnaires developed by staff of the parent study that asked about gender, marital status, race/ethnicity, socioeconomic status, education, income, current medical diagnoses, medication/ supplement use and health risk behaviors such as coffee, alcohol, and tobacco use. 


\section{Physical Activity Levels}

Physical activity level was measured using the International Physical Activity

Questionnaire (IPAQ), ${ }^{91}$ which provides individual domain-specific scores for walking, moderate-intensity and vigorous-intensity activity within the domains of work, transportation, domestic chores and gardening, and leisure-time. To measure the volume of activity, each type of activity was weighted by its energy requirement defined as the MET-min. METs are metabolic equivalents that are computed for each specific activity using defined formulas, and then multiplied by the minutes performed to derive METminute scores, which are equal to kilocalories for a 60 kg person. ${ }^{91}$

The IPAQ was developed to derive comparable measurements of physical activity in international settings; therefore, being suitable for use in different languages and cultural contexts like in an ethnically-diverse city as Miami. ${ }^{92,93}$ It has also been validated in different age groups against objective measures of physical activity, physical fitness, and health outcomes. ${ }^{94}$ For instance, it was validated in an adult population (mean \pm SD: $40.7 \pm 10.3$ years old) and found to have a strong positive relationship with an activity monitor and a physical activity $\log ($ rho $=0.55, P<0.001) .{ }^{95}$ It was also validated and used in a population of elderly men and found to be reliable (test-retest reliability of 0.95) and valid when compared against pedometer use and the physical activity log, and had similar results in cohorts of postmenopausal women. ${ }^{96,97}$ Other studies have validated the IPAQ and used it successfully in populations of middle-aged and older adults and adults with different diseases, such as schizophrenia and breast cancer. ${ }^{93,98-101}$ The IPAQ correlated with measurements to other physical activity assessment methods such as the 2001 
Behavioral Risk Factor Surveillance System (BRFSS) physical activity, accelerometers, and energy expenditure as measured by doubly-labeled water, among others. ${ }^{94,102-105}$

\section{Depressive Symptoms}

Depressive symptoms were assessed using the Beck Depression Inventory (BDIII), which is a widely validated and used tool that evaluates the existence and severity of depressive symptoms based on the DSM-IV. ${ }^{106}$ It is a self-report, 21-item instrument and each item corresponds to a symptom of depression and has a four-point scale ranging from 0 to 3, except for two items that have seven options to indicate decrease or increase in appetite and sleep. The score of all items is summed to give a single score. A total score of 0-13 is considered minimal, 14-19 mild, 20-28 moderate, and 29-63 severe depressive symptoms. ${ }^{106}$ Construct validity has been assessed on its ability to differentiate non-depressed and depressed patients ( 0.92 for outpatients and 0.93 for college students). Test-retest reliability was found to be significant at 0.93 . This tool has been used in populations ages 13-80 years. ${ }^{106-109}$ In an elderly population, BDI-II has good internal consistency ( 0.86$)$, and has been positively correlated with other measures of depression, measures of stress, anxiety, and negatively with well-being. Research with this instrument has shown no statistically significant effects for ethnicity, gender, and age on BDI-II scores. ${ }^{110}$ In case a participant reported suicidal ideation, the investigators in this study contacted the study physician and/or University of Miami Mental Health Department, immediately. 


\section{Fear of Falling}

Fear of falling was another potential parameter that may have interfered with the physical assessment battery; therefore, it was assessed using the Fall Efficacy Scale International (FES-I), which evaluates the fear of falling while performing everyday activities. $^{111,112}$

\section{Anthropometrics and Body Composition}

Weight was measured using an electronic balance. Participants were asked to remove shoes and heavy outer garments like coats and to stand in the center of the balance so that the weight was distributed evenly on both feet. Height was measured using a stadiometer with a movable headpiece. Participants were asked to stand with their back to the height rule with their feet together, while the back of the head, back, buttocks, calves, and heels touched the upright tape. The participant was asked to look straight ahead so that the ear canal was level with the cheek bone. The headpiece was lowered so that the hair was pressed flat. Weight and height were recorded to the nearest $0.1 \mathrm{~kg}$ and $0.1 \mathrm{~cm}$, respectively. Body mass index (BMI) was calculated using the formula: body weight (kg)/ height (m) ${ }^{2}$ and accordingly, participants were classified into categories based on the National Heart, Lung and Blood Institute recommendations: underweight ( $\left.<18.5 \mathrm{~kg} / \mathrm{m}^{2}\right)$, normal weight $\left(18.5-24.9 \mathrm{~kg} / \mathrm{m}^{2}\right)$; overweight $\left(25-29.9 \mathrm{~kg} / \mathrm{m}^{2}\right)$, and obese $\left(>30 \mathrm{~kg} / \mathrm{m}^{2}\right)$.

Waist circumference (WC) was measured at the umbilicus and hip circumference (HC) was measured at the broadest circumference below the waist. Both of these measurements were done using a flexible but not stretchable measuring tape in three 
replicates to ensure reproducibility. The average of the three values was used to calculate waist-to-hip ratio (WHR) by dividing WC by HC. Body composition was measured using bioelectrical impedance (BIA), to determine \% lean (fat-free, \%FFM) and fat mass (\%FM).

\section{Blood Pressure and Heart Rate}

Systolic and diastolic blood pressure and heart rate were measured three times for each participant after sitting down on a chair for 10 minutes using OMRON Automatic blood pressure monitor Sem1.

\section{Dual Task Physical Performance Test}

Participants were asked to perform the following tasks in a random order, determined from a random order table.

- Usual walking (single gait task)

- Counting backward from 50 by one while standing (single cognitive task) $)^{78}$

- Counting backward from 50 by one while walking (dual task)

The spatiotemporal gait variables were measured using the GAITRite system that includes a 6 meter-long and 64 centimeter-wide walkway mat with embedded sensors. Participants were asked to wear comfortable, low-heeled shoes. Before each trial, participants' leg length was measured using a measuring tape from the trochanter of the femur to the medial malleolus. Participants were given a demonstration on how to walk on the walkway from the start to the finish line that were located 2 meters before and after the walkway to account for acceleration and deceleration. Participants were given 
standardized instructions for practice and data collection trials in which they were asked to walk only (single gait task) or walk while dual tasking without prioritizing either task on the GAITRite walkway at their preferred gait speed. Participants were required to perform three trials per data recording session. The first ten gait cycles of the three trials were used for each task to determine spatial-temporal gait parameters, which were normalized by individual leg length. The spatiotemporal variable of interest for this study was gait speed (distance walked divided by time to walk; $\mathrm{cm} / \mathrm{s}$ ). ${ }^{113}$

For the secondary single cognitive task only and the dual task, the participants were asked to count backward out loud from 50 by one until reaching 30 . The number of enumerated figures was assessed using a voice recorder while single and dual tasking, and defined as the number achieved at the completion of the walking time for the dual task. For both single and dual tasks, the numbers of figures were defined as those spoken during the time required for the completion of the dual task ${ }^{81}$ For instance, if the participant took 30 seconds to complete the dual task, the number of figures enumerated for the single task was counted for the first 30 seconds. The average of the three trials was used for analysis. The difference in dual and single task variables was calculated by subtracting the single task value from the dual task value for gait velocity and counting rate (dual task minus single task equals the difference).

\section{$\underline{\text { Statistical Analysis }}$}

Statistical analyses were performed on 97 participants. Data were analyzed using frequencies, percentages, ranges, means, and standard deviations. Variables were checked for non-normality, and if necessary, they were transformed to achieve a normal 
distribution. Spearman's correlations were used to estimate associations between vitamin D status (insufficient $=0$ and sufficient $=1$ ) and dual task physical performance variables. Paired t-tests were used to compare dual task (dual task gait speed and dual task counting rate) and single task variables (single task gait speed and single task counting rate) within the entire group, and in subgroup analysis, considering separately the sufficient and the insufficient groups. Independent t-tests were used to compare vitamin D insufficient $(25(\mathrm{OH}) \mathrm{D}<30 \mathrm{ng} / \mathrm{ml})$ and sufficient $(\geq 30 \mathrm{ng} / \mathrm{ml})$ in dual task, single task, and the difference in dual and single task variables. Repeated measures ANOVAs were used to compare the difference in dual and single task gait velocities and counting rates between vitamin $\mathrm{D}$ status categories. Logistic regressions were used to examine the relationship of vitamin D insufficiency with dual and single task gait speed and counting rate, controlling for covariates. The significance level was set at $\alpha=0.05$, and statistical analyses were performed using SPSS 21.

\section{Results}

A total of 97 participants aged 55 years or older were included in the analysis. The mean \pm SD age of the study population was $63.06 \pm 6.48$, and $45.4 \%$ were male. In this population, $44.3 \%$ were Hispanic, 35.1\% white Caucasian, and $15.5 \%$ African American (Table 1). The mean \pm SD BMI was $27.09 \pm 5.27$ and the number of diseases/disorders reported were $4.70 \pm 3.03$. On average, $75.3 \%$ of participants reported using a mean \pm SD of $2.24 \pm 2.20$ prescription medications, and $46.4 \%$ reported a history of vitamin/mineral supplement use, 79.4\% consumed coffee, $42.3 \%$ drank alcohol, and 
$11.3 \%$ were smokers. Fifty-one participants reported a history of injuries and 14 reported experiencing a fall in the past 12 months.

The mean \pm SD vitamin D level was $30.73 \pm 8.73 \mathrm{ng} / \mathrm{ml}$, ranging from 10.00 to $59.80 \mathrm{ng} / \mathrm{ml}$. The mean \pm SD dual task and single task gait velocities were $132.59 \pm$ 36.61 and $154.29 \pm 29.96 \mathrm{~cm} / \mathrm{s}$, respectively. The mean \pm SD dual task and single task counting rates were $1.24 \pm 0.29$ and $1.21 \pm 0.28$ figures/s, respectively (Table 1 ).

Spearman correlations were used to assess the relationship between vitamin D status and physical performance (Table 2). There was a significant and positive correlation between vitamin D insufficiency and slower single task counting rate $(\mathrm{r}=0.278, P=0.006)$ and dual task counting rate $(\mathrm{r}=0.258, P<0.011)$. Those who were vitamin D insufficient counted fewer figures per second in both tasks (Table 3). Vitamin D status was not significantly correlated with gait velocity during either dual or single task.

Paired t-tests, however, showed a significant difference in dual and single task gait velocity within the entire group and by each vitamin D status group (Figure 1, Table 3, all $P<0.001)$. Participants had slower gait speeds when dual tasking compared to single tasking, indicating interference of the cognitive task on gait task when dual tasking. Independent t-tests showed no significant differences between vitamin D insufficient and sufficient groups in the dual task and single task gait velocities ( $P=0.896$ and $P=0.934$, respectively). Paired t-tests showed no significant difference in dual and single task counting rate within the entire group of participants $(P=0.128)$ and those in the vitamin $\mathrm{D}$ insufficient $(P=0.473)$ and vitamin $\mathrm{D}$ sufficient categories $(P=0.151)$ (Figure 2, Table 3). Independent t-tests showed significant differences between vitamin D insufficient and 
sufficient groups in dual task and single task counting rates ( $P=0.018$ and $P=0.028$, respectively) (Table 3). Vitamin D insufficient participants counted significantly fewer figures per second when single and dual tasking as compared to vitamin D sufficient, thus having worse cognitive task performance.

One-way repeated measures ANOVA were conducted with the within-subject factor being either gait velocity difference (defined as the difference between dual and single task gait velocity) or counting rate difference (defined as the difference between dual and single task counting rate); and the between-subject factor being vitamin D status categories. The results for the ANOVAs indicated that velocity and counting rates were not significantly different by vitamin D status (Wilk’s Lambda =0.999; F $(1,95)=.11$, $P=.740)$ (Wilk’s Lambda $=.999, \mathrm{~F}(1,95)=.13, P=.718)$.

Logistic regression models were built to examine the relationship between vitamin D deficiency and gait velocity and counting rate difference in dual and single task when controlling for covariates (Table 4). Vitamin D status was not significantly associated with dual task physical performance (defined as the difference in dual and single task) in gait velocity (OR=1.00, 95\% CI: $0.98 ; 1.02, P=0.772)$ and counting rate (OR=1.684, 95\% CI: 0.15; 19.57, $P=0.677$ ), when controlling for variables that had significant correlations with or have been shown in previous research to affect either the independent and/or dependent variables like age, gender, marital status, education, employment, income, falls, number of diseases, number of injuries, prescription medications, vitamin/mineral supplement use, coffee consumption, alcohol use, smoking, weight, BMI, depressive symptoms, fear of falling, physical activity, physical performance test. 


\section{Discussion}

Vitamin D deficiency in the elderly has been linked to factors associated with disability, including cognitive impairment, poor physical performance, and increased risk of falls and fractures. ${ }^{5,29,43,83,114-116}$ Older adults are at higher risk of vitamin D deficiency due to a complex interplay between aging and the factors that affect vitamin D status such as dietary intake, skin synthesis, and bioavailability. ${ }^{62,117}$ Vitamin D deficiency has received much attention as a risk factor for falls because of its association with gait impairment (slower gait speed), global cognitive deficits, and compromised executive function. ${ }^{5,43,48,114,118}$ Nonetheless, studies that investigate the relationship between vitamin D status, gait, and cognition have looked at these factors independently. In our study a dual task physical performance test was used to examine the relationship between vitamin D status and cognition in the context of mobility, by evaluating the competition for information processing capacity between gait stability during the primary automatic task (i.e., walking) and cognitive performance during the completion of the secondary cognitive task (i.e., counting backwards from 50 by 1 ).

Dual tasking usually results in worse performance in either one or both tasks when compared to the performance of each task individually. ${ }^{88}$ In our study, we found a marked deterioration of the automatic primary motor task during dual tasking, and not the secondary cognitive task when compared to single tasking. Participants had a significantly slower gait speed when walking while counting, compared to walking only. However, counting rate was not significantly different between dual and single tasks. As shown in previous studies that compared individual's performance during dual tasking with their performance of each task individually (i.e., single vs. dual task), our results 
showed that performing a secondary cognitive task like counting backwards from 50 to one, while walking, had a destabilizing effect on gait as shown by decreased gait speed. ${ }^{76,77,80,83,119}$ This can be explained by participants prioritizing the cognitive task when dividing their limited information processing capacity during dual tasking, therefore, sacrificing gait stability by decreasing gait speed to compensate for the increased need for higher cognitive processing demanded by the secondary cognitive task.

When examining the relationship between vitamin D status and dual task physical performance, we did not find a significant association. Our results supported our hypothesis that those who were vitamin D insufficient were more likely to have cognitive deficits that would limit their information processing capacity when dual tasking. Slower dual task gait speeds and/or counting rates were compared to single task, which resulted in larger differences in both variables between tasks. Surprisingly, gait velocity and counting rate were not different for either single or dual task between the vitamin D insufficient and sufficient group. Thus, those who were vitamin D insufficient did not perform worse in dual or single task physical performance tests compared to those who were sufficient. Of importance, in subgroup analysis, when the participants in each of the vitamin D groups were considered independently, in each group those performing dual tasks seem to prioritize the cognitive over the walking task for the use of resources, since counting rate was not significantly different in counting rate, but a significant difference in gait speed compared to single tasks (Figure 1).

Even though counting rate was not significantly different between dual task and single cognitive task between vitamin D groups, we did find a significant weak 
correlation between vitamin D insufficiency and single and dual task counting rate (Table 3). An interesting finding of our study was that single and dual task counting rates were significantly lower in the vitamin D insufficient group. Those who were vitamin D insufficient had worse cognitive performance, since they counted significantly fewer figures per second compared to the vitamin D sufficient group when performing either single or dual tasks. Counting backward is a mental tracking task, meaning it is task that requires holding information while performing a mental process. Thus, mental tracking tasks are typically used to examine information processing speed, working memory, and sustained attention, all of which are part of executive function. ${ }^{83}$ Executive function refers to the cognitive processes that orchestrate goal-directed behavior and decisionmaking, like problem-solving, initiating and maintaining tasks, working memory (holding multiple pieces of transitory information and manipulating it), abstract reasoning, and dividing attention. ${ }^{22,120}$ Counting backward from 50 by 1 is a mental tracking task that can assess to some extent executive functioning; therefore, our results support previous research that found an association between vitamin $\mathrm{D}$ status and executive dysfunction. Several studies have found a significant positive correlation between vitamin D and scores of cognitive tests that assess executive function like the Digit Symbol Substitution Test ${ }^{56,70,121}$, Trail Making Test $A^{56,61,65}$, Trail Making Test $\mathrm{B}^{56,61,64-66,73}$, Block Design ${ }^{56}$, and Verbal Fluency. ${ }^{56,65}$

Executive dysfunction is common among elderly ${ }^{15-17}$, and it has been associated with increased fall risk and gait impairments. ${ }^{18-28}$ Several studies have found a significant positive association between vitamin D deficiency and slower gait speed when walking (i.e., single tasking). ${ }^{122-126}$ Although we found worse executive function in vitamin D 
insufficient subjects, we did not find a significant correlation between single gait velocity and vitamin $\mathrm{D}$ levels nor a difference in single gait velocity between vitamin $\mathrm{D}$ insufficient and sufficient groups. Executive dysfunction is sometimes present even in the absence of global cognitive impairment, and it may be present in the older adult before gait impairments are evident. ${ }^{15,18,22}$ This can explain why we observed an association between vitamin $\mathrm{D}$ deficiency and worse performance on the cognitive task and not the gait tasks. Thus, in this healthy older adult population executive function may not be diminished enough to affect gait significantly and may be more sensitive to vitamin D deficiencies than mobility limitations.

This study had several limitations. First of all, cross-sectional studies are descriptive in nature and even though they can establish association among factors, they do not prove cause and effect. Second, this study may suffer from selection bias. Age could be a possible explanation for the lack of association between gait velocity and vitamin D deficiency observed in our study. We included younger older adult participants ( $>55$ years of age) to have a wider age range for recruitment purposes; therefore, our participants were younger than what is considered "old age," with $36 \%$ and $63.8 \%$ of our participants being under the age of 60 and 65 , respectively. This added heterogeneity to our study, and since gait instability increases with age, it might be possible that our population was too young to exhibit mobility limitations. Furthermore, most studies evaluating vitamin D deficiency and physical and cognitive performance in the elderly have been done in adults either above the age of 60,65 , or 70 , making our results less comparable. 
Moreover, the participants in this study were not only younger, but also mostly healthy, since the exclusion criteria for the parent study included current diagnoses of numerous diseases/conditions that affect vitamin D metabolism/absorption and mobility, medications that disturb vitamin D metabolism, and vitamin D supplement use. Thus, this population might not be representative of the older adult population in Miami-Dade, but instead were healthy older adults who volunteered to participate and met inclusion criteria. Thus, the results of this study are not generalizable to the general Miami-Dade older adult population.

The small sample size could have also affected the results of this study. Using an independent t-test with 5\% significance and $80 \%$ power and assuming an allocation ratio of $40 \%$, based on published prevalence of vitamin D deficiency, and an effect size of 0.5 for the change in gait speed between dual and single task, the total sample size was 134 (expected 54 vitamin D deficient and 80 vitamin D sufficient). However, due to limitations of time and resources, we were only able to recruit 101 participants of which 97 were included in the analysis, reducing the power to detect significant differences in this study. Using an independent t-test with 5\% significance, the actual sample size for each group and the mean $+/$ - SD of single and dual task gait velocity and the difference between dual and single task gait velocity to calculate effect size, we calculated power to be $5 \%$. With the sample size in this study were did not have enough power to detect significant differences between vitamin D status groups. In addition, our sample had a significantly lower prevalence of vitamin D deficiency, with $10.3 \%$ of our population having 25(OH)D $<20 \mathrm{ng} / \mathrm{ml}$ and 36.1\% having between (20-30 ng/ml). Previous studies that have evaluated the relationship between vitamin D and physical performance have 
included participants with lower 25(OH)D levels, showing a relationship between vitamin D deficiency and motor capacity. This, together with the younger age group, might be why we did not find a significant association between vitamin D insufficiency and gait speed.

An additional limitation of this study was the low adjusted $\mathrm{R}^{2}$, which assesses the percentage of the variation of the dependent variable that is explained by the linear regression model. Even though it is indicative of how well the linear model fits the observations, it doesn’t provide a hypothesis test for this relationship. A low adjusted $\mathrm{R}^{2}$ means that the model is not precise. However, if the adjusted $\mathrm{R}^{2}$ is low but the predictors are statistically significant, conclusions can still be drawn about the relationship between the dependent variable and predictors. Thus, highly variable data, as indicated by low adjusted $\mathrm{R}^{2}$, can still have a significant trend that indicates the dependent variable is affected by the predictors.

Another weakness of this study is related to dual task physical performance tests. Overall, many studies show the importance of dual task effects on gait performance in older adults and its usefulness in the prediction of falls. Even though previous metaanalyses and systematic reviews concluded that gait control places demand on cognitive systems and this may increase the risk for falls in older adults, researchers recognize that methodological variations complicate the interpretation of data and challenge deriving concrete conclusions from the literature available. Therefore, the different results on dual task-related gait changes and their relationship with falls elicit some concern about the usefulness of this technique for fall prediction. The main concerns are the lack of methodological standardization, as different primary motor tasks and cognitive secondary 
tasks with diverse levels of complexity and different gait parameters, are evaluated during dual task analysis. Furthermore, even though most studies had their participants perform the single task alone, not all studies evaluated the difference in performance between a single and dual task in one or both tasks (i.e., change in performance). ${ }^{76,83}$ Some studies only compared dual task performance between groups. This raises the question of whether it is the difference in performance from single to dual tasking or the difference in dual task performance only, which is relevant for fall prediction.

To better understand the dual task-related changes and gait control mechanisms, it is important to standardize methodologies and improve their ecological validity..$^{80}$ One of the criticisms of the dual task methodology used in research studies is that it does not resemble the everyday activities of the participants like street crossing; therefore, not having ecological validity. It is difficult to analyze quantitatively, however, a nonstandardized cognitive task such as engaging in a conversation or street crossing, so having a well-defined mental tracking task improves the reliability, validity, and comparability of results. ${ }^{80}$ Thus from a review of literature we found that changes in speed while performing a simple gait task, like walking in a straight line, and a simple mental tracking secondary task, like counting backwards from 50 by 1 , using the speed analysis method or even better, a spatiotemporal assessment system like the GAITRite, yielded enough sensitivity and predictive value for falls.

Moreover, studies that use dual task physical performance tests found that decrease in speed during dual tasking was consistently found to predict falls in elderly. Previous studies have used dual task testing using gait velocity as the primary outcome variable because it is a highly reproducible and reliable measurement of mobility in older 
adults. ${ }^{2,19,127}$ Experts suggest that changes in other gait parameters, however, may be more relevant for assessing fall risk besides speed. ${ }^{118}$ For instance, stride time and stride length variability due to inconsistent stepping patterns and reduced postural control are common in many older adults whether or not they have any pathology present. ${ }^{128}$ Therefore, these variables are considered very good markers of gait control because they reflect regularity of the walking rhythm ${ }^{129-132}$ and have also been identified as risk factors for falls in prospective studies. Hence, using a different spatiotemporal variable to assess gait rather than gait speed may have yielded different results in our study.

\section{Conclusions}

When dual tasking, this healthy older adult sample prioritized the secondary cognitive task at the expense of compromising their motor capacity. Despite of these findings, we did not find a significant association between vitamin D status and the change in performance in cognitive and gait tasks when dual vs. single tasking; thus vitamin D insufficient participants did not have worse dual task performance. Motor functioning was not significantly different between vitamin D categories, but performance on the cognitive task was significantly lower in the vitamin D insufficient group. Since counting backward is a mental tracking task, which is a component of executive function, our results support a relationship between vitamin D insufficiency and impaired executive function. Executive dysfunction has been previously associated with fall risks in the elderly, and it could be a possible mediator between vitamin $\mathrm{D}$ and falls. ${ }^{73}$ Our data suggest that cognition may play a significant role in vitamin D's influence on falls, while motor function may play a lesser role. ${ }^{72}$ 
Due to the nature of this cross-sectional study, we cannot conclude that vitamin D deficiency is a cause of executive dysfunction that leads to decreased performance in mental tracking tasks. Future randomized control studies, with sufficient resources, are warranted to evaluate the change in dual task physical performance in vitamin D insufficient older adults supplemented with vitamin D and to examine the cause-effect relationship. 


\begin{tabular}{|l|c|}
\hline \multicolumn{2}{|c|}{ Table 1: Characteristics of Participants (n=97) } \\
\hline Age (years) (Mean \pm SD) & $63.1 \pm 6.5$ \\
\hline Age categories: (N (\%)) & $35(36.1)$ \\
55-60 years & $27(27.8)$ \\
60-65 years & $21(21.6)$ \\
65-70 years & $14(14.4)$ \\
\hline 70 years & $44(45.4)$ \\
\hline Male gender (N (\%)) & \\
\hline Ethnicity: (N (\%)) & $43(44.3)$ \\
Hispanic & $34(35.1)$ \\
White Caucasian & $15(15.5)$ \\
African American & $5(5.2)$ \\
\hline Other & $30.7 \pm 8.7$ \\
\hline Vitamin D levels (ng/ml) (Mean \pm SD) & $132.6 \pm 36.6$ \\
\hline Dual task gait velocity (cm/s) (Mean \pm SD) & $154.4 \pm 30.0$ \\
\hline Single task gait velocity (cm/s) (Mean \pm SD) & $1.2 \pm 0.3$ \\
\hline Dual task counting rate (figures/sec) (Mean \pm SD) & $1.21 \pm 0.3$ \\
\hline Single task counting rate (figures/sec) (Mean \pm SD) & $27.1 \pm 5.3$ \\
\hline BMI (kg/m²) (Mean \pm SD) & $30.9 \pm 9.0$ \\
\hline \%FM (Mean \pm SD) & $132.6 \pm 22.0$ \\
\hline SBP (mmHg) (Mean \pm SD) & $76.0 \pm 14.5$ \\
\hline DBP (mmHg) (Mean \pm SD) & $70.4 \pm 11.8$ \\
\hline HR (bpm) (Mean \pm SD) & $7.2 \pm 7.6$ \\
\hline Depressive symptoms (BDI Score) (Mean \pm SD) & $20.0 \pm 5.9$ \\
\hline Fear of falling (FES-I score) (Mean \pm SD) & $51(52.6)$ \\
\hline Participants reporting injuries (N (\%)) & $14(14.4)$ \\
\hline Participants reporting falls in last 12 months (N (\%)) & $4.7 \pm 3.0$ \\
\hline Number of diseases and conditions reported (Mean \pm SD) & $73(75.3)$ \\
\hline Participants using prescription medications (N (\%)) & $2.2 \pm 2.2$ \\
\hline Number of prescription medications used (Mean \pm SD) & $45(46.4)$ \\
\hline Participants reporting vitamins/minerals supplement use (N & $4283 \pm 4318$ \\
(\%)) & \\
\hline Total physical activity (IPAQ score) (Mean \pm SD) & \\
\hline SD: Standard Deviation; BMI: Body Mass Index; FM: Fat Mass; SBP: Systolic Blood Pressure; DBP: Diastolic \\
Blood Pressure; HR: Heart Rate; bpm: beats per minute; IPAQ: International Physical Activity Questionnaire; BDI: \\
Beck Depression Inventory; FES-I: Falls Efficacy Scale International & \\
\hline
\end{tabular}




\begin{tabular}{|c|c|c|}
\hline & $\begin{array}{c}\text { Spearman Correlation } \\
\text { Coefficient }\end{array}$ & $P$-value \\
\hline Dual task gait velocity $(\mathrm{cm} / \mathrm{s})$ & -0.003 & 0.977 \\
\hline Single task gait velocity $(\mathrm{cm} / \mathrm{s})$ & -0.040 & 0.698 \\
\hline $\begin{array}{l}\text { Dual and single task difference gait velocity } \\
(\mathrm{cm} / \mathrm{s})^{\mathrm{s}}\end{array}$ & -0.051 & 0.623 \\
\hline Dual task counting rate (figures/sec) & 0.258 & 0.011 \\
\hline Single task counting rate (figures/sec) & 0.278 & 0.006 \\
\hline $\begin{array}{l}\text { Dual and single task difference counting rate } \\
\text { (figures/sec) }^{\text {E }}\end{array}$ & -0.026 & 0.802 \\
\hline
\end{tabular}

Spearman Correlations between vitamin D status groups (Vitamin D insufficient = 0; Vitamin D sufficient $=1$ ) and continuous/categorical variables. ${ }^{\mathrm{E}}$ Difference in dual and single task variables is calculating by subtracting single task value from dual task value (dual task - single task $=$ difference). 


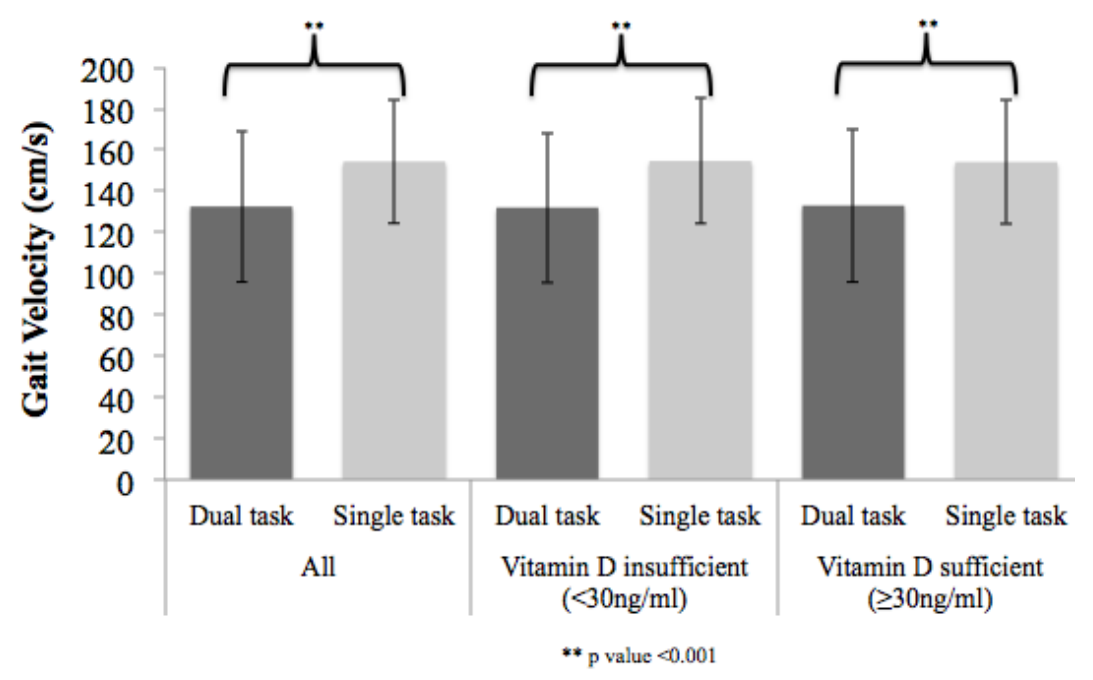

Figure 1: Comparison of Dual and Single Task Gait Velocity Within and Between Vitamin D Insufficient and Sufficient Participants.

Legend: Gait velocity is significantly higher for the entire group and the vitamin D status subgroups for single task compared to dual tasks. 


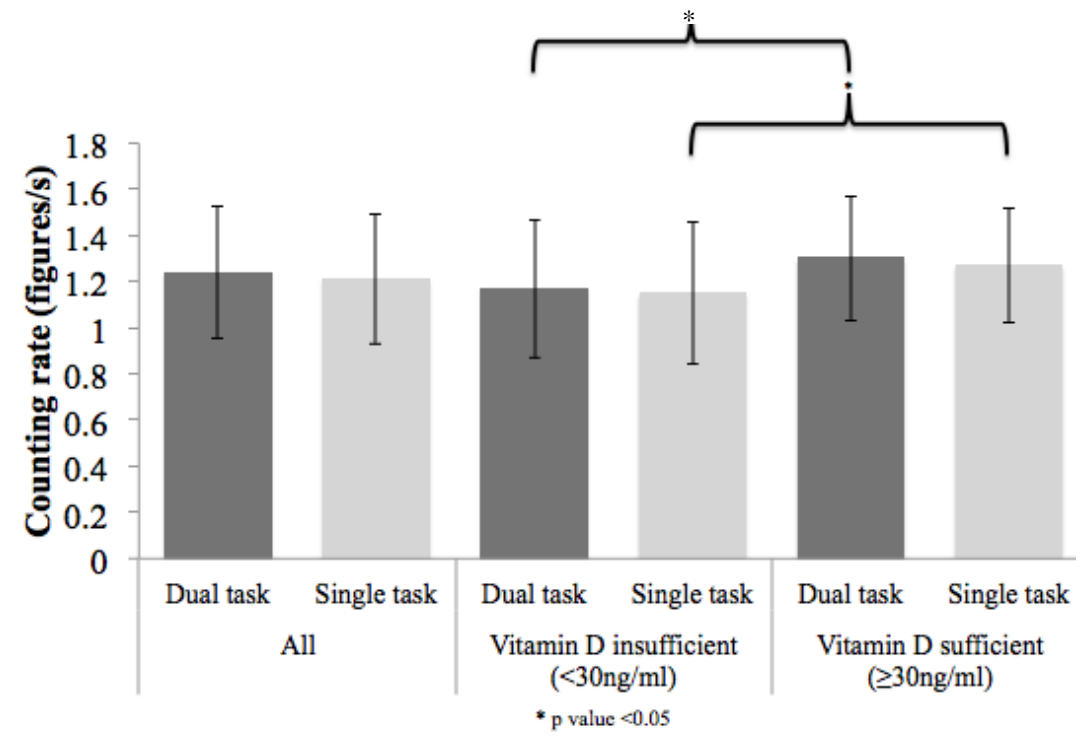

Figure 2: Comparison of Dual and Single Task Counting Rate Within and Between Vitamin D Insufficient and Sufficient Participants.

Legend: Counting rate is significantly lower in the vitamin D insufficient group compared to the sufficient group while performing dual or single task. 


\begin{tabular}{|c|c|c|c|c|c|c|}
\hline & & $\begin{array}{c}\text { Total } \\
(n=97)\end{array}$ & $\begin{array}{c}\text { Vitamin D } \\
\text { insufficient }<30 \\
\text { ng/ml } \\
(n=45)\end{array}$ & $\begin{array}{l}\text { Vitamin D sufficient } \\
\qquad 30 \mathrm{ng} / \mathrm{ml} \\
(\mathrm{n}=52)\end{array}$ & $\begin{array}{c}\text { MD between } \\
\text { vitamin D status } \\
\text { groups }\end{array}$ & $\begin{array}{c}P \text { - } \\
\text { value }^{£}\end{array}$ \\
\hline \multirow{4}{*}{$\begin{array}{c}\text { Velocity } \\
(\mathbf{c m} / \mathbf{s}) \\
(\text { Mean } \pm \text { SD) }\end{array}$} & Dual task & $132.6 \pm 36.6$ & $132.1 \pm 36.4$ & $133.1 \pm 37.1$ & -0.99 & 0.896 \\
\hline & Single task & $154.4 \pm 30.0$ & $154.7 \pm 30.3$ & $154.2 \pm 30.0$ & 0.51 & 0.934 \\
\hline & $\begin{array}{l}\text { Dual and } \\
\text { single task } \\
\text { difference }\end{array}$ & $-21.8 \pm 21.9$ & $-22.6 \pm 26.1$ & $-21.1 \pm 17.8$ & -1.5 & 0.740 \\
\hline & $\begin{array}{l}\text { Pair sample } \\
P \text {-value }\end{array}$ & $<0.001$ & $<0.001$ & $<0.001$ & & \\
\hline \multirow{4}{*}{$\begin{array}{c}\text { Counting } \\
\text { rate } \\
\text { (figures/ sec) } \\
\text { (Mean } \pm \mathrm{SD} \text { ) }\end{array}$} & Dual task & $1.2 \pm 0.3$ & $1.17 \pm 0.3$ & $1.3 \pm 0.27$ & -0.14 & 0.018 \\
\hline & Single task & $1.2 \pm 0.3$ & $1.15 \pm 0.31$ & $1.27 \pm 0.25$ & -0.06 & 0.028 \\
\hline & $\begin{array}{l}\text { Dual and } \\
\text { single task } \\
\text { difference }\end{array}$ & $0.03 \pm 0.19$ & $0.02 \pm 0.20$ & $0.04 \pm 0.18$ & -0.01 & 0.718 \\
\hline & $\begin{array}{l}\text { Pair sample } \\
\text { P-value }^{¥}\end{array}$ & 0.128 & 0.473 & 0.151 & & \\
\hline
\end{tabular}

${ }^{\text {q}}$ Paired sample t-test comparing dual and single task within total group and each vitamin D category; ${ }^{\complement}$ Independent t-test comparing vitamin D status categories. SD: Standard Deviation; MD: Mean Difference. 
Table 4: The Relationship Between Vitamin D Status and Dual to Single Task Difference in Gait Velocity and Counting Rate in Multiple Logistic Regressions

\begin{tabular}{|l|c|c|c|}
\hline & $\boldsymbol{\beta}$ (S.E.) & OR (95\% CI) & P-value \\
\hline $\begin{array}{l}\text { Dual to single task difference in } \\
\text { gait velocity }\end{array}$ & $0.00(0.010)$ & $1.003(0.98,1.02)$ & 0.772 \\
\hline $\begin{array}{l}\text { Dual to single ask difference in } \\
\text { counting rate. }\end{array}$ & $0.52(1.25)$ & $1.684(0.15,19.57)$ & 0.677 \\
\hline
\end{tabular}

Dependent: Vitamin D insufficient $<30 \mathrm{ng} / \mathrm{ml}=0$; Vitamin D sufficient $\geq 30=1$. Adjusted for: age, gender, marital status, education, employment, income, falls, number of diseases, number of injuries, prescription medications, vitamin/mineral supplement use, coffee consumption, alcohol use, smoking, weight, BMI, depressive symptoms, fear of falling, physical activity, physical performance test. $\boldsymbol{\beta}$ : Beta Coefficient; SE: Standard Error; OR: Odds Ratio; CI: Confidence Interval. 


\section{References}

1. Federal Interagency Forum on Aging-Related Statistics. Older americans 2004: Key indicators of well-being. AgingStats.gov Web site. http://www.agingstats.gov/Main_Site/Data/2004_Documents/entire_report.pdf. Updated 2004. Accessed August 31, 2015.

2. Montero-Odasso M, Casas A, Hansen KT, et al. Quantitative gait analysis under dualtask in older people with mild cognitive impairment: A reliability study. J Neuroeng Rehabil. 2009;6(1):35-40.

3. Pieterse AJ, Luttikhold TB, de Laat K, Bloem BR, van Engelen BG, Munneke M. Falls in patients with neuromuscular disorders. J Neurol Sci. 2006;251(1-2):87-90.

4. Centers for Disease Control and Prevention. Self-reported falls and fall-related injuires among persons aged $>65$ years-united states, 2006. CDC.gov Web

site. http://www.cdc.gov/mmwr/preview/mmwrhtml/mm5709a1.htm. Updated 2008. Accessed August 31, 2015.

5. Kalyani RR, Stein B, Valiyil R, Manno R, Maynard JW, Crews DC. Vitamin D treatment for the prevention of falls in older adults: Systematic review and meta-analysis. J Am Geriatr Soc. 2010;58(7):1299-1310.

6. Bridenbaugh SA, Kressig RW. Laboratory review: The role of gait analysis in seniors' mobility and fall prevention. Gerontology. 2011;57(3):256-264.

7. Winter DA, Patla AE, Frank JS, Walt SE. Biomechanical walking pattern changes in the fit and healthy elderly. Phys Ther. 1990;70(6):340-347.

8. Menz HB, Lord SR, Fitzpatrick RC. Age-related differences in walking stability. Age Ageing. 2003;32(2):137-142.

9. Judge JO, Davis RB, Ounpuu S. Step length reductions in advanced age: The role of ankle and hip kinetics. J Gerontol A Biol Sci Med Sci. 1996;51(6):303-312.

10. Judge JO, Ounpuu S, Davis RB. Effects of age on the biomechanics and physiology of gait. Clin Geriatr Med. 1996;12(4):659-678.

11. Krebs DE, Jette AM, Assmann SF. Moderate exercise improves gait stability in disabled elders. Arch Phys Med Rehabil. 1998;79(12):1489-1495.

12. Barak Y, Wagenaar RC, Holt KG. Gait characteristics of elderly people with a history of falls: A dynamic approach. Phys Ther. 2006;86(11):1501-1510. 
13. Beurskens R, Bock O. Age-related deficits of dual-task walking: A review. Neural Plast. 2012;2012(131608):1-9.

14. Lacour M, Bernard-Demanze L, Dumitrescu M. Posture control, aging, and attention resources: Models and posture-analysis methods. Neurophysiol Clin. 2008;38(6):411421.

15. Herman T, Mirelman A, Giladi N, Schweiger A, Hausdorff JM. Executive control deficits as a prodrome to falls in healthy older adults: A prospective study linking thinking, walking, and falling. J Gerontol A Biol Sci Med Sci. 2010;65(10):1086-1092.

16. Prakash RS, Erickson KI, Colcombe SJ, Kim JS, Voss MW, Kramer AF. Age-related differences in the involvement of the prefrontal cortex in attentional control. Brain Cogn. 2009;71(3):328-335.

17. Royall DR, Palmer R, Chiodo LK, Polk MJ. Declining executive control in normal aging predicts change in functional status: The freedom house study. J Am Geriatr Soc. 2004;52(3):346-352.

18. Ijmker T, Lamoth CJ. Gait and cognition: The relationship between gait stability and variability with executive function in persons with and without dementia. Gait Posture. 2012;35(1):126-130.

19. Springer S, Giladi N, Peretz C, Yogev G, Simon ES, Hausdorff JM. Dual-tasking effects on gait variability: The role of aging, falls, and executive function. Mov Disord. 2006;21(7):950-957.

20. van Iersel MB, Kessels RP, Bloem BR, Verbeek AL, Olde Rikkert MG. Executive functions are associated with gait and balance in community-living elderly people. $J$ Gerontol A Biol Sci Med Sci. 2008;63(12):1344-1349.

21. Yogev-Seligmann G, Hausdorff JM, Giladi N. The role of executive function and attention in gait. Mov Disord. 2008;23(3):329-342.

22. Kearney FC, Harwood RH, Gladman JR, Lincoln N, Masud T. The relationship between executive function and falls and gait abnormalities in older adults: A systematic review. Dement Geriatr Cogn Disord. 2013;36(1-2):20-35.

23. Hausdorff JM, Doniger GM, Springer S, Yogev G, Simon ES, Giladi N. A common cognitive profile in elderly fallers and in patients with parkinson's disease: The prominence of impaired executive function and attention. Exp Aging Res. 2006;32(4):411-429. 
24. Holtzer R, Friedman R, Lipton RB, Katz M, Xue X, Verghese J. The relationship between specific cognitive functions and falls in aging. Neuropsychology. 2007;21(5):540-548.

25. Atkinson HH, Rosano C, Simonsick EM, et al. Cognitive function, gait speed decline, and comorbidities: The health, aging and body composition study. J Gerontol A Biol Sci Med Sci. 2007;62(8):844-850.

26. Persad CC, Jones JL, Ashton-Miller JA, Alexander NB, Giordani B. Executive function and gait in older adults with cognitive impairment. J Gerontol A Biol Sci Med Sci. 2008;63(12):1350-1355.

27. Alexander NB, Hausdorff JM. Guest editorial: Linking thinking, walking, and falling. J Gerontol A Biol Sci Med Sci. 2008;63(12):1325-1328.

28. Allali G, Assal F, Kressig RW, Dubost V, Herrmann FR, Beauchet O. Impact of impaired executive function on gait stability. Dement Geriatr Cogn Disord. 2008;26(4):364-369.

29. Muir SW, Montero-Odasso M. Effect of vitamin D supplementation on muscle strength, gait and balance in older adults: A systematic review and meta-analysis. $J$ Am Geriatr Soc. 2011;59(12):2291-2300.

30. Bischoff-Ferrari HA, Giovannucci E, Willett WC, Dietrich T, Dawson-Hughes B. Estimation of optimal serum concentrations of 25-hydroxyvitamin D for multiple health outcomes. Am J Clin Nutr. 2006;84(1):18-28.

31. Dukas L, Staehelin HB, Schacht E, Bischoff HA. Better functional mobility in community-dwelling elderly is related to D-hormone serum levels and to daily calcium intake. J Nutr Health Aging. 2005;9(5):347-351.

32. Gallagher JC. The effects of calcitriol on falls and fractures and physical performance tests. J Steroid Biochem Mol Biol. 2004;89-90(1-5):497-501.

33. Houston DK, Cesari M, Ferrucci L, et al. Association between vitamin D status and physical performance: The InCHIANTI study. J Gerontol A Biol Sci Med Sci. 2007;62(4):440-446.

34. Semba RD, Garrett E, Johnson BA, Guralnik JM, Fried LP. Vitamin D deficiency among older women with and without disability. Am J Clin Nutr. 2000;72(6):1529-1534.

35. Zamboni M, Zoico E, Tosoni P, et al. Relation between vitamin D, physical performance, and disability in elderly persons. J Gerontol A Biol Sci Med Sci. 2002;57(1):7-11. 
36. Wicherts IS, van Schoor NM, Boeke AJ, et al. Vitamin D status predicts physical performance and its decline in older persons. J Clin Endocrinol Metab. 2007;92(6):20582065.

37. Toffanello ED, Perissinotto E, Sergi G, et al. Vitamin D and physical performance in elderly subjects: The pro.V.A study. PLoS One. 2012;7(4):1-9.

38. Ross AC, Manson JE, Abrams SA, et al. The 2011 report on dietary reference intakes for calcium and vitamin D from the institute of medicine: What clinicians need to know. J Clin Endocrinol Metab. 2011;96(1):53-58.

39. Robertson MC, Gillespie LD. Fall prevention in community-dwelling older adults. JAMA. 2013;309(13):1406-1407.

40. Bischoff-Ferrari HA, Dawson-Hughes B, Staehelin HB, et al. Fall prevention with supplemental and active forms of vitamin D: A meta-analysis of randomised controlled trials. BMJ. 2009;339(3692):1-11.

41. Bischoff-Ferrari HA, Dawson-Hughes B, Willett WC, et al. Effect of vitamin D on falls: A meta-analysis. JAMA. 2004;291(16):1999-2006.

42. Jackson C, Gaugris S, Sen SS, Hosking D. The effect of cholecalciferol (vitamin D3) on the risk of fall and fracture: A meta-analysis. QJM. 2007;100(4):185-192.

43. Murad MH, Elamin KB, Abu Elnour NO, et al. Clinical review: The effect of vitamin D on falls: A systematic review and meta-analysis. J Clin Endocrinol Metab. 2011;96(10):2997-3006.

44. Cranney A, Horsley T, O'Donnell S, et al. Evidence report/technology assessment: Effectiveness and safety of vitamin D in relation to bone health. Evid Rep Technol Assess (Full Rep). 2007;158(8):1-235.

45. Thomas MK, Lloyd-Jones DM, Thadhani RI, et al. Hypovitaminosis D in medical inpatients. $N$ Engl J Med. 1998;338(12):777-783.

46. Annweiler C, Beauchet O. Questioning vitamin D status of elderly fallers and nonfallers: A meta-analysis to address a 'forgotten step'. J Intern Med. 2015;277(1):1644.

47. Annweiler C, Montero-Odasso M, Schott AM, Berrut G, Fantino B, Beauchet O. Fall prevention and vitamin $\mathrm{D}$ in the elderly: An overview of the key role of the non-bone effects. J Neuroeng Rehabil. 2010;7(1):50-63. 
48. Annweiler C, Schott AM, Berrut G, Fantino B, Beauchet O. Vitamin D-related changes in physical performance: A systematic review. J Nutr Health Aging. 2009;13(10):893-898.

49. Dhesi JK, Jackson SH, Bearne LM, et al. Vitamin D supplementation improves neuromuscular function in older people who fall. Age Ageing. 2004;33(6):589-595.

50. Haroon M, FitzGerald O. Vitamin D deficiency: Subclinical and clinical consequences on musculoskeletal health. Curr Rheumatol Rep. 2012;14(3):286-293.

51. Janssen HC, Samson MM, Verhaar HJ. Vitamin D deficiency, muscle function, and falls in elderly people. Am J Clin Nutr. 2002;75(4):611-615.

52. Rejnmark L. Effects of vitamin D on muscle function and performance: A review of evidence from randomized controlled trials. Ther Adv Chronic Dis. 2011;2(1):25-37.

53. Stechschulte SA, Kirsner RS, Federman DG. Vitamin D: Bone and beyond, rationale and recommendations for supplementation. Am J Med. 2009;122(9):793-802.

54. Gschwind YJ, Bischoff-Ferrari HA, Bridenbaugh SA, Hardi I, Kressig RW. Association between serum vitamin D status and functional mobility in memory clinic patients aged 65 years and older. Gerontology. 2014;60(2):123-129.

55. Przybelski RJ, Binkley NC. Is vitamin D important for preserving cognition? A positive correlation of serum 25-hydroxyvitamin D concentration with cognitive function. Arch Biochem Biophys. 2007;460(2):202-205.

56. Buell JS, Scott TM, Dawson-Hughes B, et al. Vitamin D is associated with cognitive function in elders receiving home health services. J Gerontol A Biol Sci Med Sci. 2009;64(8):888-895.

57. Lee DM, Tajar A, Ulubaev A, et al. The association between different cognitive domains and age in a multi-centre study of middle-aged and older european men. Int $J$ Geriatr Psychiatry. 2009;24(11):1257-1266.

58. Llewellyn DJ, Langa KM, Lang IA. Serum 25-hydroxyvitamin D concentration and cognitive impairment. J Geriatr Psychiatry Neurol. 2009;22(3):188-195.

59. Wilkins CH, Birge SJ, Sheline YI, Morris JC. Vitamin D deficiency is associated with worse cognitive performance and lower bone density in older african americans. $J$ Natl Med Assoc. 2009;101(4):349-354.

60. Annweiler C, Schott AM, Allali G, et al. Association of vitamin D deficiency with cognitive impairment in older women: Cross-sectional study. Neurology. 2010;74(1):2732. 
61. Llewellyn DJ, Lang IA, Langa KM, et al. Vitamin D and risk of cognitive decline in elderly persons. Arch Intern Med. 2010;170(13):1135-1141.

62. Llewellyn DJ, Lang IA, Langa KM, Melzer D. Vitamin D and cognitive impairment in the elderly U.S. population. J Gerontol A Biol Sci Med Sci. 2011;66(1):59-65.

63. Annweiler C, Rolland Y, Schott AM, et al. Higher vitamin D dietary intake is associated with lower risk of alzheimer's disease: A 7-year follow-up. J Gerontol A Biol Sci Med Sci. 2012;67(11):1205-1211.

64. Slinin Y, Paudel M, Taylor BC, et al. Association between serum 25(OH) vitamin D and the risk of cognitive decline in older women. J Gerontol A Biol Sci Med Sci. 2012;67(10):1092-1098.

65. Brouwer-Brolsma EM, van de Rest O, Tieland M, et al. Serum 25-hydroxyvitamin D is associated with cognitive executive function in dutch prefrail and frail elderly: A crosssectional study exploring the associations of 25-hydroxyvitamin $\mathrm{D}$ with glucose metabolism, cognitive performance and depression. J Am Med Dir Assoc. 2013;14(11):8529-85217.

66. Annweiler C, Maby E, Meyerber M, Beauchet O. Hypovitaminosis D and executive dysfunction in older adults with memory complaint: A memory clinic-based study. Dement Geriatr Cogn Disord. 2014;37(5-6):286-293.

67. Chei CL, Raman P, Yin ZX, Shi XM, Zeng Y, Matchar DB. Vitamin D levels and cognition in elderly adults in china. J Am Geriatr Soc. 2014;62(11):2125-2129.

68. Hooshmand B, Lokk J, Solomon A, et al. Vitamin D in relation to cognitive impairment, cerebrospinal fluid biomarkers, and brain volumes. J Gerontol A Biol Sci Med Sci. 2014;69(9):1132-1138.

69. Toffanello ED, Coin A, Perissinotto E, et al. Vitamin D deficiency predicts cognitive decline in older men and women: The pro.V.A. study. Neurology. 2014;83(24):22922298.

70. Wilson VK, Houston DK, Kilpatrick L, et al. Relationship between 25hydroxyvitamin $\mathrm{D}$ and cognitive function in older adults: The health, aging and body composition study. J Am Geriatr Soc. 2014;62(4):636-641.

71. Houston DK, Tooze JA, Neiberg RH, et al. 25-hydroxyvitamin D status and change in physical performance and strength in older adults: The health, aging, and body composition study. Am J Epidemiol. 2012;176(11):1025-1034. 
72. Peterson A, Mattek N, Clemons A, et al. Serum vitamin D concentrations are associated with falling and cognitive function in older adults. $J$ Nutr Health Aging. 2012;16(10):898-901.

73. Menant JC, Close JC, Delbaere K, et al. Relationships between serum vitamin D levels, neuromuscular and neuropsychological function and falls in older men and women. Osteoporos Int. 2012;23(3):981-989.

74. Houston DK, Neiberg RH, Tooze JA, et al. Low 25-hydroxyvitamin D predicts the onset of mobility limitation and disability in community-dwelling older adults: The health ABC study. J Gerontol A Biol Sci Med Sci. 2013;68(2):181-187.

75. Annweiler C, Beauchet O, Bartha R, Hachinski V, Montero-Odasso M. Vitamin D and caudal primary motor cortex: A magnetic resonance spectroscopy study. PLoS One. 2014;9(1):873141-873145.

76. Al-Yahya E, Dawes H, Smith L, Dennis A, Howells K, Cockburn J. Cognitive motor interference while walking: A systematic review and meta-analysis. Neurosci Biobehav Rev. 2011;35(3):715-728.

77. Beauchet O, Allali G, Annweiler C, et al. Does change in gait while counting backward predict the occurrence of a first fall in older adults? Gerontology. 2008;54(4):217-223.

78. Beauchet O, Annweiler C, Allali G, Berrut G, Dubost V. Dual task-related changes in gait performance in older adults: A new way of predicting recurrent falls? J Am Geriatr Soc. 2008;56(1):181-182.

79. Beauchet O, Annweiler C, Allali G, Berrut G, Herrmann FR, Dubost V. Recurrent falls and dual task-related decrease in walking speed: Is there a relationship? J Am Geriatr Soc. 2008;56(7):1265-1269.

80. Beauchet O, Annweiler C, Dubost V, et al. Stops walking when talking: A predictor of falls in older adults? Eur J Neurol. 2009;16(7):786-795.

81. Beauchet O, Dubost V, Allali G, Gonthier R, Hermann FR, Kressig RW. 'Faster counting while walking' as a predictor of falls in older adults. Age Ageing. 2007;36(4):418-423.

82. Beauchet O, Kressig RW, Najafi B, Aminian K, Dubost V, Mourey F. Age-related decline of gait control under a dual-task condition. J Am Geriatr Soc. 2003;51(8):11871188. 
83. Chu YH, Tang PF, Peng YC, Chen HY. Meta-analysis of type and complexity of a secondary task during walking on the prediction of elderly falls. Geriatr Gerontol Int. 2012;13(2):289-297.

84. Hausdorff JM, Edelberg HK, Cudkowicz ME, Singh MA, Wei JY. The relationship between gait changes and falls. J Am Geriatr Soc. 1997;45(11):1406-1417.

85. Verghese J, Buschke H, Viola L, et al. Validity of divided attention tasks in predicting falls in older individuals: A preliminary study. J Am Geriatr Soc. 2002;50(9):1572-1576.

86. Yamada M, Aoyama T, Arai H, et al. Dual-task walk is a reliable predictor of falls in robust elderly adults. J Am Geriatr Soc. 2011;59(1):163-164.

87. Schmidt RA, Wrisberg CA. Processng information and making decisions. In: Wright JP, ed. Motor learning and performance. 3rd ed. Campaign, IL: Human Kinetics; 2000:55-86.

88. Yentes JM, Perell KL, Fang MA, Barr ML. Cognitive processing during gait and balance: A review. The Free Library Web site. http://www.thefreelibrary.com/Cognitive+processing+during+gait+and+balance\%3a +a+review.-a0167842473. Updated 2007. Accessed August 31, 2015.

89. Erkinjuntti T, Sulkava R, Wikstrom J, Autio L. Short portable mental status questionnaire as a screening test for dementia and delirium among the elderly. $J \mathrm{Am}$ Geriatr Soc. 1987;35(5):412-416.

90. Wagner D, Hanwell HE, Vieth R. An evaluation of automated methods for measurement of serum 25-hydroxyvitamin D. Clin Biochem. 2009;42(15):1549-1556.

91. The IPAQ Group. Guidelines for data processing and analysis of the international physical activity questionnaire (IPAQ) - short and long forms. IPAQ Web site. http://www.ipaq.ki.se/scoring.pdf. Accessed April 24, 2013.

92. Rutten A, Ziemainz H, Schena F, et al. Using different physical activity measurements in eight european countries. results of the european physical activity surveillance system (EUPASS) time series survey. Public Health Nutr. 2003;6(4):371376.

93. Bassett DR,Jr. International physical activity questionnaire: 12-country reliability and validity. Med Sci Sports Exerc. 2003;35(8):1381-1395.

94. The IPAQ Group. The international physical activity questionnaire. IPAQ Web site. https://sites.google.com/site/theipaq/. Accessed April 24, 2013. 
95. Hagstromer M, Oja P, Sjostrom M. The international physical activity questionnaire (IPAQ): A study of concurrent and construct validity. Public Health Nutr. 2006;9(6):755762.

96. Benedetti TRB, de Cesaro Antunes P, Rodriguez-Anez CR, Mazo GZ, Petrozki EL. Reproducibility and reliability of the international physical activity questionnaire in ederly men. Rev Bras Med Esporte. 2007;13 (1):9-13.

97. Benedetti TRB, Mazo GZ, Barros MV. Application of the international physical activity questionnaire (IPAQ) for evaluation of elderly women: Concurrent validity and test-retest reproducibility. Rev Bras Ciên e Mov. 2004;12(1):25-34.

98. Mader U, Martin BW, Schutz Y, Marti B. Validity of four short physical activity questionnaires in middle-aged persons. Med Sci Sports Exerc. 2006;38(7):1255-1266.

99. Kolbe-Alexander TL, Lambert EV, Harkins JB, Ekelund U. Comparison of two methods of measuring physical activity in south african older adults. J Aging Phys Act. 2006;14(1):98-114.

100. Silva RB, Costa-Paiva L, Pinto Neto AM, Braga Ade A, Morais SS. Habitual physical activity and cardiovascular risk in post menopause. Rev Assoc Med Bras. 2006;52(4):242-246.

101. da Silva RB, Costa-Paiva L, Pinto-Neto AM, Braga Ade A, Morais SS. Association between habitual physical activity and parameters of physical fitness in postmenopausal women. Climacteric. 2005;8(4):360-370.

102. Ainsworth BE, Macera CA, Jones DA, et al. Comparison of the 2001 BRFSS and the IPAQ physical activity questionnaires. Med Sci Sports Exerc. 2006;38(9):1584-1592.

103. Ekelund U, Sepp H, Brage S, et al. Criterion-related validity of the last 7-day, short form of the international physical activity questionnaire in swedish adults. Public Health Nutr. 2006;9(2):258-265.

104. Kwak L, Hagstromer M, Sjostrom M. Can the IPAQ-long be used to assess occupational physical activity? J Phys Act Health. 2012;9(8):1130-1137.

105. Arvidsson D, Slinde F, Hulthen L. Physical activity questionnaire for adolescents validated against doubly labelled water. Eur J Clin Nutr. 2005;59(3):376-383.

106. Beck AT, Steer RA, Brown GK. RCMAR measurement tools: Beck depression inventory-2nd edition (BDI-II). Medical University of South Carolina Web site. http://www.musc.edu/dfm/RCMAR/Beck.html. Accessed April 21, 2013. 
107. Beck AT, Steer RA. Internal consistencies of the original and revised beck depression inventory. J Clin Psychol. 1984;40(6):1365-1367.

108. Beck AT, Ward CH, Mendelson M, Mock J, Erbaugh J. An inventory for measuring depression. Arch Gen Psychiatry. 1961;4:561-571.

109. Richter P, Werner J, Heerlein A, Kraus A, Sauer H. On the validity of the beck depression inventory. A review. Psychopathology. 1998;31(3):160-168.

110. Segal DL, Coolidge FL, Cahill BS, O'Riley AA. Psychometric properties of the beck depression inventory II (BDI-II) among community-dwelling older adults. Behav Modif. 2008;32(1):3-20.

111. Greenberg SA. Assessment of fear of falling in older adults: The falls efficacy scaleinternational (FES-I). The Hartford Institute for Geriatric Nursing, New York University Web site. http://consultgerirn.org/uploads/File/trythis/try this_29.pdf. Updated 2011. Accessed August 31, 2015.

112. Hausdorff JM, Schweiger A, Herman T, Yogev-Seligmann G, Giladi N. Dual-task decrements in gait: Contributing factors among healthy older adults. J Gerontol A Biol Sci Med Sci. 2008;63(12):1335-1343.

113. Hyeong-Dong K. Effects of dual-tak on crossing an obstacle versus initiating gait. Journal of physical therapy science. 2008;20(4):249-253.

114. van der Schaft J, Koek HL, Dijkstra E, Verhaar HJ, van der Schouw YT, EmmelotVonk MH. The association between vitamin D and cognition: A systematic review. Ageing Res Rev. 2013;12(4):1013-1023.

115. Balion C, Griffith LE, Strifler L, et al. Vitamin D, cognition, and dementia: A systematic review and meta-analysis. Neurology. 2012;79(13):1397-1405.

116. Etgen T, Sander D, Bickel H, Sander K, Forstl H. Vitamin D deficiency, cognitive impairment and dementia: A systematic review and meta-analysis. Dement Geriatr Cogn Disord. 2012;33(5):297-305.

117. Zadshir A, Tareen N, Pan D, Norris K, Martins D. The prevalence of hypovitaminosis D among U.S. adults: Data from the NHANES III. Ethn Dis. 2005;15(4 Suppl 5):97-101.

118. Eastlack ME, Arvidson J, Snyder-Mackler L, Danoff JV, McGarvey CL. Interrater reliability of videotaped observational gait-analysis assessments. Phys Ther. 1991;71(6):465-472. 
119. Srygley JM, Mirelman A, Herman T, Giladi N, Hausdorff JM. When does walking alter thinking? age and task associated findings. Brain Res. 2009;1253:92-99.

120. Suchy Y. Executive functioning: Overview, assessment, and research issues for nonneuropsychologists. Ann Behav Med. 2009;37(2):106-116.

121. Lee DM, Tajar A, Ulubaev A, et al. Association between 25-hydroxyvitamin D levels and cognitive performance in middle-aged and older european men. $J$ Neurol Neurosurg Psychiatry. 2009;80(7):722-729.

122. Gerdhem P, Ringsberg KA, Obrant KJ, Akesson K. Association between 25hydroxy vitamin $\mathrm{D}$ levels, physical activity, muscle strength and fractures in the prospective population-based OPRA study of elderly women. Osteoporos Int. 2005;16(11):1425-1431.

123. Annweiler C, Schott AM, Montero-Odasso M, et al. Cross-sectional association between serum vitamin D concentration and walking speed measured at usual and fast pace among older women: The EPIDOS study. J Bone Miner Res. 2010;25(8):1858-1866.

124. Bischoff-Ferrari HA, Dietrich T, Orav EJ, et al. Higher 25-hydroxyvitamin D concentrations are associated with better lower-extremity function in both active and inactive persons aged > or =60 y. Am J Clin Nutr. 2004;80(3):752-758.

125. Suzuki T, Kwon J, Kim H, et al. Low serum 25-hydroxyvitamin D levels associated with falls among japanese community-dwelling elderly. J Bone Miner Res. 2008;23(8):1309-1317.

126. Boersma D, Demontiero O, Mohtasham Amiri Z, et al. Vitamin D status in relation to postural stability in the elderly. J Nutr Health Aging. 2012;16(3):270-275.

127. Montero-Odasso M, Bergman H, Phillips NA, Wong CH, Sourial N, Chertkow H. Dual-tasking and gait in people with mild cognitive impairment. the effect of working memory. BMC Geriatr. 2009;9(8):41-48.

128. Hausdorff JM, Edelberg HK, Mitchell SL, Goldberger AL, Wei JY. Increased gait unsteadiness in community-dwelling elderly fallers. Arch Phys Med Rehabil. 1997;78(3):278-283.

129. Maki BE. Gait changes in older adults: Predictors of falls or indicators of fear. $J$ Am Geriatr Soc. 1997;45(3):313-320.

130. Newell KM, Corcos DM. Issues in variability and motor control. In: K.M. Newell \& D.M. Corcos, ed. Human kinetics. 2nd ed. Champaign, IL: K.M. Newell \& D.M. Corcos; 1993:1-12. 
131. Hausdorff JM, Nelson ME, Kaliton D, et al. Etiology and modification of gait instability in older adults: A randomized controlled trial of exercise. J Appl Physiol. 2001;90(6):2117-2129.

132. Hausdorff JM, Rios DA, Edelberg HK. Gait variability and fall risk in communityliving older adults: A 1-year prospective study. Arch Phys Med Rehabil. 2001;82(8):1050-1056. 


\section{CHAPTER VI: RELATIONSHIP BETWEEN VITAMIN D STATUS AND CARDIOMETABOLIC RISK}

\section{Abstract}

Objective: The purpose of this study was to investigate the relationship between vitamin D status and a composite cardiometabolic risk score (CMRS).

Methods: Participants completed assessments that included serum vitamin D levels, surveys, and measurement of CMRS using a system that integrates body composition, endothelial function, and autonomic nervous system (ANS) activity markers. Spearman’s correlations, independent t-tests and multiple linear regressions were used to examine the relationship of vitamin D insufficiency $(25(\mathrm{OH}) \mathrm{D}<30 \mathrm{ng} / \mathrm{ml})$ and sufficiency $(25(\mathrm{OH}) \mathrm{D}$ $\geq 30 \mathrm{ng} / \mathrm{ml}$ ) with CMRS. The significance level was set at $\alpha=0.05$.

Results: The mean \pm SD vitamin D (25(OH)D) level was 30.71 \pm 8.78 , and CMRS was $5.17 \pm 3.58$. Spearman correlations showed a significant inverse correlation between insufficient vitamin D levels and CMRS $(P=0.019)$. Vitamin D insufficient participants had a significantly higher CMRS compared with vitamin D sufficient $(P=0.046)$. In adjusted multiple linear regressions, vitamin D status had a significant effect on CMRS $(P=0.016)$.

Conclusions: An inverse association between vitamin D levels and CMRS was found, possibly by mediating genomic and non-genomic mechanisms that influence ANS activity and vascular function. Thus, vitamin D insufficiency may affect cardiac performance.

Keywords: vitamin D, cardiometabolic risk, autonomic nervous system, endothelial dysfunction 


\section{Introduction}

Vitamin D deficiency and cardiovascular disease (CVD) are prevalent worldwide. ${ }^{1,2}$ Furthermore, the prevalence of vitamin D deficiency is high among those with CVD. Analysis of data from the National Health and Nutrition Examination Survey (NHANES) 2001-2004, showed that $68 \%$ of whites, $88 \%$ of Hispanics, and $97 \%$ of blacks with CVD also had vitamin D levels of less than $30 \mathrm{ng} / \mathrm{ml}$, as measured by 25hydroxyvitamin (25(OH)D). ${ }^{3,4}$ Several observational studies and meta-analyses have suggested an association of vitamin D deficiency with CVD-related outcomes and mortality. ${ }^{5-19}$ These studies reported a linear, inverse relationship between CVD risk and 25(OH)D levels between 8-24 ng/ml. ${ }^{12}$ Furthermore, vitamin D supplementation demonstrated a reduction in CVD-related death, with vitamin D intake of more than 500 IU per day improving all-cause mortality, partly by decreasing CVD mortality.,15,19

The possible relationship between vitamin D deficiency and CVD-related outcomes and mortality in both diseased and healthy populations is a growing area of research. $^{2}$ The most studied role of vitamin D is in regulating calcium homeostasis and mineral metabolism to maintain bone health. ${ }^{20}$ Vitamin D, via genomic and non-genomic actions mediated by vitamin D receptors (VDRs), however, may affect multiple cellular signaling pathways that have the potential to affect cardiovascular health. These include vitamin D effects on parathyroid hormone (PTH), the renin-angiotensin-aldosterone system (RAAS), cytokine production, endothelial growth and function, and myocyte calcium influx. ${ }^{21}$ Furthermore, vitamin D has also been shown to be involved in molecular mechanisms like biosynthesis of neurotransmitters and inflammatory signaling in areas of the central nervous system (CNS) that regulate cardiovascular activity. ${ }^{22,23}$ 
Vitamin D can permeate the blood-brain barrier and bind to VDRs located in extremely high concentrations in the midbrain and brainstem where some autonomic nervous system (ANS) neurons are located. ${ }^{22,23}$

Recent studies in healthy and diseased populations have found an association between vitamin D status and cardiac ANS function, with vitamin D deficiency related to cardiac ANS imbalance, more specifically with decreased parasympathetic nervous system (PNS) activity. ${ }^{2,24-29}$ The ANS is a branch of the peripheral nervous system that controls involuntary processes throughout the body like cardiovascular activity. ${ }^{30}$ The cardiac ANS is composed of the stimulatory post-ganglionic sympathetic plexus of nerves and the inhibitory parasympathetic Vagus nerve, which both innervate the heart and act concomitantly to control heart rate by responding to internal and external stimuli. ${ }^{26,30}$ Dysfunction of cardiac autonomic function, more specifically of the cardioprotective vagal tone, results in an imbalance between SNS and PNS, that has been well established as a risk factor for adverse cardiovascular events, such as sudden cardiac death (SCD) and congestive heart failure (CHF) in both healthy and diseased populations. $^{31-36}$

Besides its effect on heart rate, ANS activity plays a role in vascular dynamics and blood pressure control, which is also influenced by endothelial function. Low vitamin D status has also been associated with endothelial dysfunction, characterized by a decreased ability to balance vasodilation and vasoconstriction. It is usually due to an imbalance of nitric oxide bioavailability and related to prothrombotic and proinflammatory states that increase arterial stiffness. ${ }^{4,37-39}$ Thus, vitamin D plays a role in vascular health by participating in the control of vascular tone and blood pressure via 
indirect ANS activity or directly affecting the endothelium. These findings suggest that vitamin D may contribute to CVD-risk by orchestrating genomic and non-genomic regulatory activity at the vascular level and higher brain centers of the ANS.,18,40

Currently, the links between vitamin D status, ANS, and endothelial function have been evaluated independently, and no study has investigated the relationship between vitamin D and cardiometabolic risk score (CMRS) as a composite measure that integrates various CVD risk factors such as body composition, ANS activity, and endothelial function. The purpose of this study was to investigate the association between vitamin D status and CMRS. We hypothesized that those who are vitamin D insufficient (25(OH)D $<30 \mathrm{ng} / \mathrm{ml}$ ) will have significantly lower CMRS than those who are vitamin D sufficient $(\geq 30 \mathrm{ng} / \mathrm{ml})$.

\section{Methods}

\section{Study Design and Setting}

This study was approved by the IRBs of Florida International University (130390) and the University of Miami (20120195).

\section{$\underline{\text { Participants }}$}

The study enrolled 101 participants, and six were excluded due to missing data $(\mathrm{n}=95)$. Participants for this study were recruited from the parent study, a double-blinded randomized placebo-controlled clinical trial that examined the effects of vitamin D supplementation on vitamin D level, bone formation, resorption, and mineral density, flexibility, and balance in the elderly, which was conducted at the University of Miami. 
Briefly, each potential participant was screened over the phone by administering the Short Portable Mental Status Questionnaire (SPMSQ) ${ }^{41}$ to evaluate mental functioning (allowed up to 2 errors) and questions regarding general inclusion criteria such as age, and medical, pharmacological and general exclusions. Inclusion criteria for this study included: (1) Men and women age 55 or older; (2) English and Spanish speakers; (3) Community-dwelling; (4) Ability to give informed consent; (5) Ability to perform motor tasks without aid; and (6) Participating in the parent study. All participants in this study were required to sign IRB approved informed consents for both the University of Miami and Florida International University.

\section{Biomarkers}

Vitamin D Status

Vitamin D status was measured by serum 25-hydroxyvitamin D (25(OH)D). Fasting venous blood (15 ml) was collected from every participant by a certified phlebotomist in the morning after fasting. The samples were sent the same day for analysis to LabCorp (2700 N. 29 ${ }^{\text {th }}$ Ave, Suite 203A, Hollywood, Fl 33020) that used immunochemiluminometric assays (ICMA) on the DiaSorin Liaison instrument to assess $25(\mathrm{OH}) \mathrm{D}$. This is a highly automated test that measures total $25(\mathrm{OH}) \mathrm{D}$, and it has been widely used by others. ${ }^{42}$ 


\section{Surveys}

Sociodemographics, Health History, Health Risk Behaviors and Medications

Sociodemographic and health-related data were collected using questionnaires

developed by staff of the parent study that asked about gender, marital status, race/ethnicity, socioeconomic status, education, income, current medical diagnoses, medication/ supplement use and health risk behaviors such as coffee, alcohol, and tobacco use.

Physical Activity Levels

Physical activity level was measured using the International Physical Activity Questionnaire (IPAQ), ${ }^{43}$ which provides individual domain-specific scores for walking, moderate-intensity and vigorous-intensity activity within the domains of work, transportation, domestic chores and gardening, and leisure-time. To measure the volume of activity, each type of activity was weighted by its energy requirement defined as the MET-min. METs are metabolic equivalents that are computed for each specific activity using defined formulas, and then multiplied by the minutes performed to derive METminute scores, which are equal to kilocalories for a $60 \mathrm{~kg}$ person. ${ }^{43}$

The IPAQ was developed to derive comparable measurements of physical activity in international settings; therefore, being suitable for use in different languages and cultural contexts like in an ethnically-diverse city as Miami. ${ }^{44,45}$ It has also been validated in different age groups against objective measures of physical activity, physical fitness, and health outcomes. ${ }^{46}$ For instance, it was validated in an adult population (mean \pm SD: $40.7 \pm 10.3$ years old) and found to have a strong positive relationship with an activity 
monitor and a physical activity $\log (\mathrm{rho}=0.55, P<0.001) .{ }^{47}$ It was also validated and used in a population of elderly men and found to be reliable (test-retest reliability of 0.95) and valid when compared against pedometer use and the physical activity log, and had similar results in cohorts of postmenopausal women. ${ }^{48,49}$ Other studies have validated the IPAQ and used it successfully in populations of middle-aged and older adults and adults with different diseases, such as schizophrenia and breast cancer. ${ }^{45,50-53}$ The IPAQ correlated with measurements to other physical activity assessment methods such as the 2001 Behavioral Risk Factor Surveillance System (BRFSS) physical activity, accelerometers, and energy expenditure as measured by doubly-labeled water, among others. ${ }^{46,54-57}$

\section{Depressive Symptoms}

Depressive symptoms were assessed using the Beck Depression Inventory (BDIII), which is a widely validated and used tool that evaluates the existence and severity of depressive symptoms based on the DSM-IV ${ }^{58}$ It is a self-report, 21-item instrument and each item corresponds to a symptom of depression and has a four-point scale ranging from 0 to 3, except for two items that have seven options to indicate decrease or increase in appetite and sleep. The score of all items is summed to give a single score. A total score of 0-13 is considered minimal, 14-19 mild, 20-28 moderate, and 29-63 severe depressive symptoms. ${ }^{58}$ Construct validity has been assessed on its ability to differentiate non-depressed and depressed patients (0.92 for outpatients and 0.93 for college students). Test-retest reliability was found to be significant at 0.93 . This tool has been used in populations ages 13-80 years. ${ }^{58-61}$ In an elderly population, BDI-II has good internal consistency (0.86), and has been positively correlated with other measures of depression, 
measures of stress, anxiety, and negatively with well-being. Research with this instrument has shown no statistically significant effects for ethnicity, gender, and age on BDI-II scores. ${ }^{62}$ In case a participant reported suicidal ideation, the investigators in this study contacted the study physician and/or University of Miami Mental Health Department, immediately.

\section{Anthropometrics and Body Composition}

Weight was measured using an electronic balance. Participants were asked to remove shoes and heavy outer garments like coats and to stand in the center of the balance so that the weight was distributed evenly on both feet. Height was measured using a stadiometer with a movable headpiece. Participants were asked to stand with their back to the height rule with their feet together, while the back of the head, back, buttocks, calves, and heels touched the upright tape. The participant was asked to look straight ahead so that the ear canal was level with the cheek bone. The headpiece was lowered so that the hair was pressed flat. Weight and height were recorded to the nearest $0.1 \mathrm{~kg}$ and $0.1 \mathrm{~cm}$, respectively. Body mass index (BMI) was calculated using the formula: body weight (kg)/ height $(\mathrm{m})^{2}$ and accordingly, participants were classified into categories based on the National Heart, Lung and Blood Institute recommendations: underweight $\left(<18.5 \mathrm{~kg} / \mathrm{m}^{2}\right)$, normal weight $\left(18.5-24.9 \mathrm{~kg} / \mathrm{m}^{2}\right)$; overweight $\left(25-29.9 \mathrm{~kg} / \mathrm{m}^{2}\right)$, and obese $\left(>30 \mathrm{~kg} / \mathrm{m}^{2}\right)$.

Waist circumference (WC) was measured at the umbilicus and hip circumference (HC) was measured at the broadest circumference below the waist. Both of these were done using a flexible but not stretchable measuring tape in three replicates to ensure 
reproducibility. The average of the three values was used to calculate waist-to-hip ratio (WHR) by dividing WC by HC. Body composition was measured using bioelectrical impedance (BIA), to determine \% lean (fat-free, \%FFM) and fat mass (\%FM).

\section{Cardiometabolic Risk Score (CMRS)}

FDA approved and patented Electro Sensor Complex (ESC) software was used to determine CMRS. This instrument combines three devices (ES-BC, TM-Oxi and SudoPath) that use bioelectrical impedance, galvanic skin response, spectrophotometry and an oscillometric blood pressure device. It measures different parameters of body composition, endothelial function (based on pulse wave velocity) and ANS activity (based on heart rate variability and sudomotor function) during baseline and the performance of cardiac autonomic function tests (i.e., Valsalva maneuver, deep breathing, and standing up). ${ }^{63,64}$

Steps of the procedure are described elsewhere. ${ }^{63,64}$ Briefly, study staff, trained by the manufacturer, asked participants to sit on a confortable chair with their shoes and socks off, feet on the metal plates, right index finger in the pulse oximeter, and blood pressure cuff on the left arm. After inputting demographic, anthropometric and physical activity data, the software initiated the baseline assessment for 1-2 minutes while the participant was sitting down. Then the participant was asked to perform the Valsalva maneuver by clamping their nose with their left hand while trying to breath out for 15 seconds with their mouth closed, building pressure like when popping ears. After releasing their nose, participants were asked to breath deeply for 30 seconds, inhaling for 5 seconds and exhaling for 5 seconds. Finally, participants were asked to stand up, while 
straightening their left arm to their side and keeping their index finger in the pulse oximeter, and remain standing up until the assessment was completed. The whole assessment lasted about 5 minutes.

Details of the devices are discussed in previous publications and the manufacturer's website (http://www.ldteck.com) ${ }^{63,64}$ The Electro-Sensor Body Composition (ES-BC) device uses a single-frequency bioelectrical impedance analyzer to compute \%FM using accepted peer reviewed published algorithms tailored to the general and obese population based on gender, height, weight, age, and activity level. ${ }^{63,65-68}$

The TM-Oxi system assesses cardiac ANS function, including both SNS and PNS, during baseline and validated cardiac autonomic reflex tests. It uses an automatic oscillometric blood pressure device and pulse oximeter, which uses an optical technique (spectrophotometry) to measure vascular dynamics and HRV, defined as the variation in time intervals between each heart beat (i.e., R-R interval). ${ }^{69,70}$ The assessment of HRV is a valid and useful method to measure cardiac ANS activity and identifies patients with cardiac ANS dysfunction, which places them at risk of cardiac events. ${ }^{69,70}$ Briefly, the pulse oximeter directs red and infrared light into the nail bed area of the right index finger and measures the change in light absorption, reflection, and scattering between systole and diastole creating a pulsatile signal or waveform, illustrated as a plethysmograph (PTG) that varies in time with each heartbeat. The TM-Oxi applies a mathematical algorithm, the Fast Fourier Transform (FFT), to the PTG recording (FFTPTG) to manipulate the beat to beat $\mathrm{R}-\mathrm{R}$ intervals and convert the signal from a time domain to frequency domains. The frequency domains are then categorized by oscillating frequency, which are the three frequencies of HRV: (1) very low frequency (PTGVLF) 
associated with thermoregulation and sweating that results in oscillation in vasomotor tone controlled by SNS; (2) low frequency (PTGLF) related to baroreflex that is under control of both SNS and PNS; (3) high frequency (PTGHF) associated with R-R interval changes due to breathing, which is under PNS control. ${ }^{64}$ The pulse oximeter and oscillometric blood pressure device are used to measure HRV and changes in blood pressure at rest and during cardiac ANS tests to assess SNS and PNS balance.

PTG also provides information about arterial stiffness and endothelial function. The TM-Oxi system quantifies PTG into a digital volume pulse (DVP) waveform that represents the pressure wave that spreads from the heart to the periphery (systolic peak) and reflects back to the heart (diastolic peak) during the cardiac cycle. ${ }^{64,71-73}$ Arterial stiffness, which is partially a result of endothelial dysfunction, is defined as the opposition to the pressure wave in the arteries, resulting in abnormal systolic and diastolic peaks. Thus, the DVP waveform is mainly regulated by myocardial and arterial characteristics and is used by the software to calculate indicators of vascular health and arterial status. ${ }^{63,64}$

The SudoPath system measures sudomotor activity, which is controlled by post sympathetic cholinergic nerve fibers (C-fibers) that innervate sweat glands, using 2 stainless steel electrodes on which the participant places their soles of the feet, where a very high density of sweat glands are located ${ }^{64}$ This system evaluates skin blood flow (microcirculation), C-fiber condition, and sweat gland activity using the galvanic skin response. The device generates a low voltage signal with weak DC current that electrically stimulates C-fibers, which release acetylcholine, and thus, stimulate nicotinic muscarinic receptors (M-receptors) in the skin and sweat glands. ${ }^{64,74}$ This causes a 
change in blood flow and sweat production that disturbs the electrical conductance of the skin, which is then measured by the device using the principles of electrolysis as a marker for SNS function. ${ }^{64}$

The software integrates these measurements with demographic, anthropometric and physical activity data to calculate a CMRS, which is categorized as normal $(\leq 4$,$) mild$ (5-7), moderate (8-10), or high risk ( $\geq 11)$. Previous studies have shown the accuracy of these three devices, compared to standardized assessments of body composition, ANS activity, and cardiac output, and thus supporting the usefulness of these devices in detecting complications related to metabolic syndrome, diabetes and CVD. ${ }^{63}$ Recently, a study comparing diabetic and healthy controls showed that the CMRS calculated by this software is significantly correlated with glucose and insulin measured during an oral glucose tolerance tests (OGTT) and was significantly higher in participants with diabetes. Also, specificity (92\%) and sensitivity (83\%) were high for the CMRS in differentiating patients with diabetes from healthy control. ${ }^{64}$

\section{Statistical Analysis}

Statistical analyzes were performed on 95 participants. Data were analyzed using frequencies, percentages, ranges, means, and standard deviations. Variables were checked for non-normality and, if necessary, they were transformed to achieve a normal distribution. Spearman correlations between two or more categorical variables were performed to evaluate the relationship of vitamin status with CMRS. Independent t-tests or chi-square were used to compare CMRS between vitamin D insufficient (25(OH)D $<30 \mathrm{ng} / \mathrm{ml}$ ) and sufficient ( $\geq 30 \mathrm{ng} / \mathrm{ml}$ ) participants. Multiple linear regressions were used 
to examine the effect size and the change in CMRS expected from a one-unit change in vitamin D levels after adjusting for potential confounders. The significance level was set at $\alpha=0.05$, and statistical analyses were performed using SPSS 21 .

\section{Results}

The mean \pm SD 25(OH)D level was $30.71 \pm 8.78$, with $46.3 \%$ being insufficient ( $<30 \mathrm{ng} / \mathrm{ml}$ ) and $53.7 \%$ being sufficient ( $\geq 30 \mathrm{ng} / \mathrm{ml}$ ) (Table 1 ). Mean \pm SD age of the participants was $63 \pm 8.8$ years, and $45 \%$ of participants were males, $45 \%$ Hispanic, $35 \%$ white Caucasian and 16\% African American. Mean \pm SD number of diseases reported were $4.73 \pm 3.1$. The percent of participants who reported diagnoses of diseases/diorders related to the cardiovascular system are as follows: $3.2 \%$ had arrhythmia, angina or heart murmur; 38.9\% high blood pressure; 4.2\% low blood pressure; 33.7\% high cholesterol; 16.8\% high triglycerides; $6.3 \%$ circulation problems; $7.4 \%$ shortness of breath; $2.1 \%$ chronic obstructive pulmonary disease; $4.2 \%$ chronic bronchitis; 3.2\% type 1 diabetes; 11.6\% type 2 diabetes; and 2.1\% hypoglycemia. Three-quarters reported taking prescription medications and $80 \%$ taking over the counter (OTC) medications with an mean \pm SD number of $2.3 \pm 2.2$ and $1.5 \pm 1.1$ of prescription and OTC medications, respectively. In respect to health risk behaviors, $78.9 \%$, and $11.6 \%$ reported caffeine and tobacco use, respectively. The mean \pm SD number of alcoholic drinks consumed per week was $2.1 \pm 3.7$.

The mean \pm SD weight and BMI of the participants were $76.1 \pm 17.1 \mathrm{~kg}$ and $27.01 \pm 5.3 \mathrm{~kg} / \mathrm{m}^{2}$, respectively. Sixty-one percent of the participants had BMI $\geq 25$ and the mean \pm SD $\%$ FM was $30.9 \pm 9.1$. The mean \pm SD systolic and diastolic blood pressures were $132.6 \pm 22.0$ and $76.0 \pm 14.5 \mathrm{mmHg}$, respectively, and the mean $\pm \mathrm{SD}$ 
heart rate was $70.4 \pm 11.8 \mathrm{bpm}$. The mean \pm SD CMRS was $5.17 \pm 3.58$, with $50.5 \%$ having normal CMRS scores while $22.1 \%, 17.9 \%$ and $8.4 \%$ of the participants having mild, moderate and high risk of CVD, respectively.

There was a significant inverse correlation between vitamin D status and CMRS, with vitamin D insufficient participants having lower CMRS ( $\mathrm{r}=-0.241, P=0.019)$. Participants who were vitamin D insufficient had a significantly higher CMRS compared with the vitamin D sufficient group (mean difference: 1.48, $P=0.046$ ) (Table 2).

Multiple linear regressions were used to evaluate the effect of vitamin D status on CMRS (B (SE): -0.11 (0.05), 95\% CI: -0.20; -0.02, $P=0.016$ ), after controlling for covariates (Table 3). In this fully adjusted model, CMRS was expected to decrease by 0.11 points for every unit increase in vitamin D levels. Vitamin D and number of prescription medications predicted about $7 \%$ of the variation in CMRS.

\section{Discussion}

CVD risk and vitamin D status and the benefit of vitamin D supplementation on cardiovascular health is well established..$^{5-10,12-16,18,19,75}$ The observations that vitamin D deficiency, cardiac ANS and endothelial dysfunction are independently linked to CVDrelated outcomes suggest a potential relationship between vitamin D deficiency and cardiovascular risk in diseased and healthy humans. ${ }^{5,18,40}$ Vitamin D affects multiple cellular signaling pathways via genomic and non-genomic actions that have the potential to affect cardiovascular health. ${ }^{76,77}$ These include vitamin D effects on PTH, RAAS, cytokine production, myocyte calcium influx, endothelial growth and function, and

cardiac ANS activity. ${ }^{21}$ Our results support the findings from previous studies on the 
association between vitamin D deficiency and CMRS, possibly by mediating genomic and non-genomic mechanisms that influence ANS activity and vascular function, thus affecting cardiac performance. This is the first study to investigate the relationship between vitamin D status and cardiometabolic risk, using a rapid, non-invasive method that integrates measures of ANS and endothelial function, anthropometrics, lifestyle characteristics, and body composition data. Previous studies have shown a relationship between vitamin D and cardiac ANS, independent of other cardiovascular risk factors like endothelial dysfunction and increased \%FM.

In humans, the relationship between vitamin D status and ANS function has been studied in diseased and healthy populations. For instance, in 36 patients with nonischemic dilated cardiomyopathy (NIDCM), 25(OH)D was positively correlated with HRV parameters, with vitamin D insufficiency having deleterious effects on cardiac ANS function. ${ }^{28}$ Krause et al. ${ }^{78}$ showed that patients with chronic kidney disease (CKD), who have impaired vitamin D synthesis, when exposed to short-term artificial sunlight heliotherapy had a significant increase in 25(OH)D levels and an elevation in measurements of vagal activity that were severely depressed at baseline. The magnitude of 25(OH)D increase was directly correlated with the magnitude of increased cardioprotective PNS activity, implying that vitamin D levels may constitute an important role in the development of common CVD-related outcomes in this population by affecting the ANS. Chan et al. ${ }^{79}$ reported that patients with CKD demonstrated poor cardiac ANS activity, which was characterized by decreased activity of the inhibitory PNS. Furthermore, in patients with end-stage kidney disease (ESKD), depressed HRV is extremely common and usually presents as suppressed PNS activity with increased SNS 
input to the sino-atrial node. ${ }^{26,79}$ For the dissertation by Mann, ${ }^{26}$ a cross-over study was conducted in which 56 participants with ESKD on hemodialysis were randomized to either conventional ( $0.25 \mathrm{mg}$ alfacalcidol 3 times per week plus placebo 3 times per week for 6 weeks) or intensive ( $0.25 \mathrm{mg}$ alfacalcidol 3 times per week plus 50,000 IU ergocalciferol once a week plus placebo 2 days per week for 6 weeks) vitamin D therapy followed by a 12 -week washout period and another 6 weeks of vitamin D therapy. They did not observe significant changes in measures of cardiac autonomic tone, mineral metabolism or RAAS activity but an exploratory subgroup analysis found that after treatment, participants who remained vitamin D deficient $(25(\mathrm{OH}) \mathrm{D}<20 \mathrm{ng} / \mathrm{ml})$, compared to those who achieved sufficiency (> $30 \mathrm{ng} / \mathrm{ml}$ ), had significant ANS imbalance. In the ESKD population, abnormal HRV and ANS dysfunction is also common in this population; thus, putting them at higher risk of sudden arrhythmic death. ${ }^{79-85}$

Currently, only one study has evaluated the relationship between vitamin D status and Cardiac Autonomic Neuropathy (CAN) in type 2 diabetics using cardiac autonomic reflex tests. ${ }^{29}$ In this study, several HRV parameters during ANS tests were assessed and scored as normal, borderline and abnormal to calculate a CAN risk score. They found that vitamin D deficiency $(25(\mathrm{OH}) \mathrm{D}<10 \mathrm{ng} / \mathrm{ml})$ was significantly correlated with decreased HRV in the supine and upright position and those participants with vitamin D levels $<10$ $\mathrm{ng} / \mathrm{ml}$ had significantly increased CAN risk compared to those with 25(OH)D between $10-20 \mathrm{ng} / \mathrm{ml}^{29}$

In a healthy Korean population over the age of 20 years, investigators observed that 25(OH)D was positively associated with decreased HRV. ${ }^{27}$ They observed that 
vitamin D deficient individuals $(25(\mathrm{OH}) \mathrm{D}<15 \mathrm{ng} / \mathrm{ml}$ ) were 3.1 times more likely to have low HRV. In 2013, Mann et al..$^{24}$ used power spectral analysis of electrocardiogram recordings to measure HRV and thus assess cardiac ANS activity at baseline and during a graded angiotensin II challenge in 34 healthy humans. They found a significant suppression of ANS balance in vitamin D deficient $(25(\mathrm{OH}) \mathrm{D}<20 \mathrm{ng} / \mathrm{ml})$ participants at baseline, but no difference was observed during the challenge. In an intervention study, the same group demonstrated that healthy adults supplemented with 10,000 IU of vitamin D for four weeks had a significant improvement in cardiac ANS balance, specifically in enhancing the cardio-protective PNS activity. ${ }^{25}$

Besides the link between vitamin D and ANS, 25(OH)D levels have been independently associated with several tests of endothelial dysfunction, arterial stiffness, and coronary flow reserve. ${ }^{86,87}$ In addition, studies have demonstrated that vitamin D treatment improves arterial stiffness as measured by pulse wave velocity. ${ }^{88,89}$ Thus, vitamin D may affect vascular tone and blood pressure indirectly via modulation of cardiac ANS activity or directly by affecting endothelial function.

Our study, like other cross-sectional and longitudinal studies, supports a relationship between low vitamin D metabolites and cardiovascular risk. ${ }^{21}$ Crosssectional studies are descriptive in nature, and even though they can establish association among factors, they do not prove cause and effect. Thus, these associations may be confounded by reverse causality, as cardiovascular outcomes may affect vitamin D status. Interventional studies until today show a modest effect of vitamin D on hypertension and equivocal impact on arterial stiffness, endothelial function, and ANS activity. ${ }^{21}$ Despite observational and mechanistic data, which support vitamin $\mathrm{D}$ having a protective role in 
CVD, intervention studies to date are not promising. The mechanism by which vitamin D affects cardiovascular health is still unclear and the need for long-term intervention studies using cardiovascular events as a primary outcome is clear to provide answers to the many remaining questions. It is essential to determine if vitamin D supplementation has the potential for reversing the increase in CVD risk associated with vitamin D deficiency. Vitamin D supplementation may be a cost-effective treatment to improve ANS and endothelial function in healthy and chronic disease populations and thus reduce CVD risk. Based on the acceptance of preliminary findings on the effect of supplementation on CVD, a cost-benefit analysis has estimated a reduction of as many as a total of 336,000 deaths per year, including 180,000 deaths from CVD, if the United States adult population were to raise vitamin D levels above $40 \mathrm{ng} / \mathrm{ml}$. This also translates into a reduction of about $\$ 130$ billion per year in direct care costs. ${ }^{90}$

Besides its cross-sectional nature, this study has other limitations. This study may suffer from selection bias. First, we included younger older adult participants ( $>55$ years of age) to have a wider age range for recruitment purposes. Therefore, some of our participants were younger than what is considered "old age," with $36 \%$ and $63.8 \%$ of our participants being under the age of 60 and 65, respectively, and thus, adding heterogeneity to our study. Nevertheless, we did not find a significant difference in age, number of participants over the age of 60 , and number of participants over the age of 65 between vitamin D insufficient and sufficient groups. Moreover, age was not a risk factor for vitamin D insufficiency or CMRS in this study population since it was not a significant predictor of any of these two variables in regression models. Second, the participants in this study were mostly healthy, since the criteria for the parent study 
excluded current diagnoses of numerous diseases/conditions that affect vitamin D metabolism and absorption, medications that disturb vitamin D metabolism, and current vitamin D supplement use. Our sample was not randomly selected from the general older adult population in Miami-Dade, but instead were healthier older adults who volunteered to participate and met inclusion criteria. The results of this study cannot be extrapolated to the general Miami-Dade older adult population, other populationa in the United States, or globally.

An additional limitation of this study was the low adjusted $\mathrm{R}^{2}$, which assesses the percentage of the variation of the dependent variable that is explained by the linear regression model. Even though it is indicative of how well the linear model fits the observations, it doesn't provide a hypothesis test for this relationship. A low adjusted $\mathrm{R}^{2}$ means that the model is not precise. However, if the adjusted $\mathrm{R}^{2}$ is low but the predictors are statistically significant, conclusions can still be drawn about the relationship between the dependent variable and predictors. Thus, highly variable data, as indicated by low adjusted $R^{2}$, can still have a significant trend that indicates the dependent variable is affected by the predictors.

Furthermore, vitamin D is part of complex mineral metabolism functions that involves measures known to influence cardiovascular risk, including PTH, phosphate, and calcium. Our study did not measure any of these potential intermediaries between vitamin D and cardiovascular health. PTH, possibly through alteration in calcium homeostasis, has been associated with cardiomyocyte hypertrophy, increased myocardial contractility, calcification of heart valves and myocardium, and arterial stiffness, and predisposition to increased blood pressure. ${ }^{91-93}$ Also, these studies did not measure 
biomarkers that are clinically established as risk factors for CVD, such as cholesterol, triglycerides, glucose, hemoglobin A1C, and others. Moreover, we did not find a significant association between vitamin D and self-reported CVD outcomes that may affect CMRS, such as hypertension, dyslipidemia and diabetes. Thus, future studies need to consider measuring other biomarkers related to vitamin $\mathrm{D}$ and mineral metabolism to examine the possible mechanism by which this nutrient may affect cardiovascular health. The ESC system software may need to be updated to include cardiometabolic biomarker information integrated into the calculation of CMRS.

Finally, although plethysmography and pulse wave velocity have been considered valid tools for measuring HRV and arterial stiffness to evaluate ANS activity and endothelial function, no one parameter has been established as superior in their predictive ability as surrogate marker for adverse cardiovascular outcomes. ${ }^{69,94-97}$ Although shortterm analysis of HRV and endothelial function at rest may provide significant prognostic value, it limits the comparison of HRV parameters obtained during various activities that can challenge the cardiac ANS like exercise and sleep. Thus, it only measured relative changes in ANS activity rather than the absolute intensity of SNS and PNS activity. An advantage of this study, however, is the use of established tests of cardiac autonomic reflex that have been validated to detect CAN, by measuring changes in HRV and vascular dynamics during different challenges to the body.

\section{Conclusions}

Our study found a significant association of vitamin D status with CMRS, calculated from composite measures of body composition, ANS activity, and endothelial 
function by using a novel system. Thus, data suggest that vitamin D may play a significant role in CVD, probably through modulation of cardiac performance by affecting ANS activity, vascular tone, and endothelial function. Due to the nature of this cross-sectional study, we cannot conclude that vitamin D deficiency is a cause of increased cardiovascular risk. Future prospective randomized control studies, with sufficient resources, are warranted to evaluate the change in cardiometabolic risk in vitamin D insufficient older adults supplemented with vitamin D and to examine the cause-effect relationship. 


\begin{tabular}{|l|c|}
\hline Table 1: Characteristics of Participants (n=95) \\
\hline Vitamin D levels (ng/ml) (Mean \pm SD) & $30.71 \pm 8.78$ \\
\hline Age (years) (Mean \pm SD) & $62.96 \pm 6.45$ \\
\hline Male gender (N (\%)) & $43(45.3)$ \\
\hline Ethnicity (N (\%)) & $43(45.3)$ \\
Hispanic & $33(34.7)$ \\
White Caucasian & $15(15.8)$ \\
African-American & $4(4.2)$ \\
\hline Other & $44.98 \pm 21.62$ \\
\hline Years lived in the United States (Mean \pm SD) & $4.73 \pm 3.05$ \\
\hline Number of diseases or conditions (Mean \pm SD) & $71(74.7)$ \\
\hline Participants reporting prescription medication use (N (\%)) & $2.27 \pm 2.21$ \\
\hline Number of prescription medications (Mean \pm SD) & $76(80.0)$ \\
\hline Participants reporting OTC medication use (N (\%)) & $1.47 \pm 1.12$ \\
\hline Number of OTC medications (Mean \pm SD) & $75(78.9)$ \\
\hline Caffeine consumers (N (\%)) & $1.64 \pm 1.38$ \\
\hline Cups of caffeinated coffee or caffeine containing beverages per & $2.11 \pm 3.70$ \\
\hline day (Mean \pm SD) & $11(11.6)$ \\
\hline Alcoholic drinks per week (Mean \pm SD) & $76.12 \pm 17.11$ \\
\hline Smokers (N (\%)) & $27.01 \pm 5.27$ \\
\hline Weight (kg) (Mean \pm SD) & $30.92 \pm 9.09$ \\
\hline BMI (kg/m²) (Mean \pm SD) & $132.60 \pm 21.97$ \\
\hline \%FM (Mean \pm SD) & $76.03 \pm 14.48$ \\
\hline SBP (mmHg) (Mean \pm SD) & $70.43 \pm 11.83$ \\
\hline DBP (mmHg) (Mean \pm SD) & $4353.75 \pm$ \\
\hline HR (bpm) (Mean \pm SD) & 4333.15 \\
\hline Total physical activity (IPAQ MET minutes per week) & $7.21 \pm 7.62$ \\
\hline Mean \pm SD) & $595 ;$ \\
\hline Depressive symptoms (BDI score) (Mean \pm SD) & \\
\hline SD S S & \\
\hline
\end{tabular}

SD: Standard Deviation; N: Number; BMI: Body Mass Index; FM: Fat Mass; SBP: Systolic Blood Pressure; DBP: Diastolic Blood Pressure; HR: Heart Rate; bpm: beats per minute; IPAQ: International Physical Activity Questionnaire; BDI: Beck Depression Inventory. 
Table 2: Comparison of Cardiometabolic Risk Scores (CMRS) Between Vitamin D Insufficient and Sufficient Participants

\begin{tabular}{|l|c|c|c|c|c|}
\hline & $\begin{array}{c}\text { Study } \\
\text { population } \\
(\mathbf{n}=\mathbf{9 5})\end{array}$ & $\begin{array}{c}\text { Vitamin D } \\
\text { Insufficient } \\
<\mathbf{3 0} \mathbf{~ n g} / \mathbf{m l} \\
\mathbf{( n = 4 4 )}\end{array}$ & $\begin{array}{c}\text { Vitamin D } \\
\text { Sufficient } \\
\mathbf{3} \mathbf{3 0} \mathbf{~ n g} / \mathbf{m l} \\
\mathbf{( n = 5 1 )}\end{array}$ & MD & P-Value \\
\hline $\begin{array}{l}\text { CMRS } \\
\text { (Mean } \pm \text { SD) }\end{array}$ & $5.17 \pm 3.58$ & $5.95 \pm 3.29$ & $4.48 \pm 3.72$ & 1.48 & 0.046 \\
\hline
\end{tabular}

Independent t-tests. SD: Standard Deviation; MD: Mean Difference. 


\begin{tabular}{|c|c|c|c|c|}
\hline \multicolumn{5}{|c|}{$\begin{array}{l}\text { Table 3: The Relationship Between Vitamin D Levels and CMRS in Multiple } \\
\text { Linear Regressions }\end{array}$} \\
\hline \multicolumn{5}{|c|}{\begin{tabular}{l|l}
$\beta$ (S.E.) & $P$-Value \\
\end{tabular}} \\
\hline \begin{tabular}{l|l|l|l|l} 
Model 1 & Vitamin D status (ng/ml) & $-0.09(0.05)$ & 0.056 & 0.029 \\
\end{tabular} & \multicolumn{4}{|c|}{\begin{tabular}{c|c}
$\boldsymbol{\beta}$ (S.E.) & $P$-Value \\
\end{tabular}} \\
\hline Model 2 & Vitamin D status (ng/ml) & $\begin{array}{l}-0.11(0.05) \\
0.37(0.17)\end{array}$ & & 0.069 \\
\hline
\end{tabular}

Stepwise linear regression. Dependent variable:CMRS. Model 1: Vitamin D status; Model 2: Model 1

+ age, gender, marital status, race, years living in United States, education, employment, income, surgery, injury, falls, number of diseases, presence of diseases that can affect cardiovascular system (arrhythmias, high blood pressure, low blood pressure, high cholesterol, high triglycerides, circulation problems, stroke, COPD, bronchitis, shortness of breath, type 1 and type 2 diabetes, hypoglycemia), prescription medications, over the counter medications, vitamin/ mineral supplement use, coffee use, alcohol use, smoking, depressive symptoms, fear of falling, physical activity. $\boldsymbol{\beta}$ : Beta Coefficient; SE: Standard Error; CI: Confidence Interval. 


\section{References}

1. Holick MF. Vitamin D deficiency. N Engl J Med. 2007;357(3):266-281.

2. Mann MC, Hollenberg MD, Hanley DA, Ahmed SB. Vitamin D, the autonomic nervous system, and cardiovascular risk. Physiol Rep. 2015;3(4):123491-1234914.

3. Kim DH, Sabour S, Sagar UN, Adams S, Whellan DJ. Prevalence of hypovitaminosis $\mathrm{D}$ in cardiovascular diseases (from the National Health and Nutrition Examination Survey 2001 to 2004). Am J Cardiol. 2008;102(11):1540-1544.

4. Norman PE, Powell JT. Vitamin D and cardiovascular disease. Circ Res. 2014;114(2):379-393.

5. Deo R, Katz R, Shlipak MG, et al. Vitamin D, parathyroid hormone, and sudden cardiac death: Results from the cardiovascular health study. Hypertension. 2011;58(6):1021-1028.

6. Wang TJ, Pencina MJ, Booth SL, et al. Vitamin D deficiency and risk of cardiovascular disease. Circulation. 2008;117(4):503-511.

7. Perna L, Schottker B, Holleczek B, Brenner H. Serum 25-hydroxyvitamin D and incidence of fatal and nonfatal cardiovascular events: A prospective study with repeated measurements. J Clin Endocrinol Metab. 2013;98(12):4908-4915.

8. Schottker B, Jorde R, Peasey A, et al. Vitamin D and mortality: Meta-analysis of individual participant data from a large consortium of cohort studies from Europe and the United States. BMJ. 2014;348(3656):1-15.

9. Parker J, Hashmi O, Dutton D, et al. Levels of vitamin D and cardiometabolic disorders: Systematic review and meta-analysis. Maturitas. 2010;65(3):225-236.

10. Drechsler C, Pilz S, Obermayer-Pietsch B, et al. Vitamin D deficiency is associated with sudden cardiac death, combined cardiovascular events, and mortality in haemodialysis patients. Eur Heart J. 2010;31(18):2253-2261.

11. Thadhani R, Appelbaum E, Pritchett Y, et al. Vitamin D therapy and cardiac structure and function in patients with chronic kidney disease: The PRIMO randomized controlled trial. JAMA. 2012;307(7):674-684.

12. Wang L, Song Y, Manson JE, et al. Circulating 25-hydroxy-vitamin D and risk of cardiovascular disease: A meta-analysis of prospective studies. Circ Cardiovasc Qual Outcomes. 2012;5(6):819-829. 
13. Schottker B, Haug U, Schomburg L, et al. Strong associations of 25-hydroxyvitamin D concentrations with all-cause, cardiovascular, cancer, and respiratory disease mortality in a large cohort study. Am J Clin Nutr. 2013;97(4):782-793.

14. Giovannucci E, Liu Y, Hollis BW, Rimm EB. 25-hydroxyvitamin D and risk of myocardial infarction in men: A prospective study. Arch Intern Med. 2008;168(11):11741180.

15. Autier P, Gandini S. Vitamin D supplementation and total mortality: A meta-analysis of randomized controlled trials. Arch Intern Med. 2007;167(16):1730-1737.

16. Gotsman I, Shauer A, Zwas DR, et al. Vitamin D deficiency is a predictor of reduced survival in patients with heart failure; vitamin D supplementation improves outcome. Eur J Heart Fail. 2012;14(4):357-366.

17. Pilz S, Dobnig H, Fischer JE, et al. Low vitamin D levels predict stroke in patients referred to coronary angiography. Stroke. 2008;39(9):2611-2613.

18. Dobnig H, Pilz S, Scharnagl H, et al. Independent association of low serum 25hydroxyvitamin D and 1,25-dihydroxyvitamin D levels with all-cause and cardiovascular mortality. Arch Intern Med. 2008;168(12):1340-1349.

19. Wang L, Manson JE, Song Y, Sesso HD. Systematic review: Vitamin D and calcium supplementation in prevention of cardiovascular events. Ann Intern Med. 2010;152(5):315-323.

20. Holick MF. Vitamin D: A D-lightful health perspective. Nutr Rev. 2008;66(10 Suppl 2):S182-194.

21. Beveridge LA, Witham MD. Vitamin D and the cardiovascular system. Osteoporos Int. 2013;24(8):2167-2180.

22. DeLuca GC, Kimball SM, Kolasinski J, Ramagopalan SV, Ebers GC. Review: The role of vitamin D in nervous system health and disease. Neuropathol Appl Neurobiol. 2013;39(5):458-484.

23. Garcion E, Wion-Barbot N, Montero-Menei CN, Berger F, Wion D. New clues about vitamin D functions in the nervous system. Trends Endocrinol Metab. 2002;13(3):100105.

24. Mann MC, Exner DV, Hemmelgarn BR, et al. Vitamin D levels are associated with cardiac autonomic activity in healthy humans. Nutrients. 2013;5(6):2114-2127. 
25. Mann MC, Exner DV, Hemmelgarn BR, et al. Vitamin D supplementation is associated with improved modulation of cardiac autonomic tone in healthy humans. Int $J$ Cardiol. 2014;172(2):506-508.

26. Mann MC. Vitamin D and cardiac autonomic tone: Cardiovascular implications in humans with and without chronic kidney disease. [Dissertation]. Calgary, Alberta: University of Calgary; 2015.

27. Tak YJ, Lee JG, Kim YJ, Lee SY, Cho BM. 25-hydroxyvitamin D and its relationship with autonomic dysfunction using time- and frequency-domain parameters of heart rate variability in korean populations: A cross-sectional study. Nutrients. 2014;6(10):43734388.

28. Cetin M, Kozdag G, Ural D, et al. Could decreased vitamin D levels be related with impaired cardiac autonomic functions in patients with chronic heart failure: An observational study. Anadolu Kardiyol Derg. 2014;14(5):434-441.

29. Jung CH, Jung SH, Kim KJ, et al. The relationship between vitamin D status and cardiac autonomic neuropathy in patients with type 2 diabetes mellitus. Diab Vasc Dis Res. 2015;12(5):342-351.

30. Kapa S, Venkatachalam KL, Asirvatham SJ. The autonomic nervous system in cardiac electrophysiology: An elegant interaction and emerging concepts. Cardiol Rev. 2010;18(6):275-284.

31. Dekker JM, Schouten EG, Klootwijk P, Pool J, Swenne CA, Kromhout D. Heart rate variability from short electrocardiographic recordings predicts mortality from all causes in middle-aged and elderly men: The Zutphen study. Am J Epidemiol. 1997;145(10):899908.

32. Tsuji H, Venditti FJ,Jr, Manders ES, et al. Determinants of heart rate variability. $J$ Am Coll Cardiol. 1996;28(6):1539-1546.

33. Tsuji H, Larson MG, Venditti FJ,Jr, et al. Impact of reduced heart rate variability on risk for cardiac events: The Framingham Heart Study. Circulation. 1996;94(11):28502855.

34. La Rovere MT, Pinna GD, Maestri R, et al. Short-term heart rate variability strongly predicts sudden cardiac death in chronic heart failure patients. Circulation. 2003;107(4):565-570.

35. Goldberger JJ, Cain ME, Hohnloser SH, et al. American Heart association/American College of Cardiology Foundation/Heart Rhythm society: Scientific statement on noninvasive risk stratification techniques for identifying patients at risk for sudden cardiac death: A scientific statement from the American Heart Association council on 
clinical cardiology committee on electrocardiography and arrhythmias and council on epidemiology and prevention. Circulation. 2008;118(14):1497-1518.

36. Lauer MS. Autonomic function and prognosis. Cleve Clin J Med. 2009;76(Suppl 2):S18-22.

37. Cozzolino M, Ketteler M, Zehnder D. The vitamin D system: A crosstalk between the heart and kidney. Eur J Heart Fail. 2010;12(10):1031-1041.

38. Pilz S, Tomaschitz A, Drechsler C, Dekker JM, Marz W. Vitamin D deficiency and myocardial diseases. Mol Nutr Food Res. 2010;54(8):1103-1113.

39. Liu LC, Voors AA, van Veldhuisen DJ, et al. Vitamin D status and outcomes in heart failure patients. Eur J Heart Fail. 2011;13(6):619-625.

40. De Novellis V, Loffreda A, Vitagliano S, et al. Effects of dietary vitamin D deficiency on the cardiovascular system. Res Commun Chem Pathol Pharmacol. 1994;83(2):125-144.

41. Erkinjuntti T, Sulkava R, Wikstrom J, Autio L. Short portable mental status questionnaire as a screening test for dementia and delirium among the elderly. $J$ Am Geriatr Soc. 1987;35(5):412-416.

42. Wagner D, Hanwell HE, Vieth R. An evaluation of automated methods for measurement of serum 25-hydroxyvitamin D. Clin Biochem. 2009;42(15):1549-1556.

43. The IPAQ Group. Guidelines for data processing and analysis of the International Physical Activity Questionnaire (IPAQ) - short and long forms. IPAQ Web site. http://www.ipaq.ki.se/scoring.pdf. Accessed April 24, 2013.

44. Rutten A, Ziemainz H, Schena F, et al. Using different physical activity measurements in eight European countries. results of the European physical activity surveillance system (EUPASS) time series survey. Public Health Nutr. 2003;6(4):371376.

45. Bassett DR,Jr. International physical activity questionnaire: 12-country reliability and validity. Med Sci Sports Exerc. 2003;35(8):1381-1395.

46. The IPAQ Group. The International Physical Activity Questionnaire. IPAQ Web site. https://sites.google.com/site/theipaq/. Accessed April 24, 2013.

47. Hagstromer M, Oja P, Sjostrom M. The International Physical Activity Questionnaire (IPAQ): A study of concurrent and construct validity. Public Health Nutr. 2006;9(6):755762. 
48. Benedetti TRB, de Cesaro Antunes P, Rodriguez-Anez CR, Mazo GZ, Petrozki EL. Reproducibility and reliability of the International Physical Activity Questionnaire in ederly men. Rev Bras Med Esporte. 2007;13 (1):9-13.

49. Benedetti TRB, Mazo GZ, Barros MV. Application of the International Physical Activity Questionnaire (IPAQ) for evaluation of elderly women: Concurrent validity and test-retest reproducibility. Rev Bras Ciên e Mov. 2004;12(1):25-34.

50. Mader U, Martin BW, Schutz Y, Marti B. Validity of four short physical activity questionnaires in middle-aged persons. Med Sci Sports Exerc. 2006;38(7):1255-1266.

51. Kolbe-Alexander TL, Lambert EV, Harkins JB, Ekelund U. Comparison of two methods of measuring physical activity in south african older adults. J Aging Phys Act. 2006;14(1):98-114.

52. Silva RB, Costa-Paiva L, Pinto Neto AM, Braga Ade A, Morais SS. Habitual physical activity and cardiovascular risk in post menopause. Rev Assoc Med Bras. 2006;52(4):242-246.

53. da Silva RB, Costa-Paiva L, Pinto-Neto AM, Braga Ade A, Morais SS. Association between habitual physical activity and parameters of physical fitness in postmenopausal women. Climacteric. 2005;8(4):360-370.

54. Ainsworth BE, Macera CA, Jones DA, et al. Comparison of the 2001 BRFSS and the IPAQ physical activity questionnaires. Med Sci Sports Exerc. 2006;38(9):1584-1592.

55. Ekelund U, Sepp H, Brage S, et al. Criterion-related validity of the last 7-day, short form of the International Physical Activity Questionnaire in swedish adults. Public Health Nutr. 2006;9(2):258-265.

56. Kwak L, Hagstromer M, Sjostrom M. Can the IPAQ-long be used to assess occupational physical activity? J Phys Act Health. 2012;9(8):1130-1137.

57. Arvidsson D, Slinde F, Hulthen L. Physical activity questionnaire for adolescents validated against doubly labelled water. Eur J Clin Nutr. 2005;59(3):376-383.

58. Beck AT, Steer RA, Brown GK. RCMAR measurement tools: Beck depression inventory-2nd edition (BDI-II). Medical University of South Carolina Web site. http://www.musc.edu/dfm/RCMAR/Beck.html. Accessed April 21, 2013.

59. Beck AT, Steer RA. Internal consistencies of the original and revised Beck Depression Inventory. J Clin Psychol. 1984;40(6):1365-1367.

60. Beck AT, Ward CH, Mendelson M, Mock J, Erbaugh J. An inventory for measuring depression. Arch Gen Psychiatry. 1961;4:561-571. 
61. Richter P, Werner J, Heerlein A, Kraus A, Sauer H. On the validity of the Beck Depression Inventory. A review. Psychopathology. 1998;31(3):160-168.

62. Segal DL, Coolidge FL, Cahill BS, O'Riley AA. Psychometric properties of the Beck Depression Inventory II (BDI-II) among community-dwelling older adults. Behav Modif. 2008;32(1):3-20.

63. Lewis JE, Tannenbaum SL, Gao J, et al. Comparing the accuracy of ES-BC, EIS-GS, and ES oxi on body composition, autonomic nervous system activity, and cardiac output to standardized assessments. Med Devices (Auckl). 2011;4:169-177.

64. Lewis JE, Lantigua L, Atlas SE, et al. A cross-sectional assessment to detect type 2 diabetes with endothelial and autonomic nervous system markers using a novel system. $J$ Diabetes Metab Disord. 2014;13(1):118-125.

65. Brodie D, Moscrip V, Hutcheon R. Body composition measurement: A review of hydrodensitometry, anthropometry, and impedance methods. Nutrition. 1998;14(3):296310.

66. Chumlea WC, Guo SS, Kuczmarski RJ, et al. Body composition estimates from NHANES III bioelectrical impedance data. Int J Obes Relat Metab Disord. 2002;26(12):1596-1609.

67. Rigaud B, Morucci JP, Chauveau N. Bioelectrical impedance techniques in medicine. part I: Bioimpedance measurement. second section: Impedance spectrometry. Crit Rev Biomed Eng. 1996;24(4-6):257-351.

68. Schoeller DA. Bioelectrical impedance analysis. what does it measure? Ann N Y Acad Sci. 2000;904:159-162.

69. Task Force of the European Society of Cardiology and the North American Society of Pacing and Electrophysiology. Heart rate variability: Standards of measurement, physiological interpretation and clinical use. Circulation. 1996;93(5):1043-1065.

70. Rolim LC, de Souza JS, Dib SA. Tests for early diagnosis of cardiovascular autonomic neuropathy: Critical analysis and relevance. Front Endocrinol (Lausanne). 2013;4(173):1-4.

71. Alty SR, Angarita-Jaimes N, Millasseau SC, Chowienczyk PJ. Predicting arterial stiffness from the digital volume pulse waveform. IEEE Trans Biomed Eng. 2007;54(12):2268-2275.

72. Anderson TJ. Arterial stiffness or endothelial dysfunction as a surrogate marker of vascular risk. Can J Cardiol. 2006;22(Suppl B):72-80. 
73. Stoner L, Young JM, Fryer S. Assessments of arterial stiffness and endothelial function using pulse wave analysis. Int J Vasc Med. 2012;2012(903107):1-9.

74. Wilke K, Martin A, Terstegen L, Biel SS. A short history of sweat gland biology. Int J Cosmet Sci. 2007;29(3):169-179.

75. Pilz S, Marz W, Wellnitz B, et al. Association of vitamin D deficiency with heart failure and sudden cardiac death in a large cross-sectional study of patients referred for coronary angiography. J Clin Endocrinol Metab. 2008;93(10):3927-3935.

76. Boland RL. VDR activation of intracellular signaling pathways in skeletal muscle. Mol Cell Endocrinol. 2011;347(1-2):11-16.

77. Buitrago C, Pardo VG, Boland R. Role of VDR in 1alpha,25-dihydroxyvitamin D3dependent non-genomic activation of MAPKs, src and akt in skeletal muscle cells. $J$ Steroid Biochem Mol Biol. 2013;136:125-130.

78. Krause M, Anschutz W, Vettorazzi E, Breer S, Amling M, Barvencik F. Vitamin D deficiency intensifies deterioration of risk factors, such as male sex and absence of vision, leading to increased postural body sway. Gait Posture. 2014;39(1):166-171.

79. Chan CT, Levin NW, Chertow GM, et al. Determinants of cardiac autonomic dysfunction in ESRD. Clin J Am Soc Nephrol. 2010;5(10):1821-1827.

80. Oikawa K, Ishihara R, Maeda T, et al. Prognostic value of heart rate variability in patients with renal failure on hemodialysis. Int J Cardiol. 2009;131(3):370-377.

81. Pilz S, Iodice S, Zittermann A, Grant WB, Gandini S. Vitamin D status and mortality risk in CKD: A meta-analysis of prospective studies. Am J Kidney Dis. 2011;58(3):374382.

82. Chan CT. Heart rate variability in patients with end-stage renal disease: An emerging predictive tool for sudden cardiac death? Nephrol Dial Transplant. 2008;23(10):30613062.

83. Drechsler C, Verduijn M, Pilz S, et al. Vitamin D status and clinical outcomes in incident dialysis patients: Results from the NECOSAD study. Nephrol Dial Transplant. 2011;26(3):1024-1032.

84. Dusso AS, Tokumoto M. Defective renal maintenance of the vitamin D endocrine system impairs vitamin D renoprotection: A downward spiral in kidney disease. Kidney Int. 2011;79(7):715-729. 
85. Nishimura M, Tokoro T, Nishida M, et al. Sympathetic overactivity and sudden cardiac death among hemodialysis patients with left ventricular hypertrophy. Int $J$ Cardiol. 2010;142(1):80-86.

86. Al Mheid I, Patel R, Murrow J, et al. Vitamin D status is associated with arterial stiffness and vascular dysfunction in healthy humans. J Am Coll Cardiol.

2011;58(2):186-192.

87. Karohl C, Vaccarino V, Veledar E, et al. Vitamin D status and coronary flow reserve measured by positron emission tomography: A co-twin control study. J Clin Endocrinol Metab. 2013;98(1):389-397.

88. Dong Y, Stallmann-Jorgensen IS, Pollock NK, et al. A 16-week randomized clinical trial of 2000 International Units daily vitamin D3 supplementation in black youth: 25hydroxyvitamin D, adiposity, and arterial stiffness. J Clin Endocrinol Metab. 2010;95(10):4584-4591.

89. Breslavsky A, Frand J, Matas Z, Boaz M, Barnea Z, Shargorodsky M. Effect of high doses of vitamin $\mathrm{D}$ on arterial properties, adiponectin, leptin and glucose homeostasis in type 2 diabetic patients. Clin Nutr. 2013;32(6):970-975.

90. Baggerly CA, Cuomo RE, French CB, et al. Sunlight and vitamin D: Necessary for public health. J Am Coll Nutr. 2015;34(4):359-365.

91. Saleh FN, Schirmer H, Sundsfjord J, Jorde R. Parathyroid hormone and left ventricular hypertrophy. Eur Heart J. 2003;24(22):2054-2060.

92. Li Y, Chen C, Liu HL, Qian G. Vitamin D, parathyroid hormone, and heart failure in a chinese elderly population. Endocr Pract. 2015;21(1):30-40.

93. Geleijnse JM. Vitamin D and the prevention of hypertension and cardiovascular diseases: A review of the current evidence. Am J Hypertens. 2011;24(3):253-262.

94. Routledge HC, Chowdhary S, Townend JN. Heart rate variability--a therapeutic target? J Clin Pharm Ther. 2002;27(2):85-92.

95. Reed MJ, Robertson CE, Addison PS. Heart rate variability measurements and the prediction of ventricular arrhythmias. QJM. 2005;98(2):87-95.

96. Kleiger RE, Stein PK, Bigger JT,Jr. Heart rate variability: Measurement and clinical utility. Ann Noninvasive Electrocardiol. 2005;10(1):88-101.

97. Lewis MJ. Heart rate variability analysis: A tool to assess cardiac autonomic function. Comput Inform Nurs. 2005;23(6):335-341. 


\section{CHAPTER VII: SUMMARY AND CONCLUSIONS}

Our study showed that vitamin D insufficiency is common in healthy communitydwelling older adults (>55 years old) living in Miami-Dade County, especially among Hispanics. The prevalence of vitamin D deficiency (25(OH)D $<20 \mathrm{ng} / \mathrm{ml})$ and insufficiency (25(OH)D <30 ng/ml) was 10\% and 36\%, respectively, which, as expected, was lower than that reported for the general United States adult and older adult population. This was expected in a population that has a greater opportunity for vitamin D skin synthesis due to year-round sunlight availability. Our results, however, are similar to that reported in previous studies conducted in South Florida. ${ }^{1,2}$

Despite the lower prevalence of vitamin D insufficiency in this study compared to the general United States older adult population, it is still a public health concern, and identifying risk factors is critical to develop effective interventions. As expected, vitamin D intake was not significantly correlated with vitamin D status in our study, and our findings are supported by other studies that have previously shown that dietary intake has minimal contribution to vitamin D status. ${ }^{3,4}$ On the other hand, we found that lack of sun exposure, higher percent fat mass (\%FM), and lack of use of vitamin/mineral supplements were risk factors for vitamin D deficiency in this older group. Ethnicity, however, was the most consistent and important risk factor in this study population, since those who were vitamin D insufficient were more likely to be Hispanic, and thus Hispanics had significantly lower vitamin D levels than white Caucasians and AfricanAmericans. The reasons why immigrant Hispanics may be more likely to be vitamin D deficient and insufficient are unknown, but it may be due to differences in sun exposure 
behaviors, public health awareness initiatives in their home countries and less access to healthcare services due to their immigration status. Since vitamin D deficiency is linked to health risk factors, it is important that health professionals become aware of the connections of vitamin D status with intake, bioavailability, and skin synthesis, so that they are able to identify patients at risk and develop and plan pertinent interventions to prevent and correct deficiency and insufficiency, especially in vulnerable populations like Hispanics.

Vitamin D deficiency in older adults has been linked to leading causes of disability and death in the United States including cancer, diabetes, falls, fractures, and cardiovascular disease (CVD) ${ }^{5-14}$ Vitamin D deficiency has received much attention as a risk factor for falls because of its association with gait impairment (slower gait speed), global cognitive deficits, and compromised executive function. ${ }^{15-19}$ Nonetheless, studies that investigate the relationship between vitamin D status, gait and cognition have looked at these factors independently. We used the dual task physical performance test to assess the relationship between vitamin $\mathrm{D}$ and cognition, especially executive function, in the context of mobility. We evaluated the competition for information processing capacity between gait stability during the primary automatic task (i.e., walking) and cognitive performance during the completion of the secondary cognitive task (i.e., counting backwards from 50 by 1). Dual tasking usually results in worse performance in either one or both tasks when compared to performance of each task individually. ${ }^{20}$ As hypothesized, in our study we found a marked deterioration of the automatic primary motor task during dual tasking, and not the secondary cognitive task, when compared to single tasking. Thus, when dual tasking, this healthy older adult population prioritized the 
secondary cognitive task at the expense of compromising their motor capacity. Despite these findings, we did not find a significant assocation between vitamin D status and the change in peformance in cogntive and gait tasks from dual to single tasking; thus, vitamin D insufficient participants did not have worse dual task performance. No signficant differences were found between vitamin D status in motor functioning during each individual task. Interestingly, we found counting rates were significantly lower in the vitamin D insufficient group, meaning they had worse cognitive performance, since they counted significantly less figures per second compared to the vitamin D sufficient group when performing either single or dual tasks. Since counting backwards is a mental tracking task, which is a component of executive function, our results support a relationship between vitamin D insufficiency and impaired executive function. Executive dysfunction has been previously associated with fall risks in the elderly, and it could be a possible mediator between vitamin D and falls. ${ }^{21}$ Our data suggest that cognition may play a signifcant role in vitamin D's influence on falls, while motor function may play a lesser role in healthy young older adults. ${ }^{22}$

Furthermore, our results support previous studies that found an association between vitamin $\mathrm{D}$ deficiency and cardiometabolic risk, We found a significant association of vitamin D status with cardiometabolic risk score (CMRS), calculated from composite measures of body composition, autonomic nervous system (ANS) activity and endothelial function by using a novel system. Our data suggest that vitamin D may play a signifcant role on CVD, probably through modulation of cardic performance by mediating genomic and non-genomic mechanisms that affect ANS activity, vascular tone and endothelial function. This is the first study to investigate the relationship between 
vitamin D status and cardiometabolic risk, using a rapid, non-invasive method that integrates measures of ANS and endothelial function, anthropometrics, lifestyle characteristics, and body composition data. Previous studies have shown a relationship between vitamin D and cardiac ANS, independent of other cardiovascular risk factors like endothelial dysfunction and increased \%FM.

\section{References}

1. Lagari V, Gomez-Marin O, Levis S. The role of vitamin D in improving physical performance in the elderly. $J$ Bone Miner Res. 2013;28(10):2194-2201.

2. Smolar DE, Engstrom GA, Diaz S, Tappen R, Ouslander JG. Ethnic differences in vitamin D insufficiency in South Florida community-dwelling older adults. J Am Geriatr Soc. 2012;60(10):1990-1991.

3. Whiting SJ, Calvo MS. Correcting poor vitamin D status: Do older adults need higher repletion doses of vitamin D3 than younger adults? Mol Nutr Food Res. 2010;54(8):1077-1084.

4. Whiting SJ, Calvo MS. Dietary recommendations to meet both endocrine and autocrine needs of vitamin D. J Steroid Biochem Mol Biol. 2005;97(1-2):7-12.

5. Baggerly CA, Cuomo RE, French CB, et al. Sunlight and vitamin D: Necessary for public health. J Am Coll Nutr. 2015;34(4):359-365.

6. Toffanello ED, Perissinotto E, Sergi G, et al. Vitamin D and physical performance in elderly subjects: The Pro.V.A study. PLoS One. 2012;7(4):1-9.

7. Zamboni M, Zoico E, Tosoni P, et al. Relation between vitamin D, physical performance, and disability in elderly persons. J Gerontol A Biol Sci Med Sci. 2002;57(1):7-11.

8. Muir SW, Montero-Odasso M. Effect of vitamin D supplementation on muscle strength, gait and balance in older adults: A systematic review and meta-analysis. $J$ Am Geriatr Soc. 2011;59(12):2291-2300.

9. Bischoff-Ferrari HA, Giovannucci E, Willett WC, Dietrich T, Dawson-Hughes B. Estimation of optimal serum concentrations of 25-hydroxyvitamin D for multiple health outcomes. Am J Clin Nutr. 2006;84(1):18-28. 
10. Dukas L, Staehelin HB, Schacht E, Bischoff HA. Better functional mobility in community-dwelling elderly is related to D-hormone serum levels and to daily calcium intake. J Nutr Health Aging. 2005;9(5):347-351.

11. Gallagher JC. The effects of calcitriol on falls and fractures and physical performance tests. J Steroid Biochem Mol Biol. 2004;89-90(1-5):497-501.

12. Houston DK, Cesari M, Ferrucci L, et al. Association between vitamin D status and physical performance: The InCHIANTI study. J Gerontol A Biol Sci Med Sci. 2007;62(4):440-446.

13. Wicherts IS, van Schoor NM, Boeke AJ, et al. Vitamin D status predicts physical performance and its decline in older persons. J Clin Endocrinol Metab. 2007;92(6):20582065.

14. Semba RD, Houston DK, Bandinelli S, et al. Relationship of 25-hydroxyvitamin D with all-cause and cardiovascular disease mortality in older community-dwelling adults. Eur J Clin Nutr. 2010;64(2):203-209.

15. van der Schaft J, Koek HL, Dijkstra E, Verhaar HJ, van der Schouw YT, EmmelotVonk MH. The association between vitamin D and cognition: A systematic review. Ageing Res Rev. 2013;12(4):1013-1023.

16. Murad MH, Elamin KB, Abu Elnour NO, et al. Clinical review: The effect of vitamin D on falls: A systematic review and meta-analysis. J Clin Endocrinol Metab. 2011;96(10):2997-3006.

17. Kalyani RR, Stein B, Valiyil R, Manno R, Maynard JW, Crews DC. Vitamin D treatment for the prevention of falls in older adults: Systematic review and meta-analysis. J Am Geriatr Soc. 2010;58(7):1299-1310.

18. Annweiler C, Schott AM, Berrut G, Fantino B, Beauchet O. Vitamin D-related changes in physical performance: A systematic review. J Nutr Health Aging. 2009;13(10):893-898.

19. Eastlack ME, Arvidson J, Snyder-Mackler L, Danoff JV, McGarvey CL. Interrater reliability of videotaped observational gait-analysis assessments. Phys Ther. 1991;71(6):465-472.

20. Yentes JM, Perell KL, Fang MA, Barr ML. Cognitive processing during gait and balance: A review. The Free Library Web site. http://www.thefreelibrary.com/Cognitive+processing+during+gait+and+balance\%3a +a+review.-a0167842473. Updated 2007. Accessed August 31, 2015. 
21. Menant JC, Close JC, Delbaere K, et al. Relationships between serum vitamin D levels, neuromuscular and neuropsychological function and falls in older men and women. Osteoporos Int. 2012;23(3):981-989.

22. Peterson A, Mattek N, Clemons A, et al. Serum vitamin D concentrations are associated with falling and cognitive function in older adults. $J$ Nutr Health Aging. 2012;16(10):898-901. 


\section{CHAPTER VIII: STRENGTHS AND LIMITATIONS}

Cross-sectional studies can establish association among factors; however, they do not prove cause and effect. However, understanding the relationship between nutrition and disease is the foundation for developing interventions that seek to enhance nutritional status to prevent or ameliorate continued proliferation of chronic diseases during the process of aging. Thus, this study provides the foundation for future longitudinal interventional studies that investigate the cause and effect relationship between vitamin D status, nutritional supplementation, and non-skeletal outcomes such as cardiometabolic risk and falls associated with cognitive executive function during mobility.

Another limitation of this study was selection bias. Besides the expected higher sun exposure of this population, the broader age criterion could be a possible explanation for the lower prevalence of vitamin D insufficiency observed in our study. In addition, the participants in this study were healthier, since the exclusion criteria for the parent study included current diagnoses of numerous diseases/conditions. Thus, this was not a randomly selected sample from the general older adult population in Miami-Dade, but instead were healthier older adults who volunteered to participate and met inclusion criteria. Volunteer bias may be a strong limitation, as volunteers have been found to be more intelligent, have higher social status and the need for approval, and be less authoritarian and conforming than the general population. ${ }^{1}$ Furthermore, small sample size could have also affected the results of this study. Due to limitations of time and resources, we were only able to recruit 97 participants, reducing the power to detect significant differences in this study. 
Other limitations include over-and under- reporting in surveys, the amount of error inherent to short food frequency questionnaires, and the lack of ecological validity of the dual task physical performance test and cardiometabolic risk assessment. Despite the limitations in study design and tools used, we did find significant findings in relation with vitamin D status and executive function and cardiovascular risk in this healthy young older adult population. This may indicate that healthy older adults may be at risk of developing health consequences from vitamin D insufficiency at a younger age and before any cognitive impairment and cardiometabolic risks are evident. Furthermore, the major strength of this study was that it used novel tests to assess non-skeletal outcomes that have been previously associated with vitamin D insufficiency and deficiency. These allowed for the evaluation of the relationship of vitamin D status with cognition in the context of mobility and with other risk factors for cardiovascular disease. Thus, future studies evaluating the relationship between this nutrient and nonskeletal health outcomes in the elderly should consider including younger older adults to determine the early onset of health consequences related to vitamin D status

\section{References}

1. Heiman GW. Research methods in psychology. 3rd ed. Boston, MA: Houghton Mifflin Company; 2002. 


\section{CHAPTER IX: FUTURE RESEARCH}

Future double-blind longitudinal randomized controlled clinical trials, with significant resources to support a bigger sample size, are warranted to evaluate the determinants of vitamin D status, the long-term consequences of vitamin D deficiency/insufficiency, and the effect of vitamin D supplementation on non-skeletal outcomes in healthy middle-aged and older adults with vitamin D insufficiency and/or deficiency. This type of study is necessary to determine a causal relationship between vitamin D status and non-skeletal outcomes, such as cognition in the context of mobility (as measured by dual task physical performance tests) and cardiometabolic risk (as measured by a composite score involving several cardiovascular risk factors).

This study provides data to support the need for further research that investigates the determinants of vitamin D status living in sunny South Florida. Despite the lower prevalence of vitamin D insufficiency in this study compared to the general United States older adult population, it is still a public health concern. Identifying risk factors is critical, so that health professionals become aware of the connections of vitamin D status with intake, bioavailability, and skin synthesis. Thus, clinicians need to identify patients at risk of vitamin D deficiency and insufficiency and develop pertinent interventions in order to prevent and correct these, especially in vulnerable populations such as the immigrant Hispanic community. It is important to determine the barriers to sun exposure and vitamin D supplementation that makes this population vulnerable to vitamin D insufficiency and at risk of developing chronic diseases associated with this nutrient deficiency. 
Findings from our study support further research that investigates the benefit of vitamin D supplementation in this population. Our results support a relationship between vitamin $\mathrm{D}$ deficiency and executive dysfunction, suggesting that cognition may play a signifcant role in vitamin D’s influence on falls, while motor function may play a lesser role in this healthy younger older adult population. Future interventions are warranted to determine if vitamin D deficiency is a cause of executive dysfunction that leads to decreased performance in mental tracking tasks during dual tasking. Furthermore, our study supports a relationship between vitamin D and cardiometabolic risk, suggesting vitamin D may mediate its effects on cardiovascular health through modulation of the autonomic nervous system (ANS) and vascular dynamics. Despite observational and mechanistic data, which support vitamin D having protective role in CVD, intervention studies to date are controversial. The mechanism by which vitamin $\mathrm{D}$ affects cardiovascular health is still unclear and the need for long-term intervention studies using cardiovascular events as a primary outcome is clear to provide answers to the many remaining questions. It is essential to determine if vitamin $\mathrm{D}$ supplementation has the potential for reversing the increase in CVD risk associated with vitamin D deficiency.

Vitamin D supplementation may be a cost-effective treatment for improving and/or maintaining the health of both healthy and populations with chronic disease. This type of intervention may reduce the risk of developing chronic disease. A cost-benefit analysis has estimated a reduction of as many as a total of 336,000 deaths per year if the United States adult population were to raise vitamin D levels above $40 \mathrm{ng} / \mathrm{ml}$. This also translates into a reduction of about $\$ 130$ billion per year in direct healthcare costs. ${ }^{1}$ 


\section{References}

1. Baggerly CA, Cuomo RE, French CB, et al. Sunlight and vitamin D: Necessary for public health. J Am Coll Nutr. 2015;34(4):359-365. 
APPENDIX A 


\begin{tabular}{|c|c|c|c|c|}
\hline & $\begin{array}{l}\text { Author, } \\
\text { Year, Study } \\
\text { Design }\end{array}$ & $\begin{array}{l}\text { Study } \\
\text { Population }\end{array}$ & Outcomes & Conclusions \\
\hline 1 & $\begin{array}{l}\text { Verreault et } \\
\text { al. }(2002)^{1} \\
\text { Longitudinal } \\
\text { (3 yrs.) }\end{array}$ & $\begin{array}{l}628 \\
\text { postmenopausal } \\
\text { women (>65 } \\
\text { years old) from } \\
\text { WHAS study in } \\
\text { USA. }\end{array}$ & $\begin{array}{l}25(\mathrm{OH}) D(\mathrm{ng} / \mathrm{ml}) \\
\text { Gait velocity (time } \\
\text { (s) to walk } 4 \mathrm{~m} \text { at } \\
\text { usual gait) }\end{array}$ & $\begin{array}{l}\text { No significant findings. } 25(\mathrm{OH}) \mathrm{D} \text { Continuous: mean of } 21.2 \text { and } \\
\text { median of } 19.8 \text {. Categorical, } 25(\mathrm{OH}) D \text { cut off groups and } \% \\
\text { sample: }<10: 12.4 \% \text {. Baseline } 25(\mathrm{OH}) \text { D to gait velocity: not } \\
\text { significant (p value NR). No association between low } 25(\mathrm{OH}) D \\
\text { and decline in gait velocity through time ( }<10 \mathrm{ng} / \mathrm{ml}: \mathrm{p}=0.98 ; 10- \\
21 \mathrm{ng} / \mathrm{ml}: \mathrm{p}=0.76) \text {. }\end{array}$ \\
\hline 2 & $\begin{array}{l}\text { Zamboni et } \\
\text { al. }(2002)^{2} \\
\text { Cross- } \\
\text { sectional }\end{array}$ & $\begin{array}{l}269 \text { adults (68- } \\
75 \text { years old) in } \\
\text { Verona. Mean } \\
+/- \text { SD age of } \\
\text { women and men } \\
71.9+/-2.4 \text { and } \\
71.8+/-2.1 \\
\text { years. }\end{array}$ & $\begin{array}{l}25(\mathrm{OH}) D(\mathrm{ng} / \mathrm{ml}) \\
\text { Gait velocity } \\
\text { (distance }(\mathrm{cm}) \\
\text { walked in } 6 \text { min. } \\
\text { at normal velocity) }\end{array}$ & $\begin{array}{l}\text { No significant findings. } 25(\mathrm{OH}) \mathrm{D} \text { Continuous: mean }+/- \text { SD for } \\
\text { women and men of } 13.2+/-9.6 \text { and } 22.6+/-15.0 \text {, respectively. Men } \\
\text { vs. women: } \mathrm{p}<0.001 .25(\mathrm{OH}) \mathrm{D} \text { cut off categories and \% sample: } \\
\text { women }<15: 50.8 \% \text { and }>15: 49.2 \% \text {; men }<15: 35.1 \% \text { and }>15 \text { : } \\
\text { 64.9\%. Gait velocity: mean distance }+/- \text { SD for women and men } \\
\text { of } 340.9+/-64.2 \text { and 391.2+/-69.4, respectively. Men vs., women: } \\
\mathrm{p}<0.001 .25(\mathrm{OH}) D \text { to distance: not significant in men }(\mathrm{r}=0.04) \text { and } \\
\text { women }(\mathrm{r}=0.13 \text {; both } \mathrm{p}>0.05) \text {. Difference in distance between } \\
25(\mathrm{OH}) \mathrm{D}<15 \text { and }>15 \text { : not significant in men }(\mathrm{p}=0.214) \text { and } \\
\text { women }(\mathrm{p}=0.156) \text {. }\end{array}$ \\
\hline 3 & $\begin{array}{l}\text { Bischoff- } \\
\text { Ferrari et al. } \\
(2004)^{3} \\
\text { Cross } \\
\text { sectional }\end{array}$ & $\begin{array}{l}4100 \text { adults }(60- \\
90 \text { years old) } \\
\text { from NHANES } \\
\text { 1988-1994. } \\
\text { Mean }+/- \text { SD } \\
\text { age: } 71.4+/-7.9 \\
\text { years. }\end{array}$ & $\begin{array}{l}25(\mathrm{OH}) D(\mathrm{ng} / \mathrm{ml}) \\
\text { Gait velocity (time } \\
\text { (s) to walk 8ft } \\
(2.4 \mathrm{~m}) .\end{array}$ & $\begin{array}{l}\text { Significant findings: lower } 25(\mathbf{O H}) \text { D, slower gait velocity. } \\
\text { 25(OH)D continuous: mean of 26.3. 25(OH)D quintiles and } \\
\text { ranges: Q1: 3.5-17.4; Q2: 17.5-22.7; Q3: 22.7-27.8; Q4: 27.9- } \\
\text { 34.4; Q5: 34.5-160.3. Gait velocity: mean time +/- SD (s) of } \\
\text { 3.7+/-1.6s. Difference in time between quintiles: p for trend } \\
<0.0001 . \text { Fully adjusted model: Q2-Q5 were significantly different } \\
(\text { all } p<0.05) \text { from Q1 (p for trend <0.001). Regression plots: time } \\
\text { decreased throughout range of 9.0-37.6ng/ml but most } \\
\text { improvement between 9-16ng/ml }\end{array}$ \\
\hline
\end{tabular}




\begin{tabular}{|c|c|c|c|c|}
\hline \multicolumn{5}{|c|}{ Table 1 continued. } \\
\hline & $\begin{array}{l}\text { Author, Year, } \\
\text { Study Design }\end{array}$ & $\begin{array}{l}\text { Study } \\
\text { Population }\end{array}$ & Outcomes & Conclusions \\
\hline 4 & $\begin{array}{l}\text { Gerdhem et al. } \\
(2005)^{4} \\
\text { Cross-sectional }\end{array}$ & $\begin{array}{l}986 \\
\text { ambulatory } \\
\text { women }(>75 \\
\text { years old) } \\
\text { from OPRA } \\
\text { study in } \\
\text { Sweden. }\end{array}$ & $\begin{array}{l}25(\mathrm{OH}) \mathrm{D} \\
\text { (ng/ml) } \\
\text { Gait velocity } \\
\text { (time (s) to walk } \\
\text { 30m and turn } \\
\text { back at fastest } \\
\text { pace) }\end{array}$ & 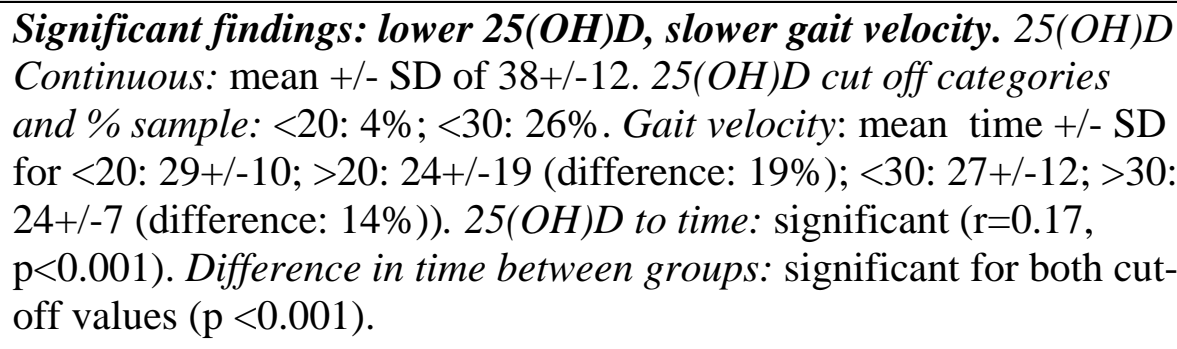 \\
\hline 5 & $\begin{array}{l}\text { Faulkner et al. } \\
(2006)^{5} \\
\text { Cross-sectional }\end{array}$ & $\begin{array}{l}389 \text { women } \\
\text { (>65 years } \\
\text { old) from } \\
\text { SOF in USA. } \\
\text { Median age } \\
\text { (IQR): } 70 \\
\text { years }(67-75)\end{array}$ & $\begin{array}{l}25(\mathrm{OH}) \mathrm{D} \\
(\mathrm{ng} / \mathrm{ml}) \\
\text { Gait velocity } \\
\text { (calculated from } \\
\text { time (s) to walk } \\
6 \mathrm{~m} \text { at rapid or } \\
\text { usual pace; } \mathrm{m} / \mathrm{s} \text { ) }\end{array}$ & $\begin{array}{l}\text { No significant findings. } 25(\mathrm{OH}) \mathrm{D} \text { Continuous (ng/ml): median } \\
\text { (IQR) of } 25(19.0-31.0) .25(\mathrm{OH}) D \text { cut off categories and \% sample: } \\
\text { <10: 2.6\%. 25(OH)D quartiles and range: Q1: 7-22; Q2: 23-30; Q3: } \\
\text { 31-40; Q4: 41-220. Gait velocity: mean +/- SD of 1.01+/-0.22. } \\
\text { 25(OH)D to gait velocity: not significant ( }>0.05) \text {. Difference in Gait } \\
\text { between quartiles: not significant ( } \mathrm{p} \text { trend= } 0.784) \text {. }\end{array}$ \\
\hline 6 & $\begin{array}{l}\text { Suzuki et al. } \\
(2008)^{6} \\
\text { Cross-sectional }\end{array}$ & $\begin{array}{l}2044 \text { adults } \\
\text { (>65 years } \\
\text { old) in Tokyo. } \\
\text { Mean +/- SD } \\
\text { age of men } \\
\text { and women: } \\
74.5+/-5.1 \\
\text { and } 75.4+/- \\
4.7 \text { years, } \\
\text { respectively. }\end{array}$ & $\begin{array}{l}25(\mathrm{OH}) \mathrm{D} \\
(\mathrm{ng} / \mathrm{ml}) \\
\text { Gait velocity } \\
\text { (calculated from } \\
\text { time (s) to walk } \\
5 \mathrm{~m} \text { at normal } \\
\text { velocity, } \mathrm{m} / \mathrm{s} \text { ) }\end{array}$ & $\begin{array}{l}\text { Significant findings: lower } 25(\mathrm{OH}) \mathrm{D} \text {, slower gait velocity. } 25(\mathrm{OH}) D \\
\text { continuous: mean +/- SD men and women of } 28.5+/-5 \text { and } 24.2+/- \\
\text { 4.9, respectively. Men vs. women: } \mathrm{p}<0.001 .25(\mathrm{OH}) D \text { quartiles and } \\
\text { ranges for men (Q1: }<25 \text {; Q2: 25-29; Q3: 29-32; Q4: }>32) \text { and } \\
\text { women (Q1: <21; Q2: 21-24; Q3: 24-28; Q4: }>28) .25(\mathrm{OH}) D \text { cut of } \\
\text { groups and \% sample for men (<20: 4.8\%) and women }(<20 \text { : } \\
\text { 17.7\%). Gait velocity: mean +/- SD of men }(1.23+/-0.26) \text { and } \\
\text { women: (1.18+/-0.29). Difference in gait between } Q 1 \text { and Q4 and cut } \\
\text { off groups: not significant in men, significant in women (both } \\
\mathrm{p}<0.001) \text {. Adjusted model: significant in men: }(\mathrm{p}=0.012) \text { and women } \\
(\mathrm{p}<0.001)\end{array}$ \\
\hline
\end{tabular}




\begin{tabular}{|c|c|c|c|c|}
\hline \multicolumn{5}{|c|}{ Table 1 continued. } \\
\hline & $\begin{array}{l}\text { Author, } \\
\text { Year, Study } \\
\text { Design }\end{array}$ & Study Population & Outcomes & Conclusions \\
\hline 7 & $\begin{array}{l}\text { Annweiler et } \\
\text { al. }(2010)^{7} \\
\text { Cross- } \\
\text { sectional }\end{array}$ & $\begin{array}{l}739 \text { women }(>75 \\
\text { years old) from } \\
\text { EPIDOS study } \\
\text { cohort in France. } \\
\text { Mean }+/- \text { SD } \\
\text { age: } 80.2+/-3.5 \\
\text { years. }\end{array}$ & $\begin{array}{l}25(\mathrm{OH}) \mathrm{D} \\
\text { (ng/ml) } \\
\text { Gait velocity } \\
\text { (calculated } \\
\text { from time (s) to } \\
\text { walk } 6 \mathrm{~m} \text { at } \\
\text { usual and } \\
\text { fastest) }\end{array}$ & $\begin{array}{l}\text { Significant findings: lower } 25(\mathbf{O H}) \mathbf{D} \text {, slower fast gait velocity. } \\
25(\mathrm{OH}) D \text { cut offs categories and \% sample: }<10: 17 \% ; 10-20 \text { : } \\
55 \% ; 20-30: 18 \% ;>30: 10 \% \text {. Gait velocity: mean }+/-\mathrm{SD} \text { of usual } \\
\text { and fastest } 0.87+/-0.22 \text { and } 1.010+/-0.27 \text {, respectively. Difference } \\
\text { in usual gait velocity between groups: not significant }(\mathrm{p}=0.145) \text {. } \\
\text { Difference in fast gait velocity between groups: significant }(\mathrm{p}= \\
0.021, \mathrm{p} \text { trend } 0.007) \text {. Adjusted model for fast pace: significant }(\beta= \\
0.18, \mathrm{p}=0.033) \text {. }\end{array}$ \\
\hline 8 & $\begin{array}{l}\text { Chan et al. } \\
(2012)^{8} \\
\text { Longitudinal } \\
\text { (4 yrs.) }\end{array}$ & $\begin{array}{l}714 \text { men }(>65 \\
\text { years old) from } \\
\text { MrOS in Hong } \\
\text { Kong. Mean +/- } \\
\text { SD age: } 72.8+/- \\
5.1 \text { years. }\end{array}$ & $\begin{array}{l}25(\mathrm{OH}) \mathrm{D} \\
\text { (ng/ml) } \\
\text { Gait velocity } \\
\text { (calculated } \\
\text { from time (s) to } \\
\text { walk 6m at } \\
\text { normal pace). }\end{array}$ & $\begin{array}{l}\text { No significant findings. } 25(\mathrm{OH}) D \text { Continuous: mean of } 31.2 . \\
25(\mathrm{OH}) D \text { cut off categories and \% sample: }<20: 5.9 \% ; 20-30 \text { : } \\
\text { 41.5\%; > 30: 52.6\%. 25(OH)D quartiles and ranges: Q1: <25; Q2: } \\
\text { 25.3-30.4; Q3: 30.5-36.5; Q4: }>36.5 \text {. Difference in gait velocity } \\
\text { between quartiles: not significant ( } \mathrm{p}=0.08) \text {. Change at } 4 \text { years for } \\
\text { ALL quartiles: not significant }(\mathrm{p}=0.93) \text {. }\end{array}$ \\
\hline 9 & $\begin{array}{l}\text { Boersma et } \\
\text { al. }(2012)^{9} \\
\text { Cross- } \\
\text { sectional }\end{array}$ & $\begin{array}{l}145 \text { adult }(>65 \\
\text { years old) fallers } \\
\text { in Australia. Mean } \\
+/- \text { SD age } \\
\text { (range): } 79.1+/- \\
7.8 \text { years }(73-88) \text {. }\end{array}$ & $\begin{array}{l}25(\mathrm{OH}) D \\
\text { (ng/ml) } \\
\text { Gait velocity } \\
\text { (measured } \\
\text { using } \\
\text { GAITRITE, } \\
\text { m/s). }\end{array}$ & $\begin{array}{l}\text { Significant findings: lower } 25(\mathbf{O H}) \text { D, slower gait velocity. } \\
25(\mathrm{OH}) \mathrm{D} \text { cut off categories and \% sample: }<12: 26 \% ; 12-20: 19 \% \text {; } \\
\text { >20:54\%. Gait velocity: mean }+/-\mathrm{SD} \text { of } 0.55+/-0.5 . \text { Gait velocity } \\
\text { difference between groups: significant }(\mathrm{p}<0.05) \text {. Adjusted model: } \\
\text { significant }(\mathrm{B}=0.26, \mathrm{p}=0.045) \text {. }\end{array}$ \\
\hline
\end{tabular}




\begin{tabular}{|c|c|c|c|c|}
\hline \multicolumn{5}{|c|}{ Table 1 continued. } \\
\hline & $\begin{array}{l}\text { Author, } \\
\text { Year, Study } \\
\text { Design }\end{array}$ & Study Population & Outcomes & Conclusions \\
\hline 10 & $\begin{array}{l}\text { Kositsawat } \\
\text { et al. } \\
(2013)^{10} \\
\text { Cross- } \\
\text { sectional }\end{array}$ & $\begin{array}{l}1826 \text { adults ( }>50 \\
\text { years old) from } \\
\text { NHANES 2001- } \\
2002 \text {. }\end{array}$ & $\begin{array}{l}25(\mathrm{OH}) D(\mathrm{ng} / \mathrm{ml}) \\
\text { Gait velocity } \\
\text { (calculated from } \\
\text { time to walk 20ft } \\
(6 \mathrm{~m}) \text { at usual } \\
\text { velocity, m/s). } \\
\text { Slow gait } \\
<0.8 \mathrm{~m} / \mathrm{s}\end{array}$ & 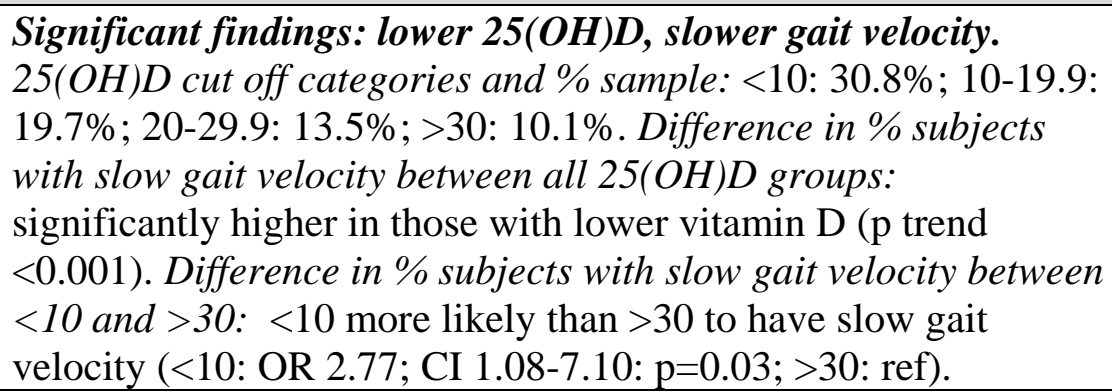 \\
\hline 11 & $\begin{array}{l}\text { Mathei et al. } \\
(2013)^{11} \\
\text { Cross- } \\
\text { sectional }\end{array}$ & $\begin{array}{l}367 \text { Caucasian } \\
\text { adults (>80 years } \\
\text { old) from BFc80+ } \\
\text { study, Belgium. } \\
\text { Mean +/- SD age: } \\
84.7+/-3.6\end{array}$ & $\begin{array}{l}25(\mathrm{OH}) D(\mathrm{ng} / \mathrm{ml}) \\
\text { Gait velocity } \\
\text { (calculated from } \\
\text { time (s) to walk } \\
\text { 3m, turn around } \\
\text { and walk back as } \\
\text { quickly as } \\
\text { possible; } \mathrm{m} / \mathrm{s}) \text {. } \\
\text { Converted into } \\
\text { gender-adjusted } \\
\text { quartiles, } \\
\text { dichotomized } \\
\text { into a score } \\
\text { above or in the } \\
\text { lowest quartile } \\
\text { (<p25). }\end{array}$ & $\begin{array}{l}\text { No significant findings. } 25(\mathrm{OH}) \mathrm{D} \text { cut off categories and \% } \\
\text { sample: }<10: 32.7 \% ; 10-19: 32.9 \% ; 20-29: 21.5 \% ;>30: 12.8 \% \text {. } \\
\text { Gait velocity: } 24.6 \% \text { were in the lowest quartile of walking } \\
\text { velocity. Difference \% participants with walking velocity }<p 25 \\
\text { between } 25(\mathrm{OH}) \text { D groups: not significant ( } \mathrm{p}=0.286) \text {. }\end{array}$ \\
\hline
\end{tabular}




\begin{tabular}{|c|c|c|c|c|c|}
\hline & $\begin{array}{l}\text { Author, } \\
\text { Year, } \\
\text { Study } \\
\text { Design }\end{array}$ & $\begin{array}{l}\text { Study } \\
\text { Population }\end{array}$ & Intervention & Outcomes & Conclusions \\
\hline 1 & $\begin{array}{l}\text { Kenny et al. } \\
(2003)^{12} \\
\text { Double } \\
\text { blind RCT }\end{array}$ & $\begin{array}{l}65 \text { men } \\
\text { (>65 years } \\
\text { old), in the } \\
\text { USA. Mean } \\
+/- \text { SD age: } \\
76+/-4 \\
\text { years. }\end{array}$ & $\begin{array}{l}\text { 1. Placebo. } \\
\text { 2. } 1000 \\
\text { IU/day } \\
\text { Vitamin D. } \\
\text { All received } \\
\text { 500mg } \\
\text { calcium. F/U } \\
\text { 6months. }\end{array}$ & $\begin{array}{l}25(\mathrm{OH}) \mathrm{D} \\
\text { (ng/ml) } \\
\text { Gait velocity } \\
\text { (time (s) to } \\
\text { walk 8ft) }\end{array}$ & $\begin{array}{l}\text { No significant findings. Baseline } 25(\mathrm{OH}) \mathrm{D} \text { for placebo and } \\
\text { intervention: mean +/- SD of } 23.6+/-7.5 \text { and } 26.0+/-6.7 \text {, } \\
\text { respectively; Between groups: } \mathrm{p}=0.21 \text {. F/U } 25(\mathrm{OH}) \mathrm{D} \text { for } \\
\text { placebo and intervention: mean }+/-\mathrm{SD} \text { of } 22.6+/-6.8 \text { and } \\
34.9+/-5.5 \text {, respectively. Baseline to F/U change in placebo } \\
\text { and intervention: } \mathrm{p}>0.05 \text { and } \mathrm{p}<0.001 \text {, respectively. Baseline } \\
\text { gait velocity between groups: } \mathrm{p}=0.63 \text {. Difference in gait } \\
\text { velocity between placebo vs. intervention at } \mathrm{F} / \mathrm{U}: \mathrm{p}=0.128 \text {; } \\
\text { group x time p value }=0.678 \text {. }\end{array}$ \\
\hline 2 & $\begin{array}{l}\text { Gallagher, } \\
\text { J.C. } \\
(2004)^{13} \\
\text { Double } \\
\text { blind RCT }\end{array}$ & $\begin{array}{l}48 \text { adults } \\
\text { (age } \\
\text { inclusion } \\
\text { not } \\
\text { reported), } \\
\text { including } \\
\text { hysterectom } \\
\text { ized women } \\
\text { in USA. } \\
\text { Mean age: } \\
72 \text { years. }\end{array}$ & $\begin{array}{l}\text { 1. Hormone } \\
\text { treatment. } 2 . \\
0.25 \text { ug } \\
\text { calcitriol } \\
\text { twice daily. } \\
\text { 3. Hormone } \\
\text { treatment + } \\
\text { calcitriol. } 4 . \\
\text { Placebo. F/U } \\
6 \text { months for } \\
3 \text { yrs. }\end{array}$ & $\begin{array}{l}25(\mathrm{OH}) D \\
\text { (ng/ml) } \\
\text { Gait velocity } \\
\text { (calculated } \\
\text { from time (s) } \\
\text { to walk 5m at } \\
\text { normal and fast } \\
\text { velocity; m/s) }\end{array}$ & $\begin{array}{l}\text { No significant findings. Decline in timed walk at 3yrs: } \\
\text { calcitriol vs. placebo: } \mathrm{p}>0.1 \text {. }\end{array}$ \\
\hline
\end{tabular}




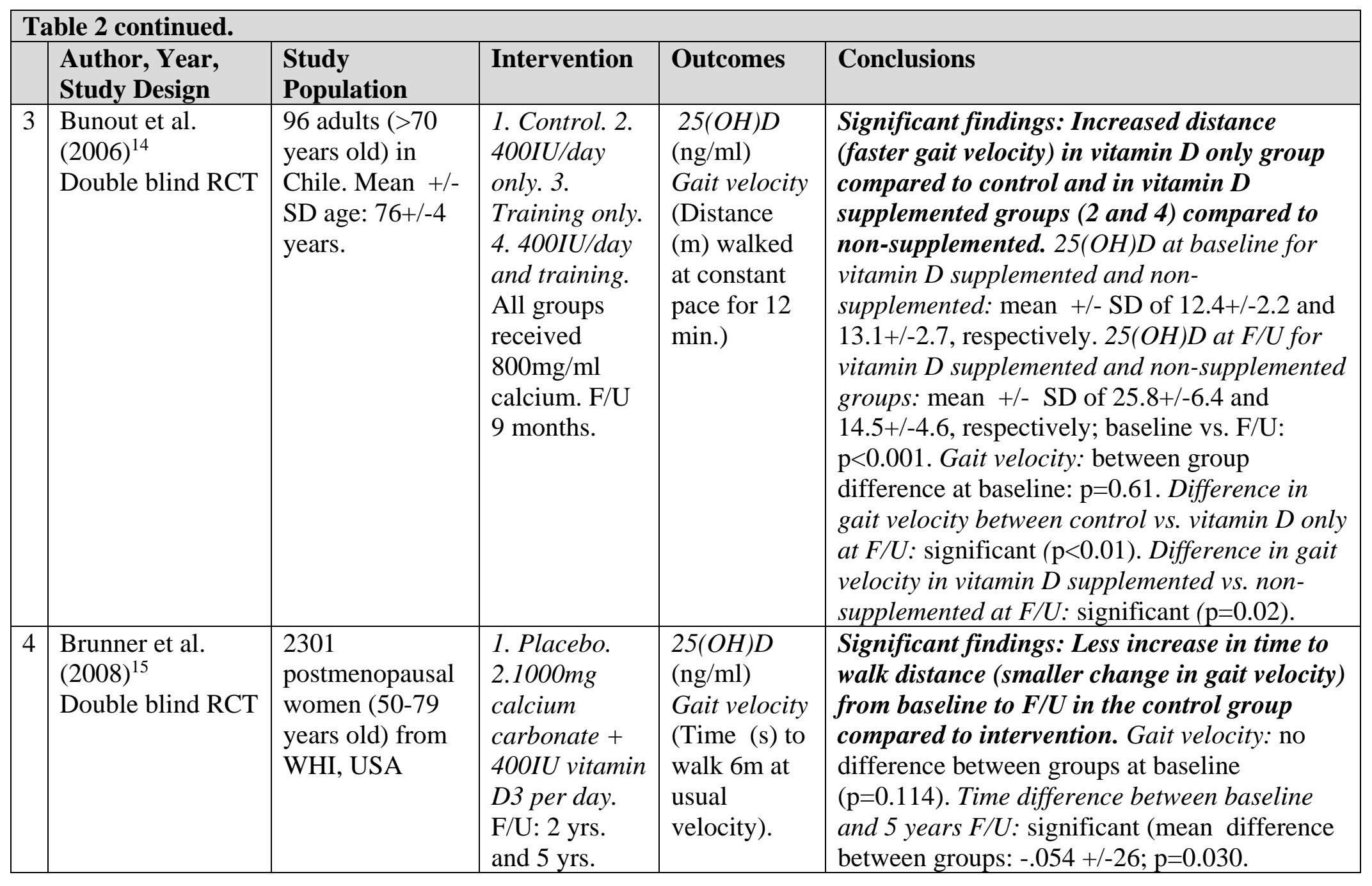




\begin{tabular}{|c|c|c|c|c|c|}
\hline \multicolumn{6}{|c|}{ Table 2 continued. } \\
\hline & $\begin{array}{l}\text { Author, Year, } \\
\text { Study Design }\end{array}$ & $\begin{array}{l}\text { Study } \\
\text { Population }\end{array}$ & Intervention & Outcomes & Conclusions \\
\hline 5 & $\begin{array}{l}\text { Lips et al. } \\
(2010)^{16} \\
\text { Double blind RCT }\end{array}$ & $\begin{array}{l}226 \text { adults }(>70 \\
\text { years) with } \\
25(\mathrm{OH}) \mathrm{D} \\
\text { between } 6-20 \\
\text { ng/ml. Mean }+/- \\
\mathrm{SD} \text { age placebo } \\
\text { and intervention: } \\
77.6+/-6.6 \text { and } \\
78.5+/-6.2 \text { years, } \\
\text { respectively. }\end{array}$ & $\begin{array}{l}\text { 1. Placebo. } 2 . \\
\text { Weekly oral } \\
8400 \text { IU D3. } \\
\text { F/U } 16 \text { weeks. }\end{array}$ & $\begin{array}{l}25(\mathrm{OH}) \mathrm{D} \\
\text { (ng/ml) } \\
\text { Gait velocity } \\
\text { (calculated } \\
\text { from time (s) } \\
\text { to walk 4m; } \\
\mathrm{cm} / \mathrm{s} \text { ) }\end{array}$ & $\begin{array}{l}\text { No significant findings. } 25(\mathrm{OH}) \mathrm{D} \text { at baseline for } \\
\text { placebo and intervention: mean }+/- \text { SD of } 14.1+/- \\
5.5 \text { and } 13.7+/-4.4 \text {, respectively; mean difference } \\
\text { of } 13 ; \mathrm{p}>0.05 .25(\mathrm{OH}) \mathrm{D} \text { at } \mathrm{F} / \mathrm{U} \text { for placebo and } \\
\text { intervention: mean of } 14.0 \text { and } 26 \text {, respectively. } \\
25(\mathrm{OH}) D \text { difference in intervention from baseline } \\
\text { to F/U: } \mathrm{p}<0.001 .25(\mathrm{OH}) D \text { difference between } \\
\text { placebo and intervention at } \mathrm{F} / \mathrm{U}: \mathrm{p}<0.001 \text {. } \\
\text { Difference in change in gait velocity from baseline } \\
\text { to F/U between groups: not significant }(\mathrm{p}=0.717) \text {. }\end{array}$ \\
\hline 6 & $\begin{array}{l}\text { Lagari et al. } \\
(2013)^{17} \\
\text { RCT }\end{array}$ & $\begin{array}{l}86 \text { adults (65-95 } \\
\text { years old) in } \\
\text { Miami Dade. } \\
\text { Mean +/- SD } \\
\text { age: } 73.4+/-6.4 \\
\text { years. }\end{array}$ & $\begin{array}{l}\text { 1. } 400 \text { IU/day } \\
\text { D3. 2. } 2000 \\
\text { IU/day D3. } \\
\text { F/U } 6 \text { months }\end{array}$ & $\begin{array}{l}25(\mathrm{OH}) D \\
\text { (ng/ml) } \\
\text { Gait velocity } \\
\text { (calculated } \\
\text { from time (s) } \\
\text { to walk 4m } \\
\text { at usual } \\
\text { velocity). }\end{array}$ & $\begin{array}{l}\text { No significant findings. } 25(\mathrm{OH}) \mathrm{D} \text { at baseline for } \\
\text { all: mean }+/- \text { SD of } 33.0+/-10 \text {; not significantly } \\
\text { different between groups within men and women } \\
\text { ( } \mathrm{p}=0.865 \text { and } \mathrm{p}=0.832 \text {, respectively). } 25(\mathrm{OH}) \mathrm{D} \\
\text { change at } \mathrm{F} / \mathrm{U} \text { : the change from baseline to follow } \\
\text { up between groups was not significant for men and } \\
\text { significant for women ( } \mathrm{p}=0.208 \text { and } \mathrm{p}=0.004) \text {. Gait } \\
\text { velocity at baseline: not significantly different } \\
\text { between groups for men ( } \mathrm{p}=0.600) \text { and women } \\
\text { ( } \mathrm{p}=0.628) \text { Difference in change in gait velocity } \\
\text { from baseline to F/U between groups: non- } \\
\text { significant for men and women ( } \mathrm{p}=0.291 \text { and } \\
\mathrm{p}=0.438 \text {, respectively). }\end{array}$ \\
\hline
\end{tabular}




\begin{tabular}{|c|c|c|c|c|}
\hline & $\begin{array}{l}\text { Author, } \\
\text { Year, Study } \\
\text { Design }\end{array}$ & Study Population & Outcomes & Conclusions \\
\hline 1 & $\begin{array}{l}\text { Przybelski } \\
\text { et al. } \\
(2007)^{18} \\
\text { Cross- } \\
\text { sectional }\end{array}$ & $\begin{array}{l}32 \text { adults in United } \\
\text { States Mean }+/- \text { SD } \\
\text { age: } 79.5+/-1.6 \text { years. }\end{array}$ & $\begin{array}{l}25(\mathrm{OH}) \mathrm{D} \\
\text { (ng/ml) } \\
\text { Cognitive test: } \\
\text { MMSE }\end{array}$ & $\begin{array}{l}\text { Significant findings: lower 25(OH)D, lower MMSE score. } \\
25(O H) D \text { Continuous: Mean }+/- \text { SD of } 21.6+/-1.6 .25(O H) D \text { to } \\
\text { MMSE score: } \text { significant }(\mathrm{p}=0.006) \text {. }\end{array}$ \\
\hline 2 & $\begin{array}{l}\text { Buell et al. } \\
(2009)^{19} \\
\text { Cross- } \\
\text { sectional }\end{array}$ & $\begin{array}{l}3133 \text { adults (65-99 years } \\
\text { old) from NAME study } \\
\text { in USA. Mean +/- SD } \\
\text { age: } 75.0+/-8.5 \text { years. }\end{array}$ & $\begin{array}{l}\text { 25(OH)D } \\
\text { (ng/ml) } \\
\text { Cognitive tests: } \\
\text { NAART. } \\
\text { WMS-III WLL, } \\
\text { WMS-III LM, } \\
\text { DSST, TMT-A, } \\
\text { TMT-B, MA, } \\
\text { WAIS-III BD, } \\
\text { MR, COWA. }\end{array}$ & $\begin{array}{l}\text { Significant findings: lower } 25(\mathrm{OH}) \mathrm{D} \text {, worse cognitive } \\
\text { performance, especially in executive function tests. } 25(\mathrm{OH}) D \\
\text { cut off categories and \% sample: }<10: 18 \% ; 10-20: 47 \% ;>20 \text { : } \\
35 \% .25(\mathrm{OH}) D \text { to cognitive tests: TMT-A ( }<<0.03) \text {, TMT-B } \\
(\mathrm{p}<0.02) \text {, DSST }(\mathrm{p}<0.001), \mathrm{MR}(\mathrm{p}<0.02) \text {, WAIS-III BD } \\
(\mathrm{p}<0.04) \text {. Differences in cognitive test scores between } \\
25(\mathrm{OH}) D \text { groups: TMT-A }(\mathrm{p}<0.05) \text {, TMT-B }(\mathrm{p}<0.05) \text {. MR } \\
(\mathrm{p}=0.03) \text {, DSST }(\mathrm{p}<0.01) .25(\mathrm{OH}) D \text { to executive function: } \\
\text { significant }(\beta=0.01, \mathrm{p}=0.001) .25(\mathrm{OH}) D \text { to } \\
\text { attention/processing velocity: significant }(\beta=0.01, \mathrm{p}=0.03) \text {. }\end{array}$ \\
\hline 3 & $\begin{array}{l}\text { Lee et al. } \\
(2009)^{20} \\
\text { Cross- } \\
\text { sectional }\end{array}$ & $\begin{array}{l}3369 \text { men }(40-79 \text { years } \\
\text { old) from EMAS, USA. } \\
\text { Mean }+/- \text { SD age: } 60+/- \\
11 \text { years. }\end{array}$ & $\begin{array}{l}25(\mathrm{OH}) D \\
\text { (ng/ml) } \\
\text { Cognitive tests: } \\
\text { ROCF, CTRM } \\
\text { test, DSST. }\end{array}$ & $\begin{array}{l}\text { Significant findings: lower } 25(\mathrm{OH}) \mathrm{D} \text {, worse cognitive } \\
\text { performance, especially for executive function tests. } \\
25(\mathrm{OH}) \mathrm{D} \text { continuous: mean }+/-\mathrm{SD} \text { of } 25.2+/-12.4 .25(\mathrm{OH}) D \\
\text { cut off categories and \% sample: }<10: 7.9 \% ; 10-19.9: 32.8 \% \text {; } \\
\text { 20-29.9: } 30.5 \% ;>30: 28.8 \% \text {. Adjusted models, } 25(\mathrm{OH}) D \text { to } \\
\text { cognitive tests: only DSST significant (p<0.01). Difference in } \\
\text { cognitive test scores between groups: significant for DSST } \\
(\mathrm{p}<0 / 05) . \text { Locally weighted and spline regression: significant } \\
\text { relationship between } 25(\mathrm{OH}) \mathrm{D} \text { and cognitive function, } \\
\text { stronger at }<14 \mathrm{ng} / \mathrm{ml} \text {. }\end{array}$ \\
\hline
\end{tabular}

Table 3 continued. 


\begin{tabular}{|c|c|c|c|c|}
\hline & $\begin{array}{l}\text { Author, } \\
\text { Year, Study } \\
\text { Design }\end{array}$ & Study Population & Outcomes & Conclusions \\
\hline 4 & $\begin{array}{l}\text { Llewellyn et } \\
\text { al. }(2009)^{21} \\
\text { Cross- } \\
\text { sectional }\end{array}$ & $\begin{array}{l}1766 \text { community- dwelling } \\
\text { and institutionalized adults } \\
\text { (>65 years old) in England. } \\
\text { Mean +/- SD age: } 78.2+/- \\
8.6 \text { years. }\end{array}$ & $\begin{array}{l}25(\mathrm{OH}) D \\
\text { (ng/ml) } \\
\text { Cognitive tests: } \\
\text { AMT Score. } \\
\text { MCI defined as } \\
3 \text { errors of } 10 .\end{array}$ & $\begin{array}{l}\text { Significant findings: increased odds of MCI in the lower } \\
\text { quartiles of 25(OH)D. 25(OH)D quartiles and ranges: Q1: } \\
\text { 3-12; Q2: 12-18; Q3: 18-26; Q4: 26-68. Cognitive status: } \\
\text { 12\% MCI. Difference in odds for cognitive impairment of } \\
\text { non-institutionalized participants between quartiles: } \\
\text { significant (p trend =0.001). }\end{array}$ \\
\hline 5 & $\begin{array}{l}\text { Wilkins et } \\
\text { al. }(2009)^{22} \\
\text { Cross- } \\
\text { sectional. }\end{array}$ & $\begin{array}{l}60 \text { adults ( }>55 \text { years old) } \\
\text { African and European } \\
\text { Americans from ADRC study } \\
\text { in United States Mean +/- } \\
\text { SD age: } 74.99+/-8.2 \text { years. }\end{array}$ & $\begin{array}{l}25(\mathrm{OH}) D \\
\text { (ng/ml) } \\
\text { Cognitive tests: } \\
\text { MMSE, SBT. }\end{array}$ & $\begin{array}{l}\text { Significant findings: lower } 25 \mathrm{OH} \text {, worse performance in } \\
\text { SBT. } 25(\mathrm{OH}) \text { D continuous: mean }+/- \text { SD of } 21.59+/-7.8 \text {. } \\
25(\mathrm{OH}) \text { D cut off categories and \% sample: }<20: 52 \% ;>20 \text { : } \\
\text { 48\%. Difference in cognitive test scores between groups: } \\
\text { significant for SBT only }(\mathrm{p}=0.016) \text {. }\end{array}$ \\
\hline 6 & $\begin{array}{l}\text { Annweiler et } \\
\text { al. }(2010)^{23} \\
\text { Cross- } \\
\text { sectional }\end{array}$ & $\begin{array}{l}752 \text { women ( }>75 \text { years old) } \\
\text { from EPIDOS in France. } \\
\text { Mean +/- SD age: } 80.4+/-3.6 \\
\text { years. }\end{array}$ & $\begin{array}{l}25(\mathrm{OH}) \mathrm{D} \\
\text { (ng/ml) } \\
\text { Cognitive tests: } \\
\text { SPMSQ score to } \\
\text { define MCI } \\
\text { (score }<8) \text {. }\end{array}$ & $\begin{array}{l}\text { Significant findings: lower } 25(\mathrm{OH}) \mathrm{D} \text {, higher odds of MCI. } \\
\text { Mean : } 7.21+/-2.09 .25(\mathrm{OH}) D \text { cut off categories and \% } \\
\text { sample: }<10: 17.2 \% ;>1082.8 \% \text {. MCI: } 10 \% \text {. Difference in } \\
\text { SPMSQ scores between groups: significant }(\mathrm{p}<0.001) \text {. } \\
\text { Difference in \% SPMSQ <8 (i.e.,MCI) between groups } \\
\text { (p=0.006). Odds of having MCI when } 25(\mathrm{OH}) D<10 \text { : } \\
\text { significant (adjusted } \mathrm{OR}=1.99, \mathrm{p}=0.017)\end{array}$ \\
\hline 7 & $\begin{array}{l}\text { Llewellyn et } \\
\text { al. (2010) } \\
\text { Longitudinal } \\
\text { (6 yrs.) }\end{array}$ & $\begin{array}{l}858 \text { adults ( }>65 \text { years old) } \\
\text { from InCHIANTI study in } \\
\text { Italy. Mean }+/- \text { SD age: } \\
73.8+/-6.4 \text { years. }\end{array}$ & $\begin{array}{l}25(\mathrm{OH}) \mathrm{D} \\
\text { (ng/ml) } \\
\text { Cognitive tests: } \\
\text { MMSE, TMT- } \\
\text { A, TMT-B. }\end{array}$ & $\begin{array}{l}\text { Significant findings: lower } 25(\mathrm{OH}) \mathrm{D} \text {, worse performance } \\
\text { in cognitive tests, especially for executive function. } \\
25(\mathrm{OH}) \mathrm{D} \text { cut off categories and \% sample: }<10: 20 \% ; 10- \\
\text { 20: } 42 \% \text {; } 20-30: 19 \% ;>30: 18 \% \text {. Cognitive score } \\
\text { differences between groups: significant MMSE, TMT-A, } \\
\text { TMT-B (all, p trend: } \mathrm{p}<0.001) \text {. Cognitive score differences } \\
\text { between }<10 \text { vs. }>20 \text { : significant MMSE (p trend }=0.02 \text { ) } \\
\text { and TMT-B (p trend =0.04). }\end{array}$ \\
\hline
\end{tabular}

Table 3 continued. 


\begin{tabular}{|c|c|c|c|c|}
\hline & $\begin{array}{l}\text { Author, } \\
\text { Year, } \\
\text { Study } \\
\text { Design } \\
\end{array}$ & $\begin{array}{l}\text { Study } \\
\text { Population }\end{array}$ & Outcomes & Conclusions \\
\hline 8 & $\begin{array}{l}\text { Seaman } \\
\text { S et al. } \\
(2010)^{25} \\
\text { Cross- } \\
\text { sectiona } \\
\text { l }\end{array}$ & $\begin{array}{l}380 \text { adults } \\
\text { (55-87 years } \\
\text { old) from } \\
\text { ZENITH study } \\
\text { in Europe. } \\
\text { Mean }+/- \text { SD } \\
\text { age: } 68.1+/-4.1 \\
\text { years. }\end{array}$ & $\begin{array}{l}25(\mathrm{OH}) \mathrm{D} \\
\text { (ng/ml) } \\
\text { Cognitive tests: } \\
\text { SWM assessed } \\
\text { by } 4 \text { parameters } \\
\text { from CANTAB }\end{array}$ & $\begin{array}{l}\text { Significant findings: lower } 25(\mathrm{OH}) \mathrm{D} \text {, lower } \mathrm{SWM} \text { scores. } 25(\mathrm{OH}) \mathrm{D} \\
\text { continuous: mean }+/-\mathrm{SD} \text { of } 30.5+/-19.3 .25(\mathrm{OH}) \mathrm{D} \text { cut off categories and } \\
\% \text { sample: }<12: 12 \% ;<20: 36 \% ;<32: 64 \% .25(\mathrm{OH}) \mathrm{D} \text { tertiles and range: } \\
\text { Q1: }<19.1 \text {; Q2: } 19.1-34.4 ; \mathrm{Q} 3:>34.4 .25(\mathrm{OH}) \mathrm{D} \text { to } 4 \text { parameters of SWM: } \\
\text { significant (all } \mathrm{p}<0.005) \text {. SWM scores of three assessments were } \\
\text { significantly lower in subjects in Q3, but not Q2, compared to Q1 (p trend } \\
=0.084) \text {. }\end{array}$ \\
\hline 9 & $\begin{array}{l}\text { Slinin et } \\
\text { al. } \\
(2010)^{26} \\
\text { Longitu } \\
\text { dinal } \\
(4.6 \\
\text { yrs. })\end{array}$ & $\begin{array}{l}1376 \text { men (>65 } \\
\text { years old) from } \\
\text { MrOS in USA. }\end{array}$ & $\begin{array}{l}25(\mathrm{OH}) \mathrm{D} \\
\text { (ng/ml) } \\
\text { Cognitive tests: } \\
\text { 3MS }<80 \text { as } \\
\text { MCI; decline } \\
>5 \text { points in } \\
\text { F/U. MCI as } \\
\text { change in } \\
\text { TMT-B at F/U. }\end{array}$ & $\begin{array}{l}\text { No significant findings. 25(OH)D cut-off categories and \% sample: }<30 \text { : } \\
\text { 75\%. 25(OH)D quartiles and range:Q1: < 19.9; Q2: 20.0-25.09; Q3: } 25.1 \\
\text {-29.79; Q4: >29.8. Cognitive status: baseline 3.4\% and F/U 22.8\% MCI } \\
\text { per 3MS, and baseline 9.3\% and F/U 8.0\% per TMT=B. Adjusted models, } \\
\text { Difference in odds of MCI (3MS) between quartiles: not significant (p } \\
\text { trend: } \mathrm{p}=0.97) \text {. Difference in odds of MCI (TMTB) between quartiles: not } \\
\text { significant (p trend: } \mathrm{p}=0.96) \text {. Difference in odds of incident MCI (3MS) } \\
\text { between quartiles: not significant (p trend = 0.10). Difference in odds of } \\
\text { incident MCI (TMTB) between quartiles: not significant ( } \mathrm{p} \text { trend >0.5). }\end{array}$ \\
\hline 10 & $\begin{array}{l}\text { Chan et } \\
\text { al. } \\
(2011)^{27} \\
\text { Case } \\
\text { control }\end{array}$ & $\begin{array}{l}939 \text { men }(>65 \\
\text { years old) from } \\
\text { Os Study in } \\
\text { Hong Kong. } \\
\text { Mean }+/- \text { SD } \\
\text { age: } 75.2+/-5.3 \\
\text { years. }\end{array}$ & $\begin{array}{l}\text { 25(OH)D } \\
\text { (ng/ml) } \\
\text { Cognitive tests: } \\
\text { MCI defined by } \\
\text { CSI-D < 28.4. }\end{array}$ & 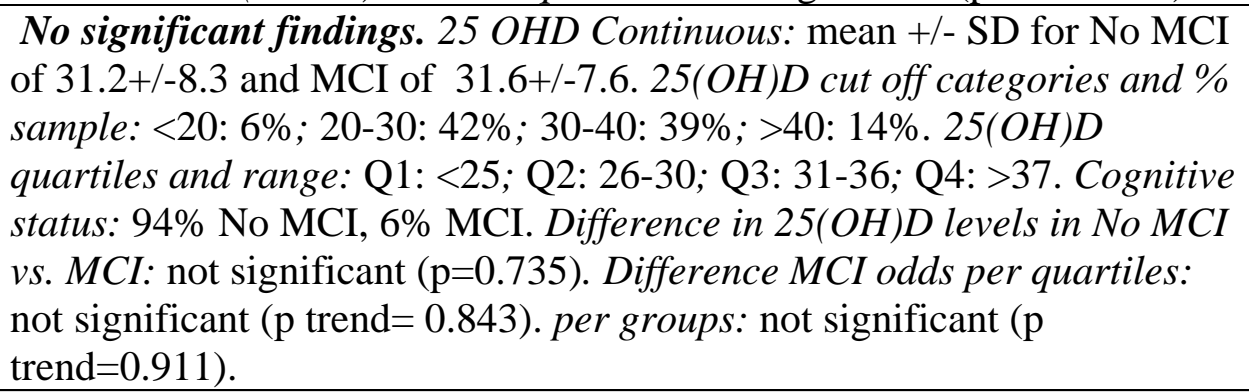 \\
\hline \multicolumn{5}{|c|}{ Table 3 continued. } \\
\hline & Author, & & & Conclusions \\
\hline
\end{tabular}




\begin{tabular}{|c|c|c|c|c|}
\hline & $\begin{array}{l}\text { Year, } \\
\text { Study } \\
\text { Design }\end{array}$ & & & \\
\hline 11 & $\begin{array}{l}\text { Llewellyn } \\
\text { et al. } \\
(2011)^{28} \\
\text { Cross- } \\
\text { sectional }\end{array}$ & $\begin{array}{l}3396 \text { adults (age } \\
\text { inclusion not reported) } \\
\text { from NHANES 1988- } \\
\text { 1994. Mean +/- SD } \\
\text { age: } 73.7+/-10.9 \text { years. }\end{array}$ & $\begin{array}{l}25(\mathrm{OH}) D(\mathrm{ng} / \mathrm{ml}) \\
\text { Cognitive tests: Global cognitive } \\
\text { function score from sum of } 6 \text { tests } \\
\text { including: } \\
\text { MMSE, East BMT, and WAIS. } \\
\text { MCI defined as lowest } 10 \% \text { of the } \\
\text { distribution of cognitive } \\
\text { performance. }\end{array}$ & $\begin{array}{l}\text { Significant findings: higher odds of } \mathbf{M C I} \\
\text { in lower 25(OH)D groups. } 25(\mathrm{OH}) \mathrm{D} \text { cut } \\
\text { off categories and \% sample: }<10: 1.8 \% \text {; } \\
\text { 10-20: } 21.8 \% \text {; } 20-30: 39.0 \% ;>30: 37.5 \% \text {. } \\
\text { Adjusted model: Difference in odds for } \\
\text { MCI between } 25(\mathrm{OH}) D \text { group: (p } \\
\text { trend=0.03). Difference in odds for MCI } \\
\text { between } 25(\mathrm{OH}) D<20 \text { vs. }>20: \mathrm{p} \\
\text { trend=0.002. Cognitive status: } 90 \% \text { No } \\
\text { MCI and } 10 \% \text { MCI. }\end{array}$ \\
\hline 12 & $\begin{array}{l}\text { Annweiler } \\
\text { et al. } \\
(2012)^{29} \\
\text { Cross- } \\
\text { sectional }\end{array}$ & $\begin{array}{l}95 \text { non demented } \\
\text { Caucasian adults (age } \\
\text { inclusion not reported) } \\
\text { with subjective memory } \\
\text { complaint from GAIT } \\
\text { study in France. Mean } \\
\text { +/- SD age: } 71.1+/-6.4 \\
\text { years. }\end{array}$ & $\begin{array}{l}25(\mathrm{OH}) D(\mathrm{ng} / \mathrm{ml}) \\
\text { Cognitive tests: MCI diagnosed by } \\
\text { multidisplinary meetings with } \\
\text { geriatricians, neurologist and } \\
\text { neuropsychologists based on } \\
\text { standardized neuropsychological } \\
\text { tests, physical examination, blood } \\
\text { tests and MRI brain imaging. MCI } \\
\text { diagnosed according to Winblad et } \\
\text { al. criteria. }\end{array}$ & $\begin{array}{l}\text { Significant findings: higher odds of MCI } \\
\text { in lower 25(OH)D quartiles. } 25(\mathrm{OH}) \mathrm{D} \\
\text { Continuous: mean +/- SD of 25.2+/-12.1 in } \\
\text { all, MCI: 21.4+/-8.7 in MCI and 28.3+/- } \\
\text { 13.7 in healthy. 25(OH)D quartiles and } \\
\text { ranges: Q1: 4-16; Q2: 16-23.6; Q3: } 24.0- \\
\text { 31.7; Q4: 32.1-75.7. Cognitive status: } 45 \% \\
\text { MCI. Difference in 25(OH)D levels } \\
\text { between MCI and healthy: significant (p } \\
\text { 0.006). Fully adjusted model: Difference in } \\
\text { odds for MCI between quartiles: } \\
\text { significant (p trend =0.003) and between } \\
\text { each quartile compared to ref (all p }<0.03) \text {. }\end{array}$ \\
\hline
\end{tabular}




\begin{tabular}{|c|c|c|c|c|}
\hline \multicolumn{5}{|c|}{ Table 3 continued. } \\
\hline & $\begin{array}{l}\text { Author, } \\
\text { Year, Study } \\
\text { Design }\end{array}$ & $\begin{array}{l}\text { Study } \\
\text { Population }\end{array}$ & Outcomes & Conclusions \\
\hline 13 & $\begin{array}{l}\text { Slinin et al. } \\
(2012)^{30} \\
\text { Longitudinal } \\
\text { ( } 2 \text { and } 4 \text { yr) }\end{array}$ & $\begin{array}{l}6257 \text { Caucasian } \\
\text { women ( }>65 \\
\text { years old) from } \\
\text { SOF in United } \\
\text { States Mean +/- } \\
\text { SD age: } 76.6+/- \\
4.7 \text { years. }\end{array}$ & $\begin{array}{l}25(\mathrm{OH}) D(\mathrm{ng} / \mathrm{ml}) \\
\text { Cognitive tests: } \\
\text { 3MS to define } \\
\text { MCI as score } \\
<21.6 \text { and TMT- } \\
\text { B to define MCI } \\
\text { as }>250 \text { s }\end{array}$ & $\begin{array}{l}\text { Significant findings: higher odds of MCI at baseline and } \\
\text { cognitive decline at F/U, defined by MMSE, in those with lower } \\
\text { 25(OH)D, not significant when MCI defined by TMT-B. } \\
\text { 25(OH)D cut off categories and \% sample: }<10: 7.3 \% \text {; } 10-19.9 \text { : } \\
\text { 32.7\%; 20-29.9: 38.6\%; >30: } 21.4 \% \text {. Cognitive status: } 7.2 \% \text { MCI } \\
\text { with both tests. Full adjusted models, Difference in odds of MCI } \\
\text { at BL (MMSE) between groups: significant (p trend = 0.029). } \\
\text { Difference in odds of cognitive decline at F/U (MMSE) between } \\
\text { groups: significant (p trend=0.003). Difference in odds of MCI at } \\
\text { baseline (TMT-B) between groups: not significant (p trend = } \\
\text { 0.314). Difference in odds of cognitive decline at F/U (TMT-B) } \\
\text { between groups: (p trend = 0.931) }\end{array}$ \\
\hline 14 & $\begin{array}{l}\text { Brouwer- } \\
\text { Brolsma et al. } \\
(2013)^{31} \\
\text { Cross- } \\
\text { sectional }\end{array}$ & $\begin{array}{l}127 \text { adults }(>65 \\
\text { years old) frail } \\
\text { or prefrail from } \\
\text { ProMuscle } \\
\text { Study in } \\
\text { Netherlands. } \\
\text { Mean }+/- \text { SD } \\
\text { age: } 79+/-7.6 \\
\text { years. }\end{array}$ & $\begin{array}{l}25(\mathrm{OH}) D(\mathrm{ng} / \mathrm{ml}) \\
\text { Cognitive tests: } \\
\text { MMSE, WLT, } \\
\text { WDS forward } \\
\text { and backward } \\
\text { test, TMT-A, } \\
\text { TMT-B, ST, VF, } \\
\text { RT. }\end{array}$ & $\begin{array}{l}\text { Significant findings: lower } 25(\mathrm{OH}) \mathrm{D} \text {, worse cognitive } \\
\text { performance in executive function test. } 25(\mathrm{OH}) \mathrm{D} \text { continuous: } \\
\text { mean of } 21.6 .25(\mathrm{OH}) \mathrm{D} \text { cut off categories and \% sample: }<12 \text { : } \\
\text { 17\%; <20: } 53 \% ;<30: 77 \% .25(\mathrm{OH}) D \text { tertiles and range: T1: 5.2- } \\
\text { 15.2; T2: } 15.2-26.0 ; \mathrm{T} 3: 26.0-65.3 \text {. Difference in cognitive test } \\
\text { score between tertiles: significant for VF and RT combined } \\
(\mathrm{p}=0.04) \text { and TMT-A and B combined }(\mathrm{p}=0.05) \text {. Fully adjusted } \\
\text { model: significantly better performance in executive function per } \\
0.4 \text { ng increase in serum } 25(\mathrm{OH}) \mathrm{D}(\mathrm{B}: 0.007, \mathrm{p}=0.01) \text {. }\end{array}$ \\
\hline
\end{tabular}




\begin{tabular}{|c|c|c|c|c|}
\hline \multicolumn{5}{|c|}{ Table 3 continued. } \\
\hline & $\begin{array}{l}\text { Author, Year, } \\
\text { Study Design }\end{array}$ & $\begin{array}{l}\text { Study } \\
\text { Population }\end{array}$ & Outcomes & Conclusions \\
\hline 15 & $\begin{array}{l}\text { Annweiler et al. } \\
(2014)^{32} \\
\text { Cross-sectional }\end{array}$ & $\begin{array}{l}100 \text { Caucasian } \\
\text { adults ( }>60 \\
\text { years old) with } \\
\text { memory } \\
\text { complaint in } \\
\text { France. Mean } \\
\text { +/- SD age: } \\
71.02+/-0.74 \\
\text { years. }\end{array}$ & $\begin{array}{l}25(\mathrm{OH}) D(\mathrm{ng} / \mathrm{ml}) \\
\text { Cognitive tests: } \\
\text { MMSE, TMT-B, N- } \\
\text { back test, ST, Go/No- } \\
\text { Go. }\end{array}$ & $\begin{array}{l}\text { Signficant findings: lower } 25(\mathrm{OH}) \mathrm{D} \text {, worse cognitive } \\
\text { performance, especially in mental flexibility. } 25(\mathrm{OH}) \mathrm{D} \\
\text { continuous: mean +/- SD of } 24.2+/-1.6 .25(\mathrm{OH}) \mathrm{D} \text { cut off } \\
\text { categories and \%sample: }<10: 6 \% \text {; } 10-20: 36 \% ;>20 \text { : } \\
58 \% \text {. Cognitive test scores differences between group: } \\
\text { not significant for MMSE, N-back test, ST, and Go/No- } \\
\text { Go (p>0.05 for all) and significant for TMT-B } \\
(\mathrm{p}<0.001) \text { Fully adjusted model: TMT-B significantly } \\
\text { associated with } 25(\mathrm{OH}) \mathrm{D}<10: \mathrm{B}: 1.48 \text {; CI: } 0.36-2.61 \text {; } \\
\mathrm{p}=0.011 \text {. }\end{array}$ \\
\hline 16 & $\begin{array}{l}\text { Chei et al. } \\
(2014)^{33} \\
\text { Cross-sectional }\end{array}$ & $\begin{array}{l}2004 \text { adults } \\
\text { (>60 years old) } \\
\text { from CLHLS } \\
\text { study in China. } \\
\text { Mean +/- SD } \\
\text { age: } 84.9+/- \\
12.7 \text { years. }\end{array}$ & $\begin{array}{l}25(\mathrm{OH}) D(\mathrm{ng} / \mathrm{ml}) \\
\text { Cognitive tests: } \\
\text { Chinese version of } \\
\text { MMSE to categorize } \\
\text { MCI (score <30). }\end{array}$ & $\begin{array}{l}\text { Significant findings: those with MCI had lower } \\
\text { 25(OH)D and odd of } \mathbf{M C I} \text { is greater in low 25(OH)D. } \\
\text { 25(OH)D continuous: mean +/- SD of } 17.3+/-7.9 \text { in all, } \\
\text { 12.8+/-6.1 in MCI and 18.2+/-7.8 in No MCI. 25(OH)D } \\
\text { quartiles and ranges: Q4: 2.3-12.7; Q3: 12.7-17.2; Q2: } \\
\text { 21.2-22.8; Q1: 22.8-83.6. Cognitive status: 18\% MCI } \\
\text { and 82\% No MCI. Difference in 25(OH)D between MCI } \\
\text { and No MCI: Significant (p=0.001). Difference in odds } \\
\text { of MCI between quartiles: significant, (p trend =0.05). }\end{array}$ \\
\hline
\end{tabular}




\begin{tabular}{|c|c|c|c|c|}
\hline \multicolumn{5}{|c|}{ Table 3 continued. } \\
\hline & $\begin{array}{l}\text { Author, Year, } \\
\text { Study Design }\end{array}$ & $\begin{array}{l}\text { Study } \\
\text { Population }\end{array}$ & Outcomes & Conclusions \\
\hline 17 & $\begin{array}{l}\text { Hooshmand et } \\
\text { al. }(2014)^{34} \\
\text { Cross-sectional }\end{array}$ & $\begin{array}{l}75 \text { adults (age } \\
\text { inclusion not } \\
\text { reported) in } \\
\text { Sweden. Mean } \\
+/- \text { SD age: } \\
61.6+/-9.1 \\
\text { years. }\end{array}$ & $\begin{array}{l}25(\mathrm{OH}) D \text { (ng/ml) } \\
\text { Cognitive tests: } \\
\text { Dementia and AD: } \\
\text { DSM-IV and } \\
\text { NINCDS-ADRDA. } \\
\text { MCI: not demented, } \\
\text { report of cognitive } \\
\text { impartment but } \\
\text { preserved basic ADL. } \\
\text { SCI: subjective } \\
\text { complaints, objective } \\
\text { impairment cognitive } \\
\text { tests. }\end{array}$ & $\begin{array}{l}\text { Significant findings: lower 25(OH)D in MCI groups } \\
\text { and higher odds of MCI with lower 25(OH)D. } \\
25(\mathrm{OH}) D \text { Continuous: mean +/ SD of } 67.3+/-26.5 \text {, } \\
\text { median (IQR) for AD of } 24.0(19.0,28.8) \text {, MCI of } \\
24.2(16.5,29.8) \text { and SCI of } 28.0(24.0,38.5) \text {. } \\
\text { Difference in } 25(\mathrm{OH}) D \text { between cognitive groups: } \\
\text { significant difference between SCI vs. AD ( }=0.014) \\
\text { and SCI vs. MCI (p=0.027) The OR for worse } \\
\text { cognitive status for each increase of } 0.4 \mathrm{ng} / \mathrm{ml} \text { in } \\
\text { 25(OH)D was } 0.972 \text { (CI } 0.953-0.991) \text {. }\end{array}$ \\
\hline 18 & $\begin{array}{l}\text { Schneider et al. } \\
(2014)^{35} \\
\text { Cross-sectional } \\
\text { and } \\
\text { longitudinal ( } 3 \\
\text { and } 10.6 \text { years) }\end{array}$ & $\begin{array}{l}1652 \text { adults } \\
\text { (45-65 years } \\
\text { old) from } \\
\text { ARIC study in } \\
\text { United States } \\
\text { Mean }+/- \text { SD } \\
\text { age: } 62.3+/- \\
4.45 \text { years. }\end{array}$ & $\begin{array}{l}25(\mathrm{OH}) D(\mathrm{ng} / \mathrm{ml}) \\
\text { Cognitive tests: } \\
\text { DWRT, DSST, VF }\end{array}$ & $\begin{array}{l}\text { No significant findings. } 25(\mathrm{OH}) D \text { Continuous: mean } \\
\text { +/- SD for whites of } 25.5+/-7.9 \text { and blacks: } 17.3+/- \\
\text { 6.3. } 25(\mathrm{OH}) \text { D tertiles and ranges: whites (T3: }<21.8 \text {; } \\
\text { T2: 21.8-28.3; T1: >28.3) and blacks (T3: }>19.3 ; \mathrm{T} 2 \text { : } \\
\text { 14.0-19.3; T1: }<14.0) .25(\mathrm{OH}) D \text { to cognitive test } \\
\text { score in whites or in blacks: not significant (all } \\
\text { p>0.05). Difference in } 25(\mathrm{OH}) \text { D levels between } \\
\text { quintiles of cognitive decline on all of the cognitive } \\
\text { tests in white or blacks at either } 3 \text { years or } 10.6 \text { years: } \\
\text { not significant (all p>0.05). Association of } 25(\mathrm{OH}) D \\
\text { with linear change in cognitive test scores: not } \\
\text { significant (all p>0.05) }\end{array}$ \\
\hline
\end{tabular}




\begin{tabular}{|c|c|c|c|c|}
\hline \multicolumn{5}{|c|}{ Table 3 continued. } \\
\hline & $\begin{array}{l}\text { Author, } \\
\text { Year, Study } \\
\text { Design }\end{array}$ & Study Population & Outcomes & Conclusions \\
\hline 19 & $\begin{array}{l}\text { Toffanello et } \\
\text { al. }(2014)^{36} \\
\text { Cross- } \\
\text { sectional and } \\
\text { Longitudinal } \\
\text { (4.4 years) }\end{array}$ & $\begin{array}{l}1927 \text { Caucasian } \\
\text { adults (age } \\
\text { inclusion not } \\
\text { reported) from Pro } \\
\text { V.A. study in Italy. } \\
\text { Mean +/- SD age: } \\
\text { 73.9+/-6.7 years. }\end{array}$ & $\begin{array}{l}25(\mathrm{OH}) D(\mathrm{ng} / \mathrm{ml}) \\
\text { Cognitive tests: } \\
\text { MMSE to define } \\
\text { MCI as score }<24 \text {. } \\
\text { A decline of } 3 \text { or } \\
\text { more points at F/U } \\
\text { defined as } \\
\text { substantial cognitive } \\
\text { decline. }\end{array}$ & 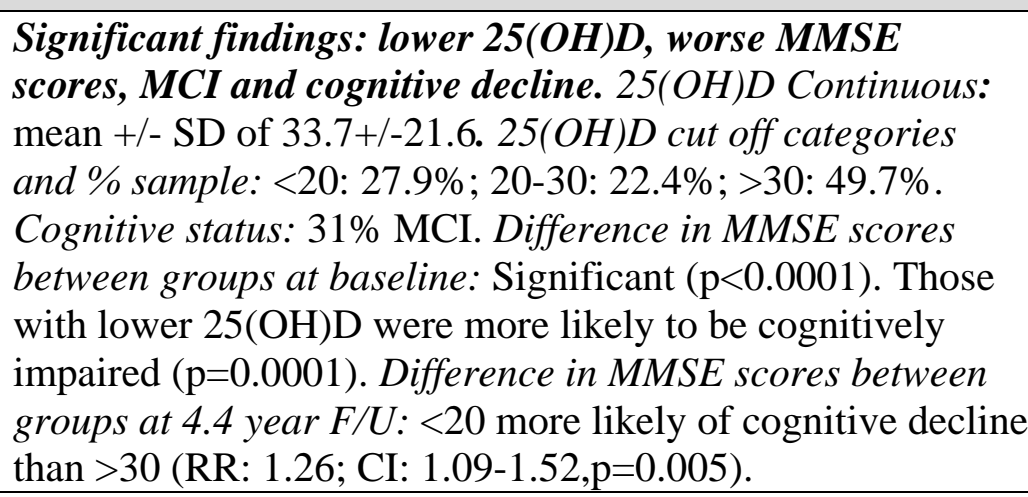 \\
\hline 20 & $\begin{array}{l}\text { Wilson et al. } \\
(2014)^{37} \\
\text { Cross- } \\
\text { sectional and } \\
\text { longitudinal } \\
\text { (4 years) }\end{array}$ & $\begin{array}{l}2777 \text { adults }(70-79 \\
\text { years old) from } \\
\text { Health ABC cohort } \\
\text { in United States } \\
\text { Mean +/- SD age: } \\
73.6+/-2.9 \text { years. }\end{array}$ & $\begin{array}{l}25(\mathrm{OH}) D(\mathrm{ng} / \mathrm{ml}) \\
\text { Cognitive tests: } \\
\text { 3MS, DSST }\end{array}$ & $\begin{array}{l}\text { Significant findings: lower } 25(\mathrm{OH}) \mathrm{D} \text {, worse cognitive } \\
\text { performance but not greater cognitive decline. } 25(\mathrm{OH}) \mathrm{D} \\
\text { cut off categories and \% sample: }<20: 32.9 \% ; 20-30: \\
35.5 \% \text {; }>30: 31.6 \text {. Baseline (adjusted model): } 25(\mathrm{OH}) \mathrm{D}<20 \\
\text { scored lower on } 3 \mathrm{MS}(\mathrm{p}=0.02) \text { and DSST than } 25(\mathrm{OH}) \mathrm{D}> \\
30(\mathrm{p}=0.01) .4 \text { year F/U (adjusted model): } 25(\mathrm{OH}) \mathrm{D} \text { to } \\
\text { cognitive decline defined by 3MS and DSST: not } \\
\text { significant. }\end{array}$ \\
\hline
\end{tabular}




\begin{tabular}{|c|c|c|c|c|}
\hline & $\begin{array}{l}\text { Author, } \\
\text { Year, } \\
\text { Study } \\
\text { Design }\end{array}$ & $\begin{array}{l}\text { Study } \\
\text { Population }\end{array}$ & Outcomes & Conclusions \\
\hline 1 & $\begin{array}{l}\text { Beauchet et } \\
\text { al. }(2011)^{38} \\
\text { Cross- } \\
\text { sectional }\end{array}$ & $\begin{array}{l}411 \text { adults } \\
\text { (>65 years } \\
\text { old) in } \\
\text { France. } \\
\text { Mean +/- } \\
\text { SD age: } \\
70.4+/-1.8 \\
\text { years. }\end{array}$ & $\begin{array}{l}25(\mathrm{OH}) D(\mathrm{ng} / \mathrm{ml}) \\
\text { Gait velocity: SMTEC system: } \\
\text { footswitches to measure temporal step } \\
\text { parameters. One trial at usual velocity } \\
\text { calculated from the Timed Up and Go } \\
\text { test }(\mathrm{m} / \mathrm{s}) . \text { Cognitive tests: Abnormal } \\
\text { episodic memory }(6 \text { memory items } \\
\text { from MMSE; score < } 6) \text { and abnormal } \\
\text { CDT were considered as cognitive } \\
\text { impairment. }\end{array}$ & $\begin{array}{l}\text { Significant findings: lower } 25(\mathbf{O H}) \text { D, slower } \\
\text { velocity. No significant findings with cognition. } \\
25(\mathrm{OH}) D \text { cut off categories and \% sample: }<10 \text { : } \\
\text { 16.6\%; } 10-30: 70.3 \% ;>30: 13.1 \% \text {. \% Cognitive } \\
\text { impaired in each group: }<10: 48.5 \% ; 10-30: \\
\text { 39.8\% >30: } 38.9 \% \text { Difference in gait velocity } \\
\text { between groups: significant ( } \mathrm{p}=0.003) \text {. Difference } \\
\text { in gait velocity between }<10 \text { vs. }>30: \text { significant } \\
\text { (p=0.002). Difference in \% cognitive impaired } \\
\text { between groups: not significant }(\mathrm{p}=0.394) \text {. }\end{array}$ \\
\hline 2 & $\begin{array}{l}\text { Houston et } \\
\text { al. }(2011)^{39} \\
\text { Cohort }\end{array}$ & $\begin{array}{l}307 \text { adults } \\
\text { (70-89 years } \\
\text { old) from x } \\
\text { LIFE-P } \\
\text { study in } \\
\text { United } \\
\text { States Mean } \\
\text { +/- SD age: } \\
76.7+/-4.3 \\
\text { years. }\end{array}$ & $\begin{array}{l}25(\mathrm{OH}) D(\mathrm{ng} / \mathrm{ml}) \\
\text { Gait velocity: time (s) to walk } 400 \mathrm{~m} \\
\text { by walking } 10 \text { times } 20 \mathrm{~m} . \\
\text { Cognitive tests: MMSE }\end{array}$ & $\begin{array}{l}\text { Significant findings: lower } 25(\mathrm{OH}) \mathrm{D} \text {, slower gait } \\
\text { velocity. No significant findings with cognition. } \\
25(\mathrm{OH}) D \text { continuous: mean of } 20.9 ., 25(\mathrm{OH}) D \\
\text { cut off categories and \% sample: }<20: 50 \% \text { and } \\
>30 \mathrm{ng} / \mathrm{ml} 10 \% \text {. Difference in gait velocity } \\
\text { between }<20 \text { vs. }>20 \text { : significant }(\mathrm{p}=0.01) \text {. } \\
\text { Difference in MMSE between groups: not } \\
\text { significant ( } \mathrm{p}=0.17) \text {. Change in vitamin D status } \\
\text { in } 12 \text { months association with changes in gait } \\
\text { velocity: not significant for increase or decrease } \\
(\mathrm{p}=0.64 \text { and } \mathrm{p}=0.13) \text {. }\end{array}$ \\
\hline
\end{tabular}




\begin{tabular}{|c|c|c|c|c|}
\hline \multicolumn{5}{|c|}{ Table 4 continued. } \\
\hline & $\begin{array}{l}\text { Author, } \\
\text { Year, Study } \\
\text { Design }\end{array}$ & $\begin{array}{l}\text { Study } \\
\text { Population }\end{array}$ & Outcomes & Conclusions \\
\hline 3 & $\begin{array}{l}\text { Houston et al. } \\
(2012)^{40} \\
\text { Longitudinal } \\
(2,46 \text { yrs.) }\end{array}$ & $\begin{array}{l}\text { 2307 adults } \\
\text { (70-79 years } \\
\text { old) from } \\
\text { Health ABC } \\
\text { study in } \\
\text { United } \\
\text { States Mean } \\
\text { +/- SD age: } \\
\text { 74.7+/-2.9 } \\
\text { years. }\end{array}$ & $\begin{array}{l}25(\mathrm{OH}) D(\mathrm{ng} / \mathrm{ml}) \\
\text { Gait velocity: calculated from time to } \\
\text { walk } 20 \mathrm{~m} \text { at usual velocity }(\mathrm{m} / \mathrm{s}) \\
\text { Cognitive tests: } 3 \mathrm{MS}\end{array}$ & 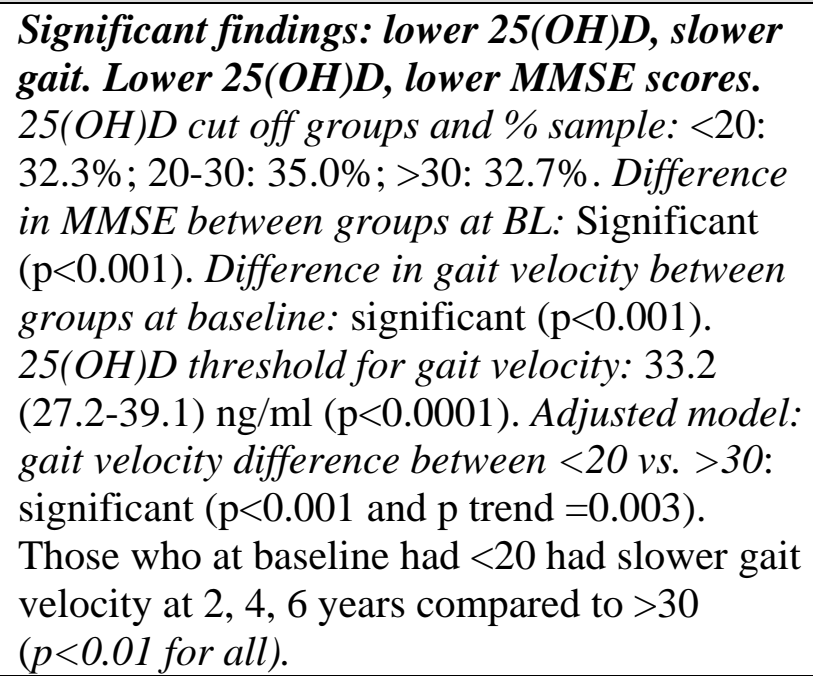 \\
\hline 4 & $\begin{array}{l}\text { Peterson et al. } \\
(2012)^{41} \\
\text { Cohort }\end{array}$ & $\begin{array}{l}159 \text { adults } \\
\text { (>70 years } \\
\text { old) from } \\
\text { ISAAC } \\
\text { study in } \\
\text { United } \\
\text { States Mean } \\
\text { age: } 85.5 \\
\text { years. }\end{array}$ & $\begin{array}{l}25(\mathrm{OH}) \mathrm{D}(\mathrm{ng} / \mathrm{ml}) \\
\text { Gait velocity: Tinetti gait velocity, } \\
\text { m/s. } \\
\text { Cognitive tests: CDR to define MCI as } \\
<0.5 \text {. DSF, DSST, TMT-A, Simple } \\
\text { and Choice RT, COT, DSB, LNS, } \\
\text { LM, DVR, CERAD WL, CERAD, } \\
\text { VFR language, WRAT-R, EBMT, } \\
\text { TMT-B, ST, VF, OMOT, PC, BD. }\end{array}$ & 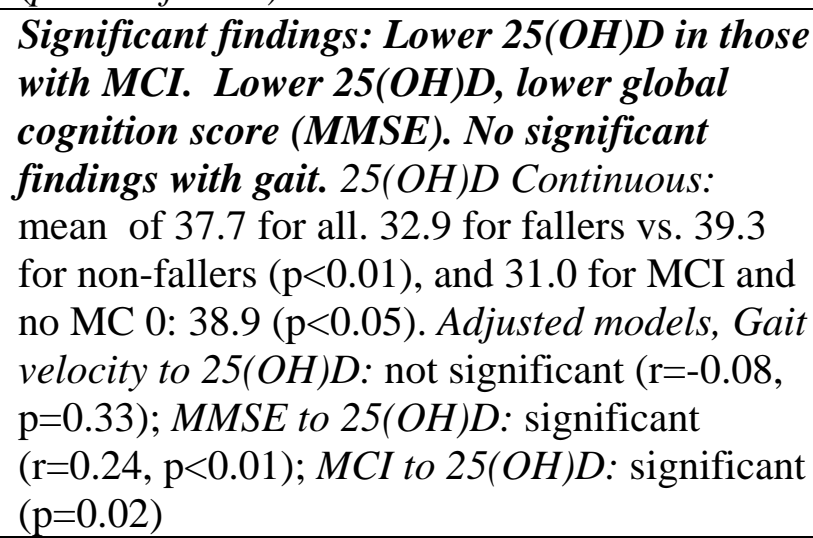 \\
\hline
\end{tabular}




\begin{tabular}{|c|c|c|c|c|}
\hline \multicolumn{5}{|c|}{ Table 4 continued. } \\
\hline & $\begin{array}{l}\text { Author, Year, } \\
\text { Study Design }\end{array}$ & Study Population & Outcomes & Conclusions \\
\hline 5 & $\begin{array}{l}\text { Menant et al. } \\
(2012)^{42} \\
\text { Cross- } \\
\text { sectional }\end{array}$ & $\begin{array}{l}463 \text { adult (70-90 years } \\
\text { old), independent in } \\
\text { ADL and able to walk } \\
\text { independently in } \\
\text { Australia. Mean +/- SD } \\
\text { age: } 78.0+/-4.6 \text { years. }\end{array}$ & $\begin{array}{l}25(\mathrm{OH}) D(\mathrm{ng} / \mathrm{ml}) \\
\text { Gait velocity: } \\
\text { calculated from time to } \\
\text { walk } 6 \mathrm{~m} \text { as part of the } \\
\text { Physiological Profile } \\
\text { Assessment. } \\
\text { Cognitive tests: } \\
\text { MMSE, DSST, TMT- } \\
\text { A, TMT-B. }\end{array}$ & $\begin{array}{l}\text { Significant findings: lower } 25(\mathrm{OH}) \mathrm{D} \text {, slower gait. } \\
\text { Lower } 25(\mathrm{OH}) \text { D, worse cognitive performance, } \\
\text { especially in executive function tests. (TMT-B). } \\
25(\mathrm{OH}) D \text { continuous: mean +/- SD of } 24.9+/-9.9 \text {. } \\
25(\mathrm{OH}) D \text { cut off categories and \% sample: all }(<20 \text { : } \\
\text { 33.3\%), men ( }<20: 22 \%) \text {, and women }(<20: 44 \%) \text {. } \\
\text { Difference in gait velocity between groups: } \\
\text { significant (p<0.01). Difference in MMSE, TMT-A, } \\
\text { DSST and BD between groups: not significant. } \\
\text { Difference in TMT-B between groups: significant } \\
(\mathrm{p}<0.05) \text {. }\end{array}$ \\
\hline 6 & $\begin{array}{l}\text { Toffanello et } \\
\text { al. }(2012)^{43} \\
\text { Cross- } \\
\text { sectional }\end{array}$ & $\begin{array}{l}2694 \text { older adults (age } \\
\text { inclusion NR) Pro.V.A., } \\
\text { Italy } \\
\text { Women: } 75.6+/-7.5 \\
\text { Men: } 76.2+/-7.8 \text {. }\end{array}$ & $\begin{array}{l}25(\mathrm{OH}) D(\mathrm{ng} / \mathrm{ml}) \\
\text { Gait velocity: } \\
\text { calculated from best } \\
\text { time (s) in } 2 \text { walks at } \\
\text { usual pace along a } 4 \mathrm{~m} . \\
\text { Cognitive tests: } \\
\text { Indexed MMSE }\end{array}$ & 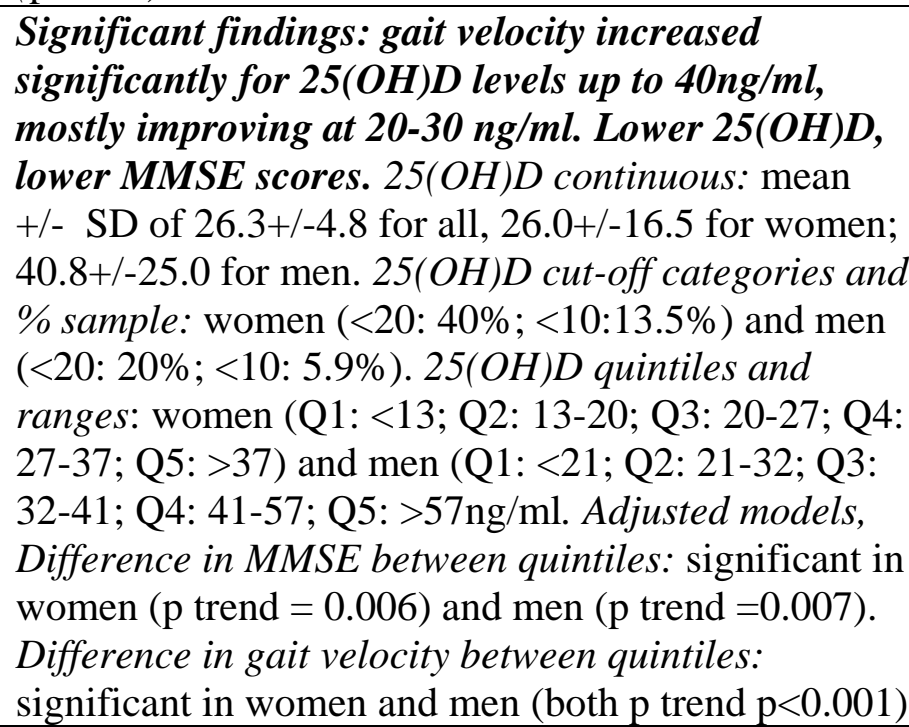 \\
\hline
\end{tabular}




\begin{tabular}{|c|c|c|c|c|}
\hline & $\begin{array}{l}\text { Author, } \\
\text { Year, Study } \\
\text { Design }\end{array}$ & Study Population & Outcomes & Conclusions \\
\hline 7 & $\begin{array}{l}\text { Houston et } \\
\text { al. }(2013)^{44} \\
\text { Cross- } \\
\text { sectional }\end{array}$ & $\begin{array}{l}2099 \text { adults }(70-79 \\
\text { years) from Health ABC } \\
\text { study in United States } \\
\text { Mean +/- SD age: } \\
74.6+/-2.9 \text { years. }\end{array}$ & $\begin{array}{l}25(\mathrm{OH}) D(\mathrm{ng} / \mathrm{ml}) \\
\text { Gait velocity: } \\
\text { calculated from time } \\
\text { (s) used to calculate } \\
\text { gait velocity, m/s. } \\
\text { Cognitive tests: } 3 \mathrm{MS} \\
\end{array}$ & $\begin{array}{l}\text { Significant findings: Lower } 25(\mathbf{O H}) \text { D, slower gait } \\
\text { velocity and lower MMSE scores. } 25(\mathrm{OH}) D \text { cut off } \\
\text { categories and \% sample: }<20: 28.9 \% ; 50-30: 36.1 \% \text {; } \\
>30: 35 \% . \text { Difference in gait velocity between groups: } \\
\text { significant }(\mathrm{p}<0.001) . \text { Difference in MMSE between } \\
\text { groups: Significant }(\mathrm{p}<0.001)\end{array}$ \\
\hline 8 & $\begin{array}{l}\text { Gschwind et } \\
\text { al. }(2014)^{45} \\
\text { Cross- } \\
\text { sectional }\end{array}$ & $\begin{array}{l}404 \text { older adult } \\
\text { attending memory clinic } \\
\text { (>65 year old). Mean } \\
\text { +/- SD age: } 77.6+/-5.8 \\
\text { years. }\end{array}$ & $\begin{array}{l}25(\mathrm{OH}) D(\mathrm{ng} / \mathrm{ml}) \\
\text { Gait velocity } \\
\text { GAITRite measured } \\
\text { usual and fast walking } \\
\text { velocity (no practice, } \\
\text { one walk, cm/s) } \\
\text { Cognitive tests: } \\
\text { MMSE }\end{array}$ & 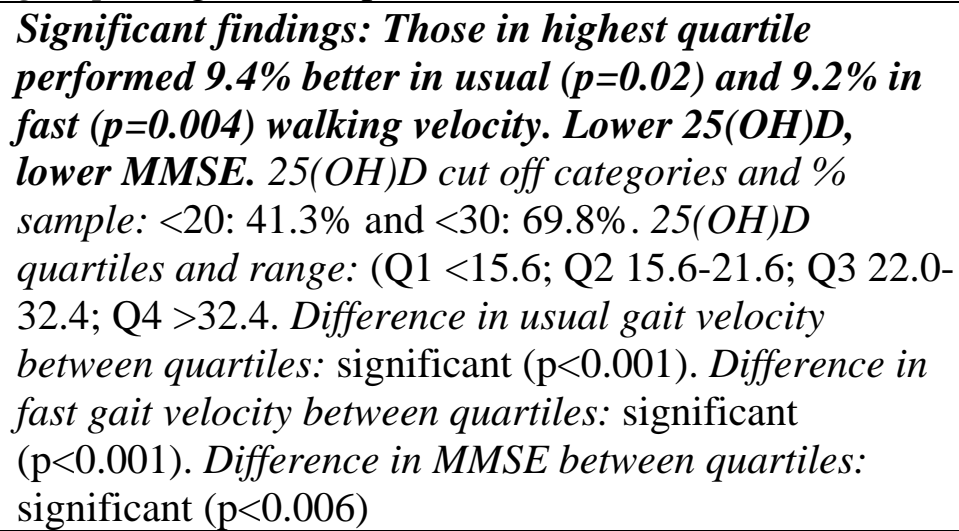 \\
\hline
\end{tabular}


APPENDIX B 


\section{DUAL TASK PHYSICAL PERFORMANCE TEST INSTRUCTIONS}

Participant ID:

Date: month/day/year

Practice trials (Same order for all participants, RECORD FOR SINGLE TASK GAIT)

\begin{tabular}{l|l}
1 & Single gait task
\end{tabular}

Data collection trials (random order) PARTICIPANT RANDOM ORDER NUMBER

\begin{tabular}{|l|l|l|l|}
\hline 1 & Single gait task & Single cognitive task & Dual task \\
\hline 2 & Single gait task & Dual task & $\begin{array}{l}\text { Single cognitive } \\
\text { task }\end{array}$ \\
\hline 3 & Single cognitive task & Single gait task & Dual task \\
\hline 4 & Single cognitive task & Dual task & Single gait task \\
\hline 5 & Dual task & Single cognitive task & Single gait task \\
\hline 6 & Dual task & Single gait task & $\begin{array}{l}\text { Single cognitive } \\
\text { task }\end{array}$ \\
\hline
\end{tabular}

If the participant brings heeled-shoes, have them remove it. NOTE:

Enter the participant ID, height, weight and leg length. Leg length:

Press start

Read Instructions before each trial.

Practice single gait task: This is the walkway that we will use for some walking tests. For each walk, you must start behind the line in front of you and continue walking until you pass the line at the other end of the walkway. To familiarize yourself with walkway, start at this line and walk across the mat at the pace you prefer during daily activities. Do not run. Continue walking until you reach the line at the other side. You can start when you are ready.

Este es el camino que vamos a utilizar para algunas pruebas de marcha. Por cada caminata, debe comenzar detrás de la línea en frente de usted y seguir caminando hasta pasar la línea en el otro extremo del camino. Para familiarizarse con el camino, comience en esta línea y camine por la alfombra al ritmo que usualmente camina durante las actividades diarias. No corra. Continúe caminando hasta llegar a la línea en el otro lado. Puede empezar cuando esté listo.

Single cognitive task: Have participant stand in the starting line. While you are standing, count backwards out loud from 50 by 1 starting. Count all the way down to 1 . If you make a mistake, don't stop and continue counting.

Haga que el participante se pare en la línea de inicio. Mientras que usted está de pie, cuente hacia atrás en voz alta de SDe 50 por 1. Cuente hasta llegar a 1. Si comete un error, no se detenga y siga contando.

Single gait task: Have participant stand in the starting line. Starting at this line, walk across the mat at a pace you prefer during daily activities. Do not run. Continue walking until you reach the line at the other side. You can start whenever you are ready. 
Haga que el participante se pare en la línea de inicio .A partir de esta línea, camine por la alfombra al ritmo que usualmente camina durante las actividades diarias. No corra. Continúe caminando hasta llegar a la línea en el otro lado. Puede empezar cuando esté listo.

Dual task: Have participant stand in the starting line. For the following test, you will walk across the mat at a pace you prefer during daily activities, while you simultaneously count backwards out loud from 50 by 1 . Do not run. If you make mistakes during counting keep on going. Continue walking without prioritizing either of the tasks until you reach the line at the other side. You can start when you are ready.

Haga que el participante se pare en la línea de inicio. Para la siguiente prueba, usted caminará a través de la alfombra al ritmo que usualmente camina durante las actividades diarias, mientras cuenta al mismo tiempo hacia atrás en voz alta de SDe 50 por 1 . No corra. Si se cometen errores durante el conteo siga contando. Continúe caminando sin dar prioridad a ninguna de las tareas hasta llegar a la línea en el otro lado. Puede empezar cuando esté listo.

\section{DUAL TASK PHYSICAL PERFORMANCE RANDOM ORDER TABLE}

\begin{tabular}{|c|c|c|c|c|c|c|c|c|c|c|c|}
\hline Number & $\begin{array}{l}\text { Task } \\
\text { order }\end{array}$ & Participant ID & Number & $\begin{array}{l}\text { Task } \\
\text { order }\end{array}$ & Participant ID & Number & $\begin{array}{l}\text { Task } \\
\text { order }\end{array}$ & Participant ID & Number & $\begin{array}{l}\text { Task } \\
\text { order }\end{array}$ & Participant ID \\
\hline 1 & 6 & & 35 & 2 & & 69 & 4 & & 103 & 4 & \\
\hline 2 & 4 & & 36 & 4 & & 70 & 5 & & 104 & 5 & \\
\hline 3 & 1 & & 37 & 2 & & 71 & 2 & & 105 & 1 & \\
\hline 4 & 2 & & 38 & 1 & & 72 & 6 & & 106 & 2 & \\
\hline 5 & 3 & & 39 & 4 & & 73 & 3 & & 107 & 6 & \\
\hline 6 & 5 & & 40 & 3 & & 74 & 6 & & 108 & 3 & \\
\hline 7 & 2 & & 41 & 5 & & 75 & 2 & & 109 & 3 & \\
\hline 8 & 4 & & 42 & 6 & & 76 & 1 & & 110 & 1 & \\
\hline 9 & 1 & & 43 & 5 & & 77 & 5 & & 111 & 4 & \\
\hline 10 & 3 & & 44 & 2 & & 78 & 4 & & 112 & 6 & \\
\hline 11 & 5 & & 45 & 3 & & 79 & 1 & & 113 & 2 & \\
\hline 12 & 6 & & 46 & 1 & & 80 & 5 & & 114 & 5 & \\
\hline 13 & 3 & & 47 & 4 & & 81 & 6 & & 115 & 5 & \\
\hline 14 & 5 & & 48 & 6 & & 82 & 2 & & 116 & 3 & \\
\hline 15 & 1 & & 49 & 1 & & 83 & 4 & & 117 & 6 & \\
\hline 16 & 4 & & 50 & 4 & & 84 & 3 & & 118 & 2 & \\
\hline 17 & 6 & & 51 & 6 & & 85 & 6 & & 119 & 1 & \\
\hline 18 & 2 & & 52 & 5 & & 86 & 5 & & 120 & 4 & \\
\hline 19 & 5 & & 53 & 2 & & 87 & 3 & & 121 & 1 & \\
\hline 20 & 3 & & 54 & 3 & & 88 & 4 & & 122 & 3 & \\
\hline 21 & 6 & & 55 & 6 & & 89 & 2 & & 123 & 2 & \\
\hline 22 & 1 & & 56 & 1 & & 90 & 1 & & 124 & 6 & \\
\hline 23 & 2 & & 57 & 4 & & 91 & 3 & & 125 & 5 & \\
\hline 24 & 4 & & 58 & 2 & & 92 & 2 & & 126 & 4 & \\
\hline 25 & 4 & & 59 & 5 & & 93 & 1 & & 127 & 6 & \\
\hline 26 & 1 & & 60 & 3 & & 94 & 6 & & 128 & 4 & \\
\hline 27 & 5 & & 61 & 1 & & 95 & 4 & & 129 & 1 & \\
\hline 28 & 3 & & 62 & 6 & & 96 & 5 & & 130 & 3 & \\
\hline 29 & 2 & & 63 & 4 & & 97 & 6 & & & & \\
\hline 30 & 6 & & 64 & 3 & & 98 & 2 & & & & \\
\hline 31 & 6 & & 65 & 2 & & 99 & 4 & & & & \\
\hline 32 & 3 & & 66 & 5 & & 100 & 5 & & & & \\
\hline 33 & 5 & & 67 & 1 & & 101 & 3 & & & & \\
\hline 34 & 1 & & 68 & 3 & & 102 & 1 & & & & \\
\hline
\end{tabular}



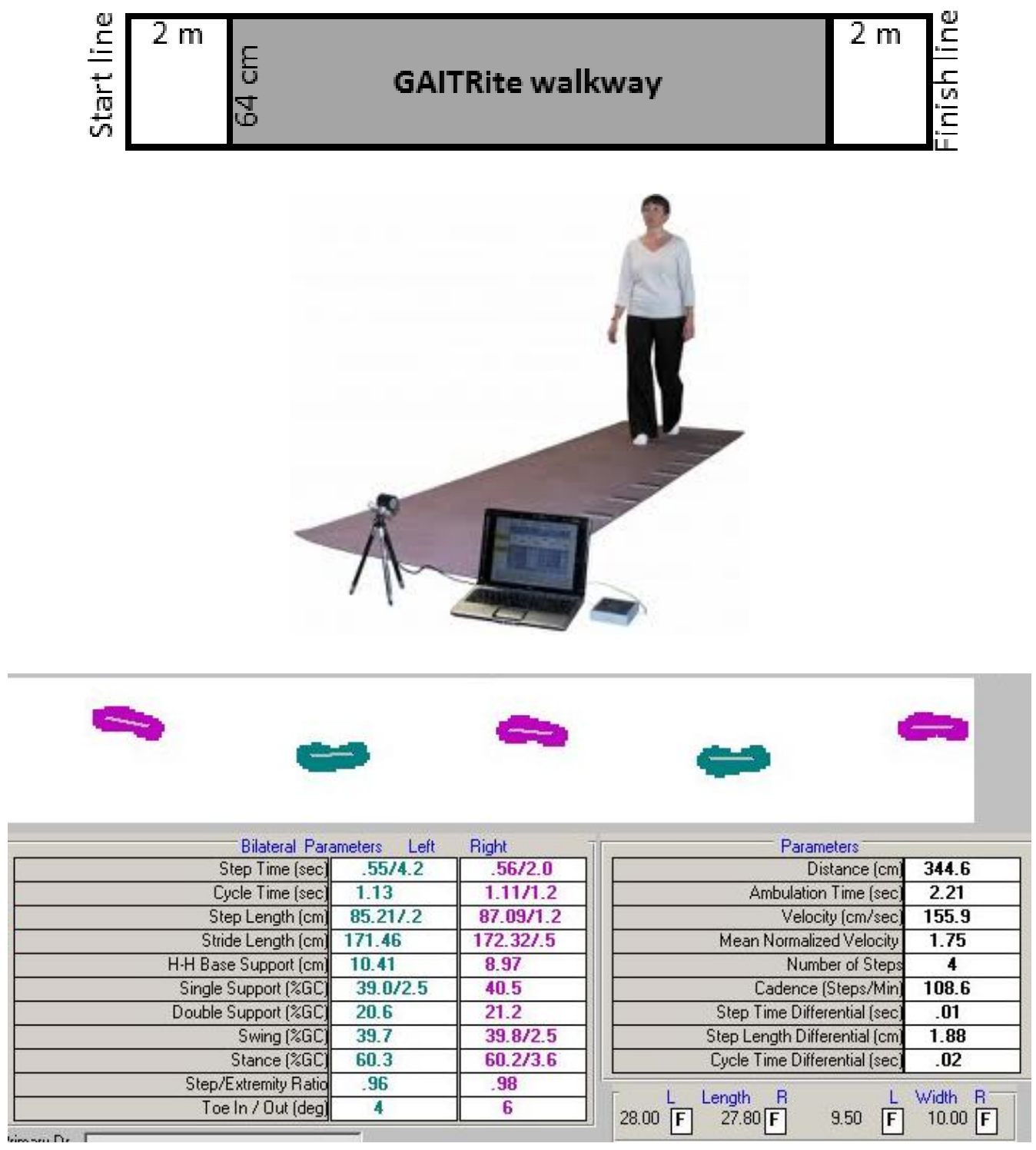

Figure 1: The GAITRite Walkay for the Assessment of Gait. Images taken from GAITRITE manual and software.

Legend: The GAITRite is a $6 \mathrm{~m}$ long walkway. The start and finish lines were placed 2 meters before and after to account for acceleration and deceleration (above). The participants were asked to walk on GAITRite during single walking and dual tasking (middle). The mat is connected to a computer software that calculates spation-temporal variables from the information gathered by the sensors (below). 


\section{ELECTRO SENSOR COMPLEX INSTRUCTIONS}

1. Clean foot plates and oximeter

2. Turn on computer: password: 12345

3. Open program using the "CMS" shortcut on desktop.

a. Write participant ID: last 2 numbers of year of birthday, 2 last numbers of phone number, space, 4 first letters of last name.

b. Gender, DOB

c. Ht, Wt, daily activity

4. Ask them to:

a. Seat

b. take of shoes and socks

c. place feet on metal foot plates

d. Make sure they are not wearing nail polish or acrylic nails. Right index finger in oximeter - push white button until power on, allow 30s to stabilize.

e. BP cuff on left arm, cord above arm and the hand resting on the table in front.

f. Arms must be placed in an extended but relaxed and comfortable position.

g. Remain perfectly still. If move, retake.

5. Move screen out of their site if possible.

6. When it starts, ask them to relax, no talking

7. Valsalva:

a. Remove feet from the plates

b. Now you are going to clamp your nose with your left hand and try to breathe out your nose while plugging it for 15 seconds, and keeping your mouth closed like you were trying to pop your ears. I will tell you when to start and when you can breathe normally.

c. Ahora se va a apretar la nariz con la mano izquierda y va a tratar de respirar por la nariz mientras la tapona durante 15 segundos y manteniendo la boca cerrada como si estuviera tratando de destapar los oídos. Le diré cuándo comenzar y cuándo puede respirar normalmente.

8. Deep Breathing 30sec:

a. Now you are going to inhale for 5 seconds and exhale for 5 seconds. I will direct you when to inhale and exhale.

b. Ahora usted va a inhalar durante 5 segundos y exhalar durante 5

9. Stand up segundos. Le indicare cuando inhalar y cuando exhalar.

a. Finally, when I say go, I want you to stand up and remain standing up until the machine finishes measuring your blood pressure.

b. Finalmente, cuando le indique, quiero que se levante de la silla y permanezca de pie hasta que el equipo termine de tomar su presión arterial. 


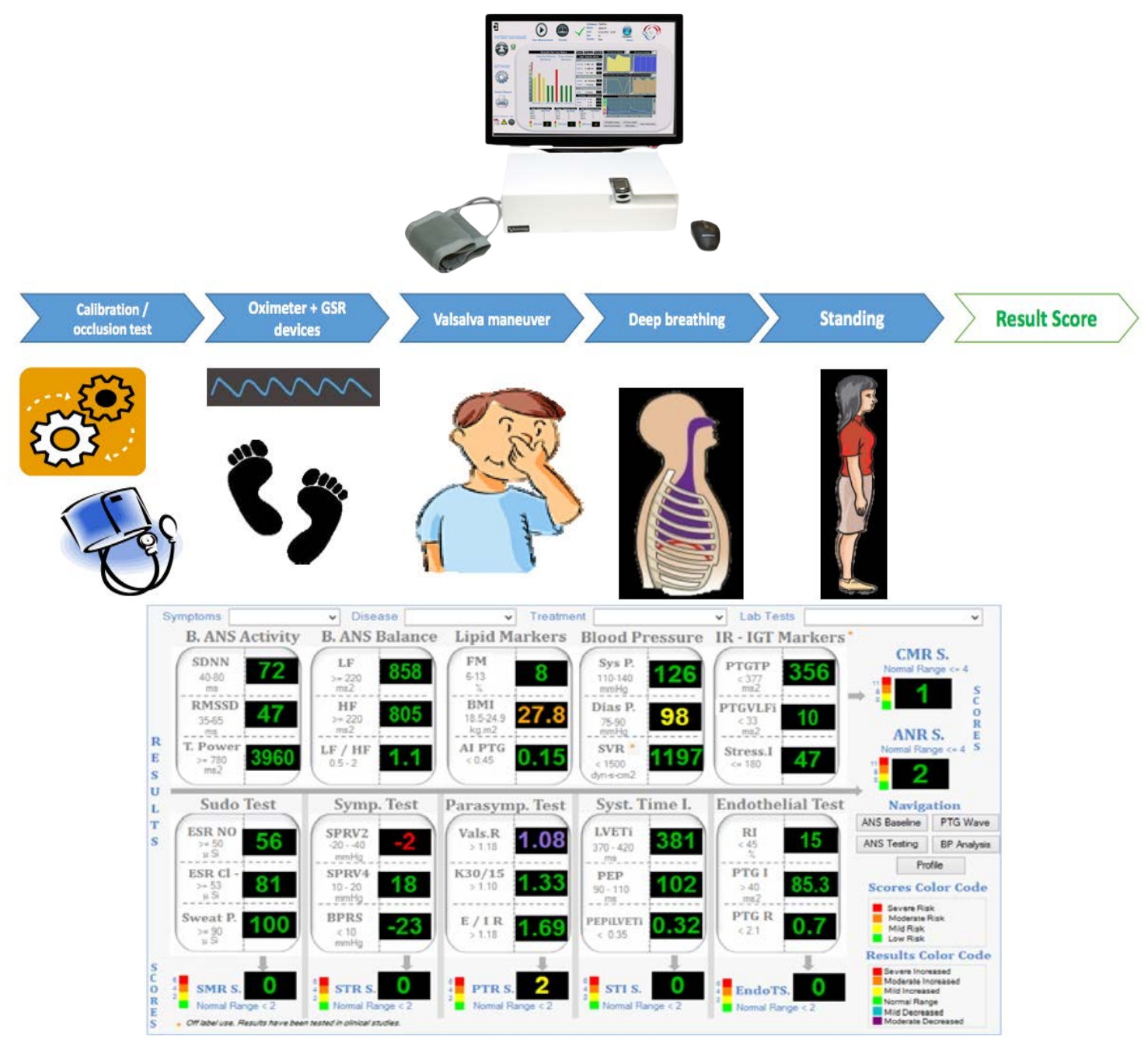

Figure 2: The Electro Sensor Complex Device and Procedure. Images taken from company website and computer software. ${ }^{46,47}$

Legend: The Electro Sensor Complex combines three devices into computer software (above). After placing the blood pressure cuff on the participant's arm, feet on the metal plates and index right finger on the pulse oximeter, the software calibrates and measures baseline data. Then the participant is asked to perform the valsava maneuver, deep breathing and standing up cardiac autonomic reflex tests (middle). Once it finishes, the software provides a result scoreboard (below). 


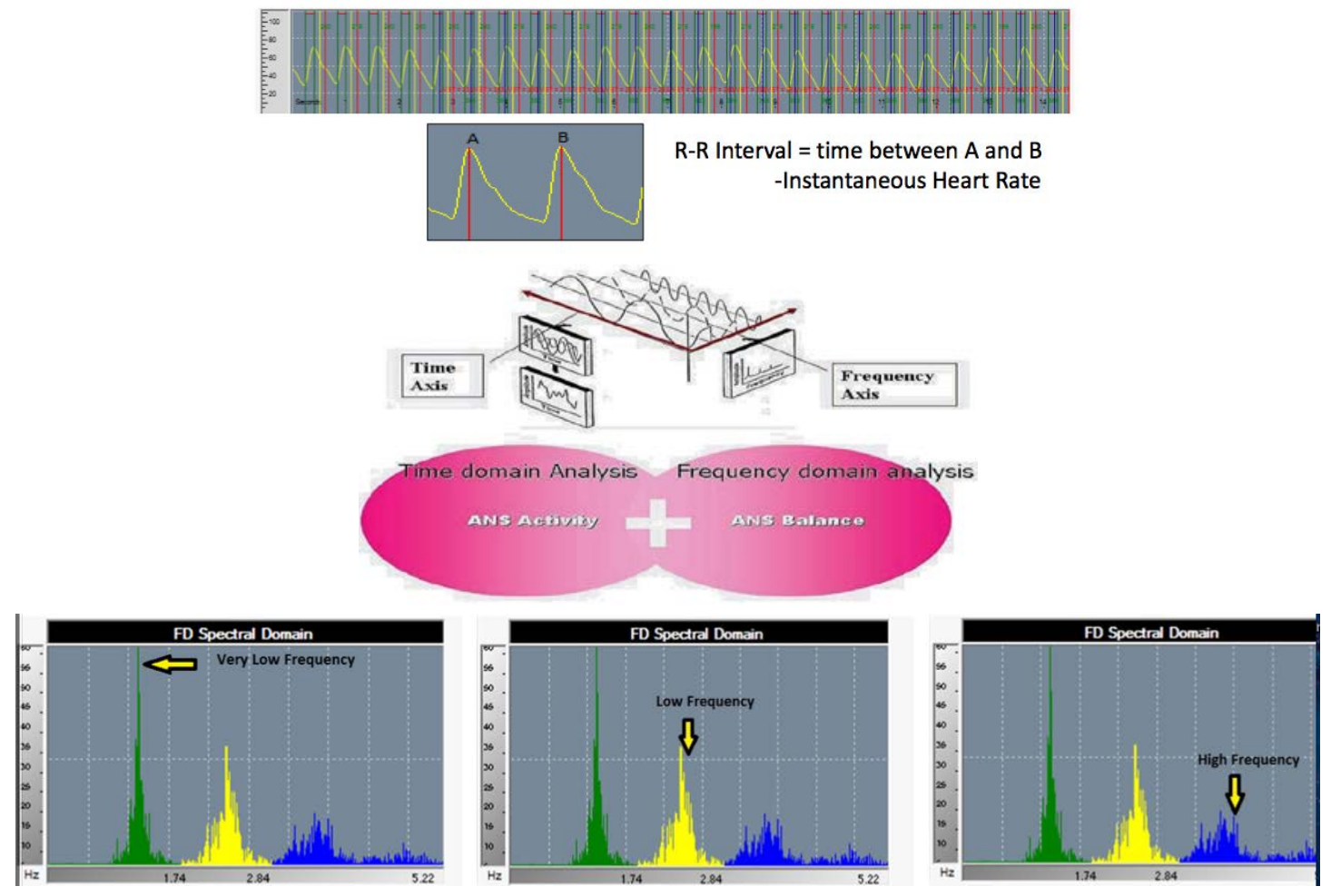

Figure 3: Heart Rate Variability Time and Frequency Domains. Images taken from company website and computer software. ${ }^{46,47}$

Legend: Example of plethysmograph used to measure heart rate variability (time from $\mathrm{R}$ to R intervals) in time domain (above), application of Fourier transform to the plethysmograph to convert from time domain into frequency domains (middle) and the three frequencies of heart rate variability (below). 


\begin{tabular}{|c|c|c|}
\hline \multicolumn{3}{|c|}{ oftware variables used to calculate CMRS } \\
\hline 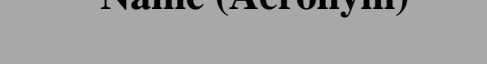 & values & \\
\hline ANS activity markers & $<2$ & \\
\hline $\begin{array}{l}\text { Standard deviation of the } \\
\text { normal wave ( SDNN) }\end{array}$ & $40-80 \mathrm{~ms}$ & $\begin{array}{l}\text { HRV time domain. Variation between each successive heartbeat. Reflects } \\
\text { overall cyclic components of HRV. Marker of SNS PNS. Decreased SDNN is } \\
\text { associated to reduced left ventricular function. }\end{array}$ \\
\hline $\begin{array}{l}\text { Square root of the mean } \\
\text { squared differences of } \\
\text { successive normal to normal } \\
\text { R-R intervals (RMS SD) }\end{array}$ & $35-65 \mathrm{~ms}$ & $\begin{array}{l}\text { HRV time domain. Indicator of PNS. Reflects the electrical stability of the } \\
\text { heart. }\end{array}$ \\
\hline Total power (PTGTP) & $>=780 \mathrm{~ms} 2$ & $\begin{array}{l}\text { HRV frequency domain. Total power of the FFT (Fast Fourier transform) } \\
\text { performed on oximeter waveform. It is the sum of the areas under the curve } \\
\text { covered by the } 3 \text {-frequency domains. Main indicator of ANS activity used to } \\
\text { define HRV score. It is usually decreased in those with chronic stress or with } \\
\text { disease. }\end{array}$ \\
\hline ANS balance markers & $<2$ & \\
\hline Low frequency (PTGLF) & $<220 \mathrm{~ms} 2$ & $\begin{array}{l}\text { HRV frequency domain. Indicator of both PNS and SNS. It is controversial } \\
\text { since it may also represent contribution influenced by RAAS and baroreceptor } \\
\text { activity generating vagal outflow. }\end{array}$ \\
\hline High frequency (PTGHF) & $>=220 \mathrm{~ms} 2$ & $\begin{array}{l}\text { HRV frequency domain. Indicator of PNS. Associated with R-R interval } \\
\text { changes related to breathing, which is under PNS control. }\end{array}$ \\
\hline $\mathrm{LF} / \mathrm{HF}$ & $0.5-2.0$ & $\begin{array}{l}\text { HRV frequency domain. Overall estimate of relative ANS balance within the } \\
\text { entire cardiac ANS. }>2 \% \text { mean s SNS predominance }<0.5 \% \text { indicates PNS } \\
\text { predominance }\end{array}$ \\
\hline
\end{tabular}




\begin{tabular}{|c|c|c|}
\hline Name (Acronym) & $\begin{array}{l}\text { Normal } \\
\text { values }\end{array}$ & Representation \\
\hline Lipid biomarkers & $<2$ & \\
\hline Fat mass & $25-31 \%$ & Energy storage of the body \\
\hline $\begin{array}{l}\text { Body mas index } \\
\text { (BMI) }\end{array}$ & $18.5-24.9$ & Body mass index $(\mathrm{kg} / \mathrm{m} 2)$ \\
\hline $\begin{array}{l}\text { Arterial stiffness } \\
\text { PTG (AIPTG) }\end{array}$ & $<0.45 \%$ & $\begin{array}{l}\text { Systematic arterial stiffness marker derived from the ascending aortic pressure waveform. } \\
\text { Marker of lipid levels, related to atherosclerosis. }\end{array}$ \\
\hline $\begin{array}{l}\text { Blood pressure } \\
\text { markers }\end{array}$ & $<2$ & \\
\hline $\begin{array}{l}\text { Systolic blood } \\
\text { pressure (SBP) }\end{array}$ & $\begin{array}{l}110-140 \\
\mathrm{mmHg}\end{array}$ & $\begin{array}{l}\text { SBP average performed during measurement. Refers to the pressure of blood in the artery } \\
\text { when the heart contracts. }\end{array}$ \\
\hline $\begin{array}{l}\text { Diastolic blood } \\
\text { pressure (DBP) }\end{array}$ & $\begin{array}{l}78-90 \\
\mathrm{mmHg}\end{array}$ & $\begin{array}{l}\text { DBP average performed during measurement. Refers to the pressure of blood in the artery } \\
\text { when the heart relaxes. }\end{array}$ \\
\hline $\begin{array}{l}\text { Systemic Vascular } \\
\text { Resistance (SVR) }\end{array}$ & $\begin{array}{l}<1500 \text { dyn- } \\
\text { s-cm2 }\end{array}$ & $\begin{array}{l}\text { Indicator of peripheral resistance to flow that must be overcome to push blood through the } \\
\text { circulatory system. }\end{array}$ \\
\hline $\begin{array}{l}\text { Insulin resistance / } \\
\text { IGT markers }\end{array}$ & $<2$ & \\
\hline $\begin{array}{l}\text { Total power index } \\
\text { (PTGTPi) }\end{array}$ & $<377 \mathrm{~ms} 2$ & $\begin{array}{l}\text { HRV frequency domain. PTGTP adjusted for fat mass. Significant marker of insulin } \\
\text { resistance. Comparing PTGTPi marker versus the euglycemic clamp, it has a sensitivity of } \\
90 \% \text { and specificity of } 90 \% \text { to detect insulin resistance. }\end{array}$ \\
\hline $\begin{array}{l}\text { Very low frequency } \\
\text { (PTGVLF) }\end{array}$ & & $\begin{array}{l}\text { HRV frequency domain. Associated with thermoregulation and sweating that results in } \\
\text { oscillation in vasomotor tone controlled by SNS and/or RAAS. }\end{array}$ \\
\hline $\begin{array}{l}\text { Very low frequency } \\
\text { index (PTGVLFi) }\end{array}$ & $<33 m s 2$ & PTGVLF adjusted by ESRNO. Marker of IGT \\
\hline $\begin{array}{l}\text { Stress index } \\
\text { (Stress_I) }\end{array}$ & $<=180 \%$ & Marker of SNS activity. Correlated with C-Reactive protein level. \\
\hline
\end{tabular}




\begin{tabular}{|c|c|c|}
\hline Name (Acronym) & $\begin{array}{l}\text { Normal } \\
\text { values }\end{array}$ & Representation \\
\hline $\begin{array}{l}\text { Sympatethic skin response } \\
\text { markers using Sudo Test (used to } \\
\text { calculate Sudomotor Response } \\
\text { Score (SMRS)) }\end{array}$ & $<2$ & $\begin{array}{l}\text { Cholinergic SNS function. Earliest detectable neurophysiologic abnormalities } \\
\text { in distal small fiber neuropathy, often associated with higher risk of kidney } \\
\text { nephropathy and retinopathy. SMRS has a sensitivity of } 91.4 \% \text { and specificity } \\
\text { of } 79.1 \% \text { to detect peripheral neuropathy in diabetic patients. }\end{array}$ \\
\hline $\begin{array}{l}\text { Electric Skin Respond to Nitric } \\
\text { Oxide (ESRNO) }\end{array}$ & $>=50 \mu \mathrm{Si}$ & $\begin{array}{l}\text { Marker of SNS function and microcirculation. The peak of the } \\
\text { electrochemical reaction on the bulk of the electrode reflects skin blood flow. } \\
\text { It has a sensitivity of } 68.4 \% \text { and specificity of } 84.4 \% \text { as a marker of } \\
\text { microcirculation disorder in diabetic patients. }\end{array}$ \\
\hline $\begin{array}{l}\text { Electric Skin Response to the } \\
\text { Chloride Ion (ESRCI) }\end{array}$ & $>=53 \mu \mathrm{Si}$ & $\begin{array}{l}\text { Electrochemical reaction on the bulk of the electrode. Peak reflects sweat } \\
\text { gland nerve density. }\end{array}$ \\
\hline Sweat Peak (Sweat_P) & $>=90 \mu \mathrm{Si}$ & $\begin{array}{l}\text { Reflects sweat gland function (sweat output) in respond to the electrical } \\
\text { stimulation }\end{array}$ \\
\hline $\begin{array}{l}\text { SNS tests (used to calculate } \\
\text { Sympathetic Test Response } \\
\text { Score (STRS)) }\end{array}$ & $<2$ & $\begin{array}{l}\text { Adrenergic SNS function. Sympathetic response failure could increase } \\
\text { cardiovascular events, and it is an indicator of CAN. }\end{array}$ \\
\hline $\begin{array}{l}\text { SBP response to Valsalva } \\
\text { maneuver in phase } 2 \text { (SPRV2) }\end{array}$ & $\begin{array}{l}-20-- \\
40 \mathrm{mmHg}\end{array}$ & Correlated with norepinephrine response (adrenergic). \\
\hline $\begin{array}{l}\text { SBP response to Valsalva } \\
\text { maneuver in phase } 4 \text { (SPRV4) }\end{array}$ & $\begin{array}{l}10-20 \\
\mathrm{mmHg}\end{array}$ & Correlated with epinephrine response. \\
\hline $\begin{array}{l}\text { Blood pressure response to } \\
\text { standing (BPRS) }\end{array}$ & $\begin{array}{l}<10 \\
\mathrm{mmHg}\end{array}$ & Reflects SNS adrenergic response to standing. \\
\hline
\end{tabular}




\begin{tabular}{|c|c|c|}
\hline Name (Acronym) & $\begin{array}{l}\text { Normal } \\
\text { values }\end{array}$ & Representation \\
\hline $\begin{array}{l}\text { PNS tests (used to calculate } \\
\text { Parasympathetic Test Response Score } \\
\text { (PTRS)) }\end{array}$ & $<2$ & $\begin{array}{l}\text { It is based on the analysis of the beat to beat heart rate changes during the } \\
\text { Valsalva maneuver, deep breathing, and postural change. PNS response } \\
\text { failure could increase cardiovascular events, and it is an indicator of CAN. } \\
\text { Associated with symptoms of dizziness or orthostatic hypotension. }\end{array}$ \\
\hline Valsalva Ratio (Vals_R) & $>1.18 \%$ & $\begin{array}{l}\text { Ratio of SPRV4 and SPVR2. Reflects PNS response. Uses heart rate } \\
\text { response to Valsalva Maneuver. }\end{array}$ \\
\hline $\begin{array}{l}\text { Heart Rate Change to Standing } \\
\text { position (K30/15 Ratio) }\end{array}$ & $>1.10 \%$ & $\begin{array}{l}\text { Evaluates the change in heart rate during the standing position. Heart rate } \\
\text { increases during the first } 15 \text { seconds and decreases until it stabilizes at } 30 \\
\text { seconds. It reflects PNS response to the change of posture and orthostatic } \\
\text { hypotension. }\end{array}$ \\
\hline Expiration/Inhalation ratio (E/I Ratio) & $>1.18 \%$ & $\begin{array}{l}\text { The heart rate ratio between expiration and inhalation during deep } \\
\text { breathing. Calculated by the longest RR interval divided by shorter RR } \\
\text { interval. Reflects PNS and it's a test of sinus arrhythmia. }\end{array}$ \\
\hline $\begin{array}{l}\text { Systolic time index (used to calculate } \\
\text { Systolic Time Interval Score (STIS)) }\end{array}$ & $<2$ & Reflects cardiac performance \\
\hline $\begin{array}{l}\text { Left ventricle ejection time index } \\
\text { (LVETi) }\end{array}$ & $\begin{array}{l}370- \\
420 \mathrm{~ms}\end{array}$ & Cardiac output adjusted with heart rate \\
\hline Pre-Ejection Period (Pep) & $\begin{array}{l}90- \\
110 \mathrm{~ms}\end{array}$ & $\begin{array}{l}\text { Systolic time interval inversely correlated with left ventricle contractility. } \\
\text { Primarily controlled by SNS beta-adrenergic activity. }\end{array}$ \\
\hline $\begin{array}{l}\text { Preejection Period Index / Left } \\
\text { Ventricle Ejection Time Index Ratio. } \\
\text { (PEPi/LVET Ratio) }\end{array}$ & $<0.35 \%$ & Correlated to cardiac performance. \\
\hline
\end{tabular}




\begin{tabular}{|c|c|c|}
\hline Name (Acronym) & $\begin{array}{l}\text { Name } \\
\text { (Acronym) }\end{array}$ & Name (Acronym) \\
\hline $\begin{array}{l}\text { Endothelial Tests (used to calculate } \\
\text { Endothelial function test Score } \\
\text { (EndoTS)) }\end{array}$ & $<2$ & $\begin{array}{l}\text { Earliest clinically detectable stage of cardiovascular disease. Marker of } \\
\text { endothelial dysfunction. }\end{array}$ \\
\hline Reflection Index (RI) & $<45 \%$ & Indicator of stiffness of the small and medium arteries. \\
\hline $\begin{array}{l}\text { Photoplethysmography Index } \\
\text { (PTGi) }\end{array}$ & $>40 \mathrm{~ms} 2$ & $\begin{array}{l}\text { HRV frequency domain. The sum of the amplitudes of the } 3 \text { frequency } \\
\text { domains. }\end{array}$ \\
\hline Plethysmography ratio (PTGr) & $<2.1 \%$ & HRV frequency domain. Ratio of the spectral analysis components \\
\hline $\begin{array}{l}\text { Cardiometabolic risk score } \\
\text { (CMRS) }\end{array}$ & $\begin{array}{l}\leq 4 \text { normal } \\
5-7 \text { mild } \\
\text { risk } \\
8-10 \\
\text { Moderate } \\
\text { Risks } \\
\geq 11 \text { high } \\
\text { risk }\end{array}$ & $\begin{array}{l}\text { Calculated from anthropometric data input in the system and the } 10 \\
\text { markers shown in grey. Each marker measured is scored as } \\
0=\text { =normal, } 1=\text { borderline or } 2=\text { abnormal and then used to calculate } \\
\text { CMRS, which is normal if }<=4 \text {, or represents mild risk (5-7), } \\
\text { moderate risk (8-10) or high risk ( }>=11) \text {. The CMRS had a sensitivity } \\
\text { of } 92 \% \text { and specificity of } 83 \% \text { (cut-off score }>4 \text { ) to detect type } 2 \\
\text { diabetes. }\end{array}$ \\
\hline
\end{tabular}


APPENDIX C 
ABBREVIATIONS AND ACRONYMS IN APPENDIX A AND B TABLES

25(OH)D

$\mathrm{AD}$

BMI

CAN

CE SDS

CI

$\mathrm{cm}$

$\mathrm{cm} / \mathrm{s}$

DBP

$\mathrm{F} / \mathrm{U}$

$\mathrm{ft}$

GDS

HRV

IGT

m

$\mathrm{m} / \mathrm{s}$

MCI

$\min$

OR

PNS

PTH

S

SBP

SNS

SCI

$\mathrm{SD}$
25- Hydroxyvitamin D

Alzheimer's Disease

Body Mass Index

Cardiac Autonomic Neuropathy

Center for Epidemiologic Studies Depression Scale

Confidence Interval

Centimeter

Centimeters per second

Diastolic Blood Pressure

Follow up

feet

Geriatric Depression Scale

Heart Rate Variability

Impaired Glucose Tolerance

Meters

Meters per second

Mild Cognitive Impairment

Minutes

Odds Ratio

Parasympathetic Nervous System

Parathyroid Hormone

Seconds

Systolic Blood Pressure

Sympathetic Nervous System

Subjective Cognitive Impairment

Standard Deviation 
ABBREVIATIONS AND ACRONYMS OF STUDIES IN APPENDIX A AND B TABLES

\begin{tabular}{|c|c|}
\hline ADRC & Alzheimer’s Disease Research Center \\
\hline ARIC & Atherosclerosis Risk in Communities Study \\
\hline $\mathrm{BFc} 80+$ & Befrail study $>80$ years old cohort. \\
\hline CLHLS & Chinese Longitudinal Healthy Longevity Survey \\
\hline EMAS & European Male Ageing Study \\
\hline EPIDOS & European Patient Information and Documentation Systems \\
\hline GAIT & Glucosamine/Chondroitin Arthritis Intervention Trial. \\
\hline Health ABC & The Health, Aging and Body Composition Study \\
\hline HSE 2000 & Healthy Survey for England 2000 \\
\hline InCHIANTI & Invecchiare in Chianti study \\
\hline ISAAC & Intelligent Systems for Assessment of Aging Changes Study \\
\hline $\begin{array}{l}\text { LIFE-P } \\
\text { Elders Pilot }\end{array}$ & The Lifestyle Interventionot significant and Independence for \\
\hline MrOS & Osteoporotic Fractures in Men Study \\
\hline NAME & Nutrition and Memory in Elders Study \\
\hline NHANES & National Health and Nutrition Examination Survey \\
\hline OPRA & Osteoporosis Prospective Risk Assessment \\
\hline Pro. V.A. & Progetto Veneto Anziani study \\
\hline SOF & Study of Osteoporotic Fractures. \\
\hline WHAS & Women's Health and Aging Study \\
\hline WHI & Women's Health Initiative \\
\hline ZENITH & $\begin{array}{l}\text { Zinc Effects in Nutrient Interactionot significant and Trends in } \\
\text { Health and Ageing }\end{array}$ \\
\hline
\end{tabular}


3MS

AMT

$\mathrm{BD}$

CANTAB

CDR

CDT

CERAD WL

CERAD VFR

COT

COWA

CSI-D

CTRM

DMS-IV

DSB

DSF

DSST

DVR

DWRT EBMT
Modified Mini Mental State Examination: global cognition Abbreviated Mental Test: global cognition

Block Design: visuospatial conot significanttruction

Cambridge Neuropsychological Testing Automated Battery: visual memory and executive function.

Clinical Dementia Rate

Clock Drawing Test: global executive function

Consortium to Establish A Registry for Alzheimer's Disease Word Recall: memory

Consortium to Establish A Registry for Alzheimer's Disease

Visual Figures Recall: memory

Crossing Off Test: processing velocity

Controlled Oral Word Association: verbal fluency

Community Screening Instrument for Dementia: global cognitive impairment.

Camden Topographical Recognition Memory (CTRM) test: visual memory and recognition and episodic memory.

Diagnostic and Statistical Manual of Mental Disorders IV

Digit Span Backward: information updating and verbal working memory

Digit Span Forward: information updating and verbal working memory

Digit Symbol Substitution in the Wechsler Adult Intelligence Scale: attention, concentration, processing velocity, working memory and executive function

Delayed Visual Reproduction: working memory

Delayed Word Recall Test: verbal learning and recent memory.

East Boston Memory Test: episodic memory 
FAB

Go/No-Go

Language WRAT-R

LM

Lnot significant

MA

MMSE

MR

N-back

NAART

NINCDS-ADRDA

OMOT

PC

ROCF

RT

SBT

SPMSQ

ST

SWM

TMT

TMT-A

TMT-B
Frontal Assessment Battery: global executive function

Go/No-Go score: motor inhibition.

Wide Range Achievement Test - Reading: memory

Logical Memory

Letter-Number Sequencing: working memory

Mental abbreviations

Mini Mental State Examination: global cognition

Matrix Reasoning: visual construction and fluid reasoning

N-back test: information updating.

North American Adult Reading Test: verbal intelligence

US. National Institute of Neurologic and Communicative

Disorders and Stroke-Alzheimer's Disease and Related Disorders Association.

Odd Man Out task: executive function

Picture Completion: visuo-spatial construction

Rey-Osterrieth Complex Figure test: visuo-constructional ability and episodic memory.

Reaction Time: processing velocity

Short Blessed Test: memory, orientation and attention

Pfeiffer Short Portable Mental State Questionnaire: global cognition

Stroop Tests- Stroop Color-Word Test for selective attention and susceptibility to behavioral interference and Stroop Interference Test for cognitive inhibition and executive function.

Spatial Working Memory, 4 parameters measured using the Cambridge Neuropsychological Testing Automated Battery

Trail Making Tests: visual attention, visuo-spatial scanning, task switching ability, sequential processing, motor velocity, attention, and executive function

Trail Making Test Part A: information processing

Trail Making Test Part B: mental shifting 
VF

WAIS-II BD

WDS

WLT

WMS-III LM

WMS-III WLL
Verbal Fluency: executive function

Wechsler Adult Intelligence Scale Block Design: visuo-spatial construction.

Wechsler Digit Span: forward and backward test for attention and working memory for executive function.

World Learning Test: direct recall, decayed recall and recognition for episodic memory.

Wechsler Memory Scale III Logical Memory: episodic memory

Wechsler Memory Scale III Word List Learning: episodic memor 


\section{References for Appendices}

1. Verreault R, Semba RD, Volpato S, Ferrucci L, Fried LP, Guralnik JM. Low serum vitamin D does not predict new disability or loss of muscle strength in older women. J Am Geriatr Soc. 2002;50(5):912-917.

2. Zamboni M, Zoico E, Tosoni P, et al. Relation between vitamin D, physical performance, and disability in elderly persons. J Gerontol A Biol Sci Med Sci. 2002;57(1):7-11.

3. Bischoff-Ferrari HA, Dietrich T, Orav EJ, et al. Higher 25-hydroxyvitamin D concentrations are associated with better lower-extremity function in both active and inactive persons aged $>$ or $=60$ y. Am J Clin Nutr. 2004;80(3):752-758.

4. Gerdhem P, Ringsberg KA, Obrant KJ, Akesson K. Association between 25hydroxy vitamin D levels, physical activity, muscle strength and fractures in the prospective population-based OPRA study of elderly women. Osteoporos Int. 2005;16(11):1425-1431.

5. Faulkner KA, Cauley JA, Zmuda JM, et al. Higher 1,25-dihydroxyvitamin D3 concentrations associated with lower fall rates in older community-dwelling women. Osteoporos Int. 2006;17(9):1318-1328.

6. Suzuki T, Kwon J, Kim H, et al. Low serum 25-hydroxyvitamin D levels associated with falls among japanese community-dwelling elderly. J Bone Miner Res. 2008;23(8):1309-1317.

7. Annweiler C, Schott AM, Montero-Odasso M, et al. Cross-sectional association between serum vitamin D concentration and walking speed measured at usual and fast pace among older women: The EPIDOS study. J Bone Miner Res. 2010;25(8):18581866.

8. Chan R, Chan D, Woo J, et al. Not all elderly people benefit from vitamin D supplementation with respect to physical function: Results from the osteoporotic fractures in men study, hong kong. J Am Geriatr Soc. 2012;60(2):290-295.

9. Boersma D, Demontiero O, Mohtasham Amiri Z, et al. Vitamin D status in relation to postural stability in the elderly. $J$ Nutr Health Aging. 2012;16(3):270-275.

10. Kositsawat J, Barry LC, Kuchel GA. C-reactive protein, vitamin D deficiency, and slow gait speed. J Am Geriatr Soc. 2013;61(9):1574-1579.

11. Mathei C, Van Pottelbergh G, Vaes B, Adriaensen W, Gruson D, Degryse JM. No relation between vitamin $\mathrm{D}$ status and physical performance in the oldest old: Results from the belfrail study. Age Ageing. 2013;42(2):186-190. 
12. Kenny AM, Biskup B, Robbins B, Marcella G, Burleson JA. Effects of vitamin D supplementation on strength, physical function, and health perception in older, community-dwelling men. J Am Geriatr Soc. 2003;51(12):1762-1767.

13. Gallagher JC. The effects of calcitriol on falls and fractures and physical performance tests. J Steroid Biochem Mol Biol. 2004;89-90(1-5):497-501.

14. Bunout D, Barrera G, Leiva L, et al. Effects of vitamin D supplementation and exercise training on physical performance in Chilean vitamin D deficient elderly subjects. Exp Gerontol. 2006;41(8):746-752.

15. Brunner RL, Cochrane B, Jackson RD, et al. Calcium, vitamin D supplementation, and physical function in the women's health initiative. J Am Diet Assoc. 2008;108(9):1472-1479.

16. Lips P, Binkley N, Pfeifer M, et al. Once-weekly dose of 8400 IU vitamin $\mathrm{D}(3)$ compared with placebo: Effects on neuromuscular function and tolerability in older adults with vitamin D insufficiency. Am J Clin Nutr. 2010;91(4):985-991.

17. Lagari V, Gomez-Marin O, Levis S. The role of vitamin D in improving physical performance in the elderly. J Bone Miner Res. 2013;28(10):2194-2201.

18. Przybelski RJ, Binkley NC. Is vitamin D important for preserving cognition? A positive correlation of serum 25-hydroxyvitamin D concentration with cognitive function. Arch Biochem Biophys. 2007;460(2):202-205.

19. Buell JS, Scott TM, Dawson-Hughes B, et al. Vitamin D is associated with cognitive function in elders receiving home health services. J Gerontol A Biol Sci Med Sci. 2009;64(8):888-895.

20. Lee DM, Tajar A, Ulubaev A, et al. Association between 25-hydroxyvitamin D levels and cognitive performance in middle-aged and older European men. $J$ Neurol Neurosurg Psychiatry. 2009;80(7):722-729.

21. Llewellyn DJ, Langa KM, Lang IA. Serum 25-hydroxyvitamin D concentration and cognitive impairment. J Geriatr Psychiatry Neurol. 2009;22(3):188-195.

22. Wilkins CH, Birge SJ, Sheline YI, Morris JC. Vitamin D deficiency is associated with worse cognitive performance and lower bone density in older African Americans. J Natl Med Assoc. 2009;101(4):349-354.

23. Annweiler C, Schott AM, Allali G, et al. Association of vitamin D deficiency with cognitive impairment in older women: Cross-sectional study. Neurology. 2010;74(1):27-32. 
24. Llewellyn DJ, Lang IA, Langa KM, et al. Vitamin D and risk of cognitive decline in elderly persons. Arch Intern Med. 2010;170(13):1135-1141.

25. Seamans KM, Hill TR, Scully L, et al. Vitamin D status and measures of cognitive function in healthy older European adults. Eur J Clin Nutr. 2010;64(10):1172-1178.

26. Slinin Y, Paudel ML, Taylor BC, et al. 25-hydroxyvitamin D levels and cognitive performance and decline in elderly men. Neurology. 2010;74(1):33-41.

27. Chan R, Chan D, Woo J, et al. Association between serum 25-hydroxyvitamin D and psychological health in older chinese men in a cohort study. $J$ Affect Disord. 2011;130(1-2):251-259.

28. Llewellyn DJ, Lang IA, Langa KM, Melzer D. Vitamin D and cognitive impairment in the elderly U.S. population. J Gerontol A Biol Sci Med Sci. 2011;66(1):59-65.

29. Annweiler C, Fantino B, Schott AM, Krolak-Salmon P, Allali G, Beauchet O. Vitamin D insufficiency and mild cognitive impairment: Cross-sectional association. Eur J Neurol. 2012;19(7):1023-1029.

30. Slinin Y, Paudel M, Taylor BC, et al. Association between serum 25(OH) vitamin $\mathrm{D}$ and the risk of cognitive decline in older women. J Gerontol A Biol Sci Med Sci. 2012;67(10):1092-1098.

31. Brouwer-Brolsma EM, van de Rest O, Tieland M, et al. Serum 25hydroxyvitamin $\mathrm{D}$ is associated with cognitive executive function in Dutch prefrail and frail elderly: A cross-sectional study exploring the associations of 25hydroxyvitamin D with glucose metabolism, cognitive performance and depression. $J$ Am Med Dir Assoc. 2013;14(11):8529-85217.

32. Annweiler C, Maby E, Meyerber M, Beauchet O. Hypovitaminosis D and executive dysfunction in older adults with memory complaint: A memory clinicbased study. Dement Geriatr Cogn Disord. 2014;37(5-6):286-293.

33. Chei CL, Raman P, Yin ZX, Shi XM, Zeng Y, Matchar DB. Vitamin D levels and cognition in elderly adults in China. J Am Geriatr Soc. 2014;62(11):2125-2129.

34. Hooshmand B, Lokk J, Solomon A, et al. Vitamin D in relation to cognitive impairment, cerebrospinal fluid biomarkers, and brain volumes. J Gerontol A Biol Sci Med Sci. 2014;69(9):1132-1138. 
35. Schneider AL, Lutsey PL, Alonso A, et al. Vitamin D and cognitive function and dementia risk in a biracial cohort: The ARIC brain MRI study. Eur J Neurol. 2014;21(9):1211-8, e69-70.

36. Toffanello ED, Coin A, Perissinotto E, et al. Vitamin D deficiency predicts cognitive decline in older men and women: The Pro.V.A. study. Neurology. 2014;83(24):2292-2298.

37. Wilson VK, Houston DK, Kilpatrick L, et al. Relationship between 25hydroxyvitamin $\mathrm{D}$ and cognitive function in older adults: The Health, Aging and Body Composition study. J Am Geriatr Soc. 2014;62(4):636-641.

38. Beauchet O, Annweiler C, Verghese J, Fantino B, Herrmann FR, Allali G. Biology of gait control: Vitamin D involvement. Neurology. 2011;76(19):1617-1622.

39. Houston DK, Tooze JA, Hausman DB, et al. Change in 25-hydroxyvitamin D and physical performance in older adults. J Gerontol A Biol Sci Med Sci. 2011;66(4):430436.

40. Houston DK, Tooze JA, Neiberg RH, et al. 25-hydroxyvitamin D status and change in physical performance and strength in older adults: The health, aging, and body composition study. Am J Epidemiol. 2012;176(11):1025-1034.

41. Peterson A, Mattek N, Clemons A, et al. Serum vitamin D concentrations are associated with falling and cognitive function in older adults. $J$ Nutr Health Aging. 2012;16(10):898-901.

42. Menant JC, Close JC, Delbaere K, et al. Relationships between serum vitamin D levels, neuromuscular and neuropsychological function and falls in older men and women. Osteoporos Int. 2012;23(3):981-989.

43. Toffanello ED, Perissinotto E, Sergi G, et al. Vitamin D and physical performance in elderly subjects: The Pro.V.A study. PLoS One. 2012;7(4):1-9.

44. Houston DK, Neiberg RH, Tooze JA, et al. Low 25-hydroxyvitamin D predicts the onset of mobility limitation and disability in community-dwelling older adults: The Health ABC study. J Gerontol A Biol Sci Med Sci. 2013;68(2):181-187.

45. Gschwind YJ, Bischoff-Ferrari HA, Bridenbaugh SA, Hardi I, Kressig RW. Association between serum vitamin D status and functional mobility in memory clinic patients aged 65 years and older. Gerontology. 2014;60(2):123-129.

46. Lewis JE, Lantigua L, Atlas SE, et al. A cross-sectional assessment to detect type 2 diabetes with endothelial and autonomic nervous system markers using a novel system. J Diabetes Metab Disord. 2014;13(1):118-125. 
47. Clinical studies and peer reviews. LD Technology Web site. http://www.ldteck.comJuly, 2015. 
VITA

JOHANNA LOPEZ

2001-2005

B.Sc., Biochemistry and Molecular Biology

University of Miami

Miami, Florida

2005-2006

Adjunct Instructor, Department of Biological Sciences Florida International University

Miami, Florida

2006-2009

MS., Molecular and Cellular Pharmacology

University of Miami

Miami, Florida

Graduate Research Assistant, Department of Molecular and Cellular Pharmacology

University of Miami

Miami, Florida

2010-2014

Graduate Teacher Assistant, Department of Dietetics and Nutrition

Florida International University

Miami, Florida

2012-2015

Doctoral Candidate

Florida International University

Miami, Florida

\section{PRESENTATIONS AND PUBLICATIONS}

Kapiloff, M.S., Lopez, J., Negro, A., Henson, E., Dodge-Kafka, K.L., \& Bauman, A.L. Calcineurin Binding to the mAKAP $\beta$ Signalosome, Experimental Biology 2008 Conference. San Diego, California.

Kohen, E., Hirschberg, J.G., Mesa, D., Santus, R., Sok, C., Gempertein, R., LeBlanc, R., Ozkutuk, N., Monem, Y.A., Monti, M., Torres, L., Lopez, M., \& Lopez, J. (2004). "Advances in Phototoxicology and Implications in Cellular Pathopharmacology" in Recent Research Developments in Photochemistry \& Photobiology, Vol. 7, Managing Editor S.G. Pandalai in Transworld Research Network, Trivandrum, Kerala, India. pp. 175-200. 
Lewis, J. E., Cutrono, S., Melillo, A., Tiozzo, E., Lopez, J., Adwan, S., Chen, L., Leonard S., Howell, M., Diaz, J., Woolger, J., Konefal, J., Paterson, E., \& Barnes, D. (2014). Dietary supplementation on quality of life in adults. Agro FOOD Industry Hi Tech, 25(2), 25-31.

Lewis, J. E., Lopez, J., Ganuza, A., Woolger, J., Chen, L.,Melillo, A., Alonso, Y., Rafatjah, S., Konefal, J., Sarabia, A., Leonard S.M., Long, E.G., \& Tiozzo, E. (2013). A pilot study eliminating immunologically-reactive foods from the diet and its effect on symptomatology and quality of life in persons with chronic migraines and headaches. Open Journal of Internal Medicine, 3, 8-14

Lewis, J.E., Lantigua, L.A., Atlas, S.E., Lopez, J. Mendez, A.,Goldberg, S., Medici, S. Konefal, J., Woolger, J.M., Tiozzo, E., Aliffe, K.H. (2014) A cross-sectional assessment to detect type 2 diabetes with endothelial and autonomic nervous system markers using a novel system. Journal of Diabetes and Metabolic Disorders, 13:118

Li, J., Negro, A., Lopez, J., Bauman, A.L., Henson, E., Dodge-Kafka K.L., \& Kapiloff, M.S. (2009). The mAKAP $\beta$ Scaffold Regulates Cardiac Myocyte Hypertrophy via Recruitment of Activated Calcineurin . Journal of Molecular and Cellular Pharmacology, 48 (2), 387-404.

Lopez, J., Tiozzo, E., Konefal, J., Adwan, S., Martinez, L.A., Villabona, J., Lopez, J., Cutrono, S., Rodriguez, A., Woolger, J.M., Lewis, J.E.. Metabolic Syndrome in an HIV Cohort on Antiretroviral Therapy. Experimental Biology 2015 Conference, Boston, Massachusetts.

Tiozzo, E., Konefal, J., Adwan, S., Martinez, L.A., Villabona, J., Lopez, J., Cutrono, S., Rodriguez, A., Woolger, J.M., Lewis, J.E. (2015). A cross-sectional assessment of metabolic syndrome in HIV-infected people of low socio-economic status receiving antiretroviral therapy. Diabetology \& Metabolic Syndrome Journal. Mar 7;7:15. doi: 10.1186/s13098-015-0008-5. eCollection 2015.

Woolger, J. Lopez, J., Melillo, A.B., Tiozzo, E., Alonso, Y., Rafatjah, S., Sarabia, A., Leonard, S.M., Long, E.G., Schoor, M., Tannenbaum, J., Konefal, J., \& Lewis, J.E. (2013). Improving quality of life in self-reported gastrointestinal disorders: An open trial of a food elimination diet guided by the ImmunoBloodprint food sensitivity test. Open Journal of Internal Medicine, 3, 106-113. 